DANIEL RODRIGO BARRETO SILVA

O CONCEITO DE INÉRCIA ADICIONAL DO ESCOAMENTO EM TORNO DE CILINDRO CIRCULAR EM OSCILAÇÃO FORÇADA 
DANIEL RODRIGO BARRETO SILVA

\title{
O CONCEITO DE INÉRCIA ADICIONAL DO ESCOAMENTO EM TORNO DE CILINDRO CIRCULAR EM OSCILAÇÃO FORÇADA
}

\author{
Dissertação apresentada à Escola \\ Politécnica da Universidade de São Paulo \\ para obtenção do título de Mestre em \\ Engenharia Mecânica
}

Orientador: Prof. Dr. Celso Pupo Pesce

São Paulo 
Este exemplar foi revisado e corrigido em relação à versão original, sob responsabilidade única do autor e com a anuência de seu orientador.

São Paulo, de agosto de 2013.

Assinatura do autor

Assinatura do orientador

FICHA CATALOGRÁFICA

Silva, Daniel Rodrigo Barreto $O$ conceito de inércia adicional do escoamento em torno de cilindro circular em oscilação forçada / D.R.B. Silva. - versão corr. -- São Paulo, 2013.

$131 \mathrm{p}$.

Dissertação (Mestrado) - Escola Politécnica da Universidade de São Paulo. Departamento de Engenharia Mecânica.

1.Inércia adicional 2.Massa adicional 3.Oscilação forçada 4.Equação de Morison I.Universidade de São Paulo. Escola Politécnica. Departamento de Engenharia Mecânica II.t. 
À memória de minha querida mãe. 


\section{AGRADECIMENTOS}

A vida nesses dois anos e meio de mestrado foi tortuosa e repleta de mudanças. Agradeço aos meus pais, pelo amor infinito e dedicação aos filhos. Ao meu irmão Junior e à minha cunhada Juliana, casal maravilhoso. À Sylvia pelo incentivo, paciência e carinho.

Ao meu orientador, Prof. Dr. Celso Pupo Pesce, exemplo de profissional e de pensamentos claros e aguçados. Muito obrigado pelas críticas, ensinamentos e ajuda nos momentos decisivos.

Ao Dr. Marcelo Fernando González Bergweiler por sugerir o desenvolvimento de um trabalho de mestrado no tema de inércia adicional e por suas perguntas simples, porém instigantes.

A todos os meus amigos que me proporcionaram momentos maravilhosos de alegria e de descontração e, indiretamente, contribuíram para este trabalho. Em especial, às minhas amigas Juliana Levino e Sibele Souza e ao meu amigo Ronaldo Aizawa. 


\section{RESUMO}

Um corpo imerso em movimento arbitrário interage com o fluido ao redor. As partículas fluidas próximas ao corpo exercem certa resistência inercial quando o corpo acelera ou desacelera, devido ao acoplamento dinâmico entre corpo e fluido. Este trabalho resolve as equações de Navier-Stokes, discretizadas pelo método dos elementos finitos, usando o programa de código aberto (LGPL) FreeFem++, e avalia as forças do escoamento que agem sobre um cilindro circular, o qual oscila harmonicamente em um fluido em repouso para números de Keulegan-Carpenter $(\mathrm{KC})$ entre 0,5 e 10, mantendo o parâmetro da frequência $\beta$ constante e igual a 35 . Os números de $\mathrm{KC}$ selecionados visam entender os conceitos de inércia adicional em fluido viscoso, desde em escoamentos simples até em escoamento mais complexos. O escoamento é bidimensional, laminar e não estacionário. A força em linha com o movimento é então decomposta, conforme equação de Morison, como a soma de uma força inercial e outra de arrasto. Os resultados possuem boa aderência com trabalhos analíticos, experimentais e numéricos anteriores disponíveis na literatura. A dinâmica do escoamento induzido pelo cilindro em movimento harmônico é rica. Para baixo $\mathrm{KC}$, o escoamento é simétrico e estável. Para valores intermediários de KC, a camada limite descola da superfície do cilindro e vórtices são emitidos a cada meio-ciclo. Para elevado KC, certa assimetria se desenvolve e vórtices são emitidos obliquamente a cada meio-ciclo.

Palavras-Chave: Inércia Adicional, Massa Adicional, Oscilação Forçada, Equação de Morison; Freefem++ 


\begin{abstract}
An immersed body in arbitrary motion interacts with the surrounding fluid. The fluid particles close to the body impart their inertial resistance when the body accelerates or decelerates, due to the dynamic coupling between body and fluid. This work solves the incompressible Navier-Stokes equation, discretized by the finite element method, using the open source (LGPL) software FreeFem++, and evaluates the flow forces that act on a circular cylinder which oscillates harmonically in a resting fluid for KeuleganCarpenter $(\mathrm{KC})$ number between 0.5 and 10 , with a constant frequency parameter $\beta$ equal to 35 . The selected KC numbers aims to understand the concepts of added inertia in viscous fluid, from simpler to more complex flows. The flow is two dimensional, laminar and unsteady. The in-line force is then decomposed, according to Morison equation, as a sum of an inertial force and a drag force. The results agree with former analytical, experimental and numerical works available in the literature. The dynamics of the flow induced by the harmonically moving cylinder is rich. For low $\mathrm{KC}$, the flow is symmetric and stable. For intermediate $\mathrm{KC}$, the boundary layer detaches from the cylinder surface and vortices are shed at each half cycle. For higher KC, certain asymmetry develops and vortices are shed obliquely at each half cycle.
\end{abstract}

Keywords: Inertial Force; Added Mass; Forced Oscillation; Morison Equation; Freefem++ 


\section{SUMÁRIO}

LISTA DE FIGURAS

LISTA DE TABELAS

LISTA DE SÍMBOLOS

1. INTRODUÇÃO 20

1.1 Motivação e Objetivos do Trabalho .................................................... 21

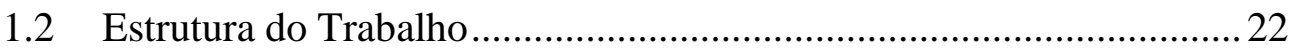

2. INÉRCIA ADICIONAL DO ESCOAMENTO EM TORNO DE CILINDRO CIRCULAR EM OSCILAÇÃO FORÇADA...

2.1 Inércia Adicional em Escoamento Potencial.......................................26

2.1.1 Método da Energia.......................................................... 28

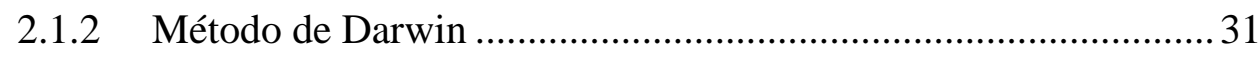

2.2 Inércia Adicional em Escoamento Viscoso....................................... 33

2.2.1 Topologia do Escoamento ................................................... 46

2.2.2 Simulações Numéricas ............................................................ 52

3. SIMULAÇÃO DO ESCOAMENTO EM TORNO DE CILINDRO CIRCULAR EM OSCILAÇÃO FORÇADA .................................................... 55

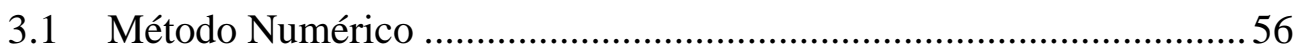

3.1.1 Restrição de Incompressibilidade .......................................... 60

3.1.2 Equação de Navier-Stokes em Referencial Não-Inercial.............60

3.1.3 Condições de Contorno.......................................................... 63

3.1.4 Discretização Temporal ..................................................... 64

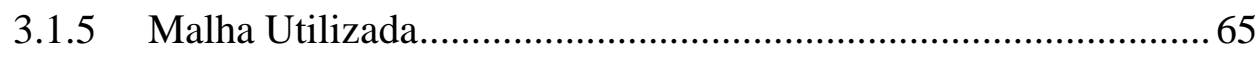

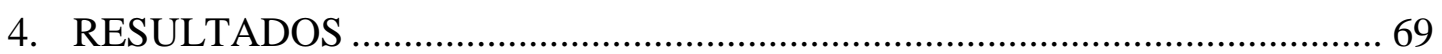

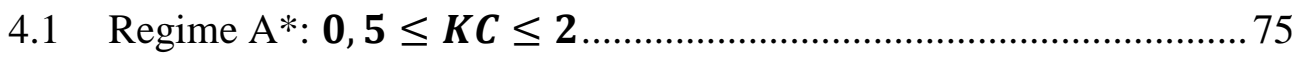

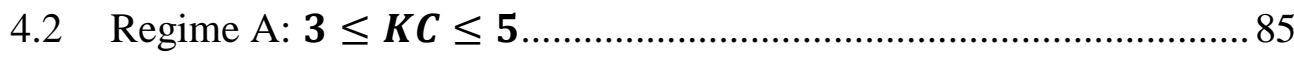




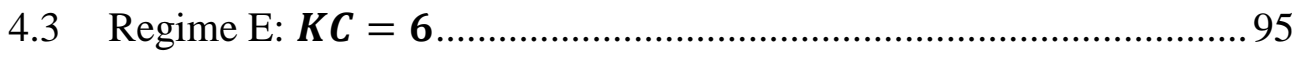

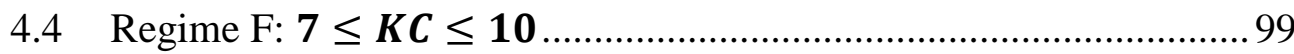

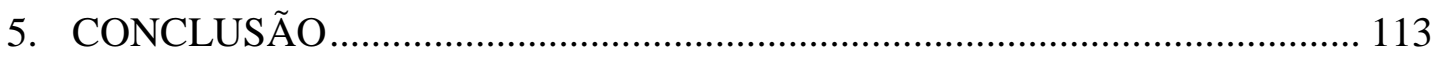

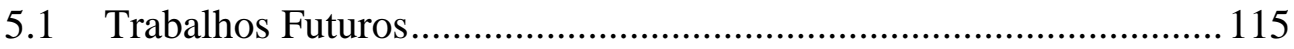

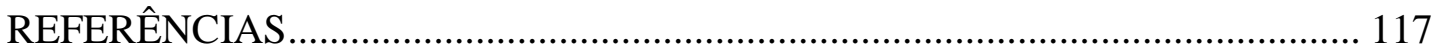

APÊNDICE A - MÉTODO DOS ELEMENTOS FINITOS................................. 123 


\section{LISTA DE FIGURAS}

Figura 1 - Plano de referência de partículas lagrangianas (DABIRI, 2006)..... 32

Figura 2 - Desenvolvimento do escoamento ao redor do cilindro (BATCHELOR, 1967)......................................................... 36

Figura 3 - Coeficiente de arrasto (KEULEGAN e CARPENTER, 1958) ........ 41

Figura 4 - Coeficiente de massa (KEULEGAN e CARPENTER, 1958) ......... 41

Figura 5 - Coeficiente de arrasto (SARPKAYA, 1977) ................................. 43

Figura 6 - Coeficiente de inércia (SARPKAYA, 1977) ................................. 43

Figura 7 - Coeficiente de arrasto: $\square \beta=53$ e $\bullet \beta=35$ (KÜHTZ, 1996) .............. 44

Figura 8 - Coeficiente de inércia: $\square \beta=53$ e $\bullet \beta=35$ (KÜHTZ, 1996) .............. 44

Figura 9 - Esquema do aparato experimental de Tatsuno e Bearman (1990): (a) cilindro circular, (b) tanque de água, (c) guia deslizante, (d) guia fixa, (e) biela-manivela e (f) motor ..................................... 47

Figura 10 - Mapa de Tatsuno e Bearman. Adaptado de Dütsh et al. (1998) .... 47

Figura 11 - Escoamento simétrico no Regime A (TATSUNO; BEARMAN, 1990)

Figura 12 - Vórtices: (a) Experimento de Honji (1981) (b) Numericamente (HONGWE; ZHAO, 2010) para $\boldsymbol{K} \boldsymbol{C}=\mathbf{2}$ e $\boldsymbol{\beta}=\mathbf{2 0 0} \ldots \ldots \ldots \ldots . . . . .49$

Figura 13 - Vórtices no Regime C (TATSUNO; BEARMAN, 1990).............. 50

Figura 14 - Assimetria no Regime D (TATSUNO; BEARMAN, 1990)..........50

Figura 15 - Regime F (TATSUNO; BEARMAN, 1990).................................51

Figura 16 - Regime G (TATSUNO; BEARMAN, 1990) ...............................52

Figura 17 - Campo de vorticidade: (a) regime A (b) regime D (c) regime F (DÜTSCH et al., 1998).......................................................... 53

Figura 18- Coeficiente de arrasto para $\boldsymbol{\beta}=\mathbf{3 5}$ (DÜTSCH et al., 1998)..........54

Figura 19 - Coeficiente de inércia para $\boldsymbol{\beta}=\mathbf{3 5}$ (DÜTSCH et al., 1998)........54 
Figura 20- Regimes da simulação no mapa de Tatsuno e Bearman. Adaptado de Dütsh et al. (1998) .................................................. 56

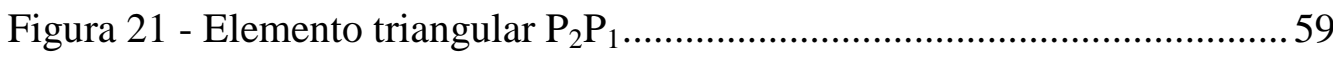

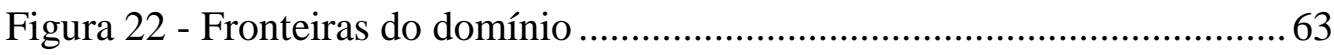

Figura 23- Malha retangular não-estruturada ..............................................67

Figura 24 - Detalhe da malha na região próxima ao cilindro ..........................6 68

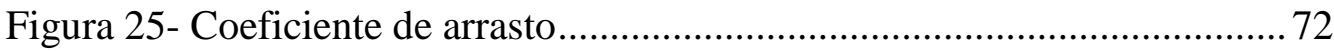

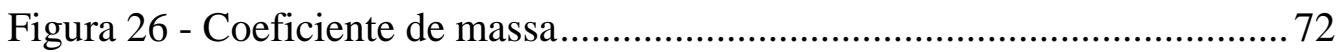

Figura 27 - Série de Fourier da força de resistência para $\mathrm{KC}=0,5$ até 5 ........ 73

Figura 28 - Série de Fourier da força de resistência para $\mathrm{KC}=6$ até 10 ......... 73

Figura 29- Fase entre força de resistência e posição do cilindro ...................... 74

Figura 30- Forças de resistência e normal $(\mathrm{Re}=17,5$ e $\mathrm{KC}=0,59) \ldots \ldots \ldots \ldots . . . . .76$

Figura 31 - Força numérica e de Morison $(\mathrm{Re}=17,5$ e $\mathrm{KC}=0,5) \ldots \ldots \ldots \ldots \ldots \ldots . . . . .76$

Figura 32 - Energia cinética do escoamento $(\mathrm{Re}=17,5$ e $\mathrm{KC}=0,5) \ldots \ldots \ldots \ldots . . . .77$

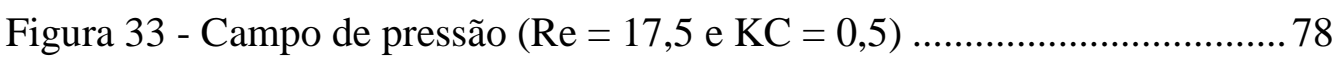

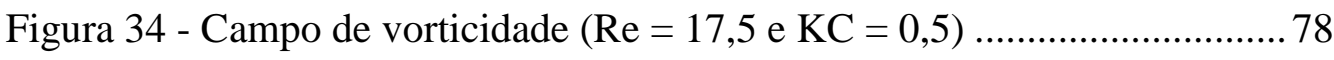

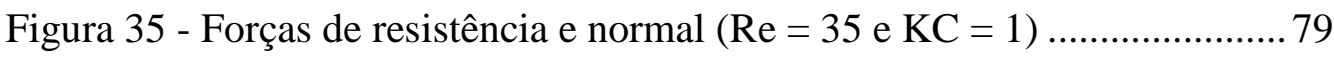

Figura 36 - Força numérica e de Morison $(\mathrm{Re}=35$ e $\mathrm{KC}=1) \ldots \ldots \ldots \ldots \ldots \ldots \ldots . . . . . . . . . . .80$

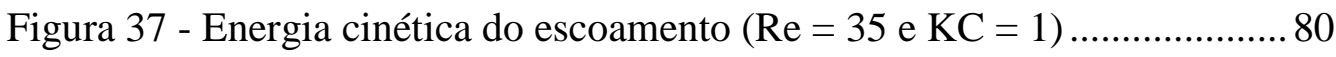

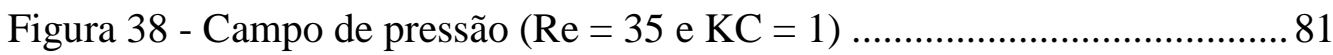

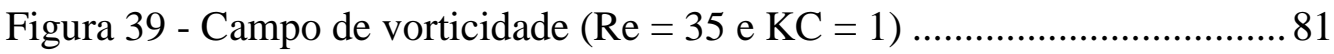

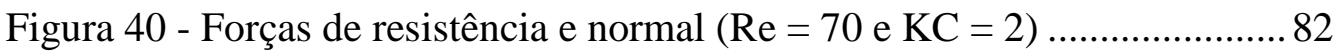

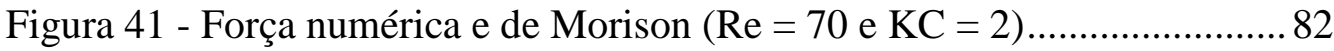

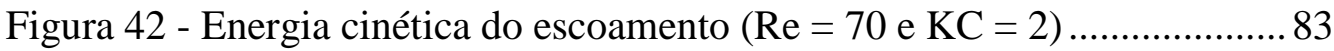

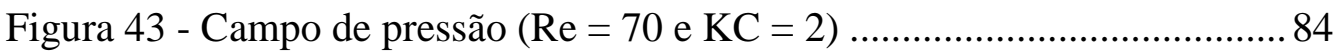

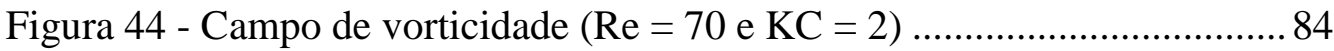


Figura 45 - Forças de resistência e normal $(\mathrm{Re}=105$ e $\mathrm{KC}=3)$..................... 86

Figura 46 - Força numérica e de Morison $(\mathrm{Re}=105$ e $\mathrm{KC}=3) \ldots \ldots \ldots \ldots \ldots \ldots \ldots . . . . . . . . .86$

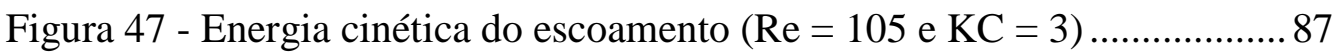

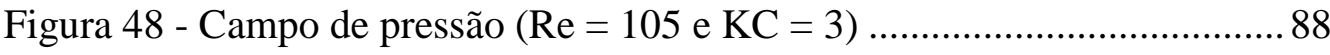

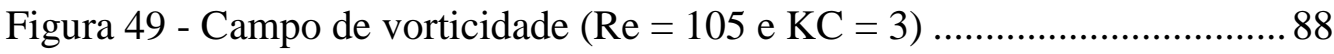

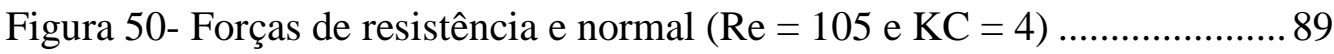

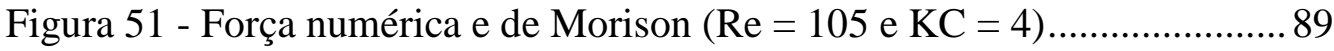

Figura 52 - Energia cinética do escoamento $(\mathrm{Re}=105$ e $\mathrm{KC}=4) \ldots \ldots \ldots \ldots \ldots . . . . .90$

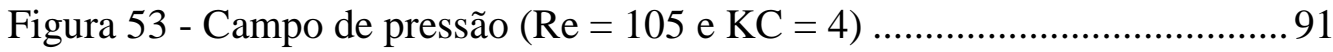

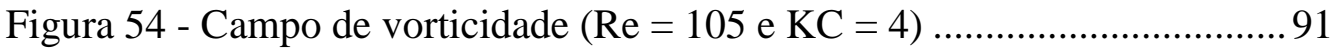

Figura 55- Forças de resistência e normal $(\mathrm{Re}=105$ e $\mathrm{KC}=5) \ldots \ldots \ldots \ldots \ldots \ldots . . . . . .92$

Figura 56 - Força numérica e de Morison $(\mathrm{Re}=105$ e $\mathrm{KC}=5) \ldots \ldots \ldots \ldots \ldots \ldots . . . . . . . . .92$

Figura 57 - Energia cinética do escoamento $(\mathrm{Re}=105$ e $\mathrm{KC}=5) \ldots \ldots \ldots \ldots \ldots . . . . .93$

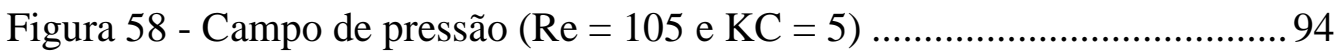

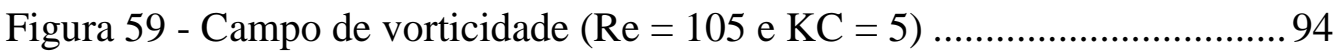

Figura 60 - Comparação da vorticidade: (a) Presente trabalho e (b) Dütsh et al. (1998) no regime E ......................................................... 95

Figura 61- Forças de resistência e normal $(\mathrm{Re}=105$ e $\mathrm{KC}=6) \ldots \ldots \ldots \ldots \ldots \ldots . . . . . . . .96$

Figura 62 - Força numérica e de Morison $(\mathrm{Re}=105$ e $\mathrm{KC}=6) \ldots \ldots \ldots \ldots \ldots \ldots . . . . . . . . .96$

Figura 63 - Diagrama de fase da força resultante $(\mathrm{Re}=105$ e $\mathrm{KC}=6)$.......... 97

Figura 64 - Energia cinética do escoamento $(\mathrm{Re}=105$ e $\mathrm{KC}=6) \ldots \ldots \ldots \ldots \ldots . . . . .97$

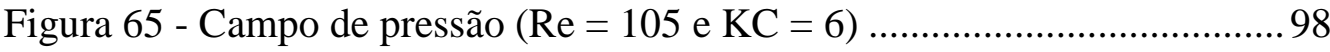

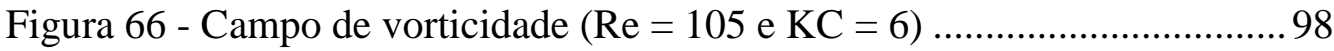

Figura 67 - Comparação dos resultados: (a ) Presente trabalho e (b) Tatsuno e Bearman (1990) para o regime $\mathrm{F}$ 99

Figura 68- Forças de resistência e normal $(\mathrm{Re}=105$ e $\mathrm{KC}=7) \ldots \ldots \ldots \ldots \ldots \ldots . . . . . .101$

Figura 69 - Força numérica e de Morison $(\mathrm{Re}=105$ e $\mathrm{KC}=7) \ldots \ldots \ldots \ldots \ldots \ldots . . . . . . . .101$ 
Figura 70 - Diagrama de fase da força resultante $(\mathrm{Re}=105$ e $\mathrm{KC}=7) \ldots \ldots . . .102$

Figura 71 - Energia cinética do escoamento $(\mathrm{Re}=105$ e $\mathrm{KC}=7) \ldots \ldots \ldots \ldots \ldots . . . . .102$

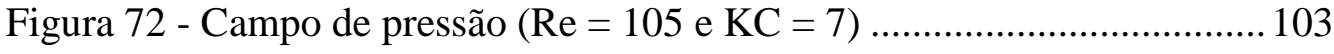

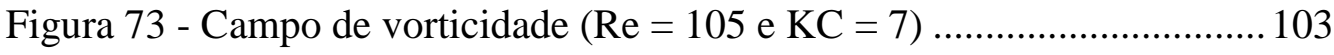

Figura 74- Forças de resistência e normal $(\mathrm{Re}=105$ e $\mathrm{KC}=8)$.................... 104

Figura 75 - Força numérica e de Morison $(\mathrm{Re}=105$ e $\mathrm{KC}=8) \ldots \ldots \ldots \ldots \ldots \ldots . . . . . . .104$

Figura 76 - Diagrama de fase da força resultante $(\mathrm{Re}=105$ e $\mathrm{KC}=8) \ldots \ldots . . .105$

Figura 77 - Energia cinética do escoamento $(\mathrm{Re}=105$ e $\mathrm{KC}=8) \ldots \ldots \ldots \ldots . . . . .105$

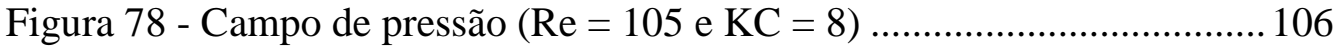

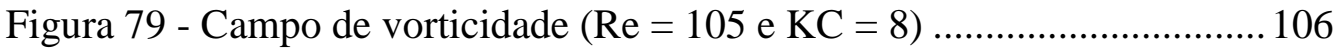

Figura 80- Forças de resistência e normal $(\mathrm{Re}=105$ e $\mathrm{KC}=9) \quad \ldots \ldots \ldots \ldots \ldots \ldots . . . . . . .107$

Figura 81 - Força numérica e de Morison $(\mathrm{Re}=105$ e $\mathrm{KC}=9) \ldots \ldots \ldots \ldots \ldots \ldots . . . . . . . .107$

Figura 82 - Diagrama de fase da força resultante $(\mathrm{Re}=105$ e $\mathrm{KC}=9) \ldots \ldots . .108$

Figura 83 - Energia cinética do escoamento $(\mathrm{Re}=105$ e $\mathrm{KC}=9) \ldots \ldots \ldots \ldots \ldots . . . .108$

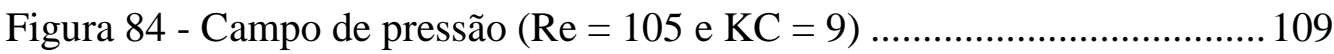

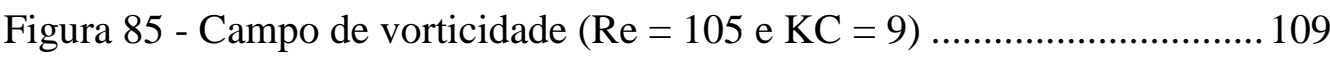

Figura 86- Forças de resistência e normal $(\mathrm{Re}=105$ e $\mathrm{KC}=10) \ldots \ldots \ldots \ldots \ldots . . . . . .110$

Figura 87 - Força numérica e de Morison $(\mathrm{Re}=105$ e $\mathrm{KC}=10) \ldots \ldots \ldots \ldots \ldots \ldots . . . . .110$

Figura 88 - Diagrama de fase da força resultante $(\mathrm{Re}=105$ e $\mathrm{KC}=10) \ldots \ldots .111$

Figura 89 - Energia cinética do escoamento $(\mathrm{Re}=105$ e $\mathrm{KC}=10) \ldots \ldots \ldots \ldots . . . .111$

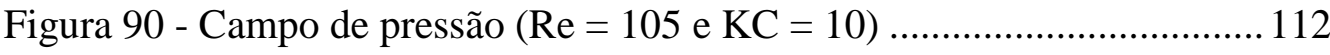

Figura 91 - Campo de vorticidade $(\mathrm{Re}=105$ e $\mathrm{KC}=10) \quad \ldots \ldots \ldots \ldots \ldots \ldots \ldots \ldots \ldots . . . . . . . . . . . .112$

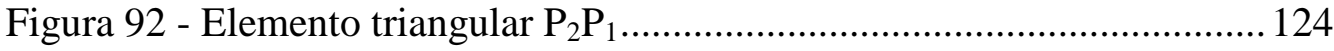

Figura 93 - Áreas formadas entre o ponto P e os vértices do triângulo.......... 125 


\section{LISTA DE TABELAS}

Tabela 1 - Resultados de Stokes (1850) para cilindro circular 39

Tabela 2 - Autores que investigaram os coeficientes de massa e de arrasto, em ordem cronológica. Adaptada de Duclercq (2010). 45

Tabela 3 - Parâmetros da simulação numérica .................................................. 55

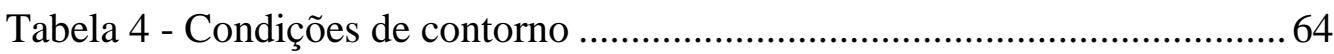

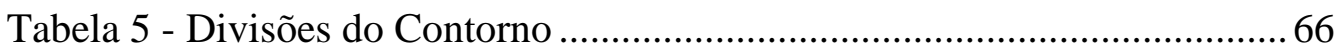

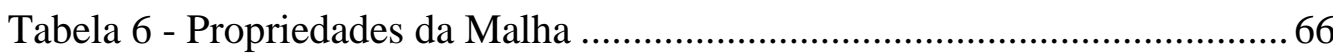

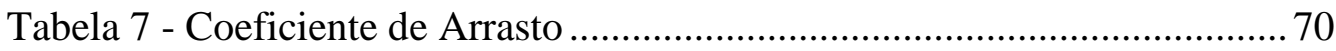

Tabela 8 - Coeficientes de Massa e de Inércia.................................................. 71

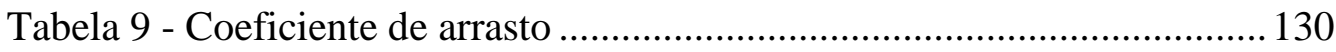

Tabela 10 - Coeficientes de arrasto e de sustentação..................................... 130 


\section{LISTA DE SÍMBOLOS}

Parâmetros Adimensionais do Escoamento

$\beta \quad$ - $\quad$ Parâmetro da frequência: $\beta=\frac{R e}{K C}=\frac{D^{2}}{v T}$

$K C \quad-\quad$ Número de Keulegan-Carpenter: $K C=\frac{U T}{D}$

$K C_{c r} \quad-\quad$ Número de Keulegan-Carpenter crítico

Re - Número de Reynolds: $R e=\frac{\rho U D}{v}$

St - $\quad$ Número de Strouhal: $S t=\frac{1}{K C}=\frac{D}{U T}$

Letras Latinas

$A_{e} \quad-\quad$ Área do elemento

$A_{1 . .3} \quad-\quad$ Áreas para cálculo das coordenadas naturais de triângulo $\left(\xi_{1}, \xi_{2}\right)$

$A_{d} \quad-\quad$ Área deslocada pelo corpo imerso

$C_{A} \quad-\quad$ Coeficiente de massa adicional (adimensional)

$C_{D} \quad-\quad$ Coeficiente de arrasto (adimensional)

$C_{M} \quad-\quad$ Coeficiente de inércia: $C_{M}=1+C_{A}$ (adimensional)

D - Diâmetro do cilindro e comprimento característico do escoamento

$E_{C} \quad-\quad$ Energia cinética do escoamento

$F_{i} \quad$ - Força do fluido sobre o corpo na direção $i$ (eixo $x_{i}$ )

$k \quad-\quad$ Coeficiente para a inércia adicional nos resultados de Stokes

$k^{\prime} \quad$ - $\quad$ Coeficiente para o arrasto nos resultados de Stokes

$m^{\prime} \quad$ - Massa equivalente do corpo com a inércia adicional do fluido 


\begin{tabular}{|c|c|c|}
\hline$m_{a}$ & - & Massa adicional \\
\hline$n$ & - & $\begin{array}{l}\text { Dimensão do espaço, } n=2 \text { ou } n=3 \text {, para domínio bidimensional e } \\
\text { tridimensional, respectivamente }\end{array}$ \\
\hline$n b$ & - & Número de elementos com aresta no contorno \\
\hline ne & - & Número de elementos \\
\hline$n_{i}$ & - & Vetor normal unitário \\
\hline$N_{1 \ldots 3}$ & - & Funções de forma lineares \\
\hline$N_{1 \ldots 6}$ & - & Funções de forma quadráticas \\
\hline$p$ & - & Campo escalar de pressão \\
\hline$p^{e}$ & - & Campo escalar de pressão no elemento \\
\hline$p^{*}$ & - & Campo escalar de pressão adimensional \\
\hline$\delta p$ & - & Função-teste da pressão para a equação da continuidade \\
\hline$\delta p^{e}$ & - & Função-teste da pressão para a equação da continuidade no elemento \\
\hline$q$ & - & Módulo da velocidade: $q=\sqrt{u_{i} u_{i}}$ \\
\hline$r$ & - & Raio em coordenadas cilíndricas \\
\hline$r_{i}$ & - & Vetor posição do referencial relativo \\
\hline$\dot{r}_{i}$ & - & Vetor velocidade do referencial relativo \\
\hline$\ddot{r}_{i}$ & - & Vetor aceleração do referencial relativo \\
\hline$\Delta R$ & - & $\begin{array}{l}\text { Diferença (Resíduo) entre a força de resistência calculada e aquela dada } \\
\text { pela equação de Morison }\end{array}$ \\
\hline$S$ & - & Fronteira interna (corpo) do domínio $\Omega$ \\
\hline
\end{tabular}


$\Delta t \quad-\quad$ Passo de tempo

$t \quad-\quad$ Tempo

$t^{*} \quad-\quad$ Tempo adimensional

$T$ - Período de oscilação e tempo característico do escoamento

$U \quad$ - Velocidade do escoamento ao longe e velocidade característica

$U_{m} \quad$ - Velocidade máxima do cilindro em oscilação harmônica

$U_{1 \ldots 6} \quad$ - Velocidades do corpo rígido: translação $U_{1 \ldots 3}$ e rotação $U_{4 \ldots 6}$

$u_{i} \quad-\quad$ Campo vetorial de velocidade

$u_{i}^{e} \quad-\quad$ Campo vetorial de velocidade no elemento

$u_{i}^{\prime} \quad$ - $\quad$ Campo vetorial de velocidade no referencial móvel

$u_{i}^{*} \quad-\quad$ Campo vetorial de velocidade adimensional

$\delta u_{i} \quad$ - $\quad$ Função-teste da velocidade

$\delta u_{i}^{e} \quad-\quad$ Função-teste da velocidade no elemento

$V_{d} \quad-\quad$ Volume deslocado pelo corpo imerso

X $\quad$ - Deslocamento líquido de uma partícula na linha de corrente

$x_{i} \quad-\quad$ Coordenadas cartesianas

$x_{i}^{\prime} \quad-\quad$ Coordenadas cartesianas no referencial móvel

$x_{i}^{*} \quad-\quad$ Coordenadas cartesianas adimesionais

$Y \quad$ - $\quad$ Integral de $X$ nas linhas de corrente (volume deslocado)

Letras Gregas 
$\Gamma \quad$ - Contorno do domínio $\bar{\Omega}$, formado pelas fronteiras interna e externa, $\Gamma=\mathrm{S}+\Sigma$, respectivamente.

$\Gamma^{D} \quad-\quad$ Contorno do domínio com condições de contorno de Dirichlet

$\Gamma_{S}^{D} \quad-\quad$ Contorno do domínio $\Gamma^{D}$ na superfície do corpo $S$

$\Gamma_{\Sigma}^{D} \quad-\quad$ Contorno do domínio $\Gamma^{D}$ no limite externo computacional $\Sigma$

$\Gamma^{N} \quad-\quad$ Contorno do domínio com condições de contorno de Neumann

$\Gamma_{S}^{N} \quad-\quad$ Contorno do domínio $\Gamma^{N}$ na superfície do corpo $S$

$\Gamma_{\Sigma}^{N} \quad-\quad$ Contorno do domínio $\Gamma^{N}$ no limite externo computacional $\Sigma$

$\theta \quad$ - Ângulo azimute em coordenadas cilíndricas

$\mu \quad$ - Viscosidade dinâmica

$v \quad-\quad$ Viscosidade cinemática: $v=\frac{\mu}{\rho}$

$\xi_{i} \quad-\quad$ Coordenadas naturais de triângulo

$\rho \quad$ - $\quad$ Densidade do fluido

$\rho^{\prime} \quad$ - $\quad$ Densidade equivalente do corpo com a inércia adicional do fluido

$\rho_{c} \quad-\quad$ Densidade do corpo

$\Sigma \quad-\quad$ Fronteira externa do domínio $\Omega$

$\phi \quad$ - $\quad$ Função potencial do escoamento

$\phi^{\prime} \quad$ - Função potencial da perturbação do escoamento devido ao corpo

$\phi_{1 \ldots 6} \quad$ - Componentes de $\phi$ para os graus de liberdade 1 a 6 do corpo 
$\psi \quad$ - $\quad$ Função de corrente do escoamento

$\Omega \quad$ - $\quad$ Interior do domínio de interesse.

$\bar{\Omega} \quad$ - $\quad$ Domínio fechado de interesse com interior $\Omega$ e fronteira $\Gamma: \bar{\Omega}=\Omega+\Gamma$.

$\Omega_{e} \quad-\quad$ Interior do domínio do elemento finito $e$

$\omega \quad$ - $\quad$ Velocidade angular de oscilação: $\omega=\frac{2 \pi}{T}$

$\omega_{i} \quad-\quad$ Vorticidade: $\omega_{i}=\epsilon_{i j k} \frac{\partial u_{j}}{\partial x_{i}}$

\section{Tensores}

$C_{A_{i j}} \quad-\quad$ Tensor dos coeficientes de massa (adimensional)

$E_{i j} \quad-\quad$ Tensor taxa de deformação do fluido

$m_{i j} \quad-\quad$ Tensor de massa adicional

$T_{i j} \quad-\quad$ Tensor de tensões do fluido

$\delta_{i j} \quad-\quad$ Delta de Kronecker: $\delta_{i j}= \begin{cases}0, & \text { se } i \neq j \\ 1, & \text { se } i=j\end{cases}$

$\epsilon_{i j k} \quad$ - Símbolo de permutação:

$\epsilon_{i j k}=\left\{\begin{array}{cc}0, & \text { se qualquer } \mathrm{i}, \mathrm{j}, \mathrm{k} \text { forem repetidos } \\ 1, & \text { se ijk for uma permutação par } \\ -1, & \text { se ijk for uma permutacao ímpar }\end{array}\right.$

Operadores
$\nabla^{2}$
Laplaciano $\nabla^{2}=\frac{\partial^{2}}{\partial \mathrm{x}_{i} \partial \mathrm{x}_{i}}$
$\frac{\partial}{\partial n} \quad-\quad$ Derivada na direção do vetor normal $n_{i}$
$\frac{d}{d t} \quad-\quad$ Derivada no tempo 
$\begin{array}{lll}\frac{d^{1 / 2}}{d t^{1 / 2}} & - & \text { Meia derivada no tempo } \\ \frac{\partial}{\partial t} & - & \text { Derivada parcial no tempo } \\ \frac{\partial}{\partial x_{i}} & - & \text { Derivada parcial na coordenada } x_{i}\end{array}$

Sistema Discreto

$\left[\begin{array}{l}B_{1} \\ B_{2}\end{array}\right]^{e} \quad-\quad$ Matrix das derivadas espaciais das funções de forma do elemento

[C] - Matrix do sistema discreto para o termo de pressão

$[C]^{e} \quad-\quad$ Matrix do elemento para o termo de pressão

$\{f\} \quad-\quad$ Matrix coluna do termo forçante do sistema discreto

$\{g\} \quad-\quad$ Matrix coluna obtida da forma discreta da equação da continuidade

$[J]^{e} \quad-\quad$ Matrix jacobiana do elemento para o mapeamento os espaços $\xi_{1} \xi_{2}$ e $x_{1} x_{2}$

$[K] \quad-\quad$ Matrix de rigidez do sistema discreto para o termo difusivo

$[K]^{e} \quad-\quad$ Matrix de rigidez do elemento para o termo difusivo

$[M] \quad$ - $\quad$ Matrix de massa do sistema discreto para a derivada local

$[M]^{e} \quad-\quad$ Matrix de massa do elemento para a derivada local

$[N(u)] \quad-\quad$ Matrix de rigidez do sistema discreto para a derivada convectiva

$[N(u)]^{e} \quad-\quad$ Matrix de rigidez do elemento para a derivada convectiva

$[N]^{e} \quad-\quad$ Matrix linha das funções de forma

$\{p\} \quad-\quad$ Matrix coluna das pressões do sistema discreto 
$\{p\}^{e} \quad-\quad$ Matrix coluna das pressões nos nós do elemento

$\left\{p_{n}^{m}\right\} \quad-\quad$ Matrix coluna das pressões do sistema discreto no passo de tempo $n$ e na iteração $m$

$\{\delta p\}^{e} \quad$ - $\quad$ Matrix coluna das funções-teste da pressão nos nós do elemento

$\{u\} \quad-\quad$ Matrix coluna do campo de velocidades do sistema discreto

$\{\dot{u}\} \quad-\quad$ Matrix coluna da aceleração do sistema discreto

$\left\{u_{i}\right\}^{e} \quad-\quad$ Matrix coluna da velocidade $u_{i}$ nos nós do elemento

$\left\{u_{n}^{m}\right\} \quad-\quad$ Matrix coluna do campo de velocidades do sistema discreto no passo de tempo $n$ e na iteração $m$

$\left\{\delta u_{i}\right\}^{e} \quad-\quad$ Matrix coluna das funções-teste da velocidade nos nós do elemento 


\section{INTRODUÇÃO}

Um corpo imerso ao se movimentar interage com o fluido ao redor, e gera um escoamento descrito por um campo vetorial de velocidade e um campo escalar de pressão. O escoamento deve atender instantaneamente às leis de conservação de massa, quantidade de movimento e energia, e satisfazer as condições de contorno das fronteiras do domínio. É interessante notar que a interação ocorre na fina interface corpo/fluido, na qual se desenvolvem tensões normais de pressão e tangenciais de cisalhamento e troca de energia. Corpo e fluido formam dois sistemas dinâmicos acoplados.

Pela primeira lei de Newton, o corpo, suposto de massa constante, resiste a qualquer tentativa de alterar seu movimento. A esta resistência cunhou-se o termo inércia. Estando imerso, o corpo sofre, adicionalmente, a resistência (inercial e viscosa) das partículas fluidas próximas ao se movimentar, devido ao acoplamento dinâmico corpo/fluido. Toda alteração do movimento do corpo deve ser acompanhada de uma alteração do movimento do fluido, a fim de compatibilizar as leis de conservação e as condições de contorno.

É usual em hidrodinâmica definir-se massa adicional de um corpo rígido, imerso em meio fluido, como a razão entre a força reativa por ele experimentada e sua aceleração relativa ao esse meio. Tal força deve ser entendida de forma generalizada, no contexto da Mecânica Analítica, posto que acelerações em uma dada direção (seja de translação ou de rotação) podem ocasionar reações inerciais nas demais direções. Encontra-se ainda a denominação imprecisa de arrasto adicional. Por definição, em hidrodinâmica e aerodinâmica, a força de arrasto está associada, intrinsecamente, à velocidade, e não à aceleração, e tem natureza essencialmente viscosa.

Para um corpo que pretende alcançar uma velocidade limite, a força de inércia adicional classifica-se como uma força de natureza transiente, pois está presente nos instantes iniciais do movimento, na fase de aceleração, e contribui para a resistência total exercida pelo fluido no corpo neste período. Caso o corpo execute um movimento variável, e.g., movimento harmônico, ela terá uma contribuição permanente.

O fluido ao escoar em torno do corpo possui energia cinética, medida relativamente a um referencial, em geral inercial, e positiva por definição. A alteração da velocidade do 
corpo deve ser acompanhada de uma mudança da energia cinética do fluido, variação esta associada ao trabalho de uma força de resistência adicional, a força de inércia fluida.

Massa adicional relaciona a aceleração do corpo imerso com a força de inércia fluida, de maneira análoga à segunda lei de Newton, i.e., multiplicando-se a massa adicional pela aceleração do corpo, obtém-se a força de inércia fluida. Esta é também uma maneira direta de se obter a massa adicional de um corpo imerso, experimental e numericamente: impõe-se uma aceleração translacional ou de rotação ao corpo e medem-se as parcelas das forças e momentos reativos que estão em fase com a aceleração. De fato, o conceito de inércia adicional é bem formalizado, matematicamente, como uma entidade tensorial.

Os conceitos de inércia adicional e massa adicional ocorrem em diversas aplicações de engenharia, quando a densidade do corpo material é comparável a do meio no qual está imerso, i.e., da mesma ordem de grandeza. Um dos efeitos mais perceptíveis deste fenômeno é o aumento do período de oscilação e a alteração do modo de vibrar de sistemas mecânicos.

\subsection{Motivação e Objetivos do Trabalho}

Este trabalho foi motivado inicialmente pela dificuldade de se calcular o tensor de massa adicional em rotores de turbinas hidráulicas e em quantificar seu efeito na redução das frequências naturais do conjunto girante. Dada a geometria curva das pás do rotor, a proximidade de fronteiras e as características do escoamento, não é direta a avaliação da massa adicional para os diversos modos de vibrar (torcionais, axiais e flexionais), que se poderia imaginar realizável a partir de geometrias simples, disponíveis na literatura.

Ao iniciar os estudos sobre inércia adicional, deparou-se com uma literatura vasta, entretanto, dispersa, e, em grande parte, restrita a fluido invíscido e escoamento irrotacional, onde primeiramente tal conceito fora definido. A fim de entender os conceitos fundamentais e a contribuição dos efeitos da viscosidade, desde em escoamentos bem comportados até em escoamentos mais complexos, a motivação original cedeu lugar ao estudo da inercial adicional e das características do escoamento 
ao redor de corpos de geometria simples. Optou-se por estudar o clássico problema da inércia adicional do escoamento induzido por um cilindro circular rígido em movimento harmônico em um fluido em repouso. Essa geometria, além de comum em engenharia, conta com resultados experimentais, analíticos e numéricos bem validados, disponíveis na literatura. Conforme será visto, em que pese a simplicidade do problema escolhido, a dinâmica do escoamento induzida pelo cilindro oscilando harmonicamente é extensa e rica.

Este trabalho possui os seguintes objetivos:

- Revisitar alguns conceitos clássicos e trabalhos fundamentais sobre inércia adicional, tanto em escoamentos potenciais como em viscosos, dispersos na literatura.

- Avaliar numericamente as forças do escoamento em torno de um cilindro circular oscilando harmonicamente em um fluido em repouso, e extrair a massa adicional desde em escoamentos bem comportados até em escoamentos mais complexos.

\subsection{Estrutura do Trabalho}

Esta dissertação está divida em cinco capítulos, incluso este introdutório, e um apêndice.

O Capítulo 2 apresenta as equações fundamentais da dinâmica dos fluidos e um histórico sucinto do desenvolvimento do conceito de inércia adicional no contexto de escoamento potencial. São apresentados dois métodos analíticos para o cálculo da massa adicional potencial. Em seguida, revisita trabalhos da pesquisa analítica, experimental e numérica sobre inércia adicional do escoamento viscoso em torno do cilindro circular em oscilação forçada.

No Capítulo 3, são detalhados o método numérico aplicado na solução das equações da dinâmica dos fluidos e as considerações feitas na simulação do escoamento em torno do cilindro circular em oscilação forçada. São discutidas as condições iniciais e de contorno, a ordem espacial e temporal do método, a tratativa do termo convectivo e da restrição de incompressibilidade, bem como tecidas considerações acerca da malha de discretização utilizada no emprego do método de elementos finitos. 
No Capítulo 4, os resultados das simulações são apresentados e comparados com trabalhos experimentais, analíticos e numéricos disponíveis na literatura.

No Capítulo 5, são feitas considerações finais e sugeridas propostas de trabalhos futuros.

O Apêndice A detalha a obtenção da forma fraca das equações de conservação de massa e da quantidade de movimento aplicada a fluidos, e a discretização pelo método dos elementos finitos. Foca-se também o aspecto computacional do problema com a determinação das matrizes de massa e rigidez. 


\section{INÉRCIA ADICIONAL DO ESCOAMENTO EM TORNO DE CILINDRO CIRCULAR EM OSCILAÇÃO FORÇADA}

Este capítulo inicia-se com as equações que regem a dinâmica dos fluidos, necessárias para o desenvolvimento do tema, e apresenta a notação a ser utilizada ao longo do texto.

O escoamento de um fluido Newtoniano pode ser descrito por um campo vetorial de velocidade $u_{i}\left(x_{i}, t\right)$ e dois campos escalares, o de pressão $p\left(x_{i}, t\right)$ e o de densidade $\rho\left(x_{i}, t\right)$. Escreve-se o princípio de conservação da massa em coordenadas cartesianas, também chamada de equação da continuidade ${ }^{1}$, segundo Aris (1989), como:

$$
\frac{\partial \rho}{\partial t}+\frac{\partial\left(\rho u_{i}\right)}{\partial x_{i}}=0
$$

Caso o escoamento seja aproximado como incompressível ${ }^{2}$, a densidade do fluido é invariante no espaço e tempo, $\rho\left(x_{i}, t\right)=c t$. Isso permite simplificar e reescrever a equação da continuidade na forma:

$$
\frac{\partial u_{i}}{\partial x_{i}}=0
$$

Um campo vetorial com essa propriedade é dito solenoidal, i.e., possui divergência nula. Neste trabalho, o escoamento é modelado como tal.

Desconsiderando as forças de campo volumétricas (e.g., gravidade), o princípio da conservação da quantidade de movimento do escoamento incompressível é regido, segundo Aris (1989), pela equação:

$$
\rho\left(\frac{\partial u_{i}}{\partial t}+u_{j} \frac{\partial u_{i}}{\partial x_{j}}\right)=\frac{\partial T_{i j}}{\partial \mathrm{x}_{j}}
$$

O primeiro termo, chamado de derivada local, é a variação temporal do campo de velocidades num ponto específico do fluido, sendo identicamente nulo para escoamento permanente. O segundo termo, chamado de derivada convectiva, é a aceleração devida a

\footnotetext{
${ }^{1}$ Neste trabalho utiliza-se a notação indicial de Einstein: índices repetidos indicam somatória de 1 até $n$, sendo $n$ a dimensão do espaço ( $n=2$ ou $n=3$, para domínio bidimensional e tridimensional, respectivamente); índices livre podem assumir valores de 1 até $n$, e dão a ordem do tensor.

${ }^{2}$ Ressalta-se que na natureza não existe, estrito senso, fluido incompressível, e todos eles apresentam certo grau de compressibilidade.
} 
uma variação espacial do campo de velocidades. Sua não linearidade impõe dificuldades na resolução analítica e numérica do escoamento.

Para um fluido desprovido de viscosidade, invíscido, o tensor de tensões $T_{i j}$ assume uma forma bastante simples ${ }^{3}$ :

$$
T_{i j}=-p \delta_{i j}
$$

As únicas tensões possíveis são aquelas normais ao volume diferencial considerado, de pressão. Apesar de hipotético, o escoamento de fluido invíscido é capaz de representar com certa fidelidade o escoamento distante de regiões nas quais os efeitos viscosos são relevantes, por exemplo, externo à camada limite.

Substituindo o tensor de tensões (4) na equação (3), obtém-se a equação de Euler:

$$
\rho\left(\frac{\partial u_{i}}{\partial t}+u_{j} \frac{\partial u_{i}}{\partial x_{j}}\right)=-\frac{\partial p}{\partial x_{i}}
$$

A conexão entre a equação da continuidade e a da conservação de quantidade de movimento é dada pela pressão. De fato, a pressão ajusta a equação da quantidade de movimento a fim que o escoamento satisfaça a restrição de incompressibilidade eq. (2) (SELIGER; WHITHAM, 1968) ${ }^{4}$ e (ARANHA, 2009).

É possível decompor o termo convectivo em duas parcelas ${ }^{5}: u_{j} \frac{\partial u_{i}}{\partial x_{j}}=\frac{1}{2} \frac{\partial\left(u_{j} u_{j}\right)}{\partial x_{i}}-$ $\epsilon_{i j k} u_{j} \omega_{k}$, com $\omega_{k}=\epsilon_{i j k} \frac{\partial u_{j}}{\partial x_{i}}$ sendo o rotacional do campo de velocidades. Para o escoamento invíscido e irrotacional, $\omega_{k}=0$, existe uma função potencial $\phi$ cujo gradiente resulta no campo de velocidade, $u_{i}=\frac{\partial \phi}{\partial x_{i}}(\mathrm{LAMB}, 1932)$. Fazendo $q=\sqrt{u_{i} u_{i}}$ o módulo da velocidade, obtém-se a clássica equação de Bernoulli:

$$
\frac{\partial \phi}{\partial t}+\frac{1}{2} q^{2}+\frac{p}{\rho}=c t e
$$

\footnotetext{
${ }^{3} \delta_{i j}$ é o delta de Kronecker: $\delta_{i j}= \begin{cases}0, & \text { se } i \neq j \\ 1, & \text { se } i=j\end{cases}$
}

${ }^{4}$ Conforme Seliger e Whitham (1968), nestas condições a pressão é a Lagrangiana do sistema fluidodinâmico.

$$
{ }^{5} \epsilon_{i j k} \text { é símbolo de permutação: } \epsilon_{i j k}=\left\{\begin{array}{cl}
0, & \text { se qualquer } \mathrm{i}, \mathrm{j}, \mathrm{k} \text { forem repetidos } \\
1, & \text { se ijk for uma permutação par } \\
-1, & \text { se ijk for uma permutacao ímpar }
\end{array}\right.
$$


Da equação da continuidade (2) aplicada ao campo de velocidades, neste caso dado pelo gradiente da função potencial, o escoamento fica regido pela equação de Laplace e respectivas condições de contorno (naturais e/ou essenciais):

$$
\frac{\partial^{2} \phi}{\partial \mathrm{x}_{i} \partial \mathrm{x}_{i}}=0 \text { ou } \nabla^{2} \phi=0
$$

A equação de Laplace é uma equação diferencial de derivadas parciais, elíptica e linear, cujas soluções podem ser combinadas a fim de se obter escoamentos mais complexos. Dentre as propriedades do escoamento potencial e incompressível, demonstra-se que ele possui energia cinética mínima (LAMB, 1932) e que existe apenas um escoamento possível satisfazendo as condições de contorno. Por outro lado, o escoamento não mais apresenta a multiplicidade de fenômenos associados com a vorticidade (LIGHTHILL, 1986).

Dado o caráter elíptico da equação de Laplace, condições de contorno são necessárias em todas as fronteiras do domínio. Na fronteira sólida (corpo), a condição (natural) de impenetrabilidade da superfície exige que corpo e fluido possuam a mesma velocidade normal à superfície do corpo. Na fronteira externa, distante do corpo, impõese a velocidade do fluido ao longe.

Em princípio, tendo disponível a função potencial de velocidade $\phi$ para o escoamento em torno de um corpo, satisfazendo as condições de contorno, é possível extrair o tensor de massa adicional. Isso será explorado a seguir, junto com um breve histórico do desenvolvimento do tema.

\subsection{Inércia Adicional em Escoamento Potencial}

A noção de inércia adicional foi introduzida no estudo das pequenas oscilações do pêndulo esférico imerso em água por Chevalier Dubuat em 1776 (KOROTKIN, 2010). Cientistas a ele contemporâneos trabalharam na determinação experimental do período de oscilação de pêndulos esféricos imersos em diversos meios com elevada precisão; citam-se vácuo, água, ar e hidrogênio. Aventar o empuxo de Arquimedes não era suficiente para explicar o aumento do período de oscilação que foi, por muito tempo, a única correção aplicada ao problema. Em um movimento pendular, a oscilação é a resposta de uma excitação inicial com o fluido em repouso. Comumente, aplica-se ao 
pêndulo um deslocamento de sua posição de equilíbrio estável soltando-o para oscilar livremente. A velocidade do corpo varia continuamente, e, portanto, a inércia adicional tem uma contribuição permanente no movimento e na dinâmica do sistema.

A expressão exata para a massa adicional de uma esfera foi obtida por Poisson em 1831 e confirmada por George Green (1833) para um elipsoide, com as hipóteses de pequenas oscilações, fluido invíscido e incompressível e movimento irrotacional (escoamento potencial).

Green expressa a massa adicional como um aumento fictício da densidade do corpo. $\mathrm{Na}$ equação dinâmica de movimento do pêndulo esférico ${ }^{6}$, por exemplo, sua massa é reescrita como $m^{\prime}=\rho^{\prime} V_{d}$, na qual $\rho^{\prime}=\rho_{c}+\frac{1}{2} \rho$, sendo $\rho_{c}$ e $\rho$ a densidade, respectivamente, do corpo e do fluido. $V_{d}$ é o volume deslocado de fluido. Dessa maneira, reduz-se a influência do fluido na dinâmica do movimento a um equivalente incremento de massa. Para a esfera, a massa adicional é metade da massa de fluido deslocada pelo corpo.

Esta representação difundiu o conceito impreciso de "massa adicional". Na realidade nenhuma massa é adicionada ou subtraída do corpo; o meio fluido é acelerado (desacelerado), e existe uma variação positiva (negativa) de sua energia cinética em função da aceleração do corpo, devido ao acoplamento dinâmico entre ambos (SARPKAYA, 2010).

Kirchhoff (1870) utilizou o princípio de Hamilton e a formulação da Mecânica Analítica para escrever as equações dinâmicas do movimento de um corpo rígido com seis graus de liberdade (três coordenadas de translação e três coordenadas de rotação) imerso em fluido invíscido e irrotacional.

Para um corpo rígido com três direções de translação e três eixos de rotação, a massa adicional é expressa na forma de um tensor de segunda ordem, o qual relaciona a aceleração em um dos graus de liberdade com o efeito inercial no demais. Entretanto, soluções analíticas para o escoamento potencial estão disponíveis apenas para geometrias simples (KOROTKIN, 2010). Para geometrias mais complexas ou condições de fronteira diversas, utilizam-se métodos experimentais ou numéricos.

\footnotetext{
${ }^{6}$ São desprezados os efeitos inerciais e de arrasto no fio pendente.
} 
Curiosamente, apesar de a inércia adicional ser um fenômeno dinâmico, i.e., de manifestar sua presença apenas quando o corpo é acelerado, para o escoamento potencial, a massa adicional pode ser calculada a partir do movimento instantâneo do corpo. Na realidade, tal fato está intrinsicamente ligado a ser o escoamento potencial destituído de memória.

\subsubsection{Método da Energia}

A equação diferencial parcial de Laplace (7) é linear, e as soluções para os movimentos de translação (velocidades de translação: $U_{1} \ldots U_{3}$ ) e de rotação (velocidades de rotação: $U_{4} \ldots U_{6}$ ) do corpo rígido podem ser linearmente combinadas:

$$
\phi=U_{1} \phi_{1}+U_{2} \phi_{2}+U_{3} \phi_{3}+U_{4} \phi_{4}+U_{5} \phi_{5}+U_{6} \phi_{6}
$$

Ao integrar no domínio a contribuição da energia cinética das partículas, escreve-se a energia cinética do fluido como:

$$
E_{C}=\frac{1}{2} \int_{\Omega} \rho q^{2} d \Omega
$$

Na qual, $q$ é o módulo do vetor velocidade:

$$
q=\sqrt{u_{i} u_{i}}
$$

Para escoamento potencial, o campo de velocidades é determinado pelo gradiente da função potencial, portanto:

$$
E_{C}=\frac{1}{2} \int_{\Omega} \rho \frac{\partial \phi}{\partial x_{i}} \frac{\partial \phi}{\partial x_{i}} d \Omega
$$

Aplica-se então o teorema de Green a fim de transformar a integral de volume acima em uma integral de superfície:

$$
\begin{gathered}
E_{C}=\frac{1}{2} \int_{\Omega} \rho \frac{\partial \phi}{\partial x_{i}} \frac{\partial \phi}{\partial x_{i}} d \Omega=-\frac{1}{2} \int_{\mathrm{S}+\Sigma} \rho \phi \frac{\partial \phi}{\partial x_{i}} \mathrm{n}_{i} d \Gamma \\
=-\frac{1}{2} \int_{\mathrm{S}+\Sigma} \rho \phi \frac{\partial \phi}{\partial \mathrm{n}} d \Gamma
\end{gathered}
$$

na qual, $S$ e $\Sigma$ são as superfícies do sólido imerso e de uma esfera que o contém, de raio muito maior que o sólido, respectivamente. $\mathrm{O}$ sinal negativo na equação é 
necessário a fim de se obter valores positivos, pois o corpo é enxergado como um "buraco" no domínio, limitado pelas superfícies $S$ e $\Sigma$, e a normal aponta, matematicamente, para o seu interior em $S$.

Assumindo que as derivadas parciais de $\phi$ tendam a zero, conforme o raio da esfera $\Sigma$ tende $\mathrm{a} \infty$ :

$$
E_{C}=-\frac{1}{2} \int_{\mathrm{S}} \rho \phi \frac{\partial \phi}{\partial \mathrm{n}} d \Gamma
$$

Esta condição é necessária para que a integral convirja e impede que uma velocidade finita se estendendo até infinito resulte em uma energia cinética infinita do fluido, a qual não poderia ser gerada por forças finitas em um período finito de tempo pelo sólido (LAMB, 1932). Outra implicação é a invariância em uma mudança de referencial galileana, e o escoamento uniforme deve ser subtraído do cálculo da energia cinética do fluido.

Substituindo a equação (8) na equação (13), obtém-se:

$$
E_{C}=\frac{1}{2} \sum_{i=1}^{6} \sum_{j=1}^{6} m_{i j} U_{i} U_{j}
$$

Sendo os $m_{i j}$ dados por

$$
m_{i j}=-\rho \int_{\mathrm{S}} \phi_{i} \frac{\partial \phi_{j}}{\partial \mathrm{n}} d \Gamma
$$

Os coeficientes $m_{i j}$ formam o tensor de massa adicional. No presente caso, de um corpo imerso em um fluido que se estende em todas as direções até o infinito, o tensor de massa adicional depende apenas da geometria do corpo, da densidade do fluido e do sistema de coordenadas utilizado. Quando próximo a uma superfície livre ou sólida (fixa ou outros corpos), a forma integral dada pela equação (12) deve considerá-las, fazendo com que o tensor de massa adicional dependa não apenas da geometria do corpo mas também de sua posição.

Adimensionaliza-se o tensor de massa adicional dividindo-se cada termo $m_{i j}$ pela massa deslocada de fluido $\rho V_{d}$. Os termos $C_{A_{i j}}$ são chamados de coeficientes de massa adicional: 


$$
C_{A_{i j}}=\frac{m_{i j}}{\rho V_{d}}=-\frac{1}{V_{d}} \int_{\mathrm{S}} \phi_{i} \frac{\partial \phi_{j}}{\partial \mathrm{n}} d \Gamma
$$

No caso bidimensional, utiliza-se a área deslocada, $A_{d}$. Caso o interesse seja em uma direção específica, diz-se apenas massa adicional $m_{a}$ e coeficiente de massa $C_{A}$.

As partículas fluidas possuem claramente velocidades e acelerações distintas do movimento do corpo, com exceção daquelas da interface, que apresentam a mesma componente normal de velocidade, podendo, entretanto, deslizar tangencialmente na superfície do corpo no escoamento potencial. Pelo desenvolvimento acima, nota-se que o tensor de massa adicional está intimamente relacionado com a energia cinética do fluido para uma dada condição cinemática (velocidades) do corpo sólido.

A função potencial de velocidade e a energia cinética do fluido são expressas, respectivamente, como uma combinação linear e uma função quadrática (positiva definida) das velocidades generalizadas do corpo. Ao combinar a energia cinética do fluido com a do corpo na formulação da Mecânica Analítica, trata-se o sistema dinâmico como único e resume-se o comportamento do fluido ao tensor de massa adicional (KIRCHHOFF, 1870) e (LAMB, 1932).

Para um cilindro circular de diâmetro $D$ que se se movimenta com velocidades de translação $U_{1}$ e $U_{2}$, nos eixos $x_{1}$ e $x_{2}$, a ele perpendiculares, a função potencial de velocidade $\phi$, no instante em que ele passa pela origem do sistema de coordenadas, é expressa, sem perda de generalidade, por:

$$
\phi=U_{1} \phi_{1}+U_{2} \phi_{2}=U_{1}\left(\frac{D^{2}}{4} \frac{\cos \theta}{r}\right)+U_{2}\left(\frac{D^{2}}{4} \frac{\operatorname{sen} \theta}{r}\right)
$$

Assume-se implicitamente que o escoamento seja bidimensional. O cilindro circular não é capaz de induzir qualquer escoamento para uma dada velocidade de rotação $U_{6}$ em torno do eixo z, no escoamento potencial. $\log 0 \phi_{6}$ é identicamente nulo.

A condição de impenetrabilidade da superfície exige que corpo e fluido devam possuir a mesma velocidade normal na interface. Portanto, a derivada normal da função potencial deve ser igual à velocidade da superfície do cilindro:

$$
\frac{\partial \phi}{\partial \mathrm{n}}=U_{1} n_{1}+U_{2} n_{2}=U_{1} \frac{\partial \phi_{1}}{\partial \mathrm{n}}+U_{2} \frac{\partial \phi_{2}}{\partial \mathrm{n}}=-U_{1} \cos \theta-U_{2} \operatorname{sen} \theta
$$


Substituindo $\phi_{1}$ e $\frac{\partial \phi_{1}}{\partial \mathrm{n}}$ na equação (15):

$$
m_{11}=-\rho \int_{\mathrm{S}} \phi_{1} \frac{\partial \phi_{1}}{\partial \mathrm{n}} d \Gamma=\rho \int_{0}^{2 \pi}\left(\frac{D^{2}}{4} \frac{\cos \theta}{r}\right) \cos \theta r d \theta=\rho \frac{\pi D^{2}}{4}
$$

E, similarmente, para $\phi_{1} \mathrm{e} \frac{\partial \phi_{2}}{\partial \mathrm{n}}$ :

$$
m_{12}=-\rho \int_{\mathrm{S}} \phi_{1} \frac{\partial \phi_{2}}{\partial \mathrm{n}} d S=\rho \int_{0}^{2 \pi}\left(\frac{D^{2}}{4} \frac{\cos \theta}{r}\right) \operatorname{sen} \theta r d \theta=0
$$

O coeficiente $m_{22}$ deve necessariamente ser igual a $m_{11}$, dada a simetria do corpo.

$$
m_{11}=m_{22}=\rho \frac{\pi D^{2}}{4} \text { e } m_{12}=m_{66}=0
$$

No caso particular do cilindro circular, conclui-se que o coeficiente de inércia é unitário, $C_{A}=1$, e que a massa adicional coincide com a massa deslocada.

\subsubsection{Método de Darwin}

O método de Darwin (1953) demonstra a equivalência da massa adicional de um corpo em translação uniforme em escoamento potencial com a massa deslocada através de uma seção perpendicular ao movimento, antes e após a passagem do corpo. Para escoamento incompressível, utiliza-se, ao invés da massa deslocada e à parte de uma constante, o volume deslocado, denominado na literatura afim como drift volume, em inglês.

Ao se basear nas trajetórias das partículas, a passagem do corpo vindo do infinito deforma continuamente as partículas marcadas em um plano de referência lagrangiano, figura 1. As partículas não retornam às suas posições de origem após passagem do corpo e apresentam um deslocamento líquido. A equivalência desta massa deslocada com a massa adicional é surpreendente. 

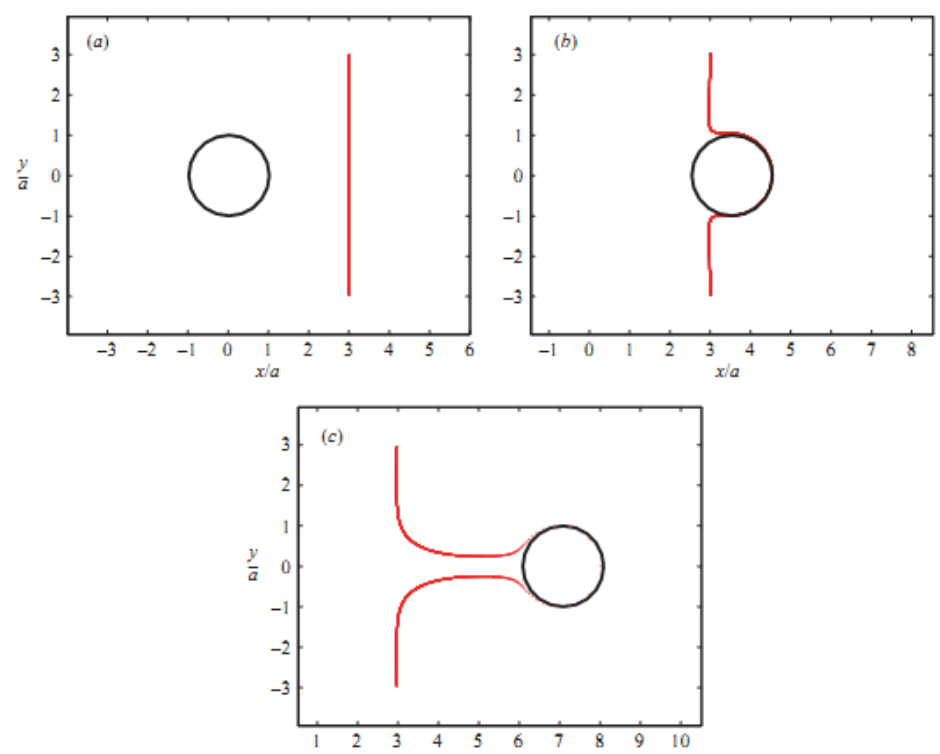

Figura 1 - Plano de referência de partículas lagrangianas (DABIRI, 2006)

Considerando o escoamento potencial bidimensional ao redor de um corpo dado pela função potencial (22), na qual as parcelas do escoamento uniforme e da perturbação são separadas:

$$
\phi=x_{1}+\phi^{\prime}
$$

As componentes do vetor velocidade nas direções $x_{1}$ e $x_{2}$, respectivamente, $u_{1}$ e $u_{2}$, são obtidas pelo gradiente da função potencial:

$$
u_{i}=\frac{\partial \phi}{\partial x_{i}} \Rightarrow u_{1}=1+\frac{\partial \phi^{\prime}}{\partial x_{1}}, u_{2}=\frac{\partial \phi^{\prime}}{\partial x_{2}}
$$

O deslocamento líquido de uma partícula em uma linha de corrente é dado pela integral a seguir, na qual é convenientemente feita uma transformação de variáveis, conforme Darwin (1953):

$$
X=\int_{-\infty}^{+\infty}\left(u_{1}-1\right) d t=\int_{-\infty}^{+\infty} \frac{\partial \phi^{\prime}}{\partial x_{1}} d t=\int_{-\infty}^{+\infty} \frac{\partial \phi^{\prime}}{\partial x_{1}} \frac{\partial\left(x_{1}, x_{2}\right)}{\partial(\phi, \psi)} d \phi
$$

Para o escoamento como um todo, é necessária a integração em todas as linhas de correntes $\psi$ a fim de se obter a área deslocada. No cálculo das integrais no domínio infinito, a ordem de integração é de extrema importância para a convergência: 


$$
Y=\int_{-\infty}^{+\infty} X d \psi=\int_{-\infty}^{+\infty} \int_{-\infty}^{+\infty} \frac{\partial \phi^{\prime}}{\partial x_{1}} \frac{\partial(x, y)}{\partial(\phi, \psi)} d \phi d \psi
$$

No caso geral tridimensional, não existem mais relações simples entre a função potencial e a de corrente, vide Yih (1957). Entretanto, seguindo um raciocínio similar ao bidimensional, Darwin (1953) também demostra a equivalência entre a massa deslocada e a massa adicional.

Duas novas demonstrações são apresentadas por Yih (1985) para o teorema de Darwin, a primeira utilizando o conceito de atraso de tempo (do inglês, time lag) e a segunda, com base nos princípios da continuidade e da conservação da quantidade de movimento.

As hipóteses de meio fluido se estendendo em todas as direções até o infinito e de que o corpo atravesse o plano de referência vindo do infinito são fundamentais nos resultados de Darwin. Eames, Belcher e Hunt (1994) generalizam esses resultados ao considerar um plano de referência de dimensões finitas e uma esfera inicialmente a uma distância finita deste plano.

\subsection{Inércia Adicional em Escoamento Viscoso}

No escoamento potencial não existe atrito entre partículas fluidas vizinhas com velocidades diferentes, e elas podem deslizar entre si, sem resistência. Em fluidos viscosos, ocorrem tensões cisalhantes. Para fluidos newtonianos, a tensão cisalhante é uma função linear da taxa de deformação (gradiente da velocidade) e da viscosidade. Sendo a viscosidade dinâmica $\mu$ e o fluido incompressível, o tensor de tensões $T_{i j}$ (4) assume a forma:

$$
T_{i j}=-p \delta_{i j}+2 \mu E_{i j}
$$

Na qual, $E_{i j}$ é o tensor taxa de deformação:

$$
E_{i j}=\frac{1}{2}\left[\frac{\partial \mathrm{u}_{i}}{\partial \mathrm{x}_{j}}+\frac{\partial \mathrm{u}_{j}}{\partial \mathrm{x}_{i}}\right]
$$


Substituindo (26) e (27) na equação da conservação da quantidade de movimento (3), obtém-se a equação de Navier-Stokes (NS):

$$
\rho\left(\frac{\partial u_{i}}{\partial t}+u_{j} \frac{\partial u_{i}}{\partial x_{j}}\right)=-\frac{\partial p}{\partial x_{i}}+\mu \frac{\partial^{2} u_{i}}{\partial x_{j} \partial x_{j}}
$$

Comparando a equação de Euler (5) com a equação de NS (28), nota-se que a equação de NS possui um termo difusivo adicional (segundo termo do lado direito da equação). Ele é responsável pelo desenvolvimento de tensões viscosas próximas à parede do corpo e pelo aparecimento dos diversos fenômenos associados com a vorticidade.

Será útil nos desenvolvimentos a seguir tratar a equação de NS em termos de variáveis adimensionais. O escoamento possui um comprimento característico $D$, relacionado com o tamanho da fronteira, uma velocidade característica $U$, ao longe ou da fronteira, e um tempo característico $T$. Ao escalar as coordenadas espaciais por $D$, a velocidade por $U$, o tempo por $T$, e a pressão por $\rho U^{2}$ as seguintes variáveis adimensionais ficam definidas:

$$
t^{*}=\frac{t}{T}, x_{i}^{*}=\frac{x_{i}}{D}, u_{i}^{*}=\frac{u_{i}}{U}, p^{*}=\frac{p}{\rho U^{2}}
$$

Adimensionaliza-se então a equação de NS (28) que fica escrita na forma:

$$
\frac{1}{K C} \frac{\partial u_{i}^{*}}{\partial t^{*}}+u_{j}^{*} \frac{\partial u_{i}^{*}}{\partial x_{j}^{*}}=-\frac{\partial p^{*}}{\partial x_{j}^{*}}+\frac{1}{R e} \frac{\partial^{2} u_{i}^{*}}{\partial x_{j}^{*} \partial x_{j}^{*}}
$$

Aparecem diretamente os adimensionais, número de Reynolds $(R e)$ e KeuleganCarpenter $(K C)$. Esta forma adimensional da equação de NS será adotada deste ponto em diante, abandonando-se os asteriscos, por simplicidade de notação.

O número de Reynolds, definido por $R e=\frac{\rho U D}{\mu}$, é uma razão entre forças de inércia $\frac{\rho U^{2}}{D}$ e viscosas $\frac{\mu U}{D^{2}}$. Ele indica o regime de escoamento, por exemplo, laminar ou turbulento, ou ainda o aparecimento de instabilidades, como a esteira de vórtices. Para escoamento em torno de cilindro circular, toma-se como comprimento característico $D$ o diâmetro do cilindro. Para escoamento oscilatório, a velocidade característica $U$ é a máxima do período. 
O número de Keulegan-Carpenter, definido por $K C=\frac{U T}{D}$, é uma razão entre as escalas da derivada convectiva, $\frac{U^{2}}{D}$, e da derivada local, $\frac{U}{T}$, para escoamento não permanente, usualmente, oscilante com período $T$.

A razão entre o número de Reynolds e o número de Keulegan-Carpenter resulta no adimensional $\beta=\frac{R e}{K C}=\frac{D^{2}}{v T}$, sendo $v=\frac{\mu}{\rho}$, a viscosidade cinemática. O parâmetro $\beta$, parâmetro da frequência ou ainda número de Stokes, elimina a dependência de ambos adimensionais, Re e KC, da velocidade característica $U$ do escoamento. Ele representa a razão entre as escalas de tempo da difusão viscosa $\frac{D^{2}}{v}$ e da oscilação do escoamento $T$.

Muito se discute a respeito da extensão dos conceitos apresentados de inércia adicional potencial para escoamento viscoso e vorticoso. A inércia adicional potencial é uma aproximação válida somente para os instantes iniciais do movimento, que se manifesta antes do desenvolvimento dos efeitos viscosos, da separação da camada limite e para pequenos deslocamentos, segundo Sarpkaya (2010).

A figura 2 mostra os estágios de desenvolvimento do escoamento ao redor de um cilindro circular fixo, típico corpo rombudo ${ }^{7}$. Nos instantes iniciais o escoamento é bem representado pelo modelo potencial no exterior de uma fina camada que se estabelece ao redor do corpo, denominada camada limite e onde os efeitos das forças viscosas prevalecem. Dada a condição de aderência, $u_{i}=0$ na superfície do cilindro, vorticidade é constantemente criada na camada limite. Se o número de Reynolds for suficiente elevado, no caso do cilindro, $5 \lesssim R e \lesssim 46$, a vorticidade gerada na interface induz a um descolamento (separação) da camada limite, denominada camada cisalhante livre, e são formados dois vórtices estacionários, contra rotativos a jusante. Com o aumento da velocidade, para $R e \gtrsim 46$, surge a primeira instabilidade do escoamento com a emissão alternada de vórtices. Eles são transportados por convecção para jusante e forma-se então a esteira de von Kármán de caráter transitório. A formação da esteira representa uma bifurcação da resposta do sistema dinâmico de um ponto de equilíbrio assintoticamente estável ( $R e \lesssim 46$ ) para um ciclo-limite assintoticamente estável $(R e \gtrsim 46)$.

\footnotetext{
${ }^{7}$ Corpo rombudo é aquele que possui uma parte considerável de seu comprimento característico exposto a escoamento separado, sendo capaz de gerar e interagir com vórtices.
} 


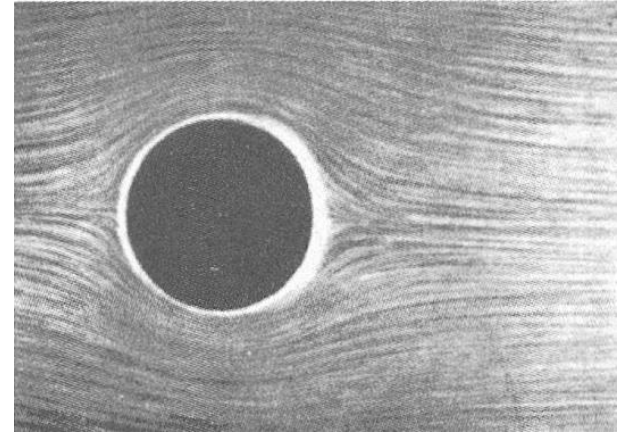

(a)

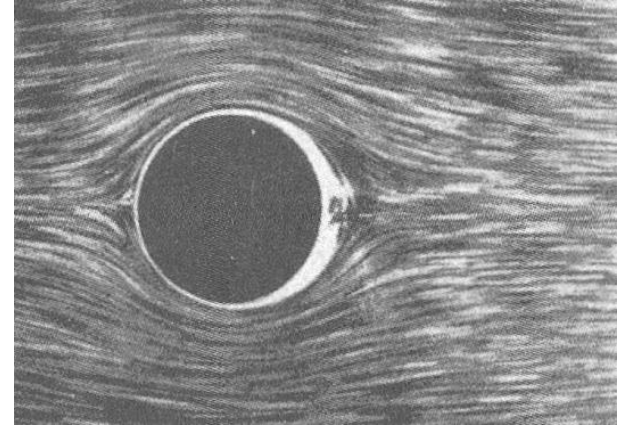

(b)

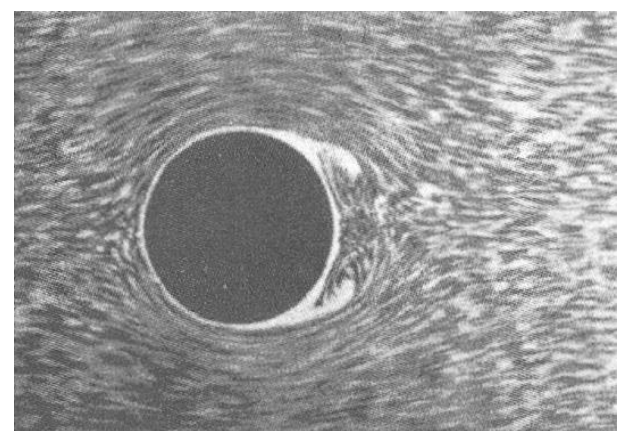

(c)

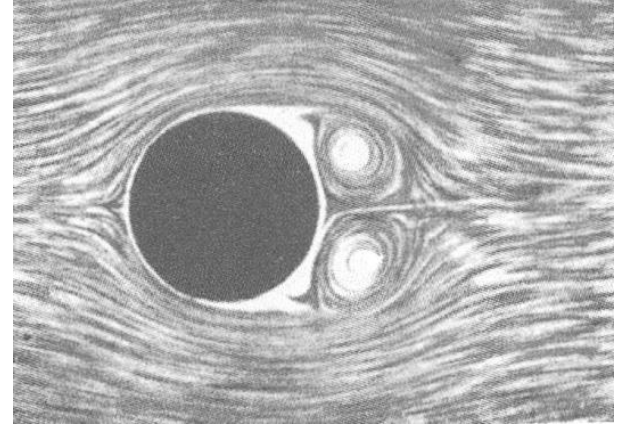

(d)

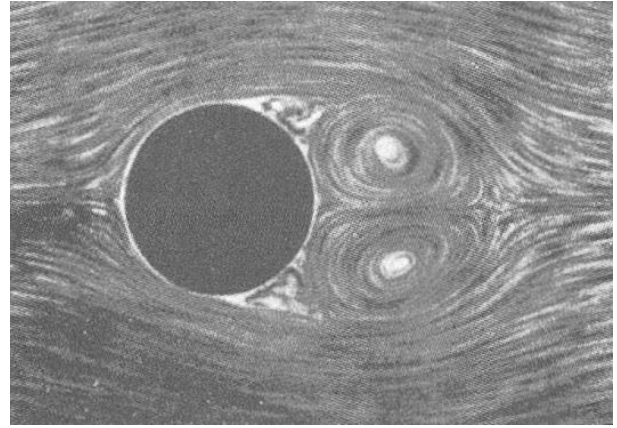

(e)

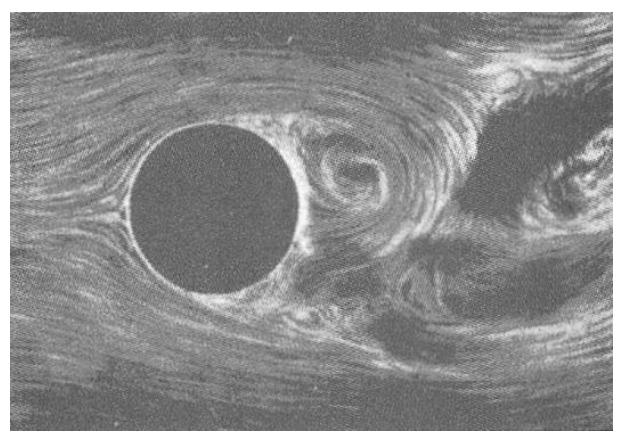

(f)

Figura 2 - Desenvolvimento do escoamento ao redor do cilindro (BATCHELOR, 1967).

Ao observar a topologia do escoamento acima, verifica-se que a vorticidade altera significativamente o campo de velocidades, seja devido à condição de aderência, do descolamento da camada limite ou de vórtices. Certamente a energia cinética do escoamento será diferente daquela do escoamento potencial. De fato, conforme teorema de Kelvin da mínima energia (LAMB, 1932), o escoamento potencial irrotacional possui a menor energia cinética que qualquer outro satisfazendo a mesma velocidade normal na fronteira, e, consequentemente, a massa adicional, definida a partir da energia cinética, será mínima para o escoamento potencial.

Chevalier Dubuat já questionava a influência da viscosidade sobre o período de oscilação de pêndulos. Ciente das limitações da teoria potencial, Stokes (1850), com as hipóteses de fluido incompressível, viscoso e pequenas oscilações, desconsiderou o 
termo convectivo não-linear ${ }^{8}$ da equação de NS e obteve a força exercida pelo fluido sobre uma esfera imersa em um fluido em repouso, e que nele desenvolve um movimento harmônico de período $T$ :

$$
F_{1}(t)=-\rho\left(\frac{1}{2}+\frac{9}{2} \sqrt{\frac{v T}{\pi D^{2}}}\right) \frac{\pi D^{3}}{6} \frac{d U_{1}}{d t}-\left(1+\frac{1}{2} \sqrt{\frac{\pi D^{2}}{v T}}\right) 3 \pi \mu D U_{1}
$$

O primeiro termo corresponde à força de inércia do fluido, oposta à aceleração da esfera. No escoamento potencial, o coeficiente de massa adicional da esfera é $C_{A}=\frac{1}{2}$. Percebe-se o acréscimo do coeficiente de massa para o escoamento de Stokes, $C_{A}=\frac{1}{2}+$ $\frac{9}{2} \sqrt{\frac{v T}{\pi D^{2}}}=\frac{1}{2}+\frac{9}{2}(\pi \beta)^{-1 / 2}$. Nota-se ainda sua dependência com o parâmetro $\beta$. O segundo termo corresponde à força de arrasto do fluido, contrária à velocidade da esfera.

O resultado de Stokes é notável ao explicar a divergência do período de oscilação encontrada para o pêndulo imerso em diferentes meios. Stokes compara seu resultado analítico com resultados experimentais anteriores e encontra excelente aderência.

A equação (31) dará origem a importantes discussões sobre a definição de inércia adicional para escoamento rotacional e não-estacionário ao redor de corpos rombudos, após um século de sua formulação, nos trabalhos de Sarpkaya $(1977,2001,2005)$ e Lighthill (1986).

Em um escoamento de Stokes transitório, surge o termo histórico, que é uma força devida à contribuição da viscosidade e da aceleração, e descreve o atraso do desenvolvimento da camada limite, conforme a velocidade $U_{1}$ varia. É também conhecido como integral da memória, pois é função de todo o passado do movimento do corpo. O resultado ${ }^{9}$ a seguir, originalmente obtido por Basset e Boussinesq para o escoamento de Stokes, expressa a força do fluido sobre a esfera como a soma de três parcelas, força de inércia potencial, força de arrasto e termo histórico:

\footnotetext{
${ }^{8}$ Denominado posteriormente de escoamento de Stokes ou creeping flow, do inglês.

${ }^{9}$ Sua dedução e discussão podem ser encontradas em Maxey e Riley (1983).
} 


$$
F_{1}(t)=-\frac{1}{2} \rho \frac{\pi D^{3}}{6} \frac{d U_{1}}{d t}-3 \pi \mu D U_{1}-6 \sqrt{\pi \rho \mu} \frac{D^{2}}{4} \int_{-\infty}^{t} \frac{\frac{d U_{1}}{d \tau}}{\sqrt{t-\tau}} d \tau
$$

No movimento harmônico, repetitivo, o termo histórico é também harmônico, e com fase entre a velocidade e a aceleração. O resultado de Stokes para a esfera pode ser interpretado como uma decomposição do termo histórico em duas componentes: uma em fase com a velocidade, e outra em fase com a aceleração. O termo histórico se enquadra adicionalmente nos conceitos de semiderivada no tempo, no contexto mais geral do denominado "cálculo a derivadas fracionárias", segundo Tatom (1988) e Oldham e Spanier (2006):

$$
F_{1}(t)=-\frac{1}{2} \rho \frac{\pi D^{3}}{6} \frac{d U_{1}}{d t}-3 \pi \mu D U_{1}-6 \sqrt{\rho \mu} \pi \frac{D^{2}}{4} \frac{d^{1 / 2} U_{1}}{d t^{1 / 2}}
$$

Sendo a velocidade da esfera expressa como $U_{1}=\cos \left(\frac{2 \pi t}{T}\right)$, as equações (31), (32) e (33) se relacionam pela derivada fracionária da função cosseno, desprezando os termos transitórios para $t \gg 1$, conforme Tatom (1988), e após certo trabalho algébrico:

$$
\frac{d^{1 / 2} U_{1}}{d t^{1 / 2}}=\int_{-\infty}^{t} \frac{\frac{d U_{1}}{d \tau}}{\sqrt{t-\tau}} d \tau=\sqrt{\frac{2 \pi}{T}} \cos \left(\frac{2 \pi t}{T}+\frac{\pi}{4}\right)
$$

Segundo Hamilton (1972), para corpos de geometria arbitrária e movimento geral, não repetitivo, não existe solução matemática similar à equação (32). Entretanto, esperase certa semelhança para o caso de cilindro circular.

Ainda no mesmo trabalho, Stokes procurou uma solução (decomposição) similar à equação (31) para o caso de cilindro circular em movimento harmônico. Apesar de não encontrar uma solução analítica, Stokes conseguiu expressar a força exercida pelo fluido no movimento harmônico de período $T$ do cilindro circular bidimensional imerso em um fluido em repouso em termos de séries numéricas. Ele apresentou seus resultados da seguinte forma:

$$
F_{1}(t)=-\rho k \frac{\pi D^{2}}{4} \frac{d U_{1}}{d t}-\rho k^{\prime} \frac{2 \pi}{T} \frac{\pi D^{2}}{4} U_{1}
$$


Na qual, os valores dos coeficientes $k$ e $k^{\prime}$ foram aproximados por séries numéricas, vide tabela 1. Eles estão diretamente relacionados com a inércia adicional e com o arrasto sobre o cilindro. De fato, é possível escrever:

$$
C_{A}=k \quad \text { e } \quad C_{D}=\frac{3}{2} \frac{\pi^{3}}{K C} k^{\prime}
$$

Na qual, $C_{D}$ é o coeficiente de arrasto, a ser definido a seguir.

Tabela 1 - Resultados de Stokes (1850) para cilindro circular

\begin{tabular}{|c|c|c||c|c|c|}
\hline$\beta$ & $k$ & $k^{\prime}$ & $\beta$ & $k$ & $k^{\prime}$ \\
\hline 0 & $\infty$ & $\infty$ & 11,230 & 1,677 & 0,7822 \\
\hline 0,025 & 19,7 & 48,63 & 12,325 & 1,646 & 0,7421 \\
\hline 0,102 & 9,166 & 16,73 & 13,471 & 1,618 & 0,7059 \\
\hline 0,229 & 6,166 & 9,258 & 14,668 & 1,592 & 0,6730 \\
\hline 0,407 & 4,771 & 6,185 & 15,915 & 1,568 & 0,6430 \\
\hline 0,637 & 3,968 & 4,567 & 17,214 & 1,546 & 0,6154 \\
\hline 0,917 & 3,445 & 3,589 & 18,564 & 1,526 & 0,5902 \\
\hline 1,248 & 3,082 & 2,936 & 19,964 & 1,507 & 0,5669 \\
\hline 1,630 & 2,812 & 2,477 & 21,416 & 1,489 & 0,5453 \\
\hline 2,063 & 2,604 & 2,137 & 22,918 & 1,473 & 0,5253 \\
\hline 2,546 & 2,439 & 1,876 & 24,472 & 1,457 & 0,5068 \\
\hline 3,081 & 2,194 & 1,678 & 26,076 & 1,443 & 0,4895 \\
\hline 3,667 & 2,102 & 1,503 & 27,731 & 1,430 & 0,4732 \\
\hline 4,304 & 2,021 & 1,365 & 29,437 & 1,417 & 0,4581 \\
\hline 4,991 & 1,951 & 1,250 & 31,194 & 1,405 & 0,4439 \\
\hline 5,730 & 1,891 & 1,153 & 33,002 & 1,394 & 0,4305 \\
\hline 6,519 & 1,891 & 1,069 & 34,861 & 1,383 & 0,4179 \\
\hline 7,359 & 1,838 & 0,9965 & 36,771 & 1,373 & 0,4060 \\
\hline 8,251 & 1,791 & 0,9332 & 38,732 & 1,363 & 0,3948 \\
\hline 9,193 & 1,749 & 0,8767 & 40,744 & 1,354 & 0,3841 \\
\hline 10,186 & 1,711 & 0,8268 & $\infty$ & 1,0 & 0,0 \\
\hline
\end{tabular}

Em 1950, Morison, Johnson e Schaaf (1950) mediram a força exercida na direção do fluxo por ondas de pequenas amplitudes sobre pilares cilíndricos fixos, e propuseram a decomposição da força em duas componentes, conforme equação (37), a seguir. A componente da força em fase com a aceleração do escoamento corresponde ao efeito inercial, enquanto o termo quadrático da velocidade, à força de arrasto. Esta equação ficou conhecida como equação de Morison, e se tornou padrão para expressar a força de ondas sobre pilares por unidade de comprimento. Entretanto, ao menos aparentemente, Morison, Johnson e Schaaf (1950) não procuraram dar uma explicação física para a 
contribuição de cada parcela da equação (37), com base no escoamento e em suas estruturas vorticosas.

$$
F_{1}(t)=C_{M} \rho \frac{\pi D^{2}}{4} \frac{d U}{d t}+\frac{1}{2} C_{D} \rho D|U| U
$$

Quando a variação do escoamento é obtida pela oscilação do fluido, estando o corpo em repouso, utiliza-se o coeficiente de inércia: $C_{M}=1+C_{A}$. A unidade deve-se à parcela do gradiente de pressão no escoamento que causa a aceleração do fluido como um todo, enquanto o coeficiente de massa adicional considera a força requerida para acelerar o escoamento ao redor do cilindro. $C_{D}$ é o coeficiente de arrasto. Os coeficientes $C_{M}$ e $C_{D}$ são determinados experimentalmente a partir do sinal de força pelo método dos mínimos quadrados, análise Fourier ou, para uma onda senoidal, a partir da média de valores medidos nos pontos onde $\frac{d U}{d t}$ e $U$ se anulam, alternadamente. Portanto, este é um método indireto para determinação dos coeficientes de massa e de arrasto.

Para curtos períodos de oscilação e pequenas amplitudes de deslocamento, o termo de inércia é dominante. Para elevados períodos de oscilação e amplitudes de deslocamentos, o termo de arrasto domina e se aproxima daquele de um corpo em movimento uniforme. A equação de Morison (37) combina, portanto, esses dois extremos. Ainda, ela é uma equação de baixa ordem, pois é capaz de representar apenas os harmônicos de primeira ordem da força de resistência. Segundo Sarpkaya (1986), a equação de Morison é semi-empírica e uma solução aproximada para um problema complexo.

Keulegan e Carpenter (1958) utilizaram um tanque de ondas para gerar uma corrente harmônica com a finalidade de investigar a dependência dos coeficientes $C_{M}$ e $C_{D}$ da equação de Morison com o número de $R e$ e $K C$, nos intervalos $4200 \leq R e \leq 29300$ e $2,7 \leq K C \leq 119,9$. Keulegan e Carpenter (1958) não utilizaram o parâmetro $\beta$ para ordenar os dados, e, sobre a dispersão de pontos, foi ajustada uma curva media, conforme pode ser observado nas figuras a seguir. 


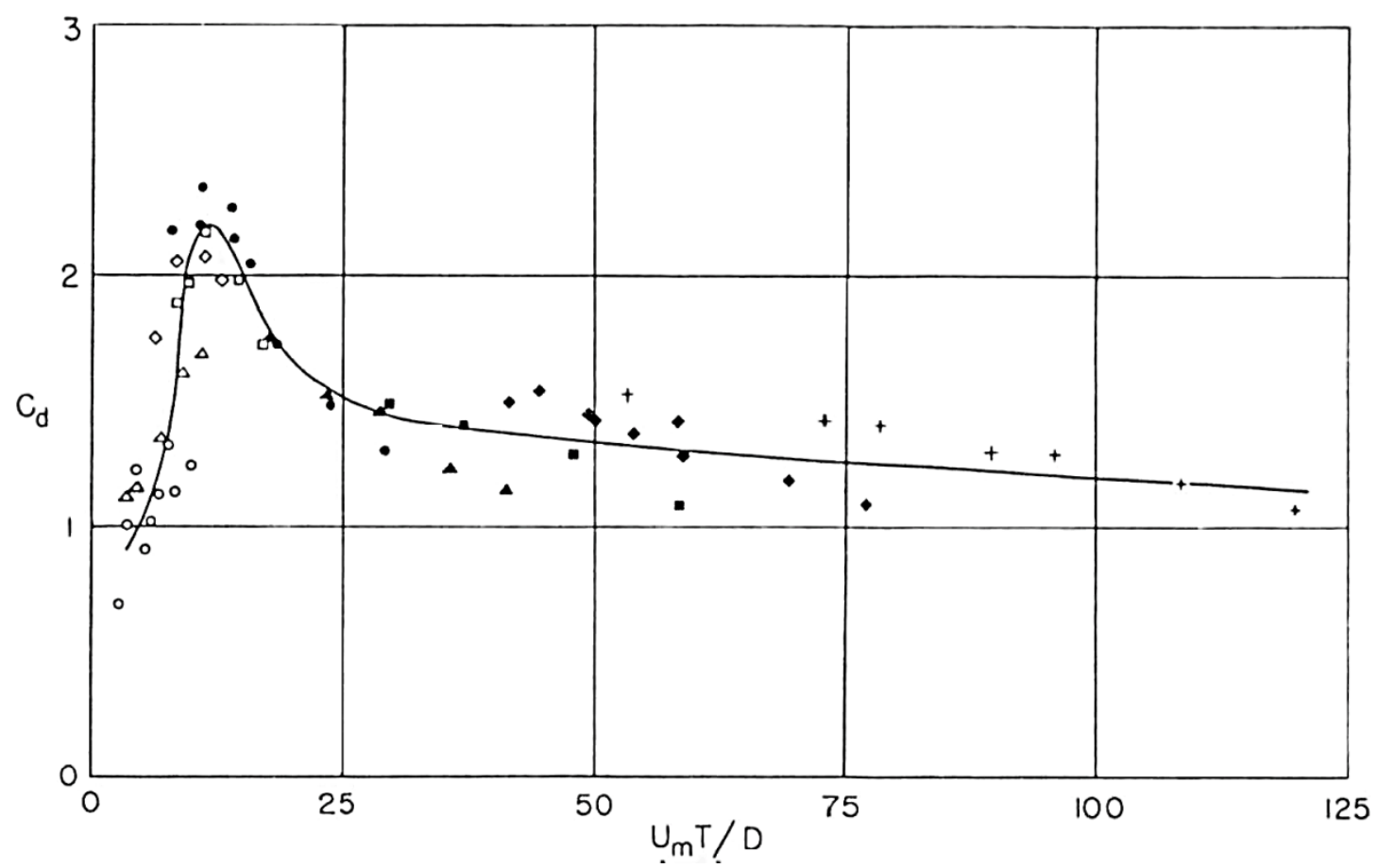

Figura 3 - Coeficiente de arrasto (KEULEGAN e CARPENTER, 1958)

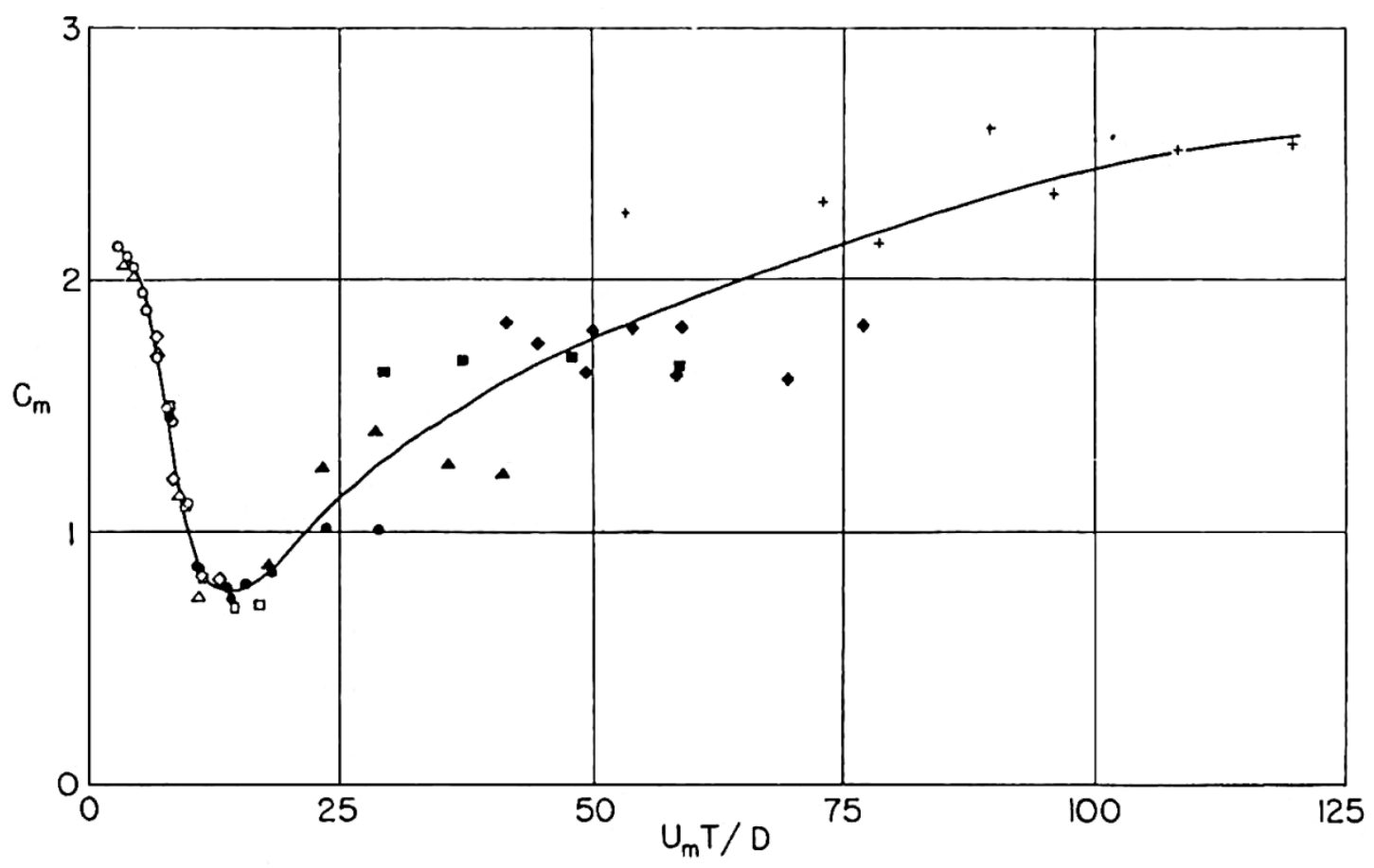

Figura 4 - Coeficiente de massa (KEULEGAN e CARPENTER, 1958) 
Wang (1968) utilizou teoria assintótica, para $K C \ll 1$ e $\beta \gg 1$, e expandiu a solução de Stokes para escoamento viscoso em torno do cilindro em termos de ordem superior, $(\pi \beta)^{-3 / 2}$. A expansão também ilustra a dependência do coeficiente de massa e de arrasto com a viscosidade através do parâmetro $\beta$ :

$$
\begin{gathered}
C_{A}=1+4(\pi \beta)^{-1 / 2}+(\pi \beta)^{-3 / 2} \\
C_{D}=\frac{3 \pi^{3}}{2 K C}\left[(\pi \beta)^{-1 / 2}+(\pi \beta)^{-1}-\frac{1}{4}(\pi \beta)^{-3 / 2}\right]
\end{gathered}
$$

Os dois primeiros termos das equações acima correspondem ao resultado de Stokes para o cilindro circular. No limite $\beta \rightarrow \infty$, o coeficiente de massa converge para o valor ideal, $C_{A} \rightarrow 1$. Para $K C \rightarrow 0$ e $\beta \rightarrow \infty$, ambos os coeficientes estão relacionados por:

$$
\frac{C_{A}-1}{K C \cdot C_{D}}=\frac{8}{3 \pi^{3}}
$$

Em 1976, ao recompilar os resultados experimentais de Keulegan e Carpenter (1958), Sarpkaya (1976) identificou certa dependência dos coeficientes com o parâmetro $\beta$. A introdução do parâmetro $\beta$ ordena os dados experimentais de maneira notável e revela padrões, ao que parecia antes dispersão.

Sarpkaya (1977) mapeou a dependência dos coeficientes de massa e arrasto para uma ampla faixa de $K C$ e $\beta$. O número de $R e$ é recuperado pela expressão, $R e=\beta \cdot K C$. As figuras 5 e 6 resumem os resultados. $\mathrm{O}$ parâmetro $\beta$ figura como fundamental para interpretação e interpolação dos dados. 


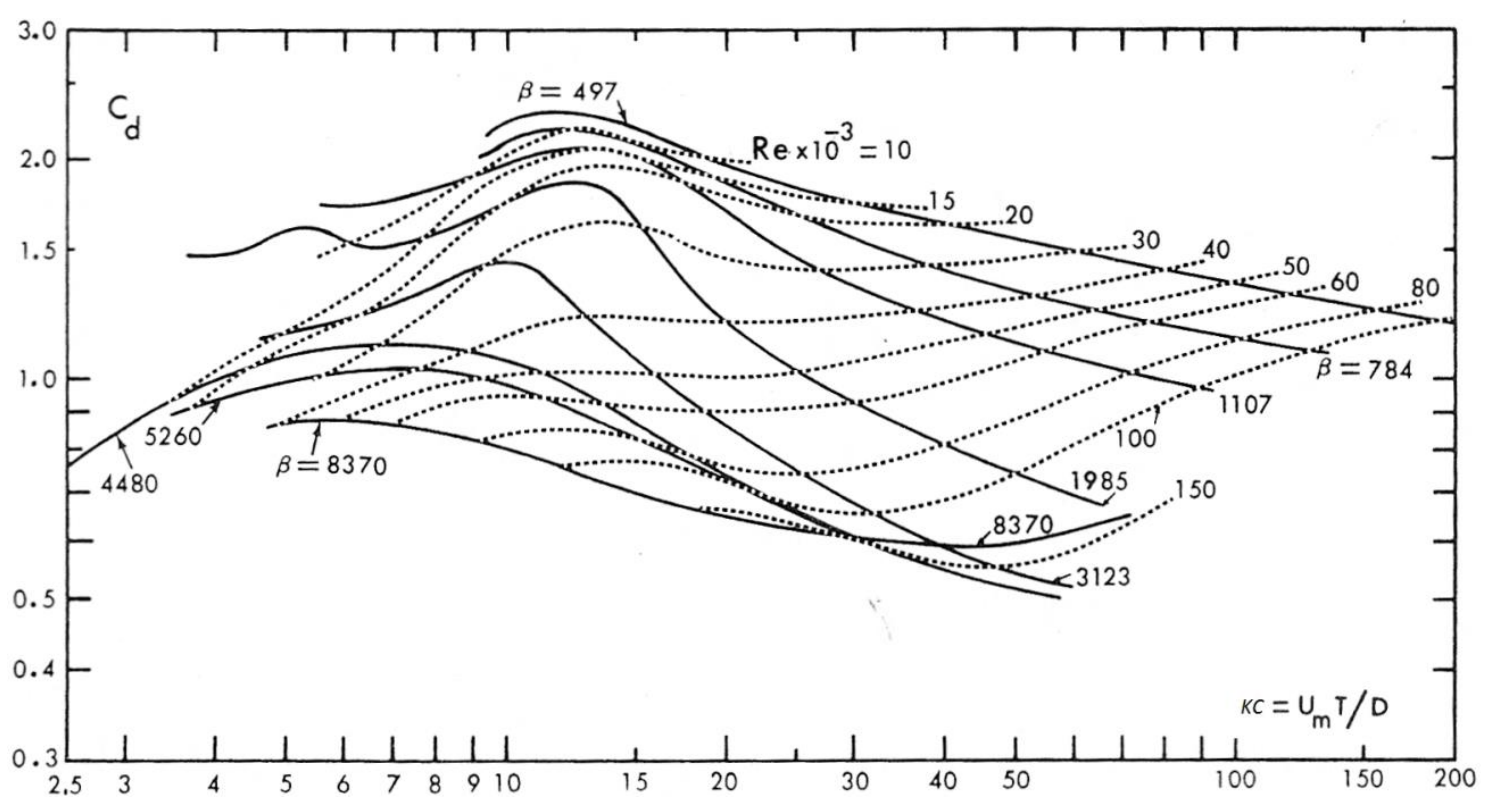

Figura 5 - Coeficiente de arrasto (SARPKAYA, 1977)

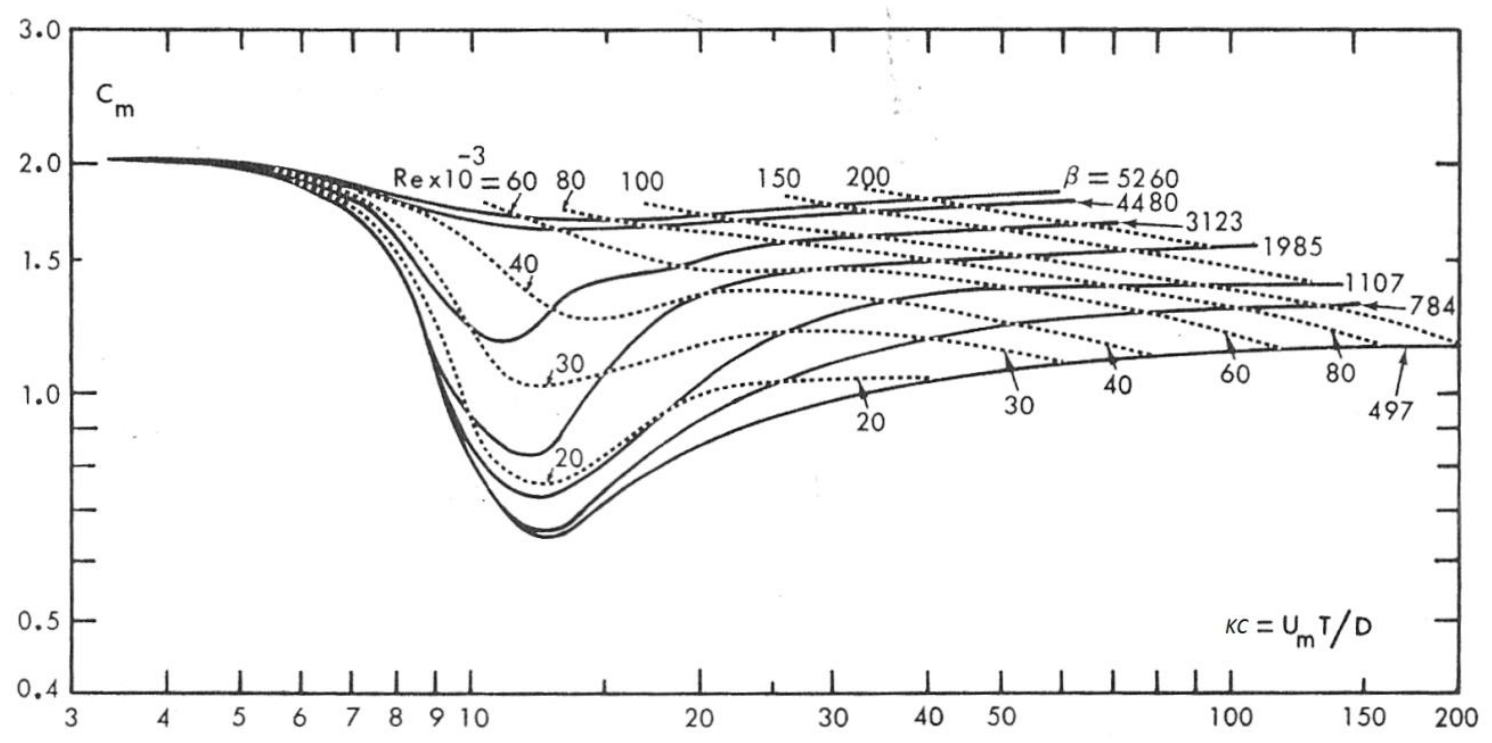

Figura 6 - Coeficiente de inércia (SARPKAYA, 1977)

Nota-se na figura 6 que o coeficiente de inércia converge para o ideal, $C_{M}=2$, para $K C \lesssim 4$ e $\beta \gg 1$. Para $4 \lesssim K C \lesssim 12$, observa-se um decréscimo (acréscimo) do coeficiente de massa (arrasto), e o mínimo (máximo) ocorre em $K \approx 12$ para um dado $\beta$. Sarpkaya (1977) denomina este fenômeno como "crise da inércia". Diferentemente dos resultados de Keulegan e Carpenter (1958), o coeficiente de inércia permanece inferior a $C_{M}<2$ para elevado $K C>50$. Adicionalmente, Sarpkaya (1977) estuda a variação dos coeficientes de arrasto e inércia com da rugosidade relativa $\frac{\varepsilon}{D}$ do cilindro. Em resumo, os coeficientes $C_{D}$ e $C_{M}$ são funções dos adimensionais, $K C, \beta$ e $\frac{\varepsilon}{D}$. No entanto, este trabalho trata apenas o caso de cilindro liso e rugosidade relativa nula. 
Bearman et al. (1985) e Sarpkaya (1986) investigaram experimentalmente a variação dos coeficientes de inércia e de arrasto para pequenos valores de $K C, 0,3 \leq K C \leq 10$, com $196 \leq \beta \leq 1665$, e $0,4 \leq K C \leq 20$, com $1035 \leq \beta \leq 11240$.

Kühtz (1996) realizou uma série de experimentos para determinação do coeficiente de inércia de arrasto para baixos valores de $K C$ e de $\beta$. As figuras 7 e 8 mostram os resultados obtidos, os quais apresentam boa aderência com os valores teórico de Stokes (1850) e de Wang (1968).

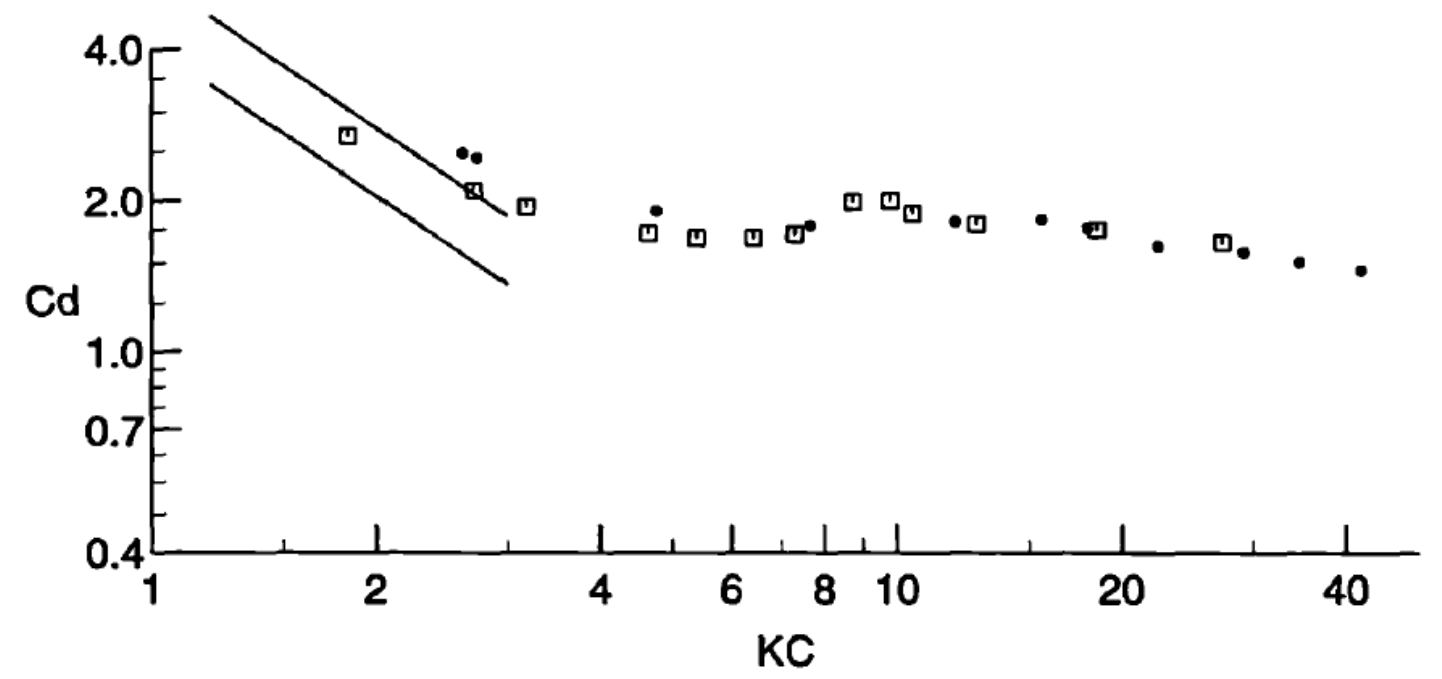

Figura 7 - Coeficiente de arrasto: $\square \beta=53$ e $\bullet \beta=35$ (KÜHTZ, 1996)

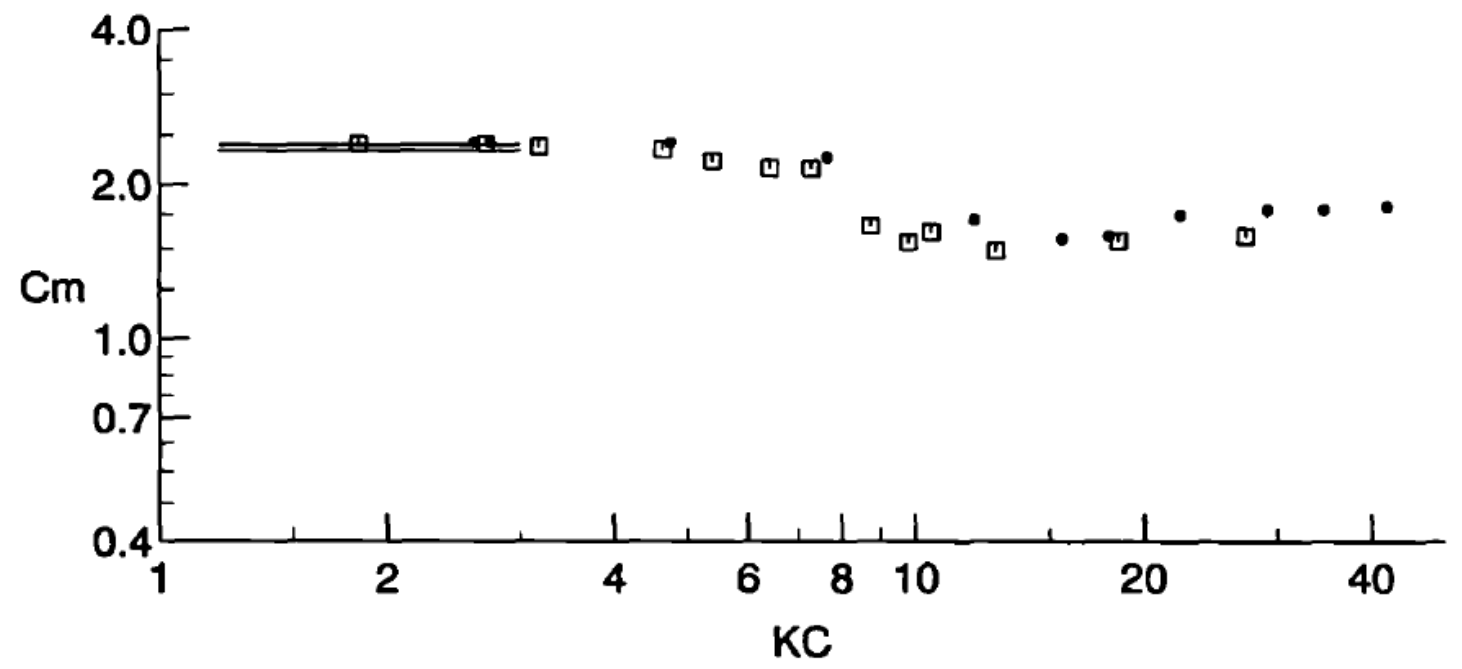

Figura 8 - Coeficiente de inércia: $\square \beta=53$ e $\bullet \beta=35$ (KÜHTZ, 1996)

A tabela 2, adaptada de Duclercq (2010), resume em ordem cronológica trabalhos importantes relacionados ao tema, e as diversas abordagens empregadas na determinação dos coeficientes de inércia e de arrasto. 
Tabela 2 - Autores que investigaram os coeficientes de massa e de arrasto, em ordem cronológica. Adaptada de Duclercq (2010).

\begin{tabular}{|c|c|c|c|}
\hline Autor(es) & Abordagem & $\beta$ & $K C$ \\
\hline Stokes (1850) e Wang (1968) & Analítica & {$[>>1]$} & {$[<<1]$} \\
\hline Keulegan e Carpenter (1958) & Experimental & {$[96,7-3000]$} & {$[2,7-119,9]$} \\
\hline Sarpkaya (1976) & Experimental & {$[497-5260]$} & {$[3,5-70]$} \\
\hline Bearman et al. (1985) & Experimental & [196 - 1665] & {$[0,3-10]$} \\
\hline Sarpkaya (1986) & Experimental & {$[1035-11240]$} & {$[0,4-20]$} \\
\hline Justesen (1991) & $\begin{array}{c}\text { Experimental e } \\
\text { Numérica }\end{array}$ & $\begin{array}{l}{[196-1035]} \\
{[196]}\end{array}$ & $\begin{array}{l}{[0,2-3]} \\
{[0,2-26]}\end{array}$ \\
\hline Kühtz (1996) & Experimental & {$[35-308]$} & {$[2-40]$} \\
\hline Lin, Beaman e Graham (1996) & Numérica & {$[76]$} & {$[1-36]$} \\
\hline Iliadis e Anagnostopoulos (1998) & Numérica & {$[34-53]$} & {$[0,2-10]$} \\
\hline Dütsh et al. (1998) & $\begin{array}{c}\text { Experimental e } \\
\text { Numérica }\end{array}$ & {$[35]$} & {$[0,5-15]$} \\
\hline Uzunoğlu, Tan e Price (2001) & Numérica & {$[35]$} & {$[0,5-8]$} \\
\hline
\end{tabular}

Em paralelo, com o avanço dos métodos numéricos e da capacidade de processamento dos computadores, diversos autores trabalharam em simulações numéricas bidimensionais e tridimensionais a fim de entender a topologia do escoamento, a dinâmica dos vórtices e recuperar os coeficientes de inércia e de arrasto obtidos experimentalmente e analiticamente, apesar de restritas a baixos números de $R e$ e do parâmetro $\beta$. Adiante será dedicado um item específico para simulações numéricas.

Uma importante discussão ocorre quando Lighthill (1986) afirma que as forças em estruturas oceânicas podem ser decompostas em duas parcelas: uma devido ao escoamento potencial e a outra, à vorticidade, as quais atuam de maneira independente. Assim, a força inercial da equação de Morison dependeria exclusivamente da parcela 
potencial do escoamento, e a parcela de arrasto, da geração e transporte da vorticidade, de maneira geral. Sarpkaya (2001), fundamentado nos resultados de Stokes (1850), critica a afirmação feita por Lighthill. De fato, ambas as parcelas são afetadas pela viscosidade, geração e emissão de vórtices no escoamento.

\subsubsection{Topologia do Escoamento}

Existem similaridades e diferenças entre o escoamento oscilatório e o uniforme. Para o escoamento oscilatório, o desprendimento de vórtices passa a depender não somente de $R e$, mas também de $K C$. No escoamento uniforme, os vórtices são sempre convectados para jusante do cilindro, enquanto no escoamento oscilatório, os vórtices formados no meio ciclo podem contornar o cilindro, quando a velocidade muda de sinal, e interagir com os vórtices sendo formados do outro lado. Esta reversão de esteira, ou reencontro de esteira, influencia a futura geração de vorticidade e afeta significativamente as forças em linha e perpendicular ao movimento (LIN; BEARMAN; GRAHAM, 1996).

Tatsuno e Bearman (1990) estudaram a topologia do escoamento para $K C<15$ e $\beta<150$. $\mathrm{O}$ aparato experimental utilizado é ilustrado na figura $9 . \mathrm{O}$ tanque de água possuia dimensões de $700 \mathrm{~mm}$ de comprimento por $300 \mathrm{~mm}$ de largura por $380 \mathrm{~mm}$ de profundidade. Foram utilizados cilindros circulares de diâmetros $10 \mathrm{~mm}$ e $15 \mathrm{~mm}$, montados na vertical e acoplados na parte superior ao mecanismo de acionamento. Outro tanque de dimensões de $2000 \mathrm{~mm}$ de comprimento por $610 \mathrm{~mm}$ de largura por $500 \mathrm{~mm}$ de profundidade fora também utilizado com cilindro de diâmetro de $20 \mathrm{~mm}$. O movimento harmônio foi gerado através um motor conectado a um mecanismo bielamanivela no primeiro tanque, e acionado por um servomotor controlado, no segundo.A folga entre o cilindro e o fundo dos tanques era de apenas $3 \mathrm{~mm}$. Duas técnicas de visualização do escoamento foram empregradas: eletrolítica e pó de alumínio. 


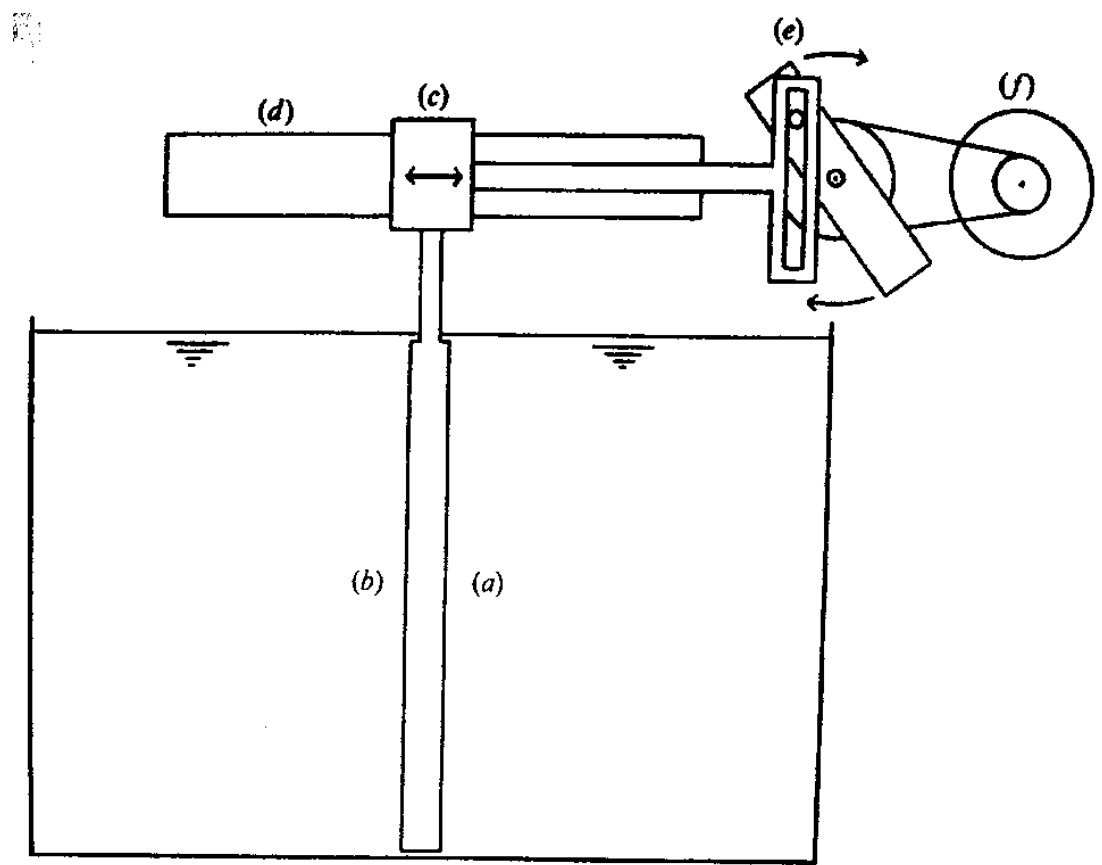

Figura 9 - Esquema do aparato experimental de Tatsuno e Bearman (1990): (a) cilindro circular, (b) tanque de água, (c) guia deslizante, (d) guia fixa, (e) biela-manivela e (f) motor

Foram mapeados oito regimes distintos de escoamento, conforme figura 10 . Os regimes mostram fraca dependência com $R e$, e, para certos $R e$, dependem exclusivamente de $K C$.

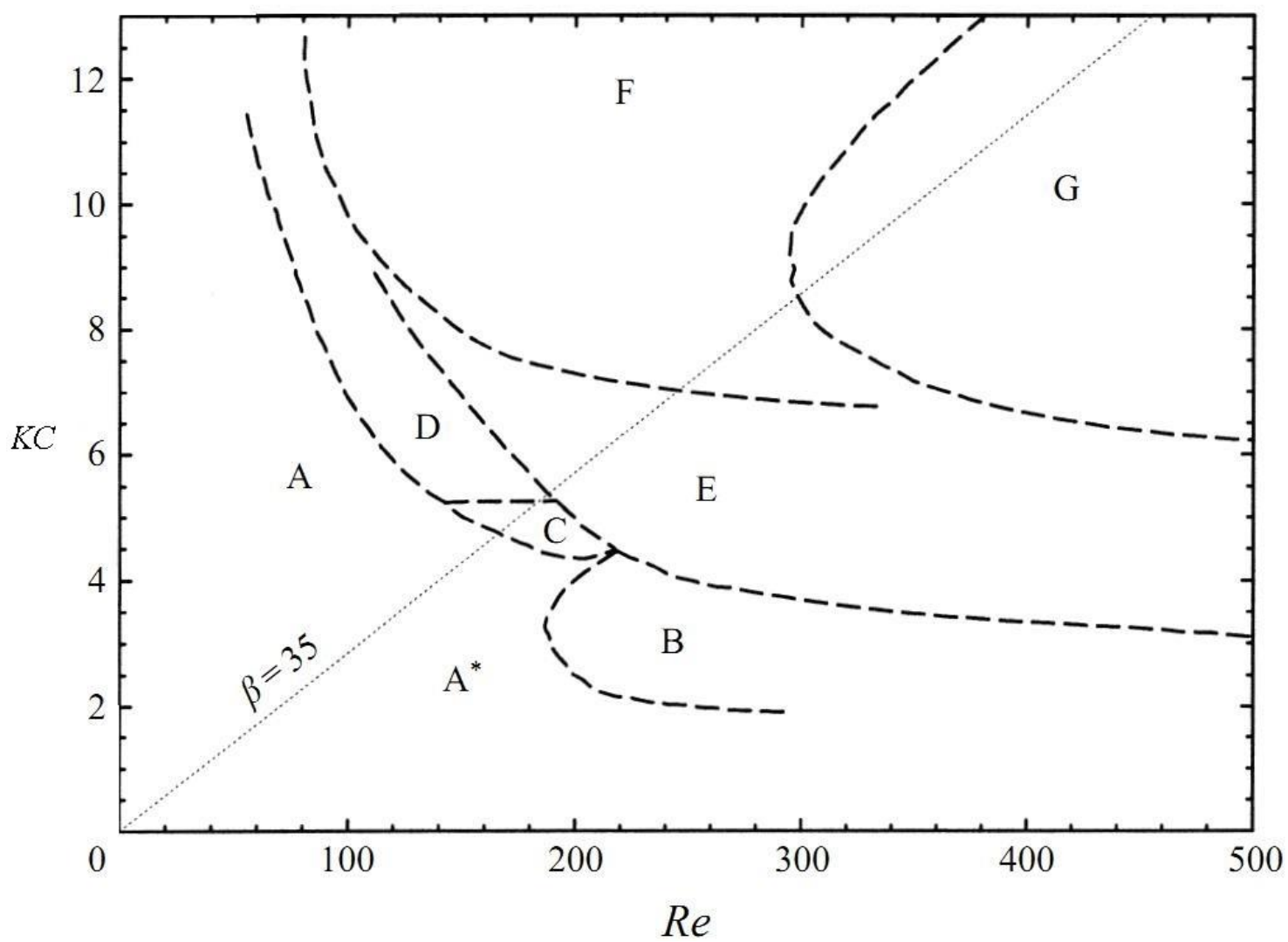

Figura 10 - Mapa de Tatsuno e Bearman. Adaptado de Dütsh et al. (1998) 
1. Regime $\mathbf{A}^{*}$ : $\mathrm{O}$ escoamento é bidimensional e simétrico. Não ocorre o desprendimento de vórtices. Os experimentos de Sarpkaya (1986) sugerem que o limiar do descolamento da camada limite ocorre no intervalo $1,5 \leq$ $K C \leq 3$, dependendo do parâmetro $\beta$. Entretanto, Justesen (1991) observou o descolamento da camada limite muito antes, para $K C=0,2$ e $\beta=196$, baseado em simulações numéricas bidimensionais. O ponto de separação foi identificado através da linha de corrente que emana da superfície do cilindro e do ponto de tensão cisalhante nula. Porém, para escoamento oscilatório e baixo $K C$, não é trivial afirmar se esse ponto de tensão cisalhante nula corresponde a uma simples inversão da velocidade na camada limite, inevitavelmente induzida pelo movimento alternado do cilindro, ou a um descolamento da camada limite induzido por um gradiente de pressão adverso. A determinação exata do valor de $K C$, em função de $\beta$, na qual ocorre a separação da camada limite é ainda um problema aberto.

2. Regime A: O escoamento é bidimensional e simétrico. Entretanto, a camada limite descola e são formados dois vórtices contra rotativos, também simétricos, atrás do cilindro, a cada meio-ciclo. Ao reverter o movimento, os vórtices são convectados e contornam o cilindro. Eles são rapidamente cancelados pela vorticidade de sinal oposta que é produzida quando da inversão de movimento e não permanecem até o próximo meio-ciclo.

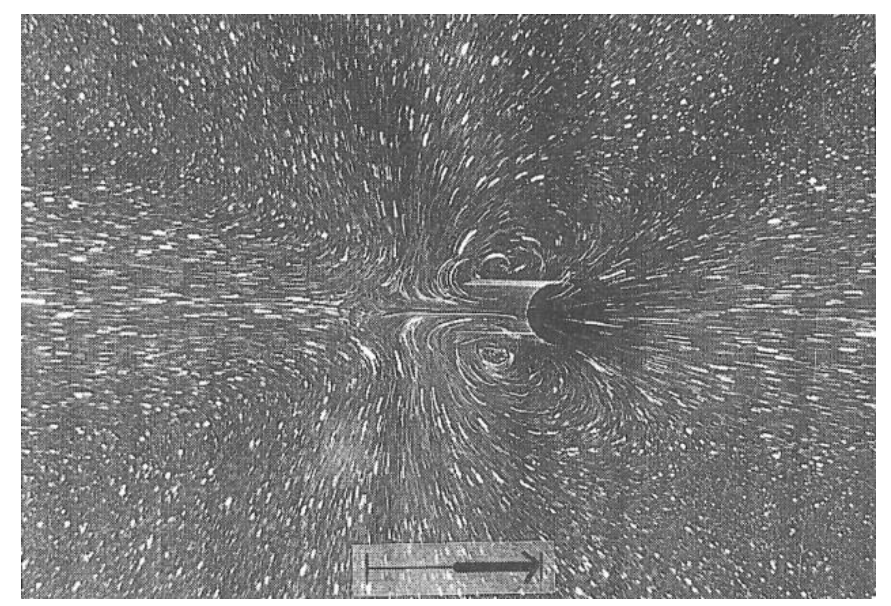

Figura 11 - Escoamento simétrico no Regime A (TATSUNO; BEARMAN, 1990)

3. Regime B: $\mathrm{O}$ escoamento se assemelha aos regimes $\mathrm{A}^{*}$ e $\mathrm{A}$ visto no plano perpendicular ao eixo do cilindro. Ao longo do eixo do cilindro aparecem alternadamente estruturas vorticais, e o escoamento é tridimensional. Honji (1981) já havia observado o aparecimento de estruturas vorticais 
igualmente espaçadas ao longo do eixo do cilindro no formato de cogumelos ao oscilar um cilindro circular harmonicamente para $70 \leq \beta \leq 700$ e $0<K C<4$, vide figura 12. Eles foram denominados posteriormente de vórtices de Honji. Essas estruturas ocorrem durante a transição do escoamento laminar bidimensional para o escoamento turbulento tridimensional (instabilidade) em certas regiões de $K C$ e $\beta$, e sua origem está associada à curvatura da camada limite ao redor do cilindro, que dá origem a forças centrífugas, conforme Hall (1984).

(a)

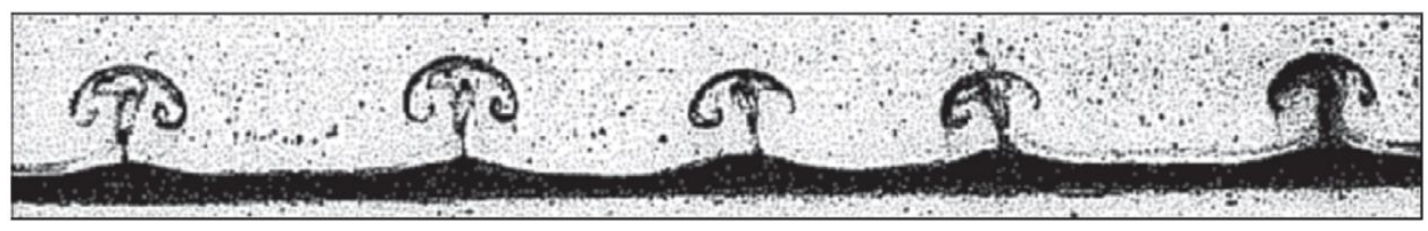

(b)

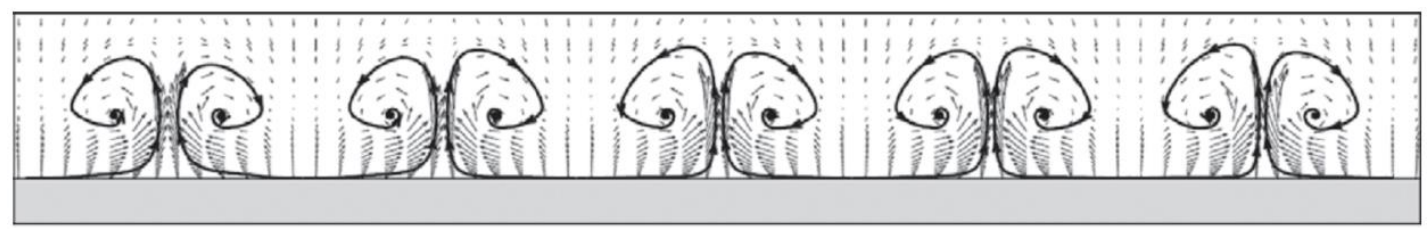

Figura 12 - Vórtices: (a) Experimento de Honji (1981) (b) Numericamente (HONGWE; ZHAO, 2010) para $K C=2$ e $\beta=200$.

Hall (1984) analisou a estabilidade deste escoamento e propôs a seguinte equação para determinação do número de Keulegan-Carpenter crítico $K_{C c r}$ para o limite de estabilidade, válido para $K C \rightarrow 0$ e $\beta \rightarrow \infty$,:

$$
K C_{c r}=5,778 \beta^{-\frac{1}{4}}\left(1+0,205 \beta^{-\frac{1}{4}}+\ldots\right)
$$

Segundo Sarpkaya (1986), o aparecimento da instabilidade e dos vórtices de Honji é acompanhado de um aumento do coeficiente de arrasto acima dos valores teóricos de Wang (1968).

Hongwe e Zhao (2010) estudaram numericamente a distribuição dos vórtices de Honji ao longo do cilindro e sua evolução para um regime turbulento para $K C=2$ e $\beta<600$. A figura 12 compara os resultados experimentais de Honji (1981) e de Hongwe e Zhao (2010), para $K C=2$ e $\beta=200$.

4. Regime C: $\mathrm{O}$ escoamento é tridimensional e apresenta uma esteira alternada de vórtices, similar à esteira de von Kármán, entretanto de sinais opostos. Ao 
inverter o movimento, ocorre o reencontro e rearranjo dos vórtices formados no ciclo anterior.

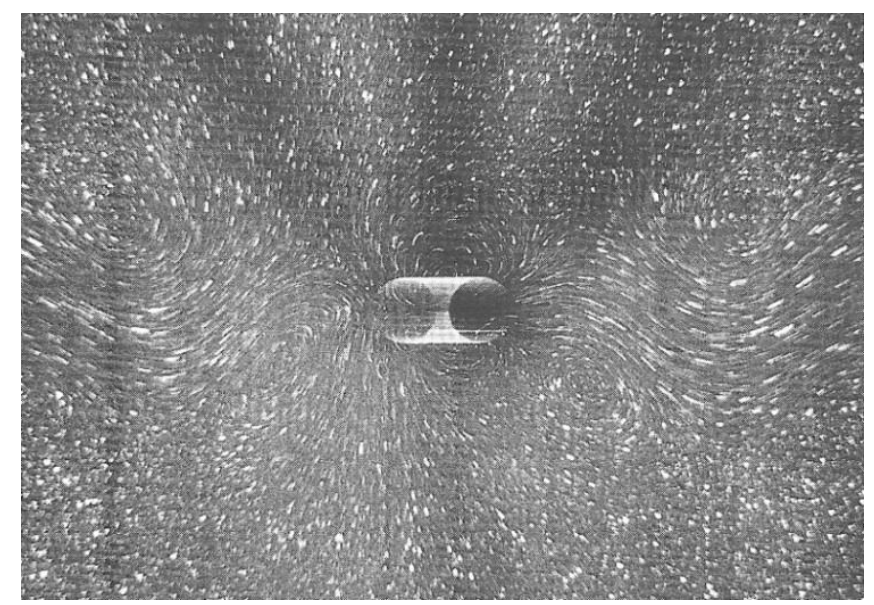

Figura 13 - Vórtices no Regime C (TATSUNO; BEARMAN, 1990)

5. Regime D: Nos regimes anteriores, o escoamento induzido pelo cilindro é convectado na direção de oscilação. Ao aumentar a amplitude de oscilação, aparece certa assimetria no padrão de formação dos vórtices. Vórtices de sinais opostos são formados de um lado e do outro do eixo de oscilação, sendo um deles mais alongado. Ao reverter o sentido de movimento, ocorre uma emissão oblíqua de pares de vórtices contra rotativos, do lado daquele vórtice que se desenvolveu mais mais alongado. Esses vórtices se deslocam em uma direção inclinada em "V" e em apenas um dos lados do cilindro. O escoamento induzido desvia daquele da oscilação. O padrão se torna mais curvo, fechamento do "V", com o aumento do parâmetro $\beta$. O escoamento é tridimensional.

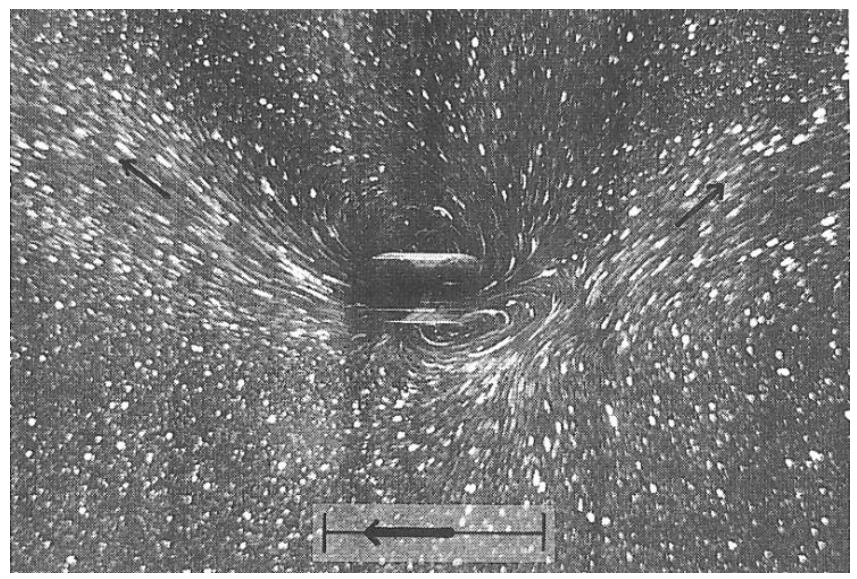

Figura 14 - Assimetria no Regime D (TATSUNO; BEARMAN, 1990) 
6. Regime E: Este regime se assemelha ao anterior, entretanto, o padrão assimétrico se alterna intermitentemente entre um lado e outro do cilindro. Nehari, Armenio e Ballio (2004) realizaram simulações numéricas bidimensionais e tridimensionais e observaram que o regime $\mathrm{D}$ é também intermitente para um número elevado de ciclos. Assim, os regimes D e E se confundem.

7. Regime F: O escoamento é tridimensional e assimétrico. Vórtices são formados de maneira desigual de um lado e do outro do eixo de oscilação. A cada meio-ciclo, dois vórtices de sinais opostos são emitidos de um lado do eixo de oscilação do cilindro, e no outro meio-ciclo, do outro lado. Longe do cilindro, os vórtices seguem uma direção quase paralela ao eixo de oscilação. Nehari, Armenio e Ballio (2004) observaram que o regime F é também intermitente, e o padrão assimétrico se alterna entre um lado e outro do cilindro para um número elevado de ciclos.

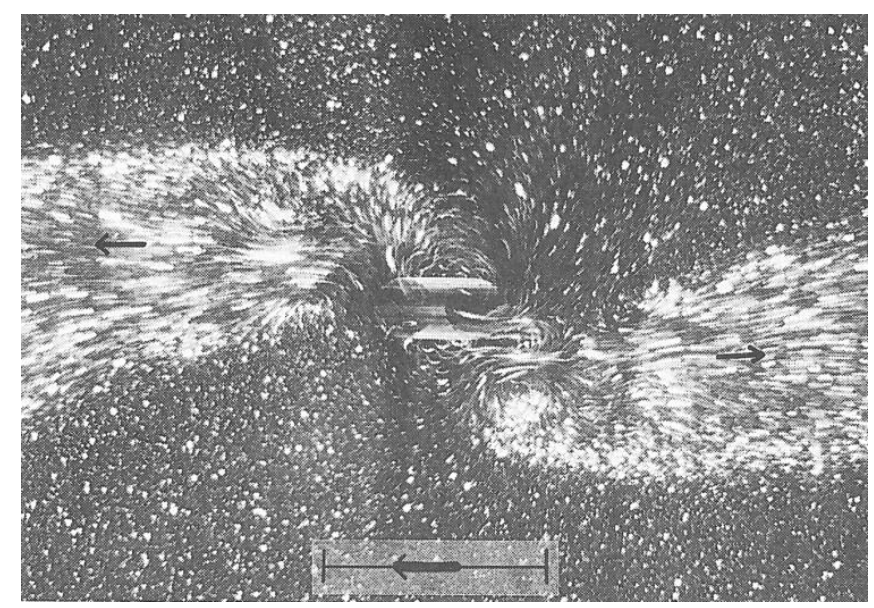

Figura 15 - Regime F (TATSUNO; BEARMAN, 1990)

8. Regime G: O escoamento é tridimensional e assimétrico. Dois vórtices contra rotativos são formados: um permanece solidário atrás do cilindro e o outro é emitido obliquamente. Ao inverter o movimento, o vórtice atrás do cilindro é emitido e outro vórtice solidário começa a se desenvolver. 


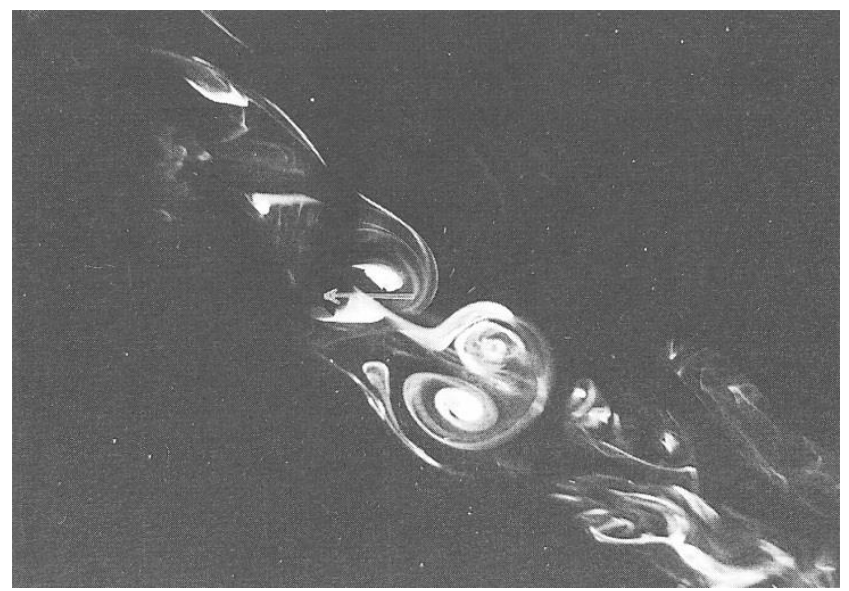

Figura 16 - Regime G (TATSUNO; BEARMAN, 1990)

\subsubsection{Simulações Numéricas}

A simulação dos vórtices de Honji, da transição para a turbulência e dos regimes do escoamento, com exceção dos regimes $\mathrm{A}$ e $\mathrm{A}^{*}$, exige um modelo numérico tridimensional, com consequente aumento do esforço computacional. Apesar disso, diversas simulações bidimensionais para baixo valores de $K C$ e $\beta$ foram reportadas na literatura, as quais reproduziram bem as características relevantes da topologia do escoamento nos diversos regimes e apresentaram boa aderência com resultados experimentais e analíticos para os coeficientes de inércia e de arrasto. Citam-se os trabalhos de Justesen (1991), Lin, Bearman e Graham (1996), Iliadis e Anagnostopoulos (1998), Dütsh et al. (1998) e Uzunoğlu, Tan e Price (2001).

Dütsh et al. (1998) utilizaram o método dos volumes finitos para resolver as equações de $\mathrm{NS}$ em um referencial não inercial para $\mathrm{KC}=5$ (regime $\mathrm{A}$ ) e $\mathrm{KC}=10$ (regime $\mathrm{F}$ ) $\operatorname{com} \beta=20$, e para $\mathrm{KC}=0,5$ até $\mathrm{KC}=15 \operatorname{com} \beta=35$. A figura 17 ilustra o campo de vorticidade obtido nos regimes A, D e F. É possível identificar o padrão simétrico do regime A e os padrões assimétricos dos regimes D e F. Os coeficientes de inércia e de arrasto apresentam boa aderência com os resultados analíticos de Stokes (1850) e Wang (1968) e experimentais de Kühtz (1996), vide figuras 18 e 19.

Nehari, Armenio e Ballio (2004) realizaram simulações tridimensionais nos regimes D e F. Dentre as diversas conclusões do trabalho, foi observado que naqueles regimes as características bidimensionais do escoamento não são qualitativamente afetadas pelos efeitos tridimensionais. Especificamente, os padrões assimétricos dos regimes D e F são características intrínsecas do escoamento bidimensional. A componente da força de resistência, em linha com o movimento, é fracamente afetada pela tridimensionalidade 
do escoamento. Isso corrobora a aderência dos resultados numéricos bidimensionais com os dados experimentais. A força normal é significativamente afetada pela tridimensionalidade do escoamento, e sua predição mais acurada requer um modelo numérico tridimensional.

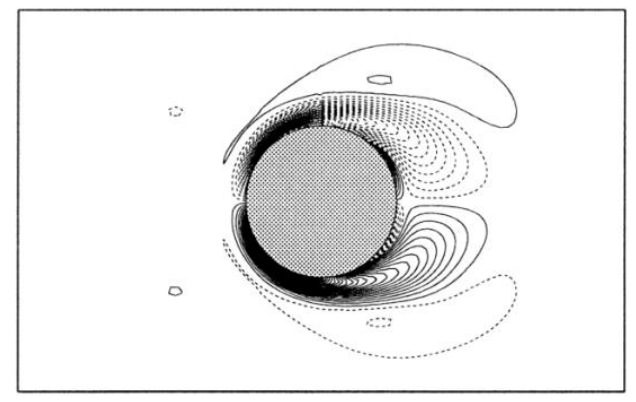

(a) $K C=5$ e $\beta=20$

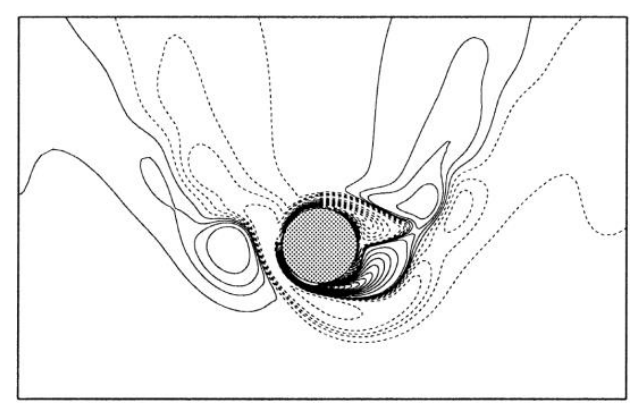

(b) $K C=6$ e $\beta=35$

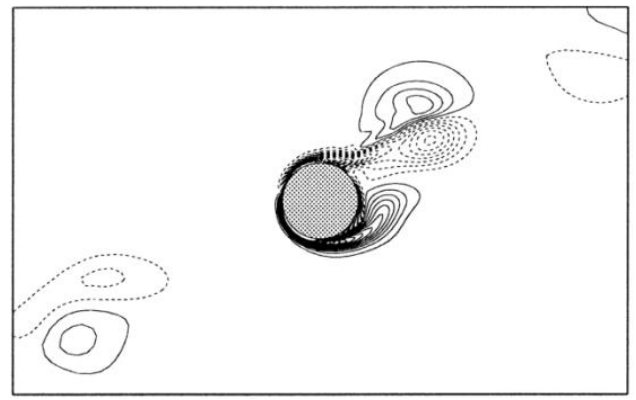

(c) $K C=10$ e $\beta=20$

Figura 17 - Campo de vorticidade: (a) regime A (b) regime D (c) regime F (DÜTSCH et al., 1998)

A dinâmica do escoamento induzida pelo cilindro oscilando é rica e extensa e atraiu a atenção de diversos pesquisadores desde o século XIX até os dias atuais. Em resumo, inicialmente os modelos matemáticos avançaram a fim de recuperar e explicar o período de oscilação do pêndulo imerso. No século XX, grande esforço científico foi empenhado no estudo da ação de ondas (fluido oscilatório) sobre estruturas cilíndricas fixas e com um ou dois graus de liberdade restritos elasticamente. Recentemente, outros aspectos do problema são estudados. Citam-se os detalhes das estruturas vorticais tridimensionais, da transição para a turbulência e da instabilidade dos regimes, vide 
Yang e Rockwell (2002), Nehari, Armenio e Ballio (2004), Elston, Blackburn e Sheridan (2006), Hongwe e Zhao (2010) e Duclercq (2010). Este trabalho prossegue com a realização de simulações numéricas do escoamento induzido pelo cilindro oscilando. Este problema é fundamental e de grande relevância, quando do estudo de vibrações de tubos imersos em água em repouso. Em particular, no contexto da engenharia oceânica, movimentos impostos ao tubo em uma direção a ele perpendicular, podem causar movimentos em direção transversal.

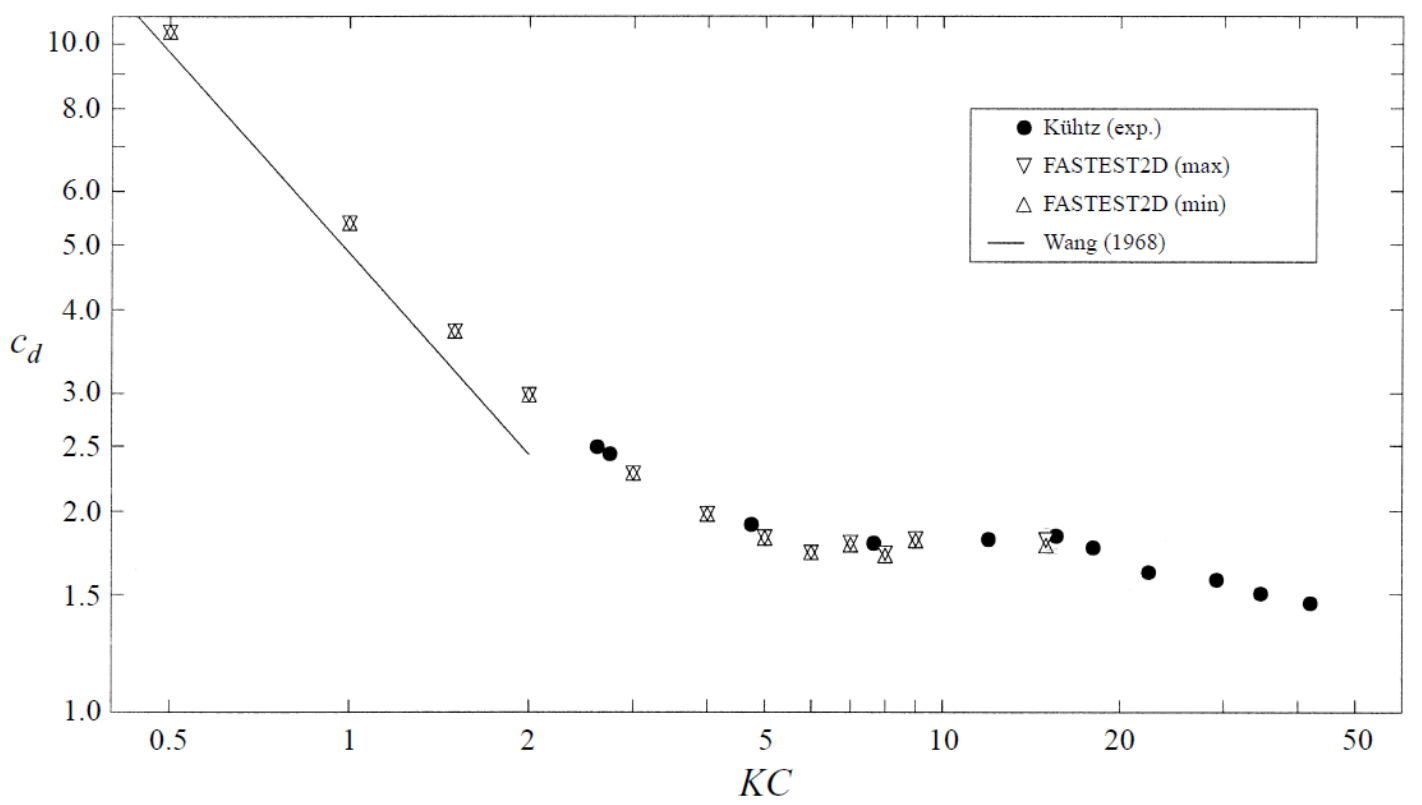

Figura 18- Coeficiente de arrasto para $\beta=35$ (DÜTSCH et al., 1998).

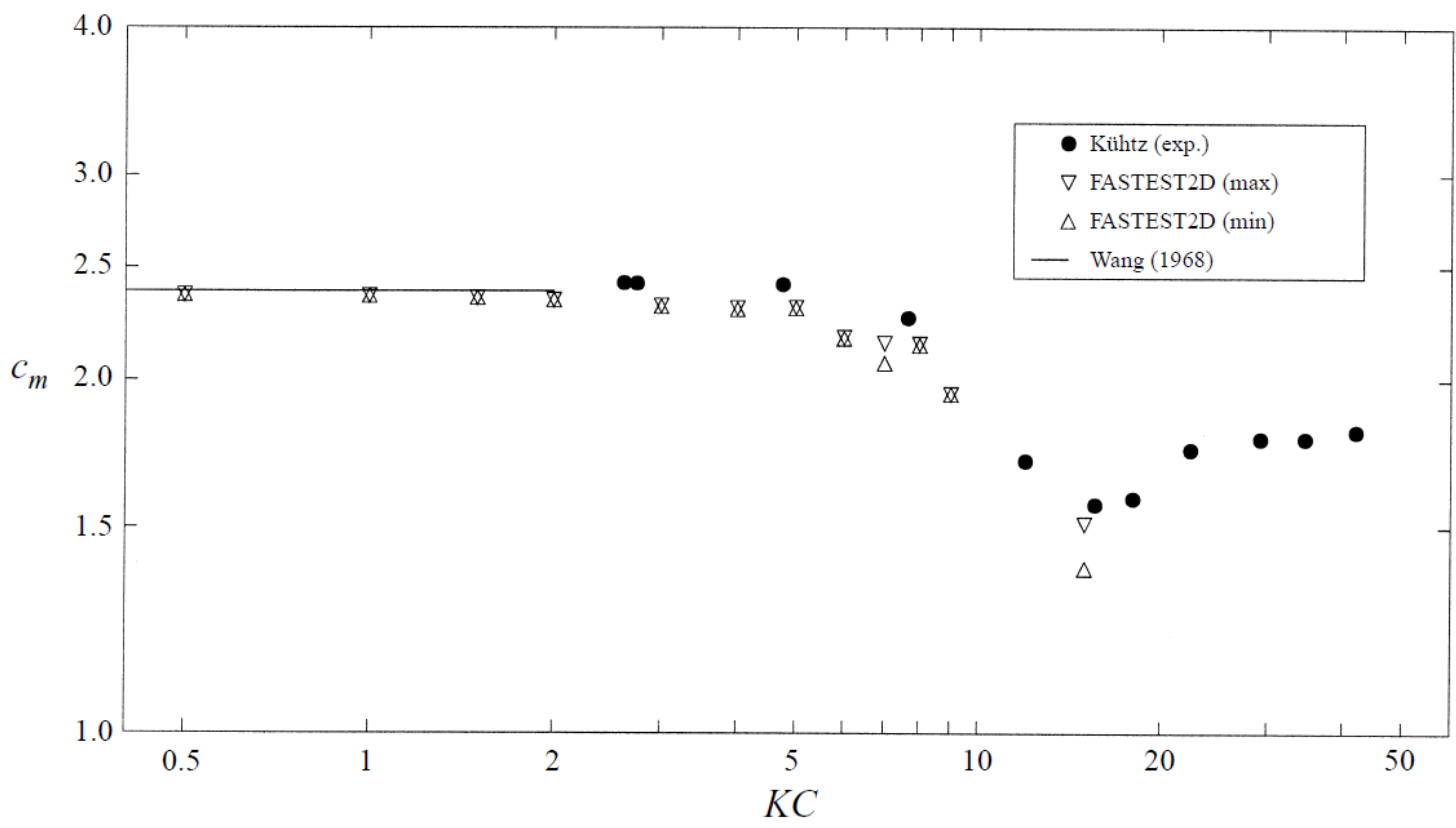

Figura 19 - Coeficiente de inércia para $\beta=35$ (DÜTSCH et al., 1998). 


\section{SIMULAÇÃO DO ESCOAMENTO EM TORNO DE CILINDRO CIRCULAR EM OSCILAÇÃO FORÇADA}

Após revisitar conceitos clássicos e trabalhos fundamentais sobre inércia adicional, potencial e viscosa, este trabalho investiga numericamente a variação do coeficiente de massa de um cilindro circular, suposto rígido, imerso em um fluido newtoniano incompressível e forçado a oscilar harmonicamente em função dos números adimensionais $R e$ e $K C$. O modelo do escoamento é bidimensional. O escoamento resultante é claramente não permanente. Com o fluido em repouso, a velocidade do cilindro é imposta harmonicamente no eixo horizontal. O escoamento é avaliado para os $R e$ e $K C$ nos intervalos $17,5 \leq R e \leq 350$ e $0,5 \leq K C \leq 10$, mantendo fixo o parametro $\beta=\frac{R e}{K C}=35$, conforme tabela 3. Sendo o movimento harmônico e as funções trigonométricas infinitamente diferenciáveis/integráveis, ao impor a velocidade do cilindro, a amplitude e aceleração do movimento são consequentes.

Tabela 3 - Parâmetros da simulação numérica

\begin{tabular}{l|l}
\hline Parâmetro da Frequência & $\beta=35$ \\
\hline Número de Keulegan-Carpenter & $K C=0,5 / 1 / 2 / 3 / 4 / 5 / 6 / 7 / 8 / 9 / 10$ \\
\hline Número de Reynolds & $R e=17,5 / 35 / 70 / 105 / 140 / 175$ \\
$210 / 245 / 280 / 315 / 350$ \\
\hline \hline
\end{tabular}

A escolha destes valores está alinhada com um dos objetivos deste trabalho: o de entender os conceitos fundamentais da inércia adicional, a contribuição da viscosidade e as características do escoamento ao redor de corpos de geometria simples, desde em escoamentos bem comportados até em escoamentos mais complexos. A evolução da complexidade do escoamento pode ser observada pelo mapa de Tatsuno e Bearman, ao plotar a linha $\beta=35$ e os pontos correspondentes à simulação numérica, figura 20. 


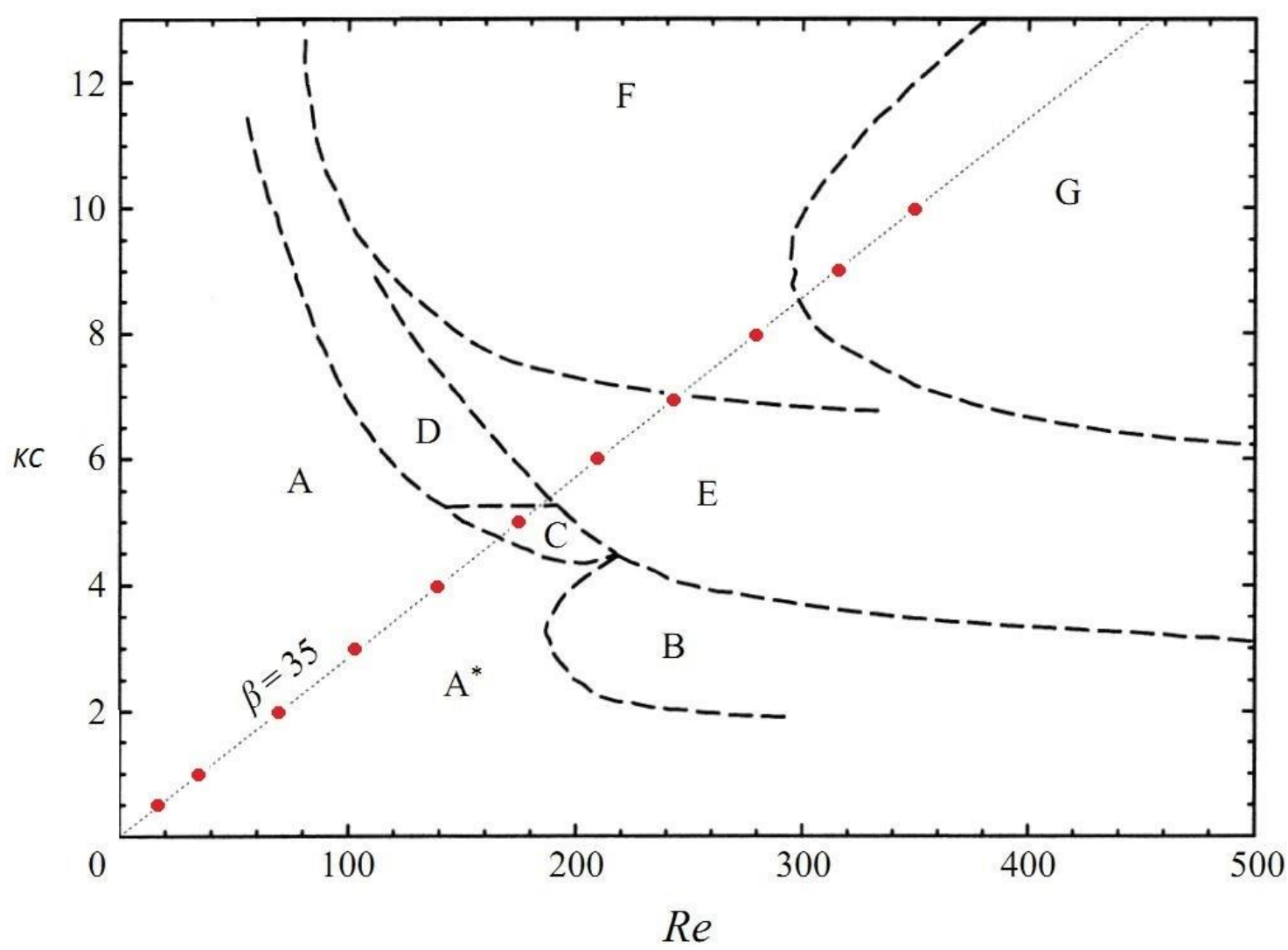

Figura 20- Regimes da simulação no mapa de Tatsuno e Bearman. Adaptado de Dütsh et al. (1998)

Registra-se a força resultante, em linha e normal ao movimento; desde os instantes iniciais até um número elevado de ciclos, da ordem de 30 ciclos. Os coeficientes de arrasto e de massa da equação de Morison (37) são então calculados pelo método dos mínimos quadrados. Comparam-se os resultados com aqueles obtidos por Wang (1968), Kühtz (1996), Dütsh et al. (1998) e Uzunoğlu, Tan e Price (2001).

Adicionalmente, calcula-se a energia cinética do fluido no domínio em cada instante. Investiga-se sua evolução temporal e se a redução gradual do coeficiente de massa observado para 0,5 $\leq K C \leq 10$ é também acompanhada de uma redução da variação da energia cinética do fluido no ciclo.

\subsection{Método Numérico}

Para a resolução numérica do escoamento em torno do cilindro oscilando, faz-se necessária uma ferramenta de cálculo precisa e robusta. Escoamentos ao redor de corpos rombudos com camadas cisalhantes livres (descolamentos) são em geral transientes, tanto em regime laminar quanto turbulento. A interação com corpos imersos, i.e., 
determinação da força e da resposta dinâmica, representa um esforço computacional significativo.

Optou-se pela ferramenta de código aberto Freefem $++{ }^{10}$ em sua versão 3.20, desenvolvido e mantido pelo Professor Frédéric Hecht da Universidade Pierre e Marie Curie de Paris. O Freefem++ é capaz de resolver equações de derivadas parciais elípticas, parabólicas e hiperbólicas na formulação variacional pelo Método dos Elementos Finitos (MEF), e possui as seguintes características:

- Linguagem de programação de alto-nível própria com sintaxe similar à linguagem $\mathrm{C}$

- Flexibilidade de adaptar o código conforme necessidade

- Algoritmos otimizados para a solução numérica - direta ou iterativa - de sistemas lineares esparsos e não simétricos

- Gerador de malha triangular não estruturada integrado

- Variedade razoável de elementos triangulares até quarta ordem

O MEF provê um formalismo para geração de um conjunto de equações discretas a fim de aproximar a solução de equação diferencial parcial. Teve início na indústria aeronáutica na década de 60 do século XX, aplicado à análise estrutural. É um caso particular do método dos resíduos ponderados na formulação de Galerkin.

Ressalta-se que a programação do método dos elementos finitos é bem estruturada, flexível para inclusão de novos elementos e compatível com problemas acoplados multidisciplinares, por exemplo, interação fluido-estrutura.

Para problemas auto-adjuntos, é possível obter um funcional e a matriz do sistema linear é simétrica, e o método de Galerkin ótimo. Porém, quando aplicado a fluidos, o termo convectivo é não-linear e gera matrizes não-simétricas, e sua importância cresce com aumento do número de Reynolds (ZIENKIWICZ; TAYLOR; NITHIARASU, 2005).

Para aplicação do método dos elementos finitos, é necessária uma formulação integral da equação de NS. Multiplica-se a equação de NS (30) por uma função-teste $\delta u_{i}$, e integra-se no domínio $\Omega$ (limitado):

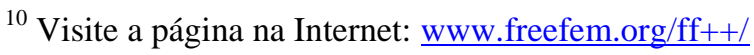




$$
\int_{\Omega} \delta u_{i} \frac{1}{K C} \frac{\partial u_{i}}{\partial t}+\delta u_{i} u_{j} \frac{\partial u_{i}}{\partial x_{j}} d \Omega=\int_{\Omega} \delta u_{i}\left(-\frac{\partial p}{\partial \mathrm{x}_{i}}+\frac{1}{R e} \frac{\partial^{2} u_{i}}{\partial x_{j} \partial x_{j}}\right) d \Omega
$$

Aplica-se então o teorema da divergência de Gauss nos termos de pressão e difusivo:

$$
\begin{aligned}
& \int_{\Omega} \delta u_{i} \frac{1}{K C} \frac{\partial u_{i}}{\partial t}+\delta u_{i} u_{j} \frac{\partial u_{i}}{\partial x_{j}}+\frac{1}{R e} \frac{\partial \delta u_{i}}{\partial x_{j}} \frac{\partial u_{i}}{\partial x_{j}}-p \frac{\partial \delta u_{i}}{\partial \mathrm{x}_{i}} d \Omega \\
= & \int_{\Gamma^{N}} \delta u_{i}\left(-p n_{i}+\frac{1}{R e} \frac{\partial u_{i}}{\partial x_{j}} n_{j}\right) d \Gamma
\end{aligned}
$$

A fronteira do domínio é particionada em $\Gamma=\Gamma^{D}+\Gamma^{N}$. A região $\Gamma^{D}$ corresponde àquela na qual a velocidade é especificada, e a função-teste $\delta u_{i}$ é identicamente nula. Na região $\Gamma^{N}$, a velocidade é desconhecida e, usualmente, faz-se $-p n_{i}+\frac{1}{R e} \frac{\partial u_{i}}{\partial x_{j}} n_{j}=0$. Essas condições de contorno são denominadas, respectivamente, de Dirichlet e de Neumann. O método dos elementos finitos apresenta um tratamento consistente das condições de contorno. De fato, o lado direito da equação (43) corresponde à condição de Neumann (natural) obtida diretamente da formulação fraca.

Procede-se similarmente para a equação da continuidade (2), i.e, multiplicando-a por uma função-teste $\delta p$, que representa uma arbitrária variação de pressão ${ }^{11}$, e integrando-a no domínio $\Omega$ :

$$
\int_{\Omega} \delta p \frac{\partial u_{i}}{\partial x_{i}}=0
$$

Em seguida, particiona-se o domínio em um número finito de subdomínios e pontos nodais discretos, nos quais a solução é procurada. A discretização do domínio é a primeira aproximação introduzida na solução do problema. A solução é aproximada por uma combinação linear das velocidades e pressões (incógnitas) nodais e de funções de interpolação ou de base. As funções de interpolação aproximam a solução dentro do subdomínio por polinômios lineares ou de ordem superior, são unitárias nos nós, alternadamente, e identicamente nulas fora do subdomínio. O subdomínio, os nós pertencentes a ele (internos e na fronteira) e as funções de interpolação constituem um

${ }^{11}$ Lembrando que a pressão é, neste caso, a função lagrangeana, conforme Seliger e Whitham (1968) 
elemento finito. Em princípio, emprega-se o método dos resíduos ponderados na formulação de Galerkin, no qual as funções-teste são iguais às funções de interpolação.

A grande flexibilidade do método dos elementos finitos está na diversidade de elementos disponíveis e em permitir um refinamento local nas regiões com geometria complexas ou nas quais a solução apresenta gradientes elevados.

Neste trabalho utilizam-se elementos triangulares com 3 nós por aresta (total de 6 nós), denominado $\mathrm{P}_{2} \mathrm{P}_{1}$, vide figura 21. É um elemento clássico, amplamente testado e sua estabilidade é consagrada (GRESHO; SANI, 2000). Os campos de velocidades e de pressão são aproximados, respectivamente, por polinômios quadráticos e lineares (ordem inferior). Portanto, tanto a velocidade quanto a pressão são contínuas nas interfaces entre os elementos da malha.

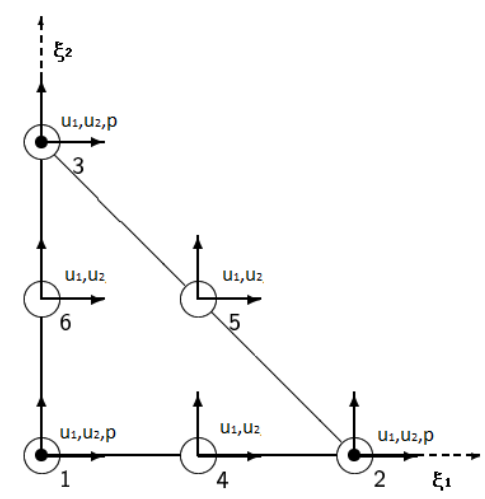

Figura 21 - Elemento triangular $\mathbf{P}_{2} \mathbf{P}_{1}$

Transforma-se então o sistema contínuo em um conjunto finito de equações algébricas para os graus de liberdade (nós). Por fim, é possível reescrever as equações na forma matricial compacta, e o sistema linear resultante é não-linear e com elevada esparsidade:

$$
\begin{gathered}
\frac{1}{K C}[M]\{\dot{u}\}+\left([N(u)]+\frac{1}{R e}[K]\right)\{u\}-[C] \cdot\{p\}=\{f\} \\
{[C]^{t}\{u\}=\{g\}}
\end{gathered}
$$

No Apêndice A, as etapas de discretização das equações diferencias são apresentadas em maiores detalhes. Explora-se também o aspecto computacional do problema com roteiro para a obtenção dessas matrizes. 


\subsubsection{Restrição de Incompressibilidade}

A restrição de incompressibilidade impõe certo grau de dificuldade à solução numérica do problema de escoamento. O acoplamento entre a equação de NS e da continuidade é dado implicitamente pela pressão. Portanto, a pressão tem a função de auto-ajustar a equação de NS de forma a manter a propriedade solenoidal (incompressibilidade) do campo de velocidades.

Para escoamentos invíscidos, regidos pela equação de Euler (5), Seliger e Whitham (1968) demonstraram a equivalência da pressão com a densidade lagrangeana. Isto é válido mesmo para escoamentos compressíveis e rotacionais, basta que seja o fluido invíscido (SELIGER; WHITHAM, 1968) e (CASETTA; PESCE, 2011, 2013). Tal conceito pode servir como base ao estudo da equação de NS.

Os métodos comumente utilizados para contornar esta dificuldade são: método das penalidades, equação de Poisson para a pressão e formulação mista, que resultam em equações algébricas de índice zero, um e dois, respectivamente, conforme Gresho e Sani (2000).

Neste trabalho optou-se pela formulação mista, também denominado método $u-p$. As equações discretas de NS (45) e da continuidade (46) são resolvidas simultaneamente. Portanto, mantém-se a formulação original do problema. Por outro lado, há um aumento do sistema linear a ser resolvido, a matriz resultante é esparsa, não simétrica e com uma estrutura simplética $^{12}$ (ARANHA, 2009).

\subsubsection{Equação de Navier-Stokes em Referencial Não-Inercial}

A simulação do escoamento ao redor de um corpo em movimento variável exige técnicas específicas. Para o presente trabalho, avaliaram-se as seguintes possibilidades:

- Malha deslizante: são utilizadas duas malhas, uma interna, móvel, que envolve o corpo até certo limite no interior do domínio, e outra externa, desde o limite interior até a borda externa do domínio. A malha externa se mantém fixa, enquanto a interna acompanha o movimento do corpo. Na interface entre as duas malhas, com sobreposição ou não de elementos, são empregados algoritmos de interpolação para a velocidade e a pressão.

\footnotetext{
12 A estrutura simplética origina-se da forma como os operadores gradiente e divergente discretos se relacionam pela matrix $[C]$ e sua transposta, $[C]^{t}$, respectivamente, nas equações $(45)$ e (46).
} 
- Malha deformável: em cada passo de tempo, a malha deve ser ajustada à nova posição do corpo. Ela pode ser inteiramente refeita ou apenas deformada com base na nova posição do corpo. O custo computacional é alto, pois as matrizes do sistema devem ser constantemente atualizadas, os elementos podem se tornar extremamente deformados com consequentes problemas de condicionamento das matrizes resultantes e faz-se necessário um gerador automático de malha.

- Método das fronteiras imersas: utiliza-se uma malha fixa para o fluido no domínio inteiro, desconsiderando o corpo, e mapeia-se a interface entre corpo e fluido. A presença do corpo é introduzida no fluido por forças na interface, que compatibilizam as condições de contorno de impenetrabilidade e de aderência da fronteira sólida. O método é extremamente poderoso, entretanto, a implementação numérica é elaborada.

- Referencial não-inercial: o escoamento é resolvido em um referencial móvel, fixado ao corpo. Sendo o movimento do corpo variável, o referencial é nãoinercial, e seus efeitos devem ser compensados. São então introduzidas forças de inércia de campo (termo fonte) no fluido. Tanto as forças de inércia quanto as condições de contorno devem ser atualizadas a cada passo de tempo, o que penaliza a estabilidade numérica, entretanto, mantém-se invariável a malha.

Optou-se pela última técnica, devido a sua implementação simples e por manter a estrutura do código praticamente inalterada, exceto pela compensação do efeito do referencial não-inercial. Esta técnica já foi bastante explorada; citam-se os trabalhos de Meneghini e Bearman (1995), Li, Sherwin e Bearman (2000) e Gioria (2010). Ao se manter a malha fixa em relação ao cilindro, evita-se a reconstrução das matrizes a cada intervalo de tempo e a deformação excessiva dos elementos.

Sendo $r_{i}(t)$ a posição do referencial móvel, fixado no corpo, em função do tempo, as coordenadas entre o referencial absoluto e o relativo se relacionam por:

$$
x_{i}=x_{i}^{\prime}+r_{i}
$$

Nesta notação, o apóstrofo denota as coordenadas no referencial móvel. A relação entre velocidades é obtida diretamente pela derivada temporal:

$$
u_{i}=u_{i}^{\prime}+\dot{r}_{i}
$$


As derivadas espaciais não se alteram (LI; SHERWIN; BEARMAN, 2000):

$$
\frac{\partial}{\partial x_{i}^{\prime}}=\frac{\partial x_{j}}{\partial x_{i}^{\prime}} \frac{\partial}{\partial x_{j}}=\frac{\partial}{\partial x_{i}}
$$

Portanto, os operadores divergente e gradiente permanecem invariantes. Escrevem-se assim o gradiente da pressão, o termo difusivo e o termo convectivo da equação de NS (30) no referencial móvel, respectivamente, como:

$$
\begin{gathered}
\frac{\partial p}{\partial x_{i}^{\prime}}=\frac{\partial p}{\partial \mathrm{x}_{i}} \\
\frac{\partial^{2} u_{i}^{\prime}}{\partial x_{j}^{\prime} \partial x_{j}^{\prime}}=\frac{\partial^{2} u_{i}}{\partial x_{j} \partial x_{j}} \\
u_{j} \frac{\partial u_{i}}{\partial x_{j}}=\left[u_{j}^{\prime}+\dot{r}_{j}\right] \frac{\partial\left[u_{i}^{\prime}+\dot{r}_{i}\right]}{\partial x_{j}^{\prime}}=u_{j}^{\prime} \frac{\partial u_{i}^{\prime}}{\partial x_{j}^{\prime}}+\dot{r}_{j} \frac{\partial u_{i}^{\prime}}{\partial x_{j}^{\prime}}
\end{gathered}
$$

Relaciona-se a derivada temporal (termo local) da equação de NS (30), conforme Li, Sherwin e Bearman (2000):

$$
\left(\frac{\partial u_{i}}{\partial t}\right)_{a}=-\dot{r}_{j} \frac{\partial u_{i}}{\partial x_{j}^{\prime}}+\left(\frac{\partial u_{i}}{\partial t}\right)_{r}
$$

Substituindo $u_{i}=u_{i}^{\prime}+\dot{r}_{i}$, obtém-se:

$$
\left(\frac{\partial u_{i}}{\partial t}\right)_{a}=-\dot{r}_{j} \frac{\partial u_{i}^{\prime}}{\partial x_{j}^{\prime}}+\left(\frac{\partial u_{i}^{\prime}}{\partial t}\right)_{r}+\ddot{r}_{i}
$$

Por fim, obtém-se a equação de NS no referencial móvel:

$$
\frac{1}{K C} \frac{\partial u_{i}}{\partial t}+u_{j} \frac{\partial u_{i}}{\partial x_{j}}=-\frac{\partial p}{\partial \mathrm{x}_{i}}+\frac{1}{R e} \frac{\partial^{2} u_{i}}{\partial x_{j} \partial x_{j}}-\frac{1}{K C} \ddot{r}_{i}
$$

Nota-se que o mesmo resultado poderia ser obtido simplesmente adicionando-se a força de inércia específica do lado direito da equação. Li, Sherwin e Bearman (2000) apresentam a dedução para o caso mais geral de movimento do referencial não-inercial, com translação e rotação. 
Após o cálculo, faz-se necessário um pós-processamento a fim de retornar para o referencial inercial. A força resultante no cilindro e a vorticidade se mantêm inalteradas (LI; SHERWIN; BEARMAN, 2000).

\subsubsection{Condições de Contorno}

São discutidas a seguir as condições de contorno apropriadas para simulação do escoamento ao redor do cilindro oscilando. Gresho e Sani (2000) ressaltam a importância da consistência das condições de contorno e iniciais aplicadas ao escoamento a fim de se obter um problema bem-posto, evitar multiplicidade de soluções ou mesmo restringir demais a solução.

A figura 22 apresenta as fronteiras do domínio $\Omega$, nas quais devem ser especificadas as condições de contorno. A fronteira interna corresponde à superfícies do cilindro $\Gamma_{S}^{D}, \mathrm{e}$ as laterais correspondem ao fluido ao longe $\Gamma_{\Sigma}^{D}, \operatorname{com} \Gamma^{D}=\Gamma_{S}^{D} \cup \Gamma_{\Sigma}^{D}$. No referencial inercial, assume-se que o fluido está em repouso ao longe, onde o escoamento induzido pelo corpo é pequeno. Faz-se então $u_{i}=0$ em $\Gamma_{\Sigma}^{D}$. Na superfície do cilindro, a velocidade é imposta harmonicamente, e o escoamento deve satisfazer à condição de impenetrabilidade do corpo, portanto, $u_{i}=U_{i}$.

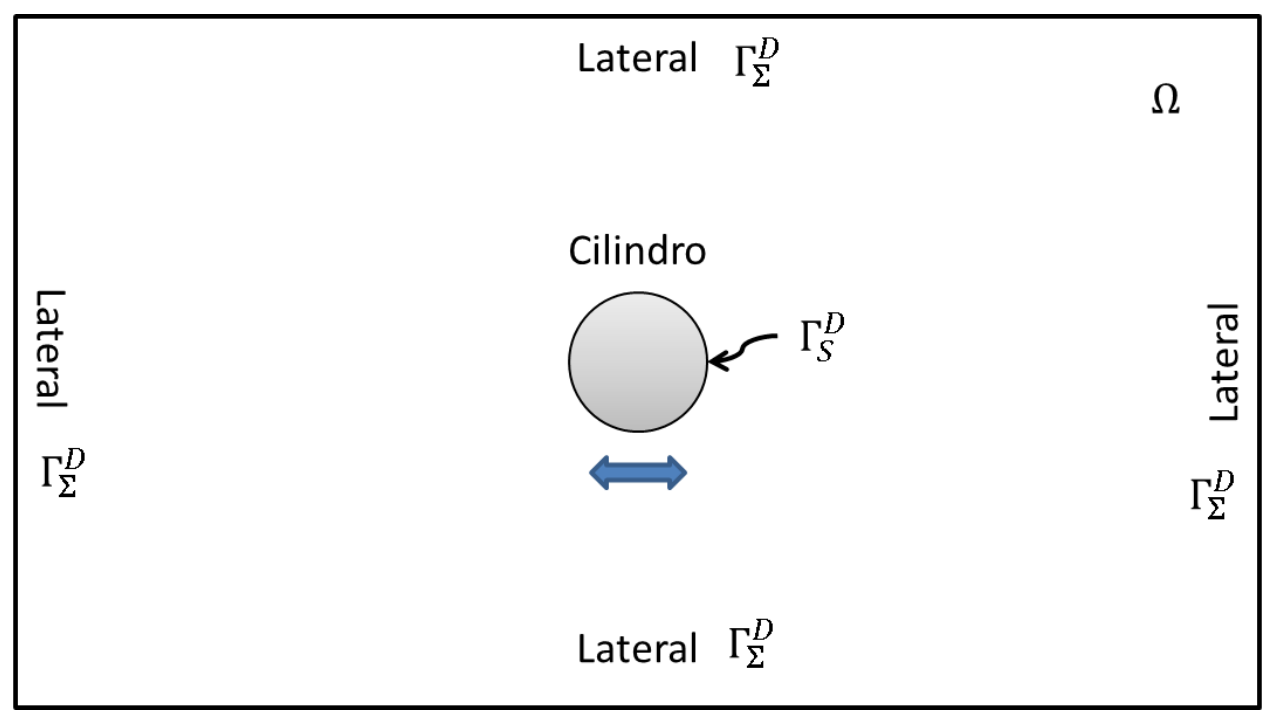

Figura 22 - Fronteiras do domínio 
Tabela 4 - Condições de contorno

\begin{tabular}{c|c|c|c|c}
\hline \hline Local & Contorno & Tipo & $\begin{array}{c}\text { Condição } \\
\text { (Ref. Inercial) }\end{array}$ & $\begin{array}{c}\text { Condição } \\
\text { (Ref. Não-Inercial) }\end{array}$ \\
\hline Laterais & $\Gamma_{\Sigma}^{D}$ & Dirichlet & $u_{i}=0$ & $u_{i}=\left\{\begin{array}{cc}-U \cdot \cos (\omega t) \\
0\end{array}, i=1\right.$ \\
Corpo & $\Gamma_{S}^{D}$ & Dirichlet & $U_{i}=\left\{\begin{array}{cc}U \cdot \cos (\omega t) \\
0 \\
u_{i}=U_{i}\end{array}, i=2\right.$ \\
\hline \hline
\end{tabular}

A solução numérica no referencial não-inercial modifica significativamente as condições do contorno do problema acima expostas. Ao invés de estacionário, o fluido ao longe é visto como oscilatório, com velocidade oposta à do cilindro. Na superfície do cilindro $\Gamma_{S}^{D}$, a condição de aderência e impenetrabilidade do escoamento na parede resume-se a $u_{i}=0$.

Tabela 4 compara as condições de contorno em ambos os referenciais. Implicitamente, o escoamento satisfaz também a condição de incompressibilidade global para todo $t \geq 0$, i.e., o fluxo mássico total dever ser identicamente nulo:

$$
\int_{\Gamma} u_{i} n_{i} d \Gamma=0
$$

\subsubsection{Discretização Temporal}

Procurou-se por um método que fosse estável e de ordem superior a fim de simular o escoamento ao redor do cilindro oscilando por um número elevados de ciclos. Os métodos implícitos são consagrados por sua estabilidade. Optou-se então pela fórmula de diferenciação retrógrada (em tradução livre do inglês, backward differentiation formulae), de segunda ordem, no qual a derivada temporal da velocidade no instante $t_{n+1}$ é estimada pela derivada do polinômio interpolador da velocidade que passa pelos 
pontos $t_{n+1}, t_{n}$ e $t_{n-1}$ (FERZIGER, 1998). É um método multi-passo, utilizando a informação de dois passos anteriores. A derivada temporal de velocidade na equação (45) é aproximada por:

$$
\left\{\dot{u}_{n+1}^{m+1}\right\}=\left\{\frac{3}{2} \frac{u_{n+1}^{m+1}}{\Delta t}-2 \frac{u_{n}}{\Delta t}+\frac{1}{2} \frac{u_{n-1}}{\Delta t}\right\}
$$

Identificam-se o instante de tempo por $n$ e a iteração por $m$. A matriz de rigidez não linear, originária do termo convectivo, é resolvida por iteração. Por fim, escrevem-se as equações (45) e (46), com adição da força de inércia do referencial não-inercial (termo fonte), como:

$$
\begin{aligned}
& \frac{1}{K C}[M]\left\{\frac{u_{n+1}^{m+1}}{\Delta t}-\frac{4}{3} \frac{u_{n}}{\Delta t}+\frac{1}{3} \frac{u_{n-1}}{\Delta t}\right\}= \\
& \frac{2}{3}\left\{\left\{f_{n+1}\right\}+[C] \cdot\left\{p_{n+1}^{m+1}\right\}-\left(\left[N\left(u_{n+1}^{m}\right)\right]+\frac{1}{R e}[K]\right)\left\{u_{n+1}^{m+1}\right\}-\frac{1}{K C}\left\{\ddot{r}_{n+1}\right\}\right\} \\
& {[C]^{t}\left\{u_{n+1}^{m+1}\right\}=\left\{g_{n+1}\right\} }
\end{aligned}
$$

Adotou-se o seguinte critério de convergência, sendo | | o módulo do vetor:

$$
\sqrt{\left(\frac{\left|u_{n+1}^{m+1}-u_{n+1}^{m}\right|}{\left|u_{n+1}^{m+1}\right|}\right)^{2}+\left(\frac{\left|p_{n+1}^{m+1}-p_{n+1}^{m}\right|}{\left|p_{n+1}^{m+1}\right|}\right)^{2}}<10^{-7}
$$

A combinação da fórmula de diferenciação retrógrada no tempo e de elementos finitos $\mathrm{P}_{2} \mathrm{P}_{1}$ no espaço resulta em um método numérico de $2^{\circ}$ ordem temporal e espacial. Utilizou-se o método de Euler implícito nos dois primeiros passos de tempo para dar partida ao método.

\subsubsection{Malha Utilizada}

A discretização do domínio e geração da malha é parte fundamental do trabalho de resolução numérica do problema a fim de se obter uma solução convergente, capturar a dinâmica do escoamento nas diversas escalas e para a estabilidade do método. Para as diversas simulações, utilizou-se a mesma malha triangular não-estruturada, vide figura 23. 
Inicialmente os contornos do domínio foram divididos uniformemente, conforme a tabela 5. Em seguida, foram programados os elementos próximos à superfície do cilindro. Aumentou-se a densidade dos elementos próximo ao cilindro, na camada limite, onde ocorrem gradientes elevados de velocidades tangenciais à superfície do cilindro. Essa camada de elementos pode ser observada na figura 24. Ao redor do eixo de oscilação, também foi aumentada a densidade de elementos para capturar os efeitos viscosos e o desprendimento de vórtices.

Tabela 5 - Divisões do Contorno

\begin{tabular}{l|l}
\hline & Divisões \\
\hline \hline Cilindro & 200 \\
\hline Lateral Esquerda/Direita & 70 \\
\hline Lateral Superior/Inferior & 60 \\
\hline \hline
\end{tabular}

A tabela a seguir resume as propriedades da malha em termos de elementos e nós:

Tabela 6 - Propriedades da Malha

\begin{tabular}{l|l}
\hline \hline & Quantidade \\
\hline \hline Elementos (Triangulares) & 46156 \\
\hline Vértices & 23308 \\
\hline Nós de Velocidades & 92772 \\
\hline Nós Pressão & 23308 \\
\hline \hline
\end{tabular}

Conforme Schlichting e Gersten (2000), a espessura da camada limite ao redor do cilindro é da ordem:

$$
\delta \propto \sqrt{\frac{v T}{\pi}}
$$

Esta estimativa advém da solução da placa plana em movimento oscilatório. No presente trabalho, tem-se $\frac{\delta}{D} \approx 0,09$. Portanto, a malha próxima ao cilindro é capaz de 
capturar bem os efeitos viscosos que ocorrem nessa região. Adicionalmente, como visto, o elementos finito $\mathrm{P}_{2} \mathrm{P}_{1}$ aproxima o campo de velocidades por polinômios quadráticos. Assim, consegue-se representar os gradientes elevados e as tensões cisalhantes na camada limite com elevada fidelidade.

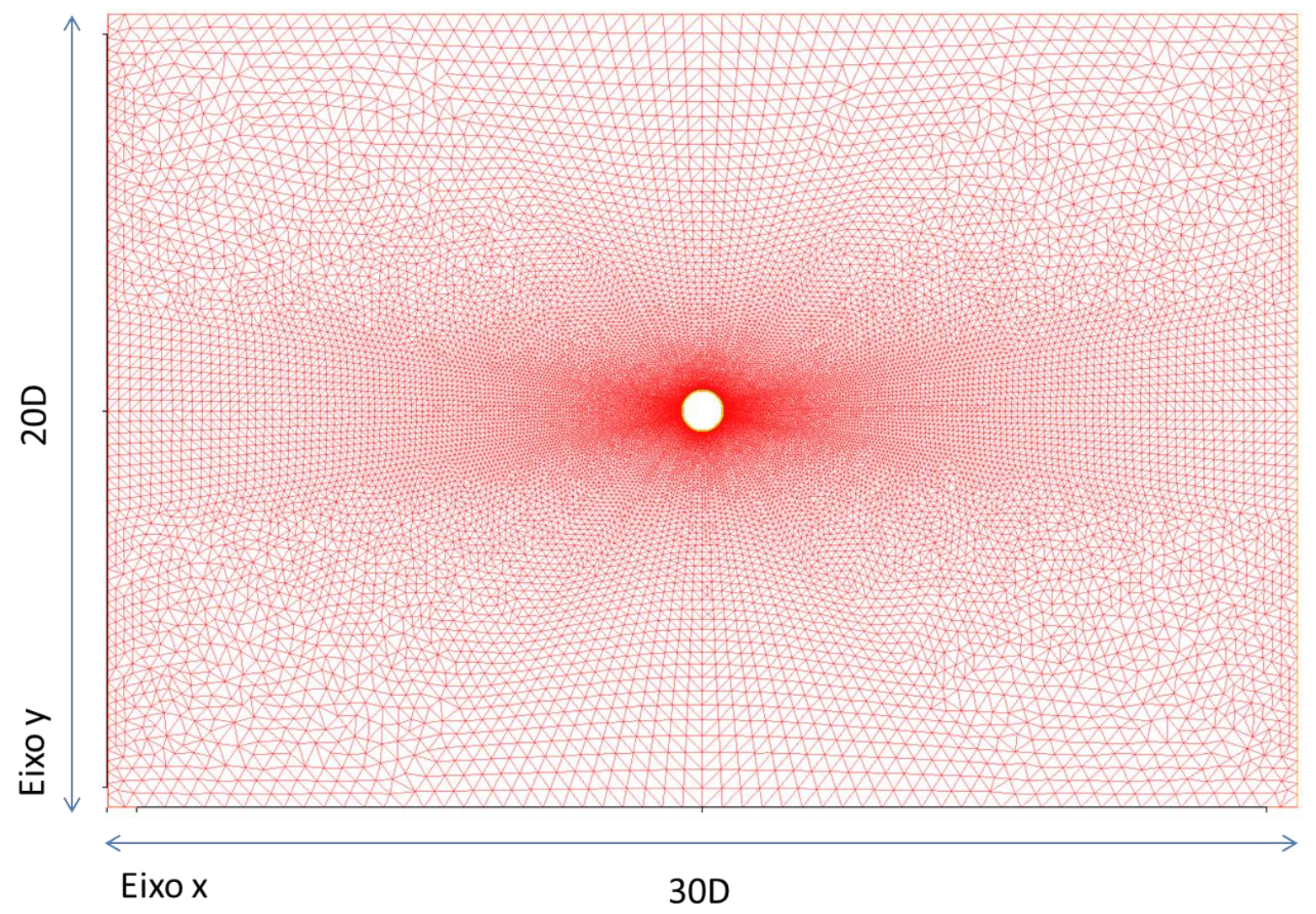

Figura 23- Malha retangular não-estruturada 


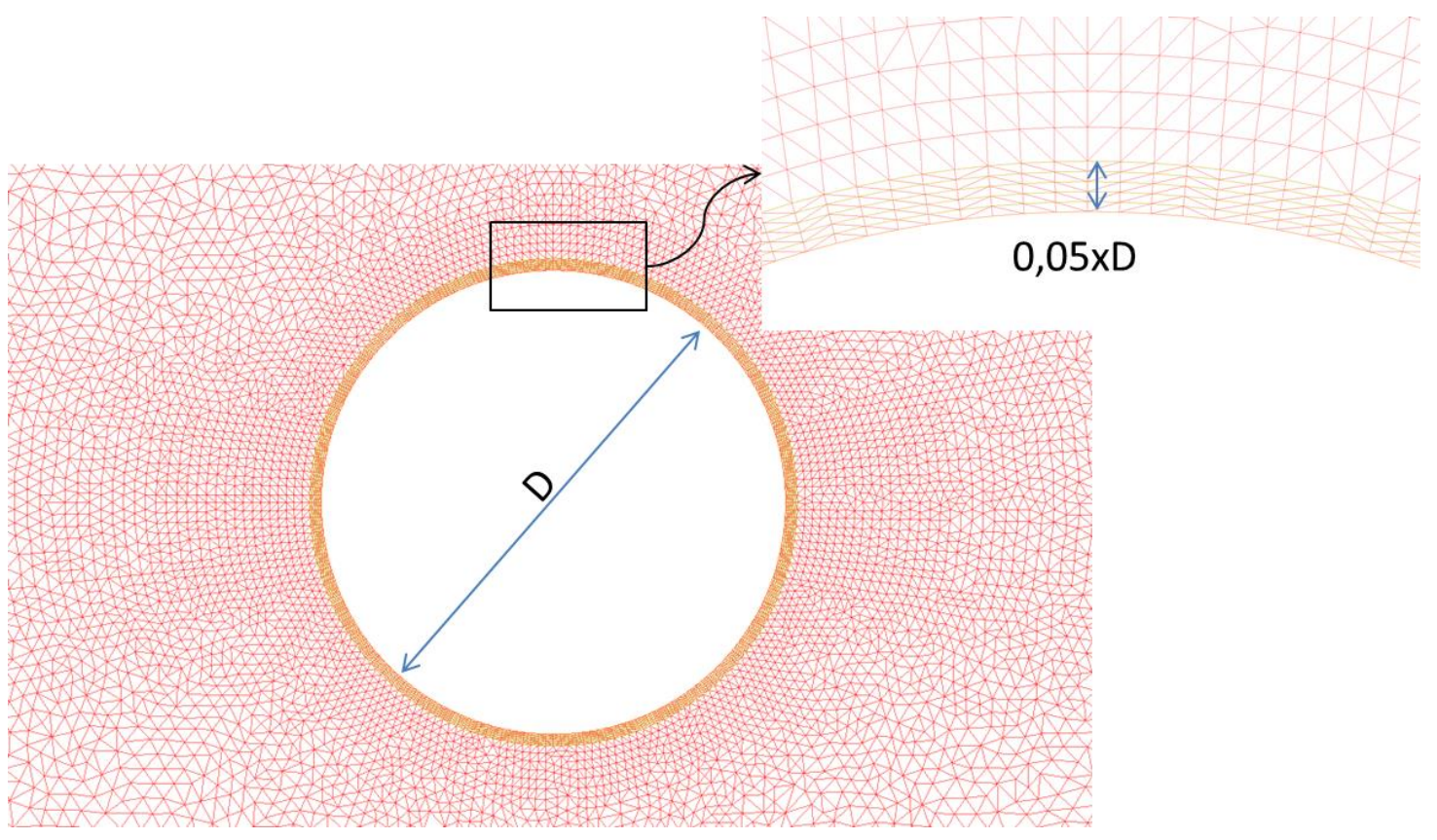

Figura 24 - Detalhe da malha na região próxima ao cilindro 


\section{RESULTADOS}

Foram simulados 30 ciclos do movimento do cilindro, partindo da origem do sistema de coordenadas inercial, com velocidade máxima e aceleração nula. As simulações capturaram bem os regimes A*, A, E e F do mapa de Tatsuno e Bearman (1990) e serão discutidas em maiores detalhes a seguir. Os coeficientes da equação de Morison (37) foram ajustados pelo método dos mínimos quadrados a partir dos últimos 5 ciclos do sinal de força, em linha com o movimento, e do conhecimento da velocidade e aceleração impostas ao cilindro (na realidade ao escoamento externo ao longe). As tabelas 7 e 8 apresentam, respectivamente, os coeficientes de arrasto e de massa. O número de Keulegan-Carpenter crítico, calculado pela equação (41), é igual a $K C_{c r}=$ 2,58 .

A força do escoamento sobre o cilindro é obtida multiplicando-se o tensor de tensões $T_{i j}$ pelo vetor normal $n_{i}$, e integrando em toda a superfície $S$ do cilindro. As forças de resistência e normal são expressas, respectivamente, por:

$$
\begin{aligned}
& F_{1}=-\int_{S}\left(-p+2 \mu \frac{\partial u_{1}}{\partial x_{1}}\right) n_{1}+\mu\left(\frac{\partial u_{1}}{\partial x_{2}}+\frac{\partial u_{2}}{\partial x_{1}}\right) n_{2} d \Gamma \\
& F_{2}=-\int_{S} \mu\left(\frac{\partial u_{1}}{\partial x_{2}}+\frac{\partial u_{2}}{\partial x_{1}}\right) n_{1}+\left(-p+2 \mu \frac{\partial u_{2}}{\partial x_{2}}\right) n_{2} d \Gamma
\end{aligned}
$$

Caso o escoamento seja simétrico em torno do eixo $x_{1}$, a força normal $F_{2}$ é nula. Em outras palavras, se os vórtices não forem emitidos simultâneamente de ambos os lados do cilindro, ou se a emissão for oblíqua, existe uma componente transversal. Nos resultados a seguir, calcula-se ainda a diferença, denominado resíduo, entre força de resistência, $F_{1}$ acima e aquela representada pela equação de Morison com os coeficientes de massa e de arrasto encontrados:

$$
\Delta R=F_{1}-\left(-C_{M} \rho \frac{\pi D^{2}}{4} \frac{d U_{1}}{d t}-\frac{1}{2} C_{D} \rho D\left|U_{1}\right| U_{1}\right)
$$


Tabela 7 - Coeficiente de Arrasto

\begin{tabular}{c|c|c}
\hline KC & $\mathrm{Re}$ & $\mathrm{C}_{\mathrm{D}}$ \\
\hline \hline 0,5 & 17,5 & 9,438 \\
\hline 1,0 & 35 & 4,853 \\
\hline 2,0 & 70 & 2,69 \\
\hline 3,0 & 105 & 2,081 \\
\hline 4,0 & 140 & 1,843 \\
\hline 5,0 & 175 & 1,730 \\
\hline 6,0 & 210 & 1,642 \\
\hline 7,0 & 245 & 1,688 \\
\hline 8,0 & 280 & 1,642 \\
\hline 10,0 & 350 & 1,690 \\
\hline 9,0 & 315 & \\
\hline
\end{tabular}


Tabela 8 - Coeficientes de Massa e de Inércia

\begin{tabular}{|c|c|c|c|}
\hline $\mathrm{KC}$ & $\mathrm{Re}$ & $\mathrm{C}_{\mathrm{A}}$ & $\mathrm{C}_{\mathrm{M}}$ \\
\hline 0,5 & 17,5 & 1,386 & 2,386 \\
\hline 1,0 & 35 & 1,380 & 2,380 \\
\hline 2,0 & 70 & 1,360 & 2,360 \\
\hline 3,0 & 105 & 1,336 & 2,336 \\
\hline 4,0 & 140 & 1,322 & 2,322 \\
\hline 5,0 & 175 & 1,317 & 2,317 \\
\hline 6,0 & 210 & 1,095 & 2,095 \\
\hline 7,0 & 245 & 1,162 & 1,162 \\
\hline 8,0 & 280 & 1,096 & 1,096 \\
\hline 9,0 & 315 & 0,875 & 1,875 \\
\hline 10,0 & 350 & 0,866 & 1,866 \\
\hline
\end{tabular}

Os resultados acima possuem boa aderência com os trabalhos de Stokes (1850), Wang (1968), Kühtz (1996), Dütsh et al. (1998) e Uzunoğlu, Tan e Price (2001). O coeficiente de arrasto decresce rapidamente e, para $K C \geq 2$, os valores obtidos começam a divergir da teoria assintótica de Wang (1968), vide figura 25 . O coeficiente de inércia mantém-se aproximadamente constante e próximo do valor teórico de Wang (1968), e decresce para $K C \geq 2$, vide figura 26 . 


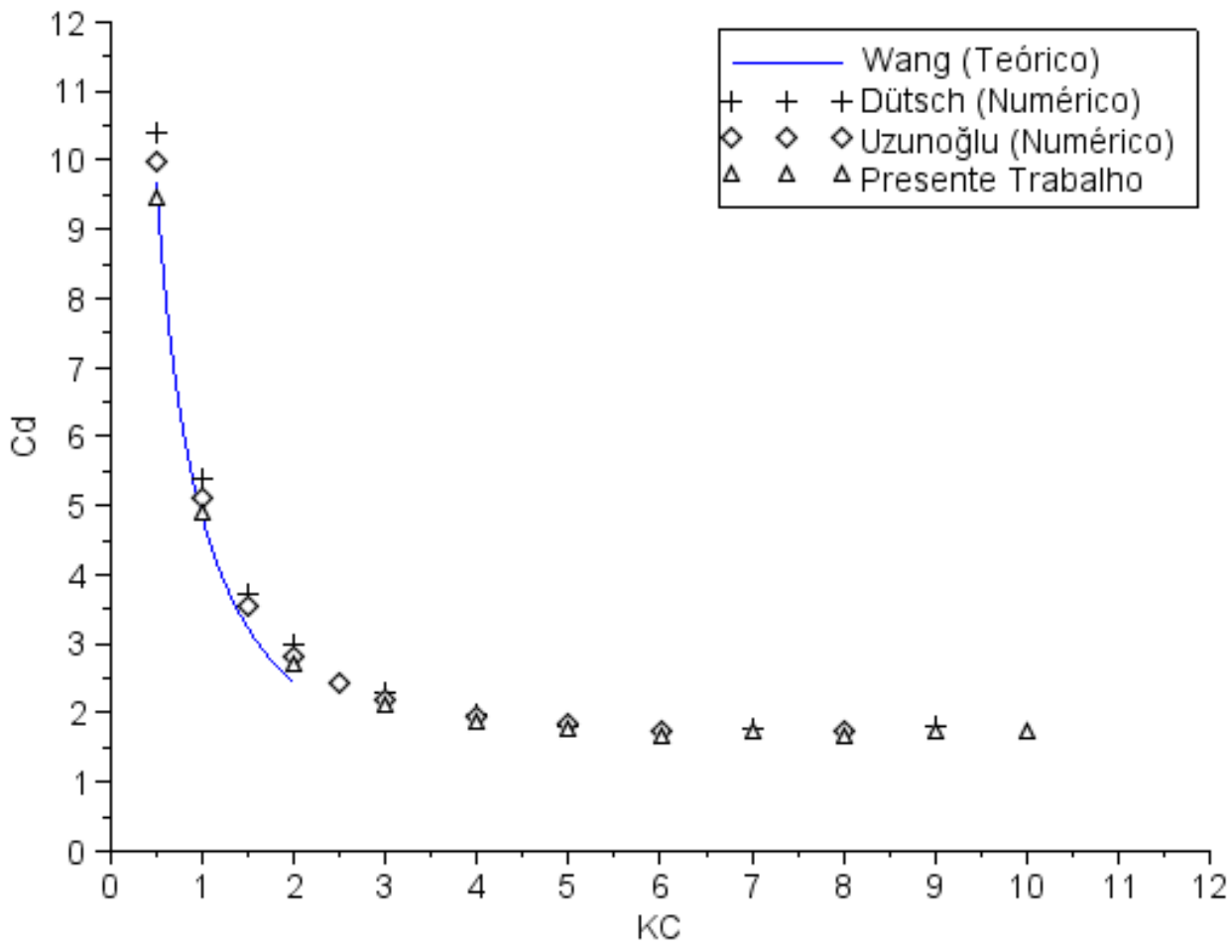

Figura 25- Coeficiente de arrasto

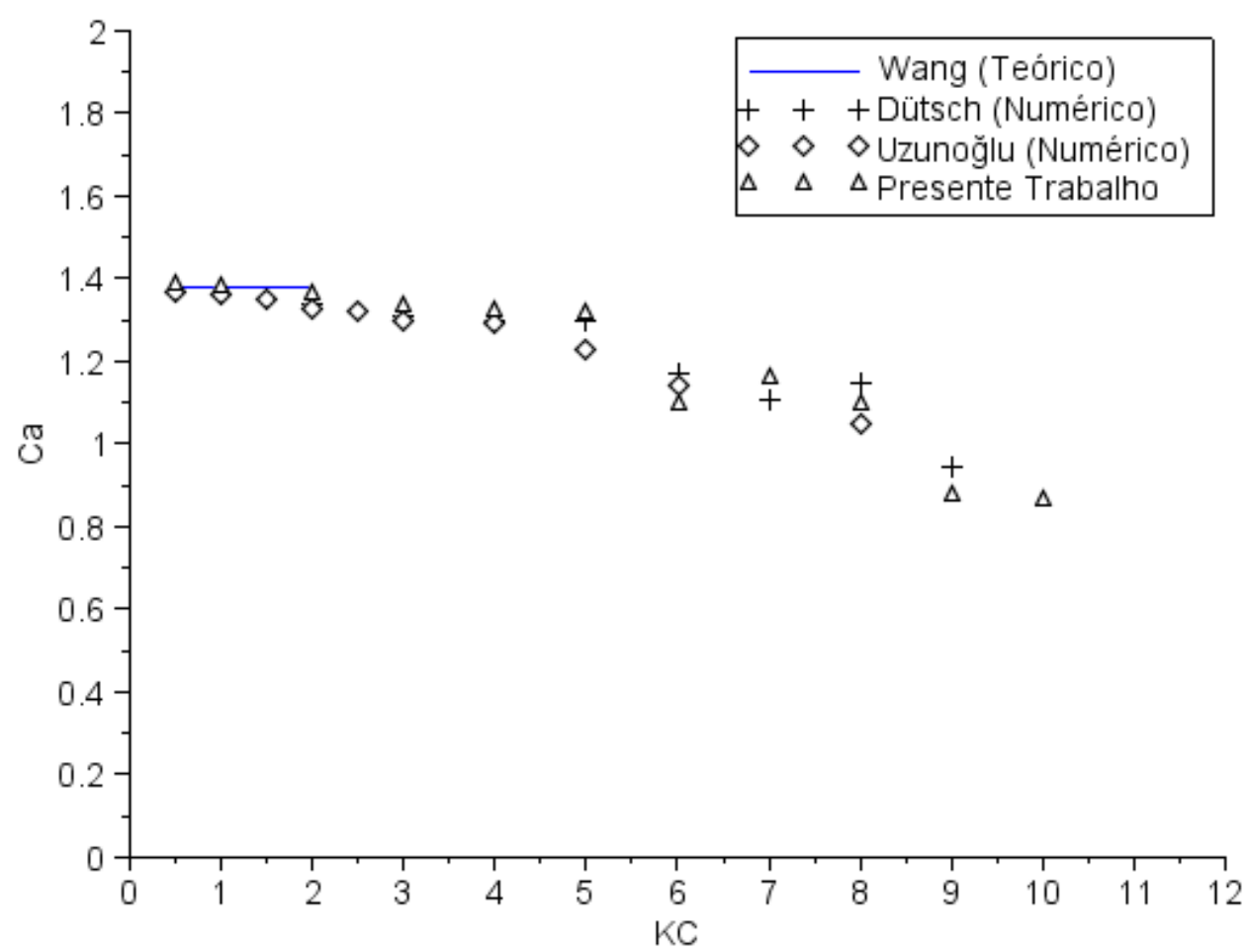

Figura 26 - Coeficiente de massa 
As figuras 27 e 28 apresentam os coeficientes da série de Fourier do sinal de força de resistência. Para $K C \leq 5$, a força é bem representada por um único harmônico de frequência igual à de oscilação do cilindro. Para $K C>5$, surgem outros harmônicos de frequência mais elevadas, apesar do harmônico principal, com frequência igual à de oscilação do cilindro, ser o mais relevante. Observa-se uma redução gradativa do harmônico principal com incremento de $K C$.

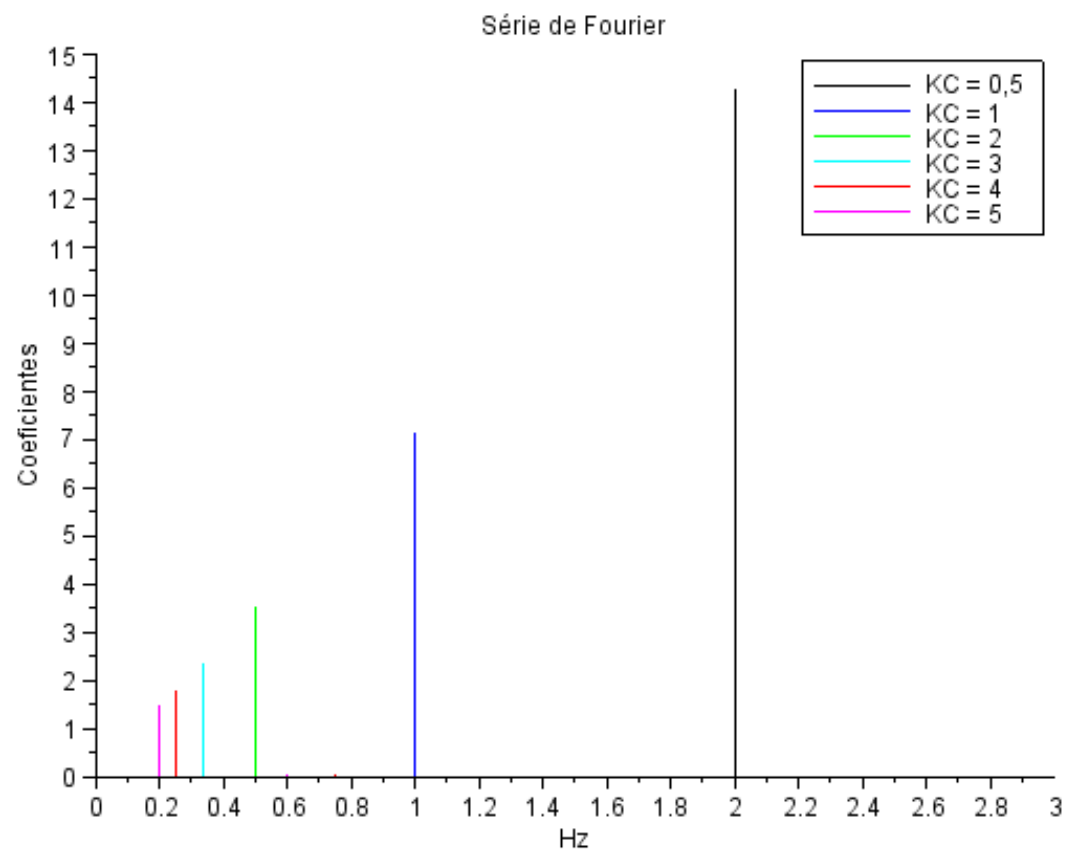

Figura 27 - Série de Fourier da força de resistência para $\mathrm{KC}=0,5$ até 5

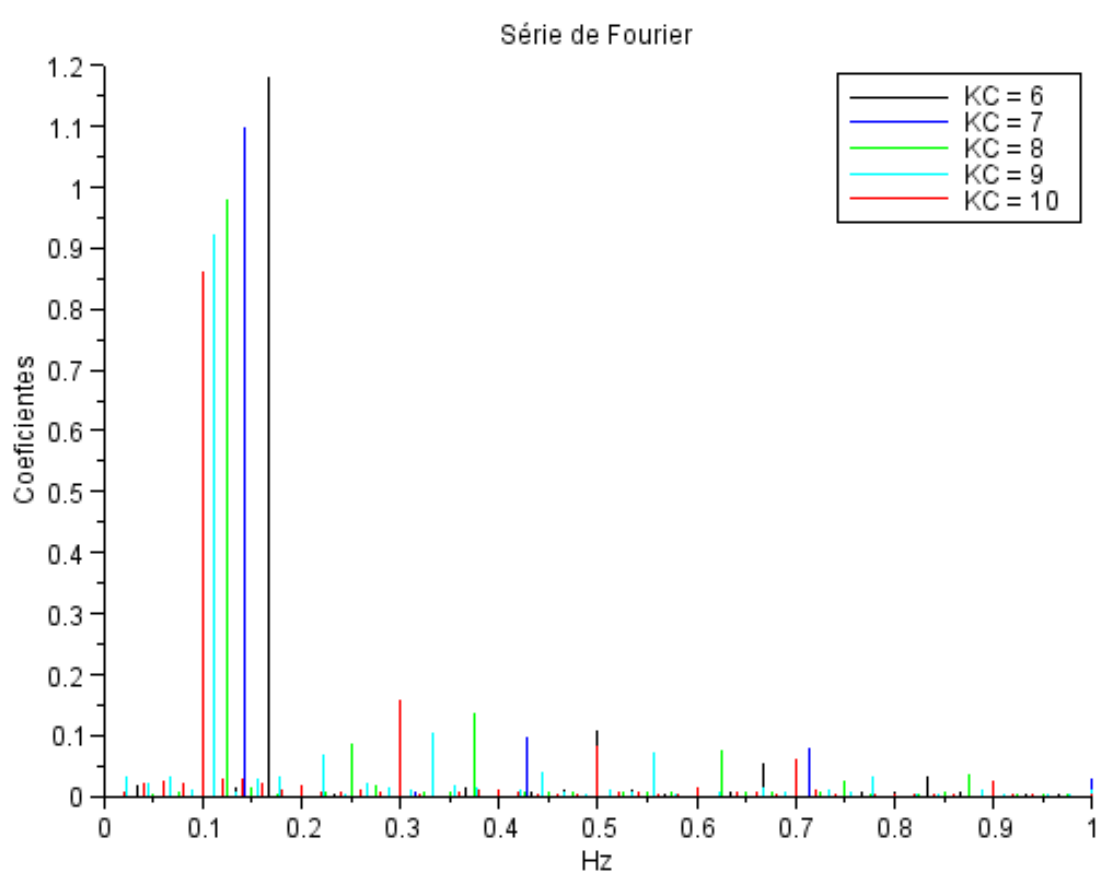

Figura 28 - Série de Fourier da força de resistência para $\mathrm{KC}=6$ até 10 
O ângulo de fase entre o primeiro harmônico da força de resistência e a posição do cilindro reduz-se gradualmente com o aumento $K C$, vide Figura 29. Para $K C \geq 6$, o escoamento é inicialmente simétrico e, após um número suficientemente grande de ciclos, aparece certa instabilidade no escoamento e assimetria no padrão de formação dos vórtices. O escoamento induzido pelo cilindro passa a ser convectado em direção oblíqua àquela de oscilação. Ao se calcular o ângulo de fase entre a força de resistência e a posição do cilindro nos primeiros 5 ciclos, com escoamento simétrico, e nos últimos 5 ciclos do movimento, com escoamento assimétrico, nota-se que, com o aparecimento da esteira transversa, o ângulo de fase reduz significativamente, conforme Figura 29.

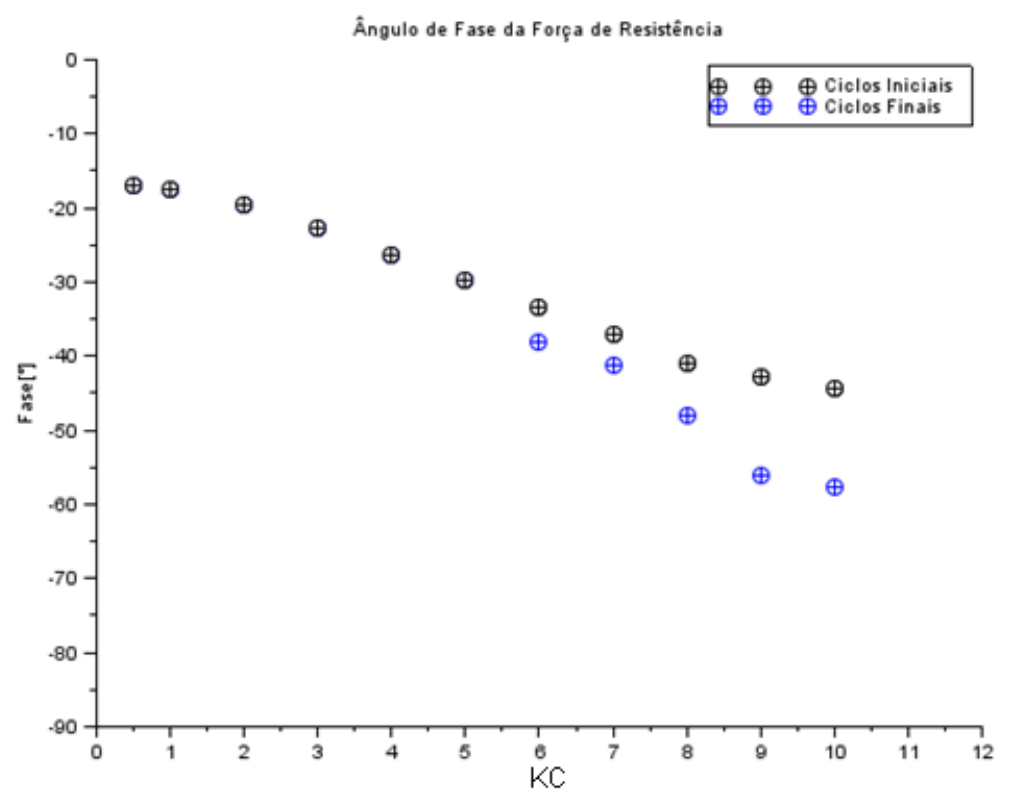

Figura 29- Fase entre força de resistência e posição do cilindro 


\subsection{Regime $\mathrm{A}^{*}: 0,5 \leq K C \leq 2$}

O escoamento para $0,5 \leq K C \leq 2$ se enquadra no regime $\mathrm{A}^{*}$ no mapa de Tatsuno e Bearman. O escoamento manteve-se estável e simétrico. A amplitude de oscilação do cilindro é de $0,08 D, 0,16 D$ e $0,32 D$ para $K C$ igual a $0,5,1$ e 2 , respectivamente.

A equação de Morison representa bem a força resultante, apesar de subestimar a amplitude máxima da força de resistência. A maior parcela da força de resistência é a força de inércia do fluido, devida à alta frequência de oscilação e aceleração do cilindro. Os picos de máximo e mínimo da força de resistência ocorrem entre as posições de velocidade máxima e nula do cilindro.

Nos extremos do deslocamento (posições $90^{\circ}$ e $270^{\circ}$ ), a velocidade do cilindro é nula. Entretanto existe um escoamento residual, cuja energia cinética não é identicamente nula. A amplitude de variação da energia cinética permanece constante. A frequência de oscilação da energia cinética é o dobro daquela do movimento, como esperado, já que a energia cinética é quadrática na velocidade. O campo de pressão nas posições $90^{\circ}$ e $270^{\circ}$ é substancialmente diferente daquele nas posições $0^{\circ}$ e $180^{\circ}$.

Não se observou zona de recirculação atrás do cilindro na posição de máxima velocidade $\left(0^{\circ}\right.$ e $\left.180^{\circ}\right)$. Vorticidade é gerada na camada limite entre as posições de mínima e máxima velocidade, e difunde-se para o interior do domínio. Ao desacelerar, vorticidade de sinal oposta é gerada na superfície do cilindro e formam-se duas camadas de vorticidade de sinal opostas. Ao reverter o movimento, a vorticidade é anulada pela vorticidade de sinal oposta e ela não sobrevive até o próximo ciclo. 

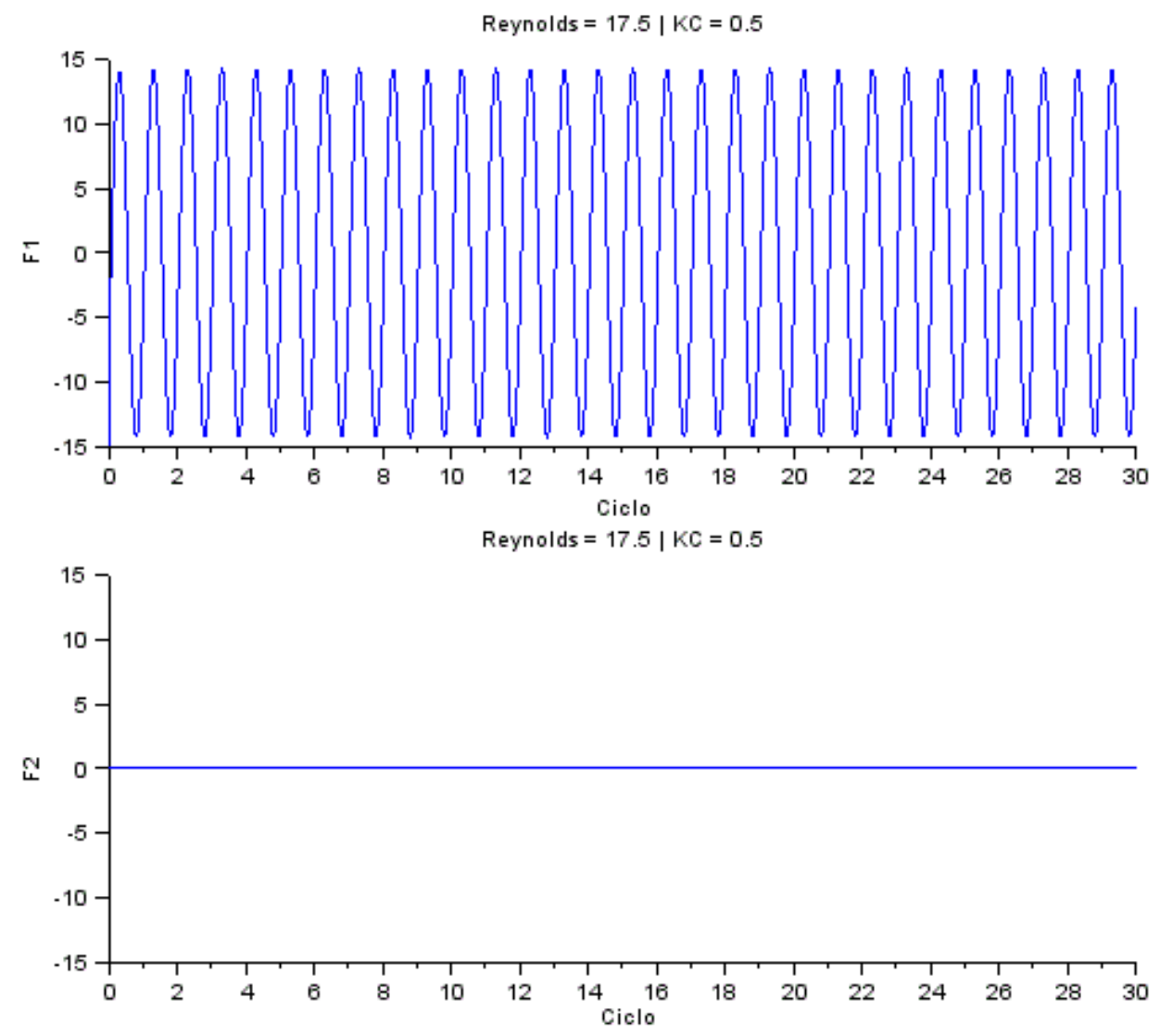

Figura 30- Forças de resistência e normal $(\operatorname{Re}=17,5$ e $\mathrm{KC}=0,59)$

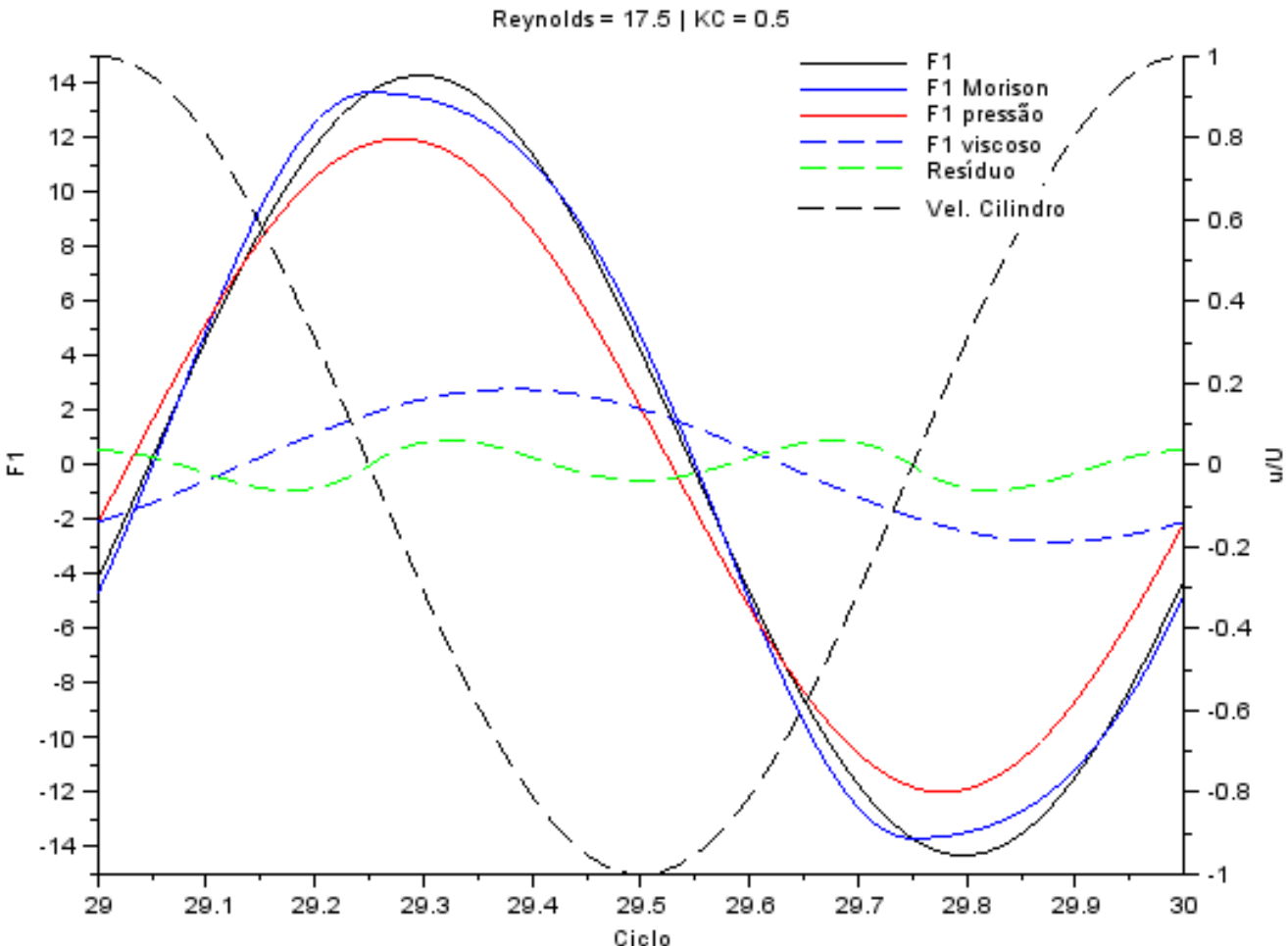

Figura 31 - Força numérica e de Morison $(\operatorname{Re}=17,5$ e $\mathrm{KC}=0,5)$ 


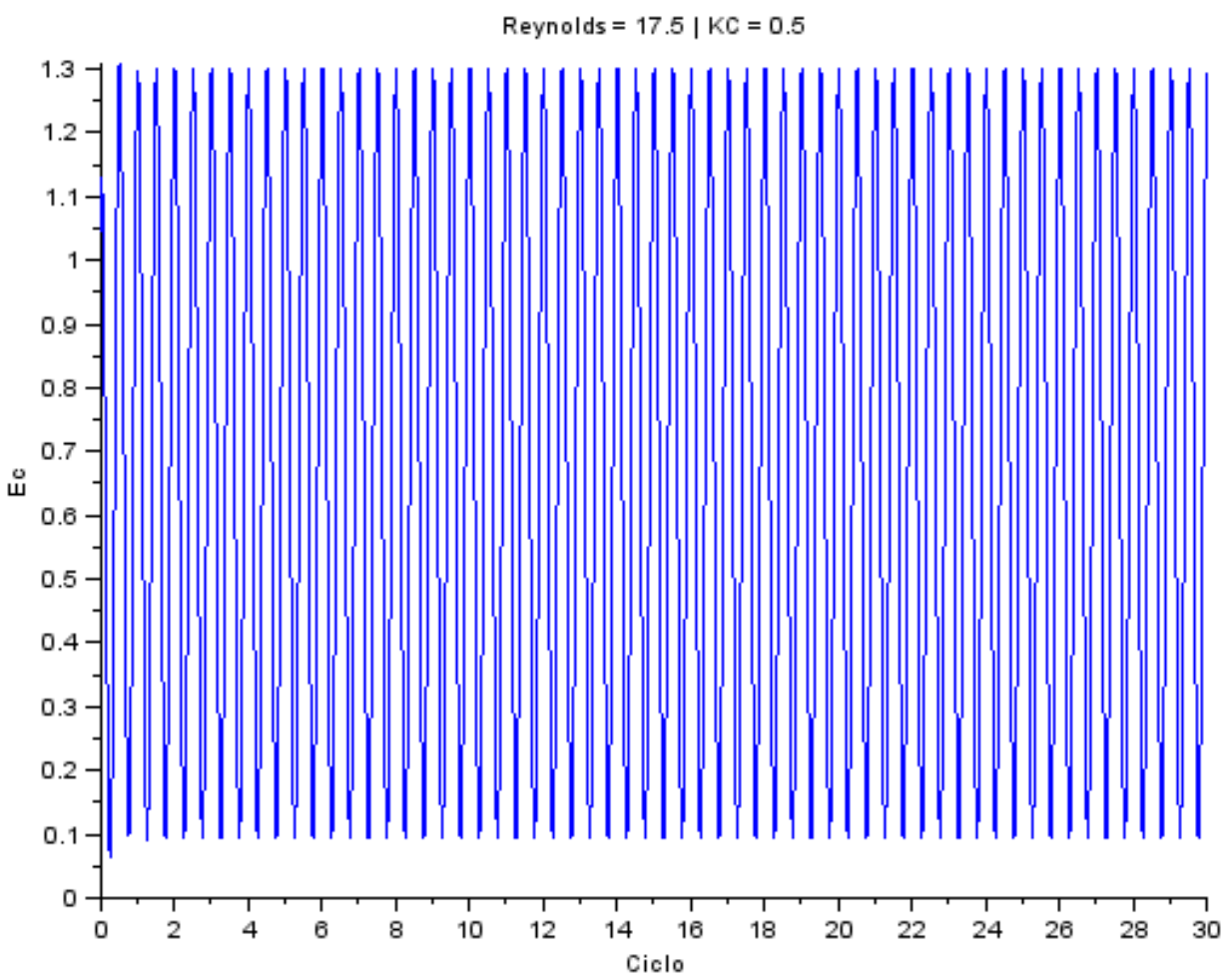

Figura 32 - Energia cinética do escoamento $(\operatorname{Re}=17,5$ e $\mathrm{KC}=0,5)$ 

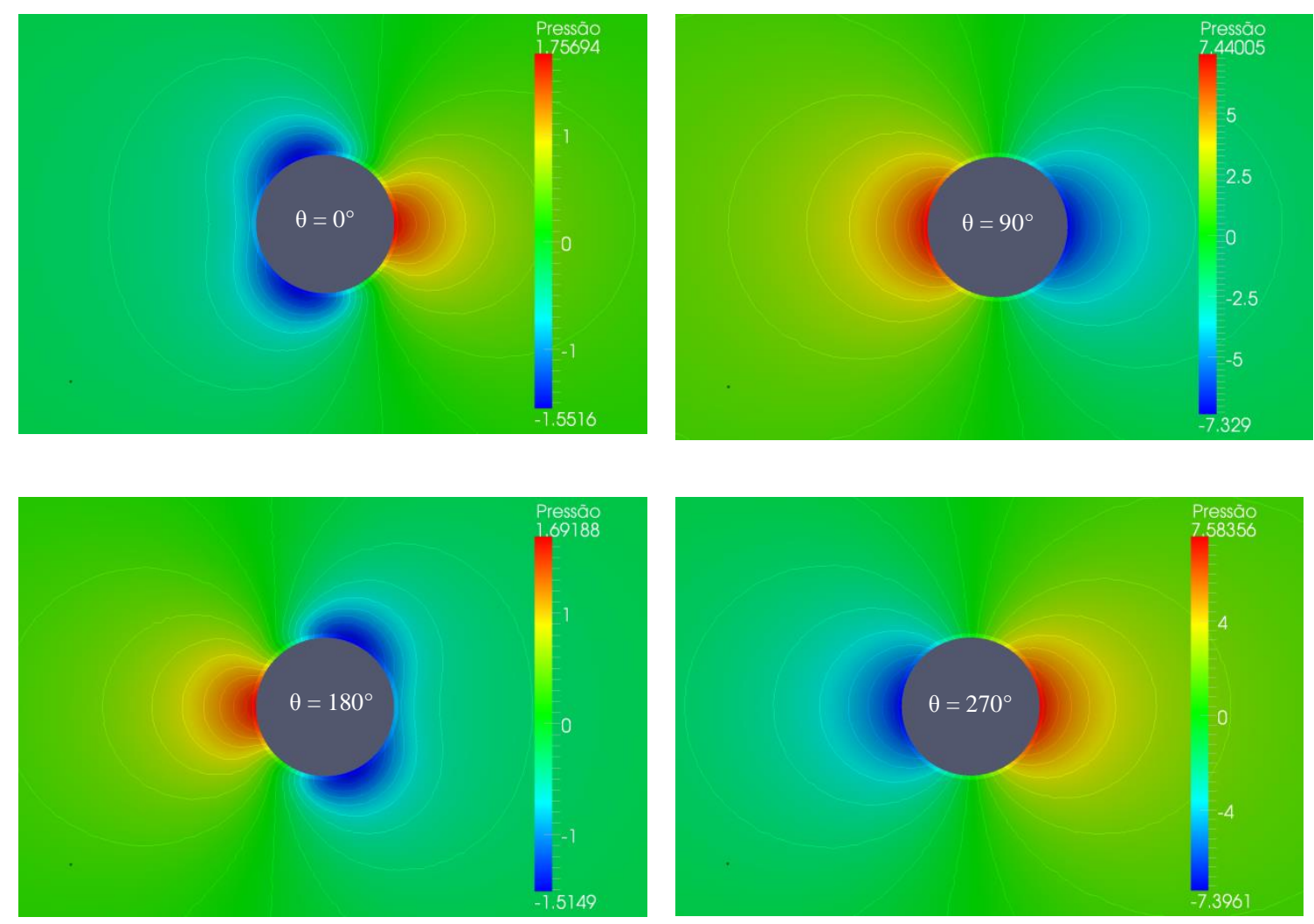

Figura 33 - Campo de pressão $(\operatorname{Re}=17,5$ e $\mathrm{KC}=0,5)$
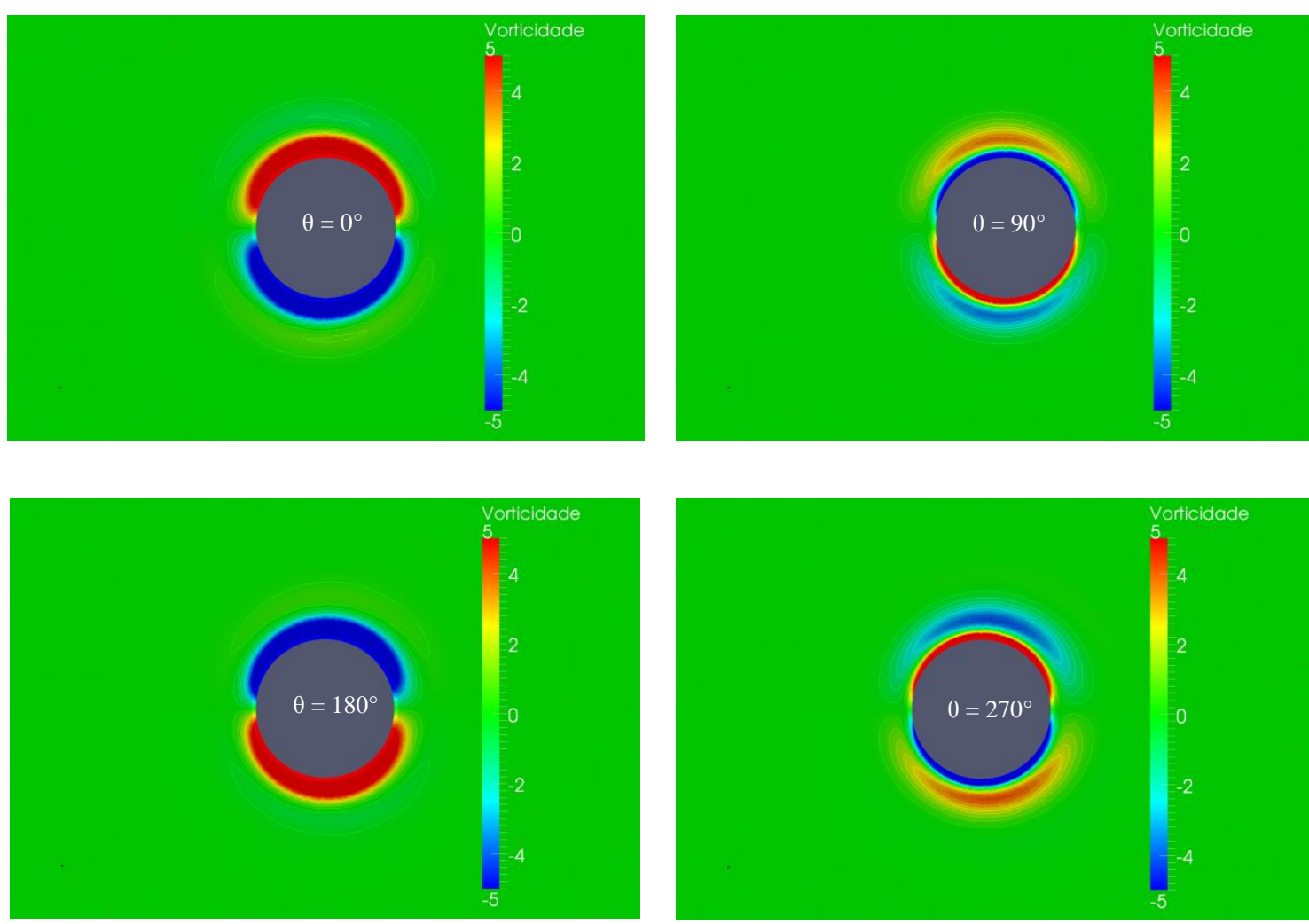

Figura 34 - Campo de vorticidade $(\operatorname{Re}=17,5$ e $\mathrm{KC}=0,5)$ 

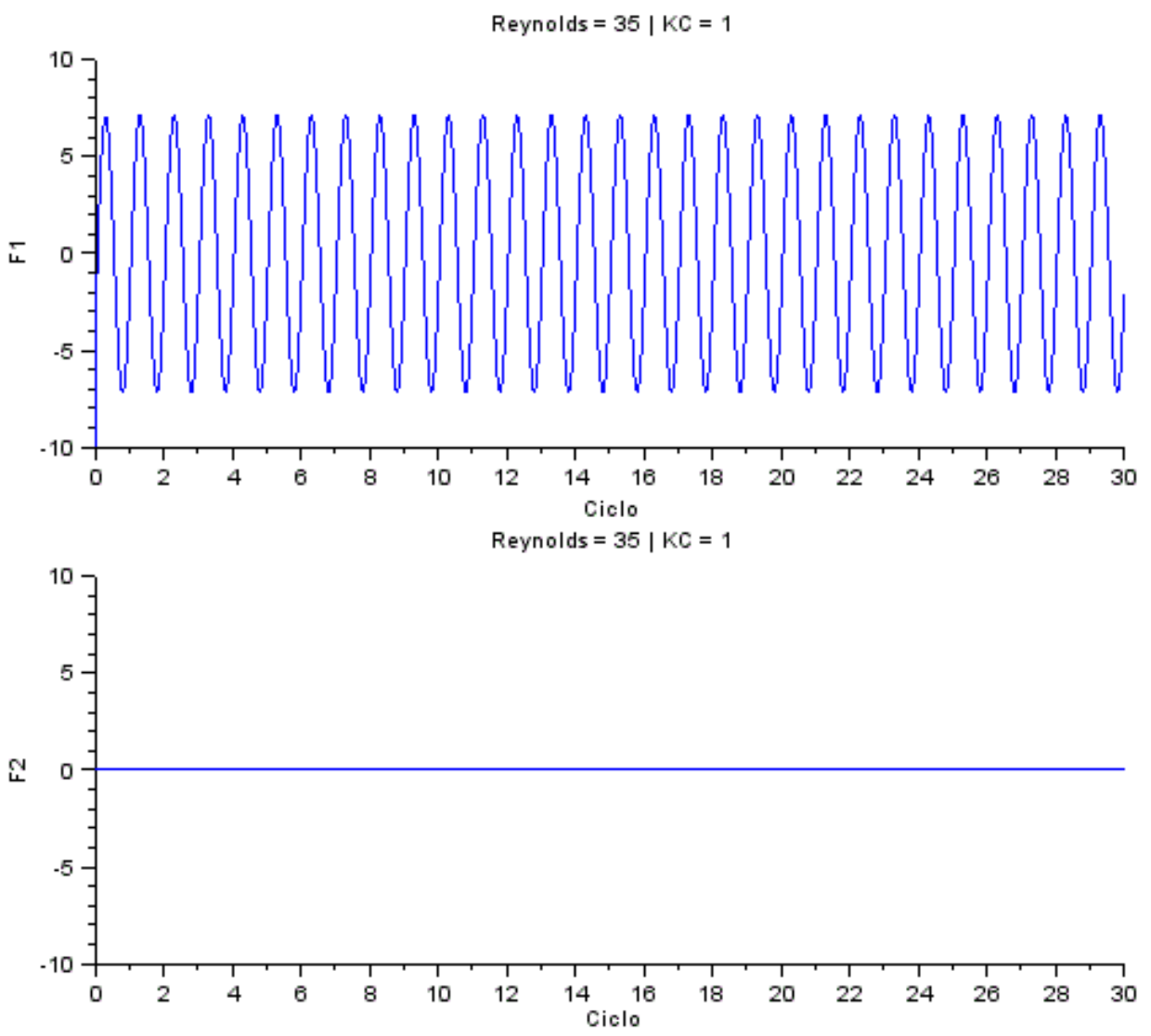

Figura 35 - Forças de resistência e normal $(\operatorname{Re}=35$ e $K C=1)$ 


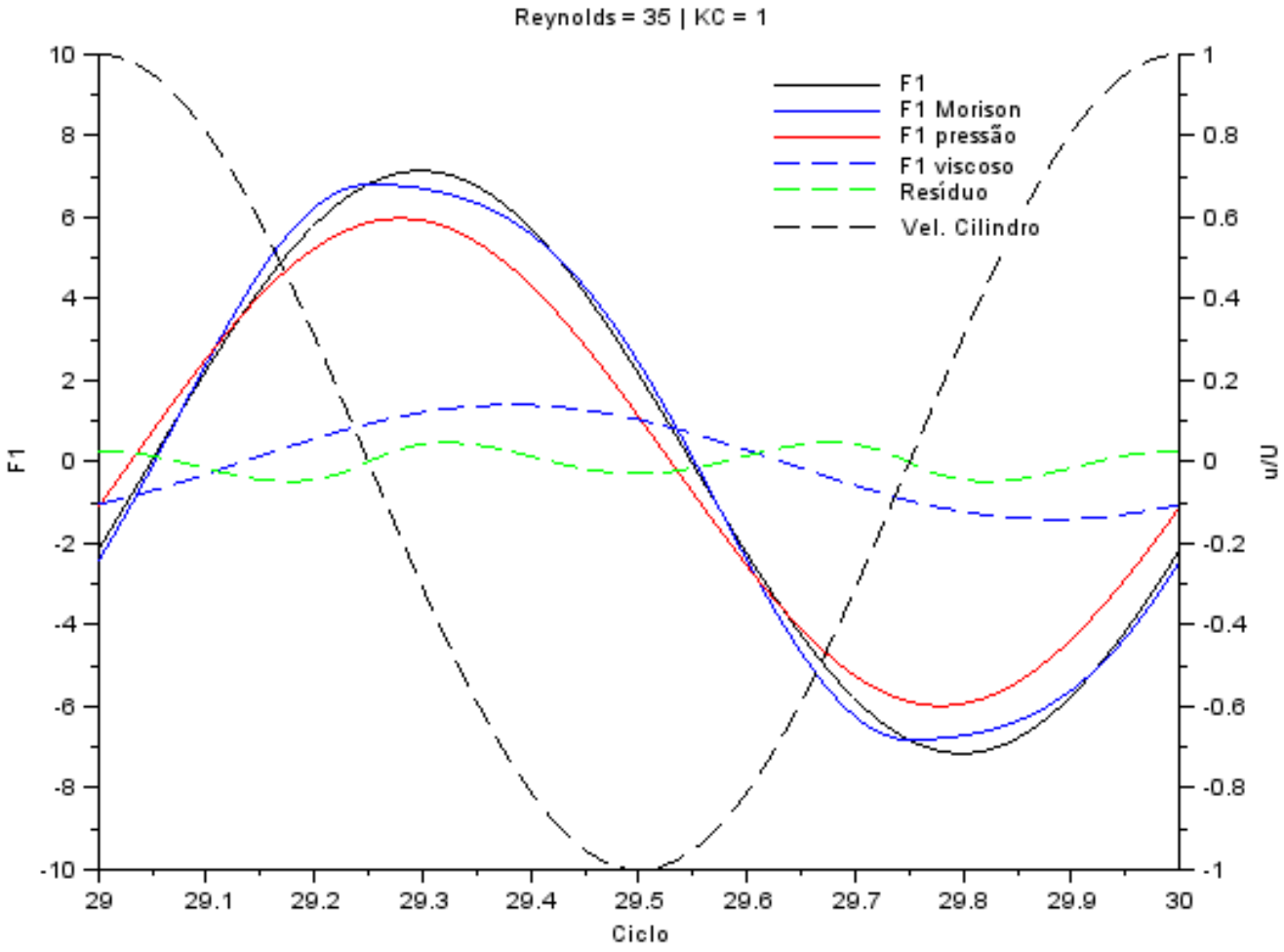

Figura 36 - Força numérica e de Morison $(\operatorname{Re}=35$ e $K C=1)$

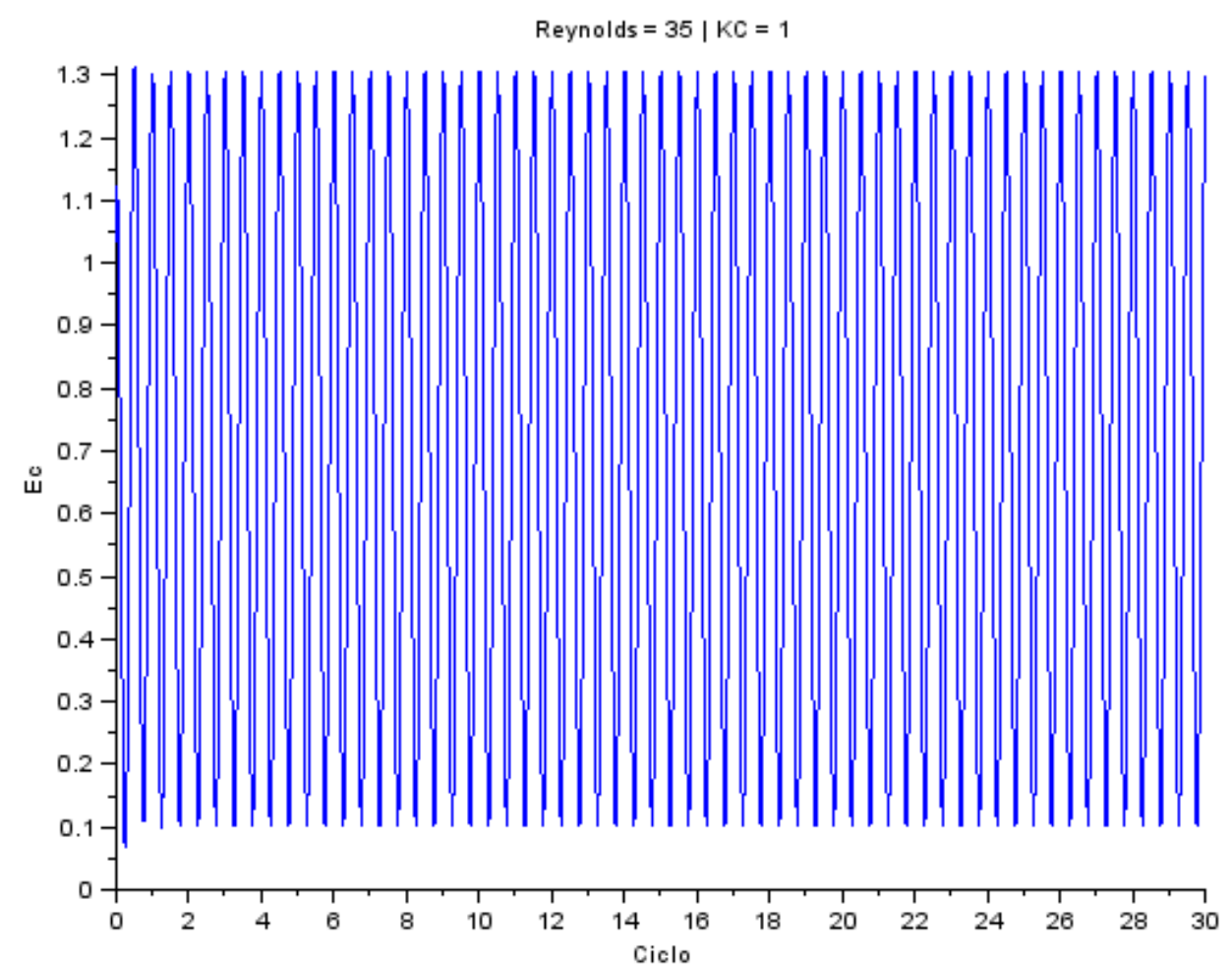

Figura 37 - Energia cinética do escoamento $(\operatorname{Re}=35$ e KC $=1)$ 

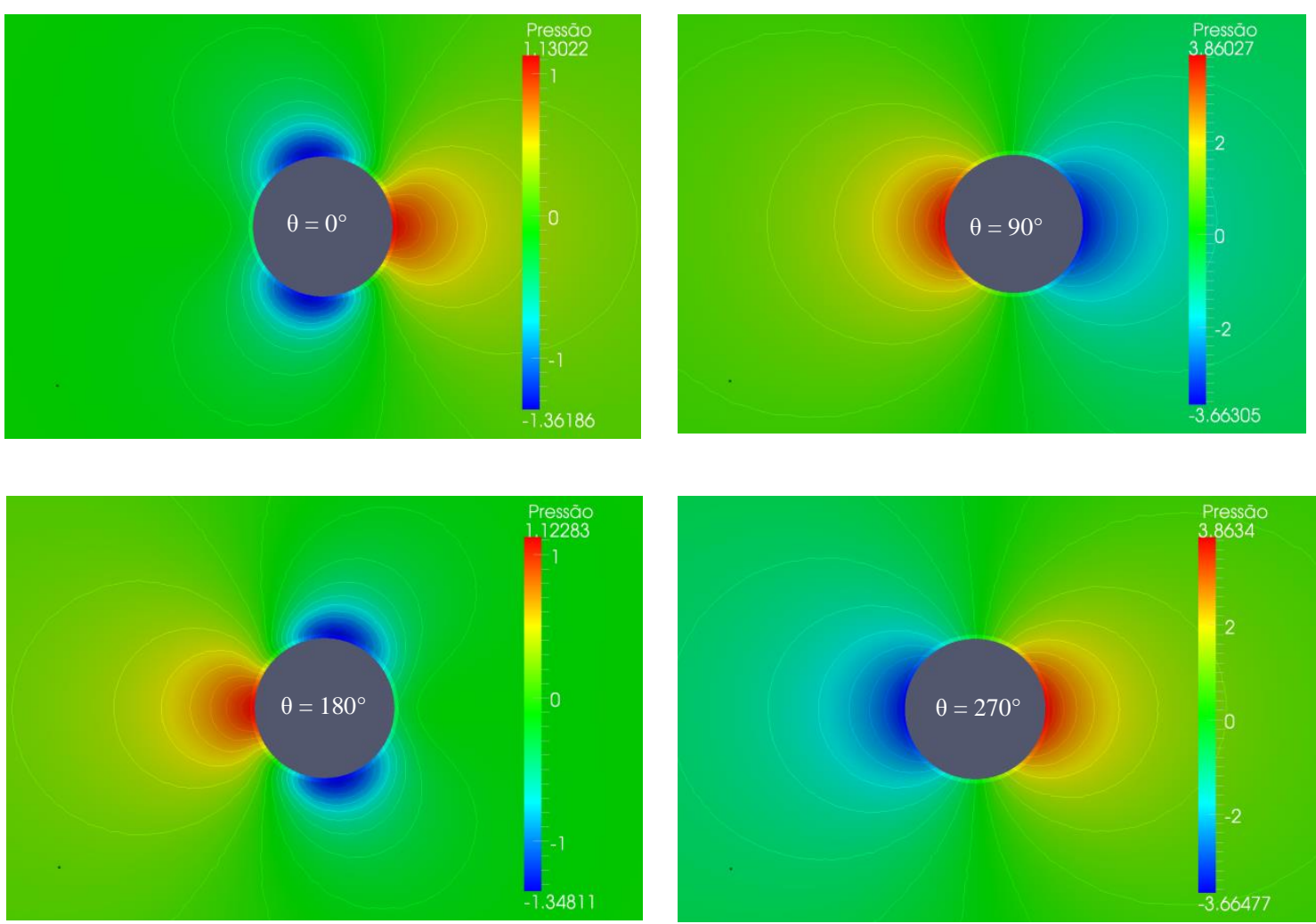

Figura 38 - Campo de pressão $(\operatorname{Re}=35$ e $K C=1)$
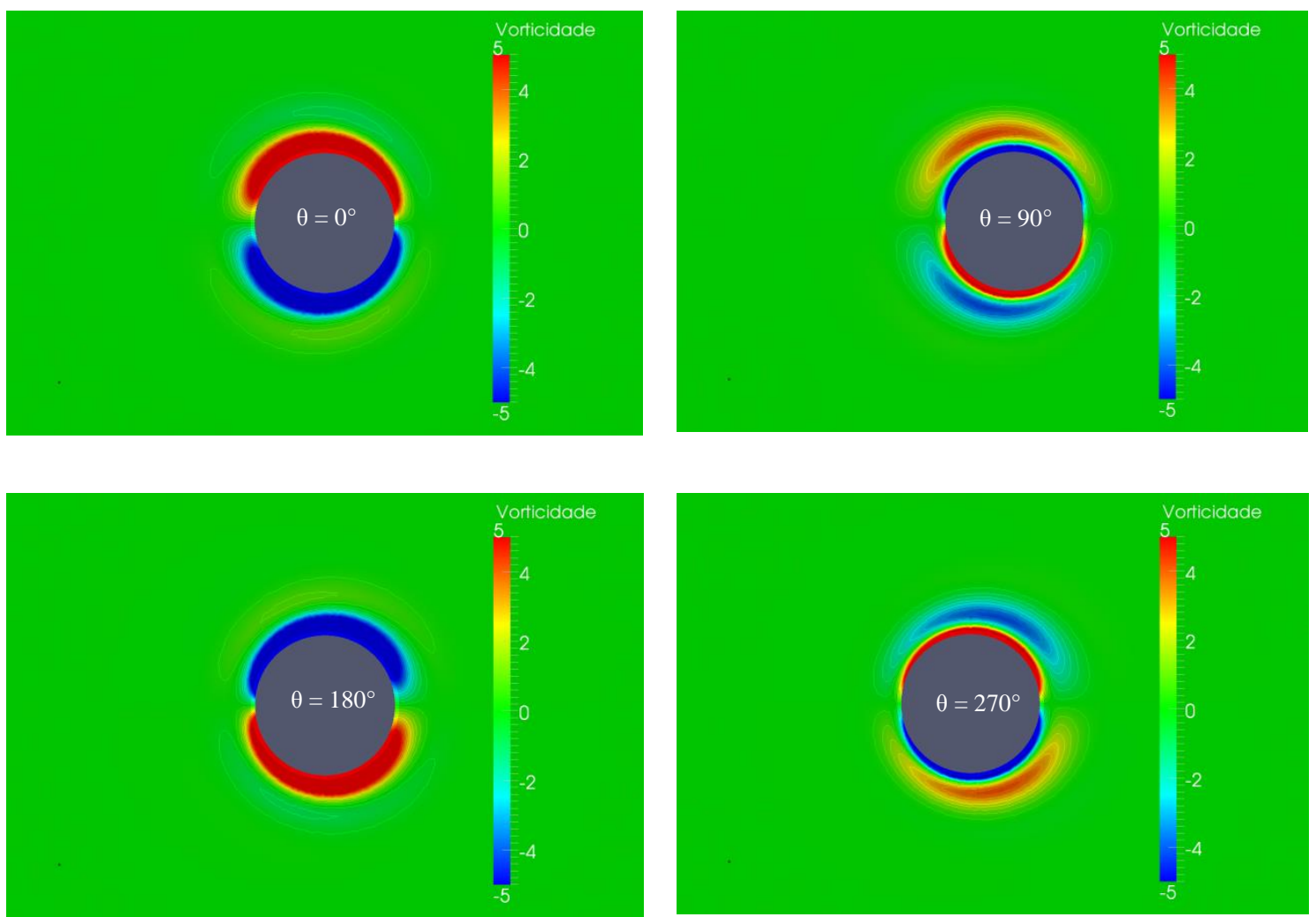

Figura 39 - Campo de vorticidade $(\operatorname{Re}=35$ e $K C=1)$ 

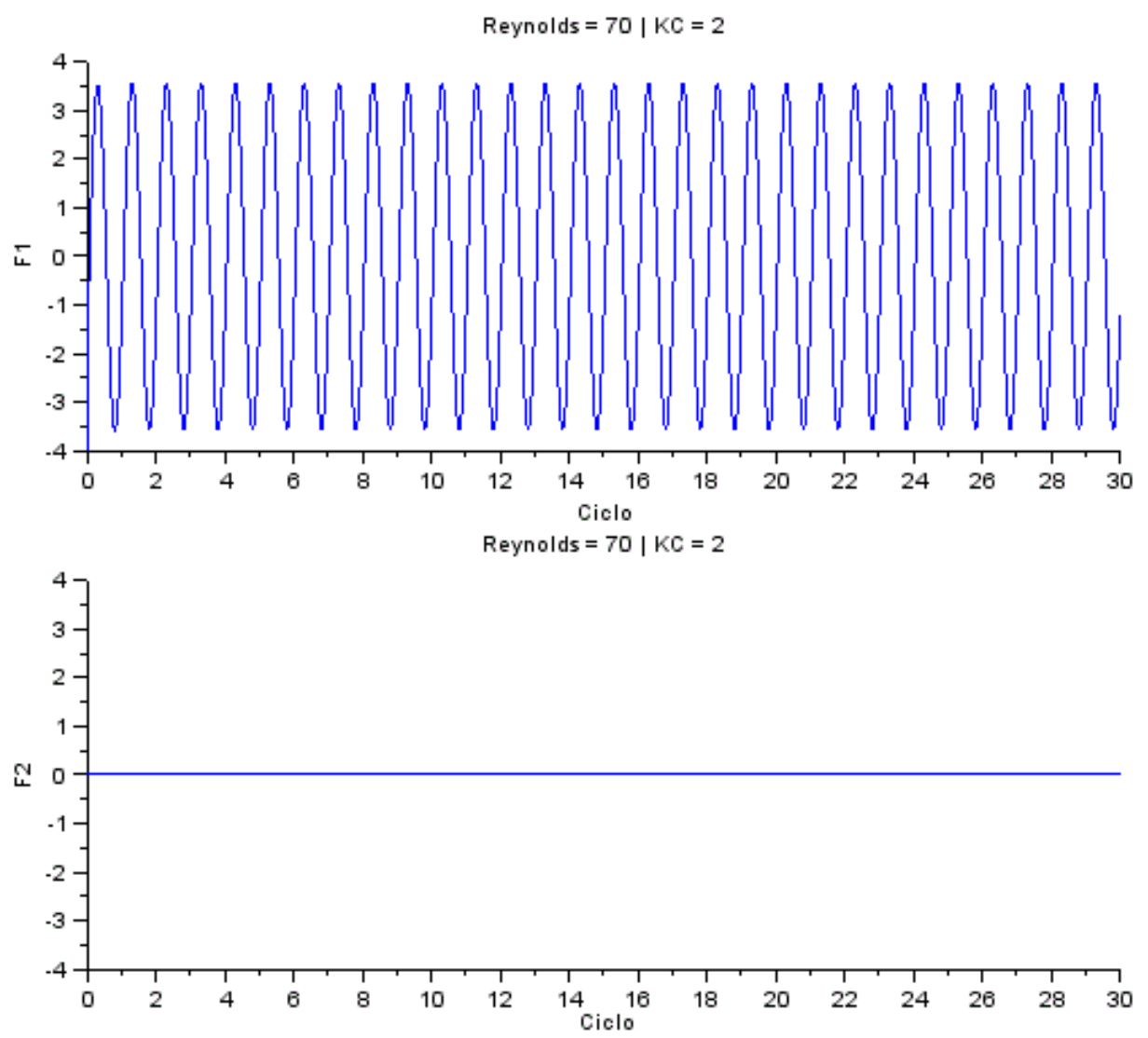

Figura 40 - Forças de resistência e normal $(\operatorname{Re}=70$ e $K C=2)$

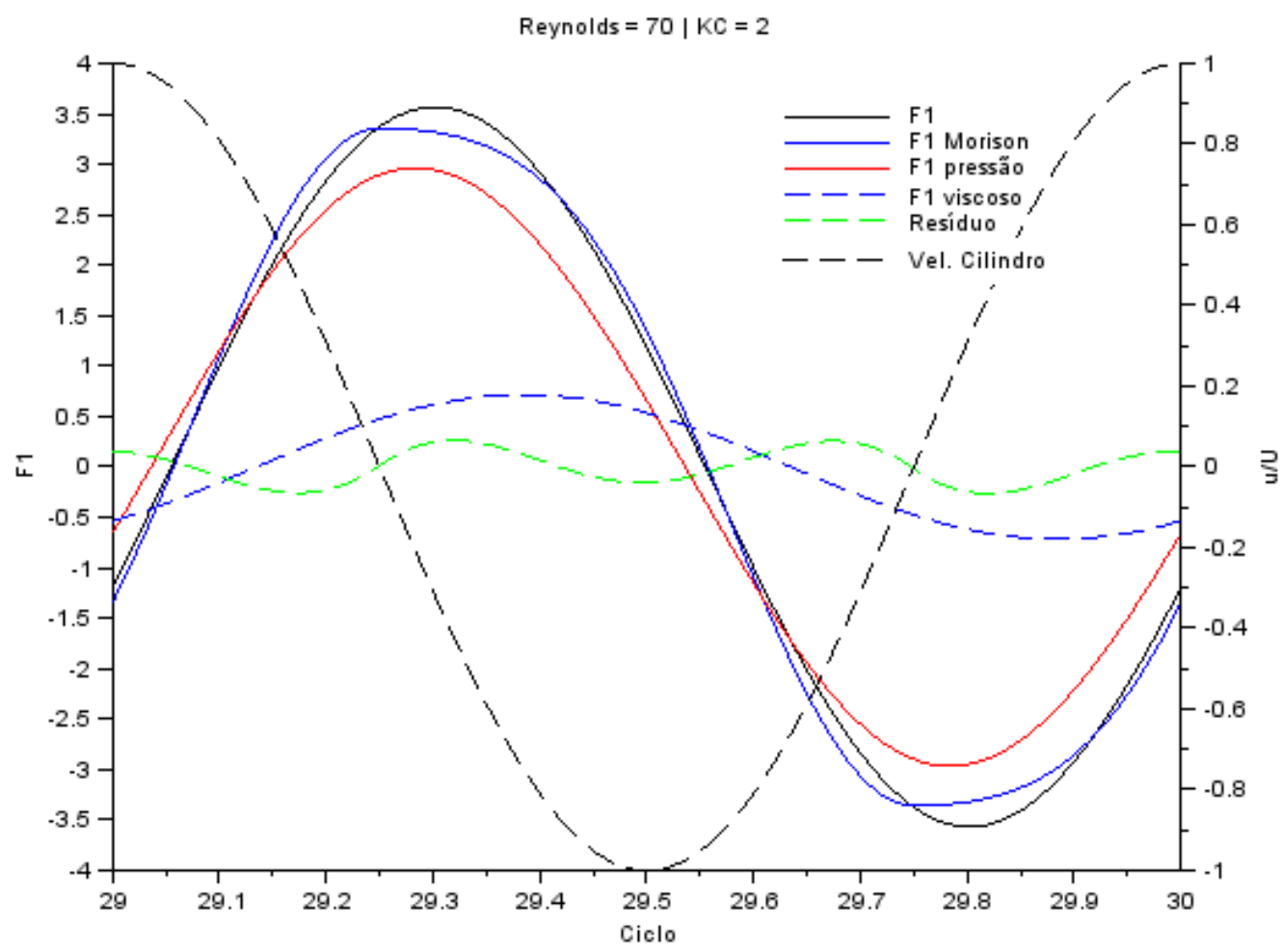

Figura 41 - Força numérica e de Morison $(\operatorname{Re}=70$ e $\mathrm{KC}=2)$ 


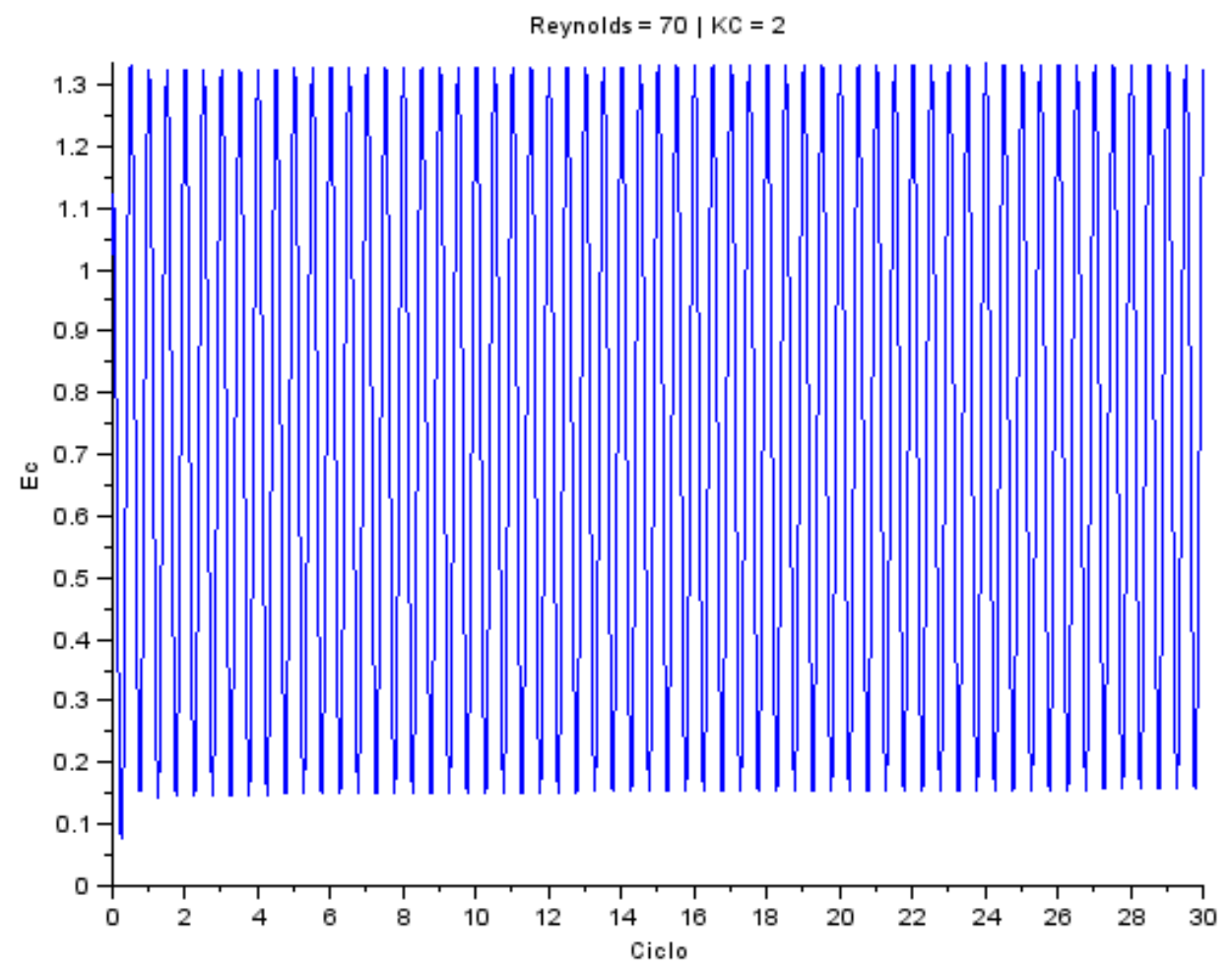

Figura 42 - Energia cinética do escoamento $(\operatorname{Re}=70$ e $\mathrm{KC}=2)$ 

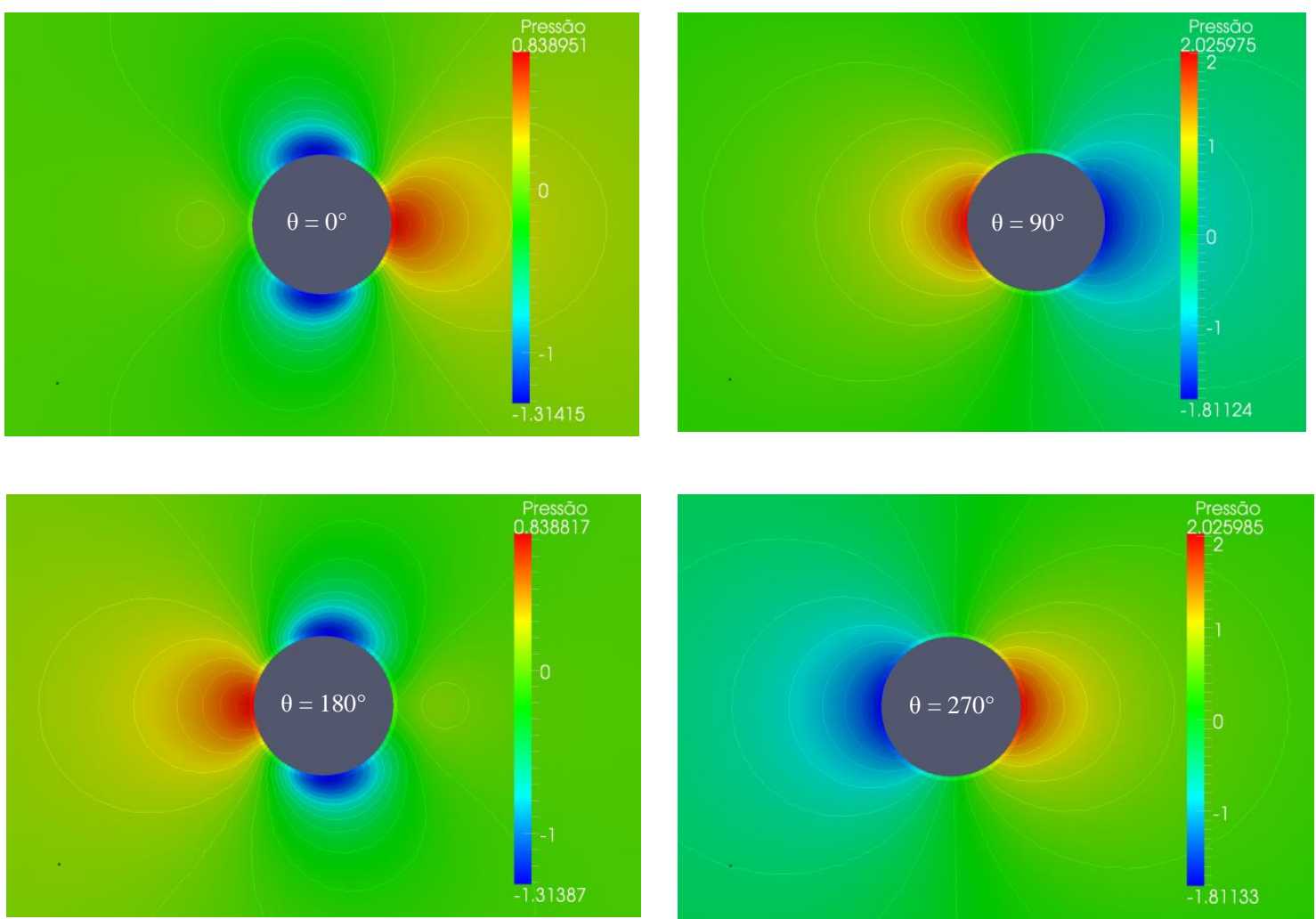

Figura 43 - Campo de pressão $(\operatorname{Re}=70$ e KC $=2)$
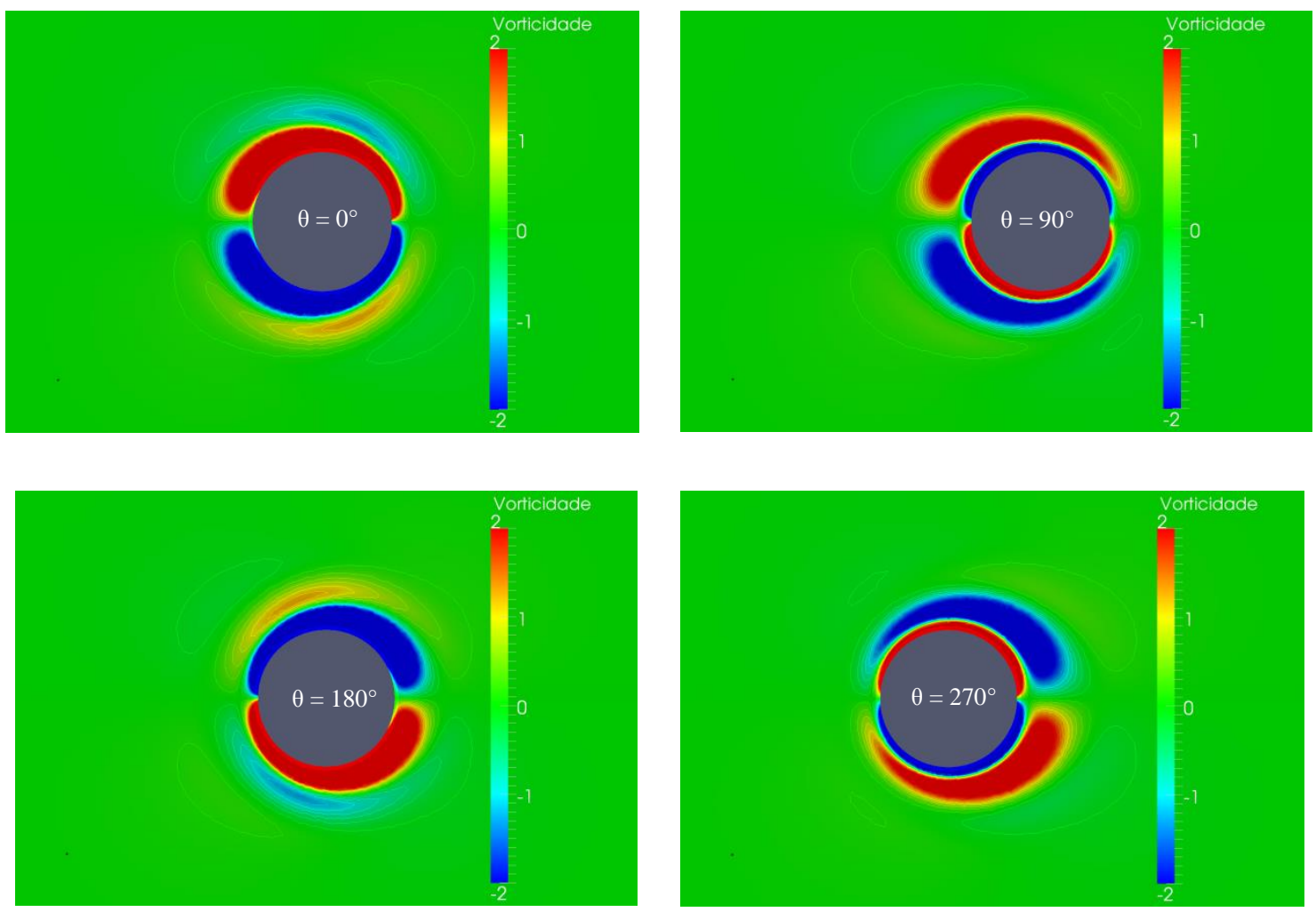

Figura 44 - Campo de vorticidade $(\operatorname{Re}=70$ e $K C=2)$ 


\subsection{Regime A: $3 \leq K C \leq 5$}

A amplitude de oscilação do cilindro é de $0,48 D, 0,64 D$ e $0,80 D$ para $K C$ igual a 3, 4 e 5, respectivamente. No mapa de Tatsuno e Bearman, o escoamento se enquadra no regime A para $K C$ igual a 3 e a 4 . O escoamento se enquadraria no regime $\mathrm{C}$ para $K C$ igual a 5. Entretanto, não ocorreu o desenvolvimento deste regime para o número de ciclos simulado, apesar de se observar o aparecimento de uma pequena força normal a partir do terceiro ciclo para $K C=5$. O escoamento manteve-se estável e simétrico, visualmente.

Na posição de máxima velocidade $\left(0^{\circ}\right.$ e $\left.180^{\circ}\right)$, formam-se duas pequenas zonas de recirculação a jusante do cilindro. Diferentemente dos casos anteriores, ao reverter o movimento, parte da vorticidade é anulada pela vorticidade de sinal oposta e parte difunde-se para o interior do domínio. Isso reflete-se na maior energia cinética do escoamento residual nas posições de velocidade nula do cilindro $\left(90^{\circ}\right.$ e $\left.270^{\circ}\right)$ que nos casos anteriores. Para $K C$ igual a 4 e a 5 , os vórtices formados contornam o cilindro e sobrevivem até o próximo meio-ciclo.

Nas posições $90^{\circ}$ e $270^{\circ}$, a pressão em ambos os lados do cilindro diferem significativamente.

A energia cinética do escoamento residual nas posições de velocidade nula do cilindro $\left(90^{\circ}\right.$ e $\left.270^{\circ}\right)$ é maior que nos casos anteriores e cresce a cada meio-ciclo, apesar da amplitude de variação da energia cinética permanecer constante. 
Reynolds $=105 \mid \mathrm{KC}=3$
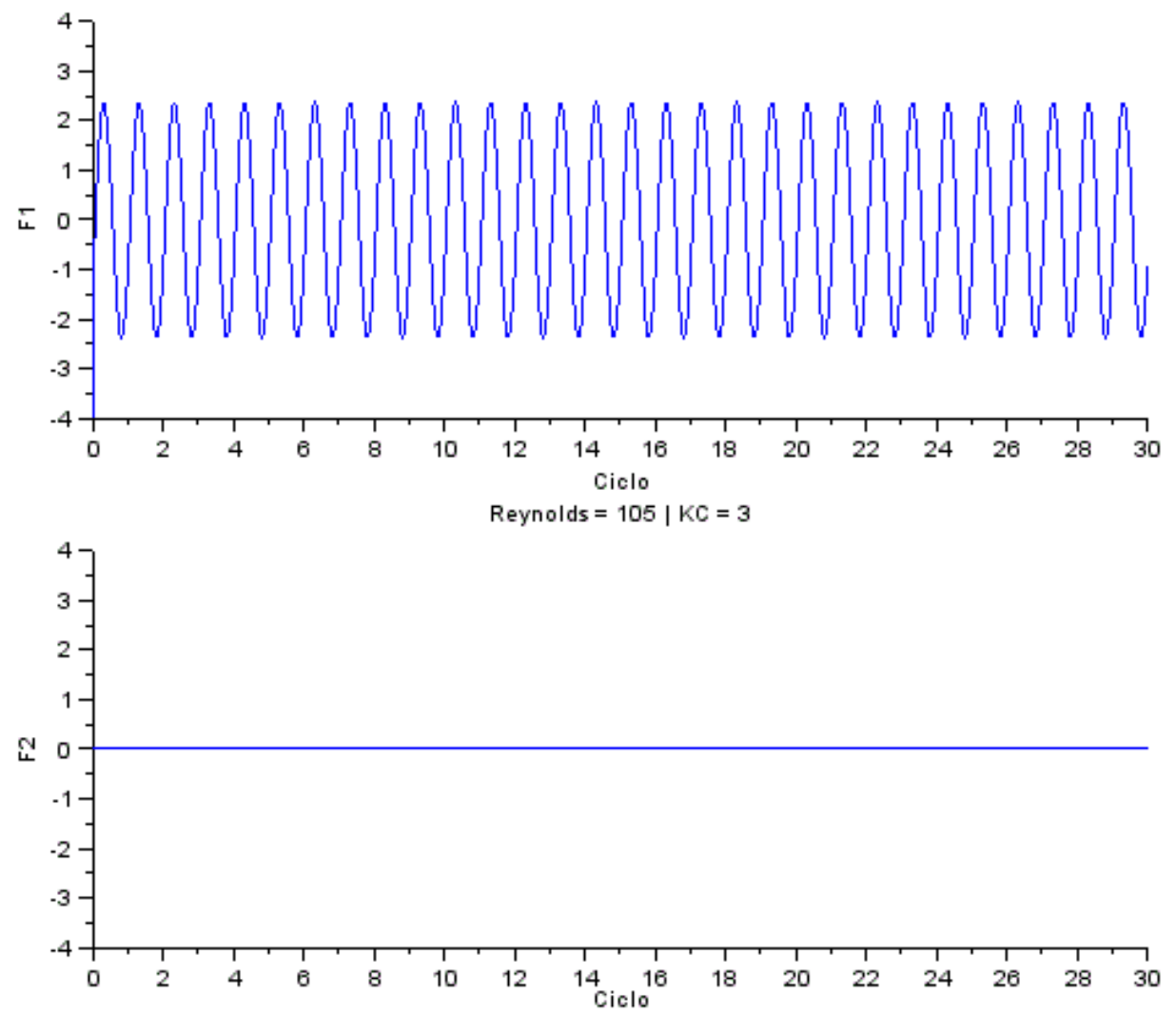

Figura 45 - Forças de resistência e normal $(\operatorname{Re}=105$ e $\mathrm{KC}=3)$

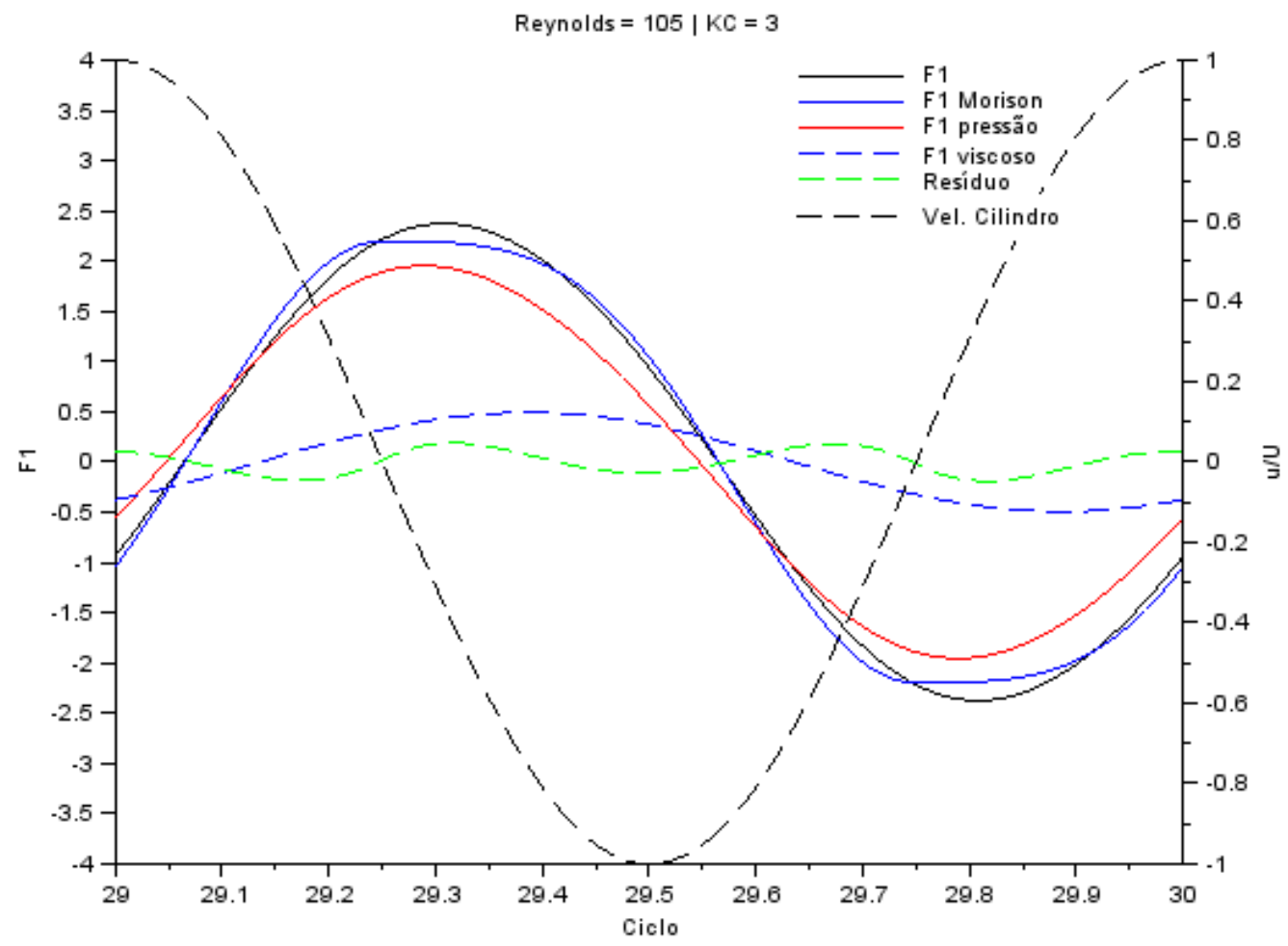

Figura 46 - Força numérica e de Morison $(\operatorname{Re}=105$ e $\mathrm{KC}=3)$ 


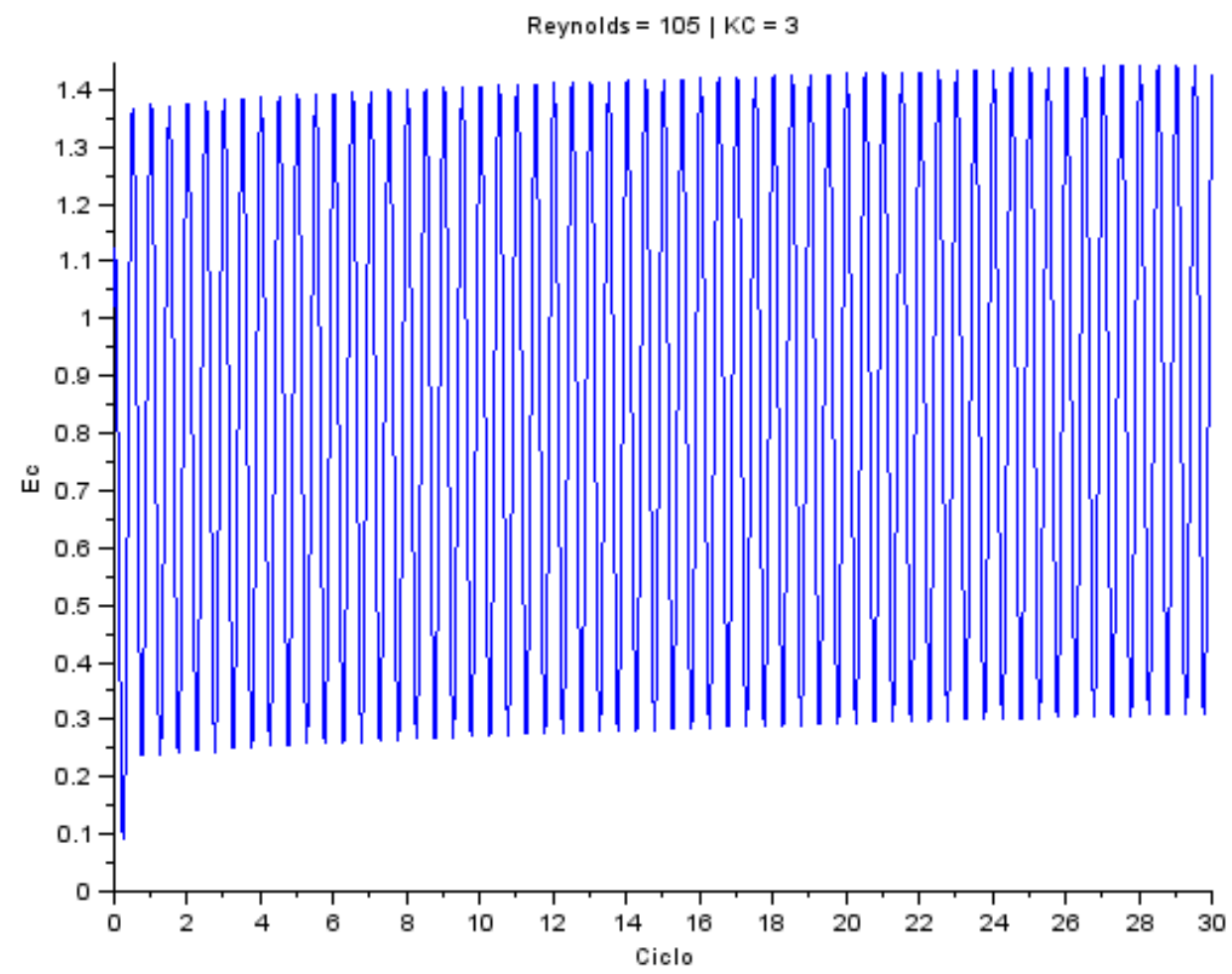

Figura 47 - Energia cinética do escoamento $(\operatorname{Re}=105$ e $\mathrm{KC}=3)$ 

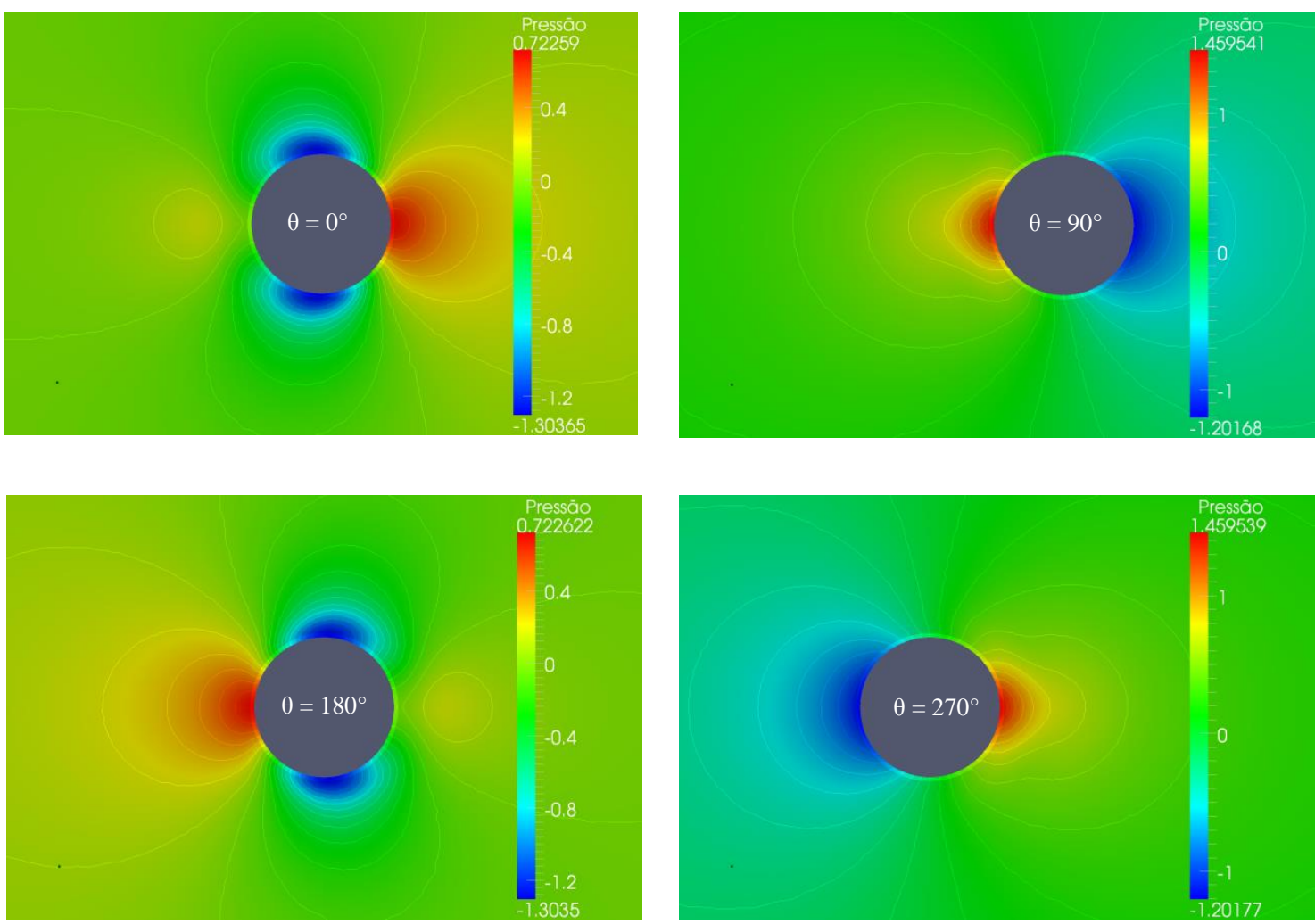

Figura 48 - Campo de pressão $(\operatorname{Re}=105$ e $K C=3)$
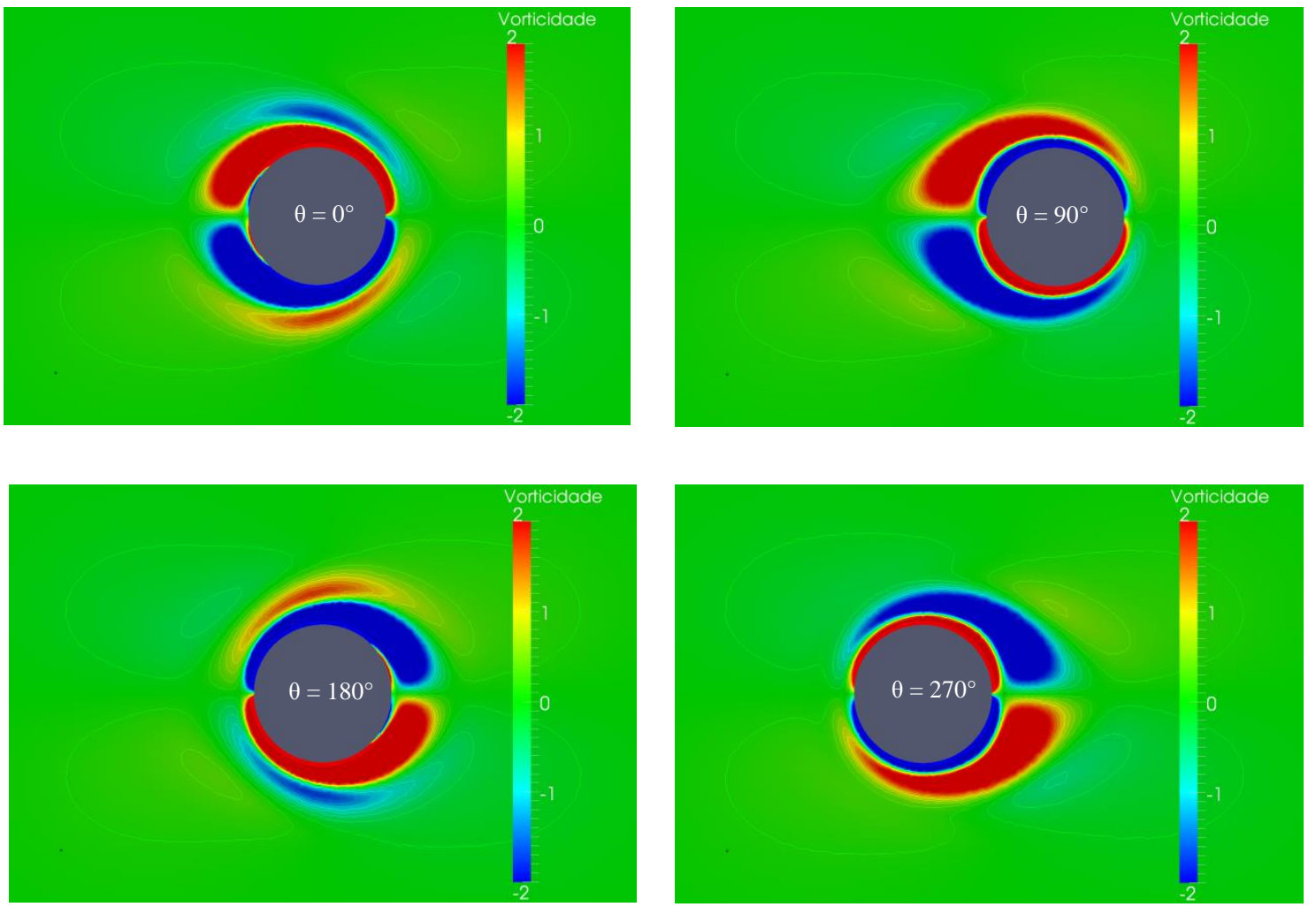

Figura 49 - Campo de vorticidade $(\operatorname{Re}=105$ e $\mathrm{KC}=3)$ 

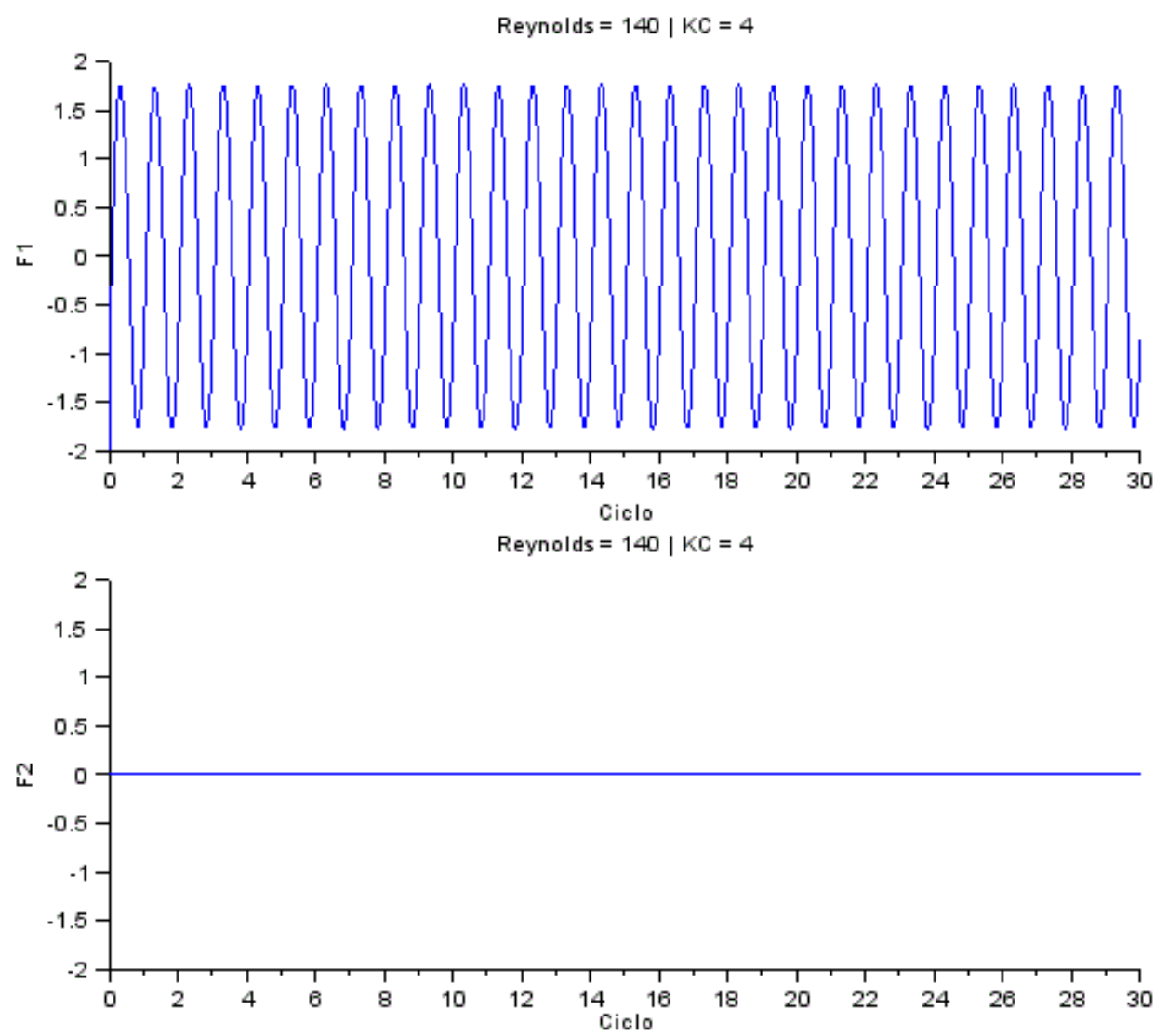

Figura 50- Forças de resistência e normal $(\operatorname{Re}=105$ e $K C=4)$

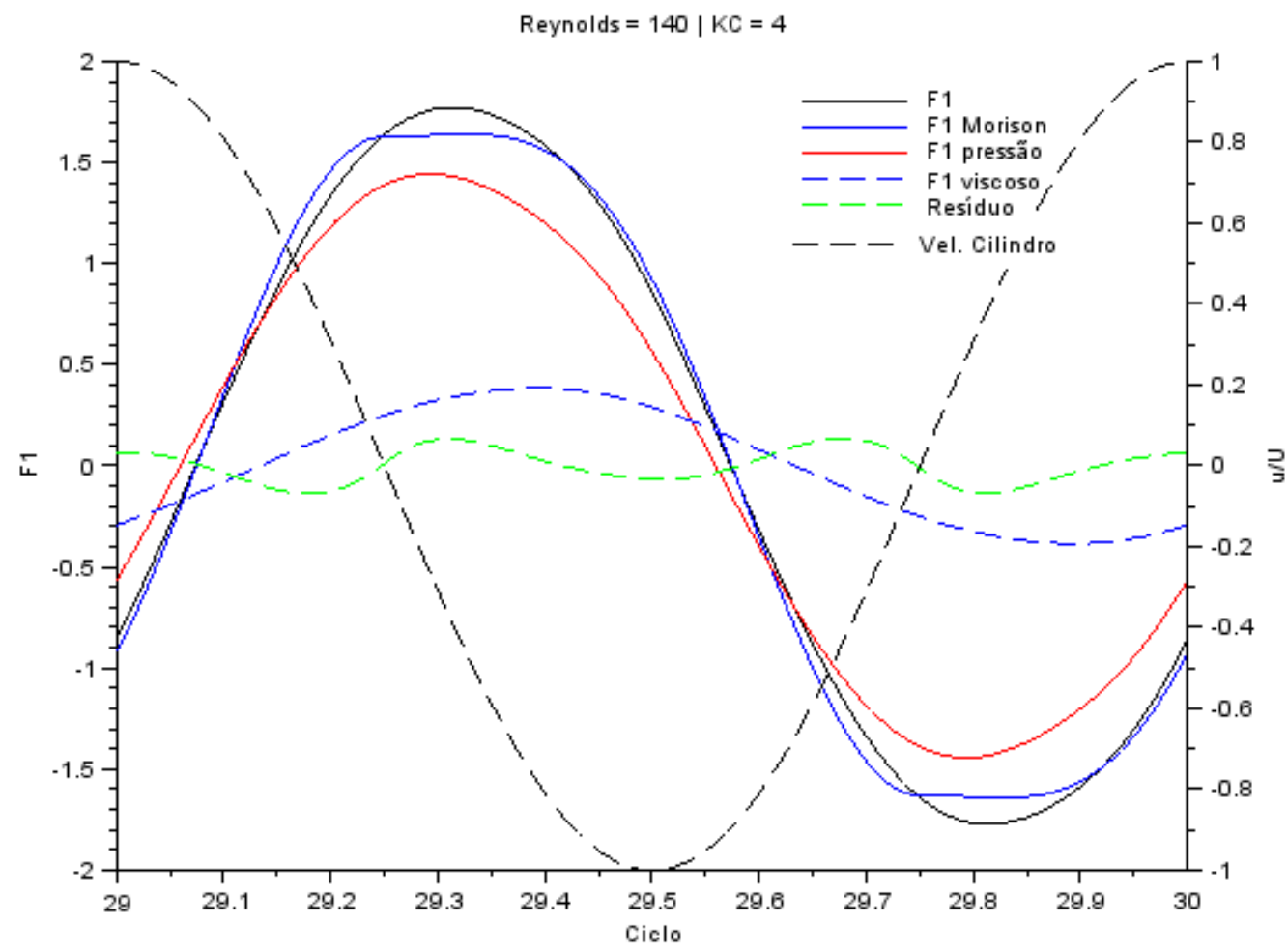

Figura 51 - Força numérica e de Morison $(\operatorname{Re}=105$ e $\mathrm{KC}=4)$ 


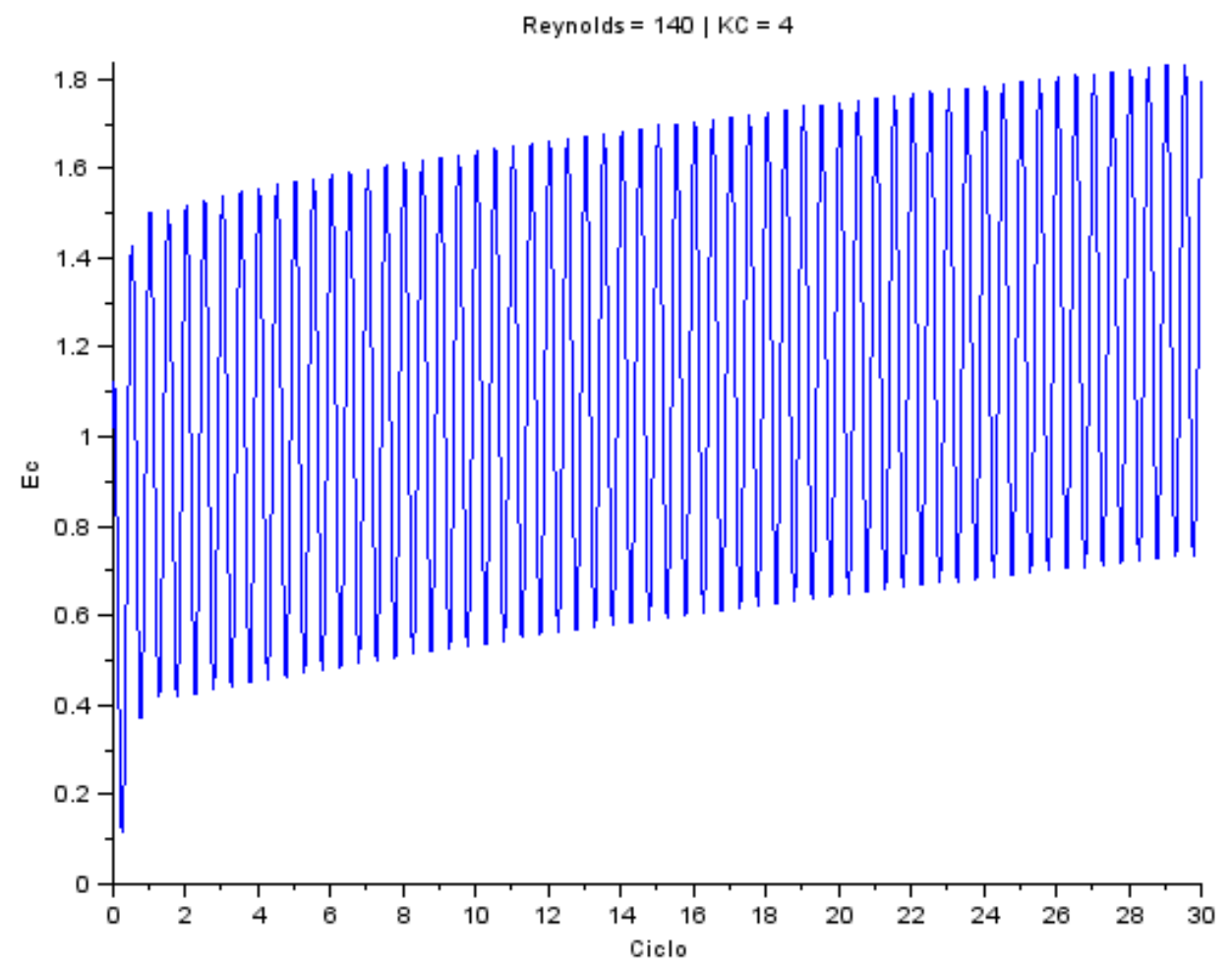

Figura 52 - Energia cinética do escoamento $(\operatorname{Re}=105$ e $\mathrm{KC}=4)$ 

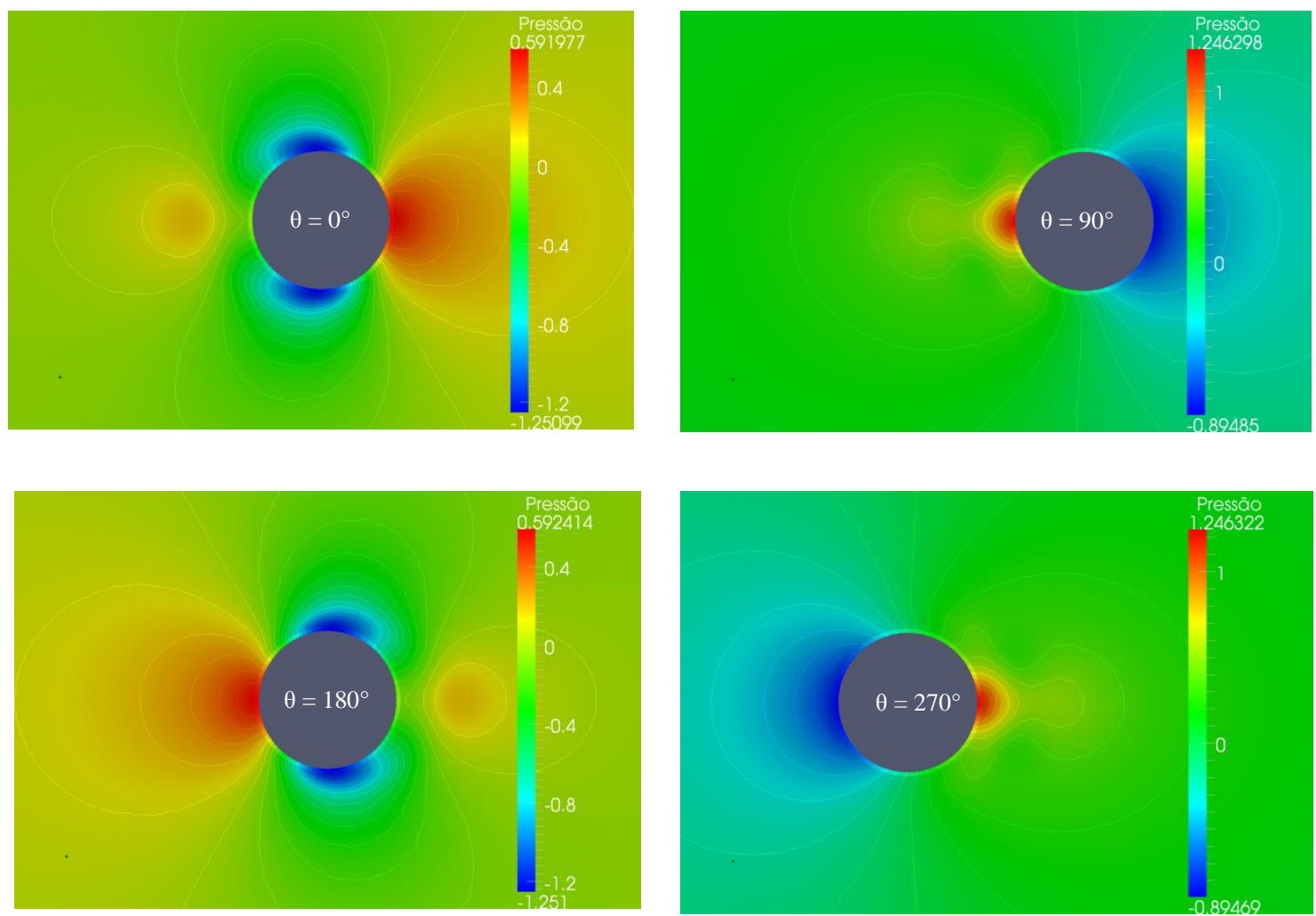

Figura 53 - Campo de pressão $(\operatorname{Re}=105$ e $\mathrm{KC}=4)$
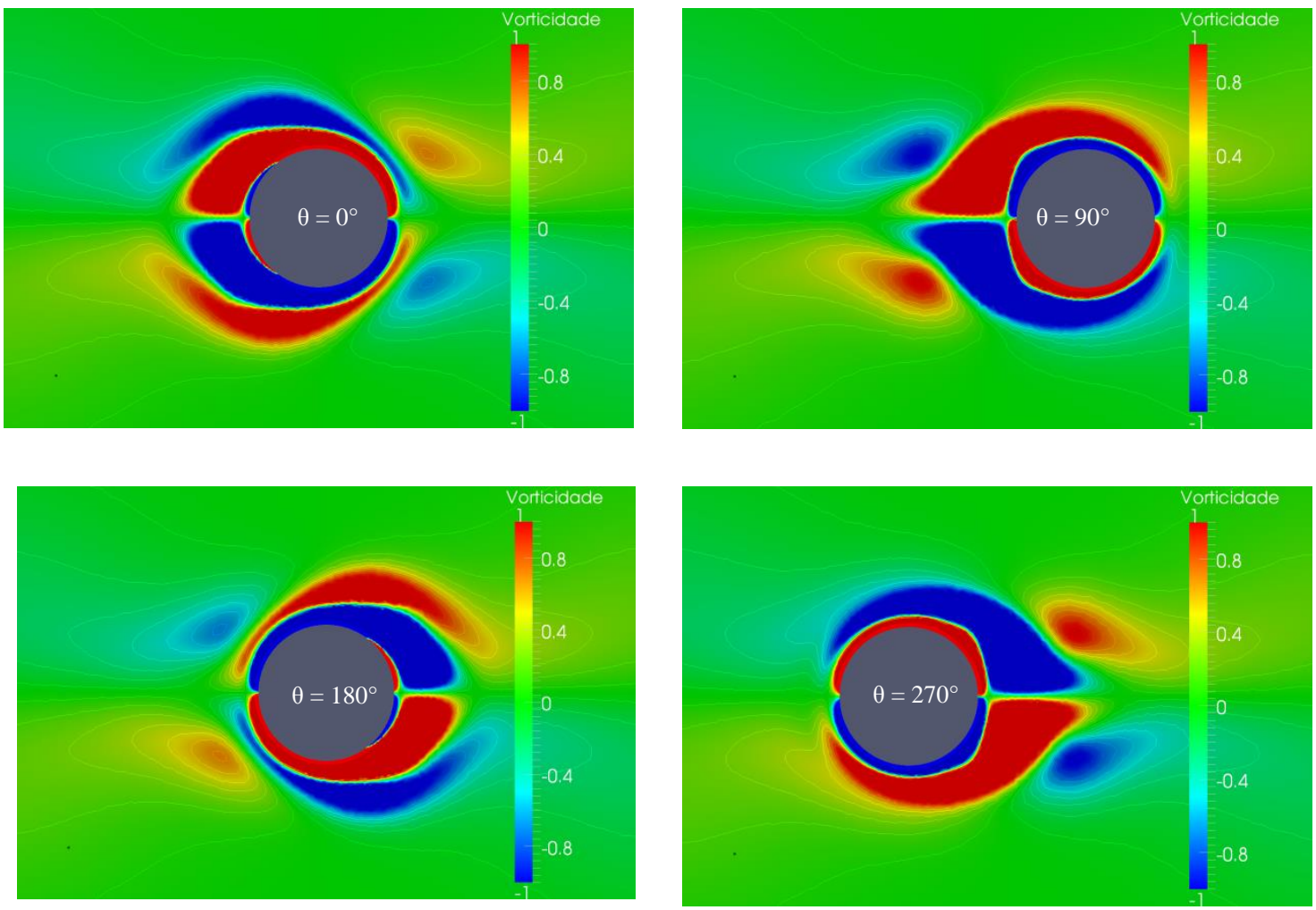

Figura 54 - Campo de vorticidade $(\operatorname{Re}=105$ e $\mathrm{KC}=4)$ 

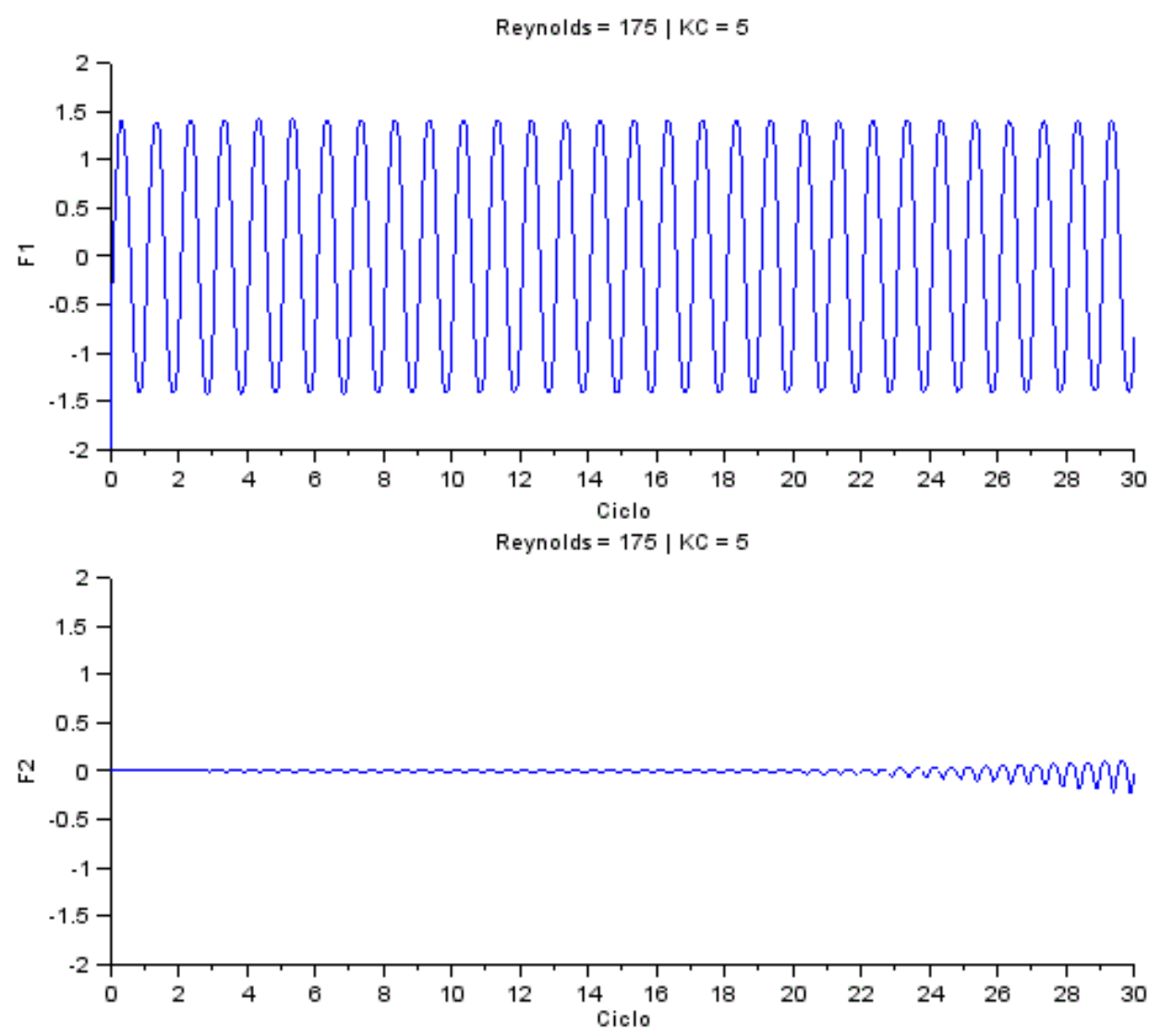

Figura 55- Forças de resistência e normal $(\operatorname{Re}=105$ e $K C=5)$

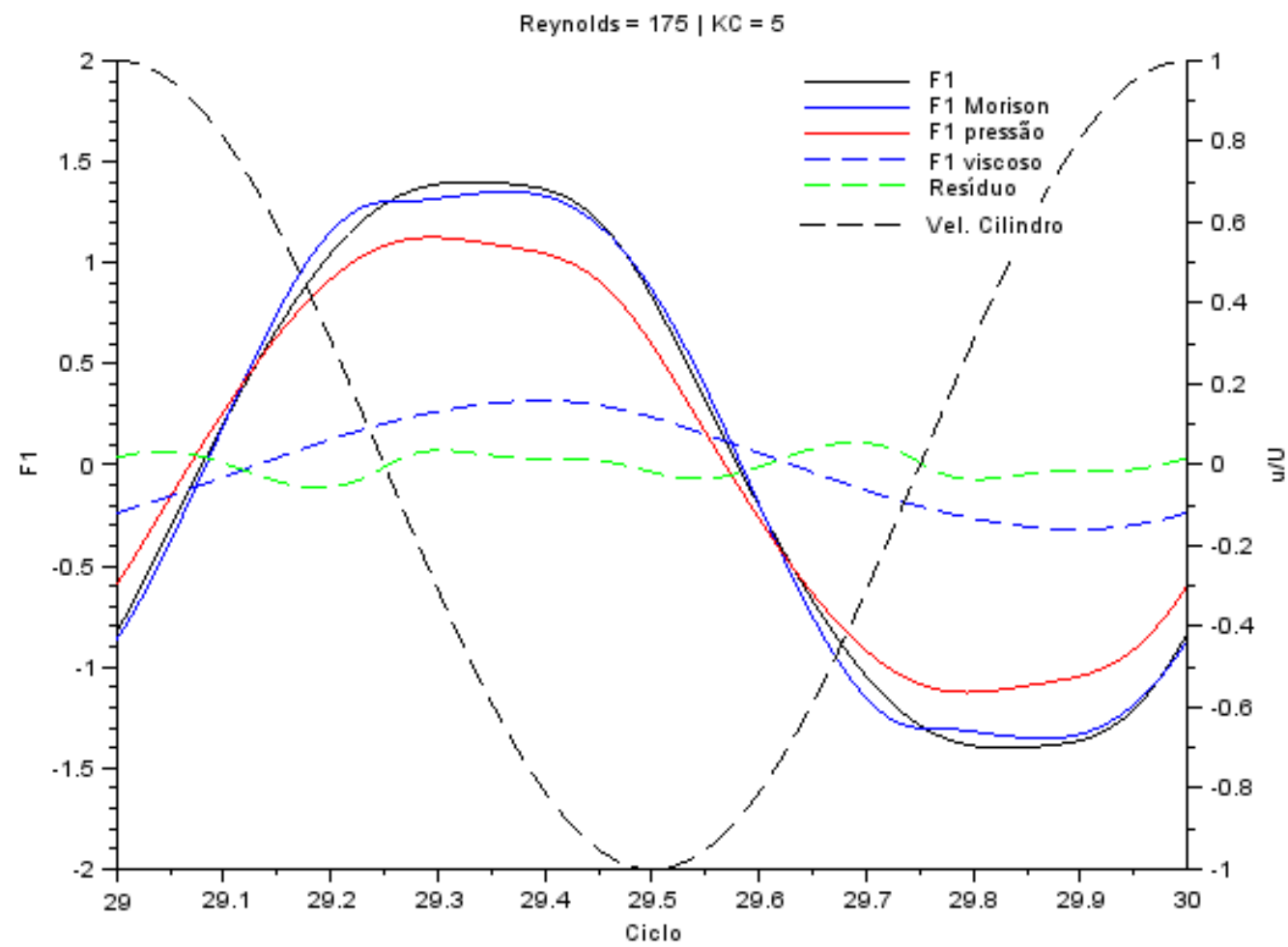

Figura 56 - Força numérica e de Morison $(\operatorname{Re}=105$ e $\mathrm{KC}=5)$ 


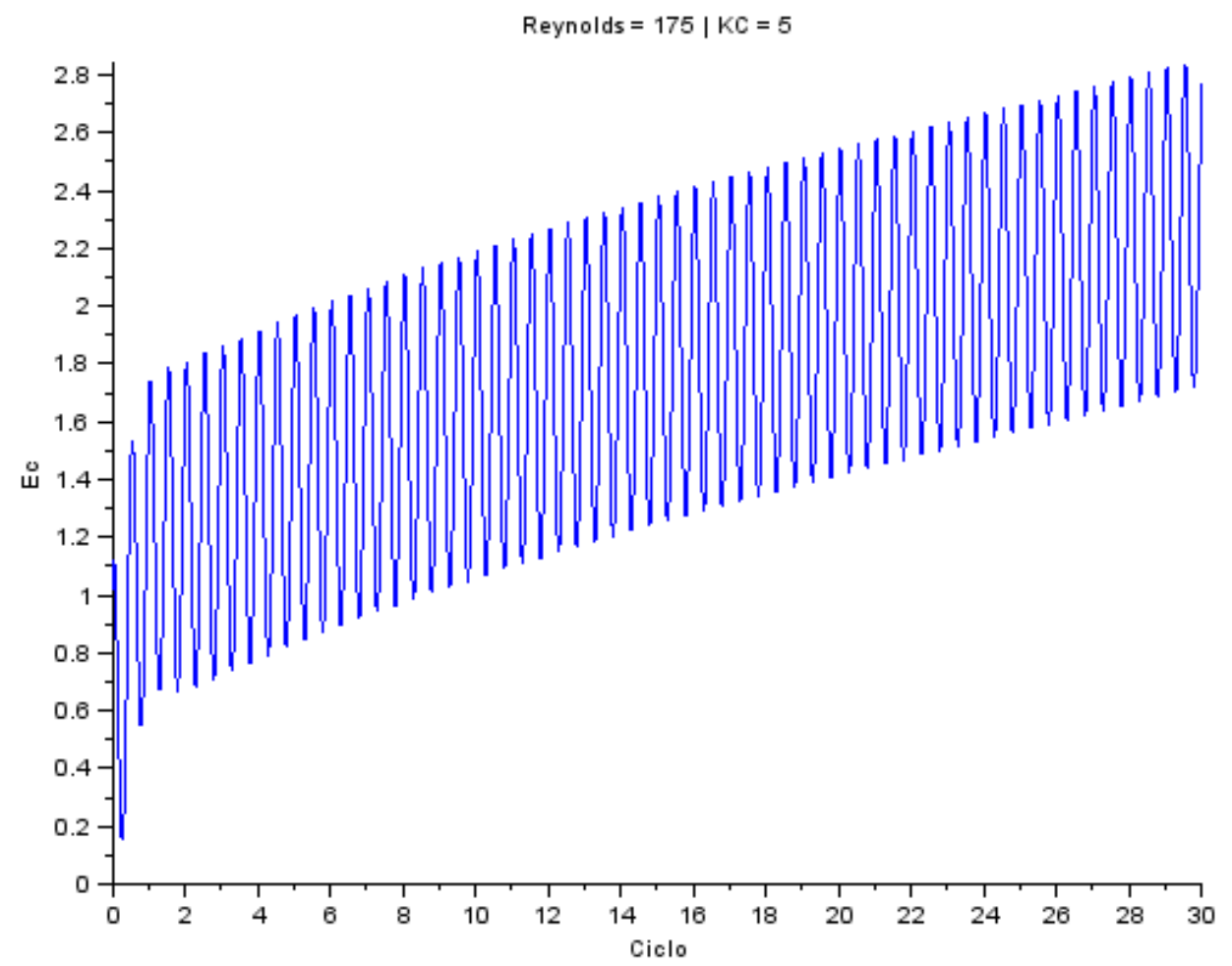

Figura 57 - Energia cinética do escoamento $(\operatorname{Re}=105$ e $\mathrm{KC}=5)$ 

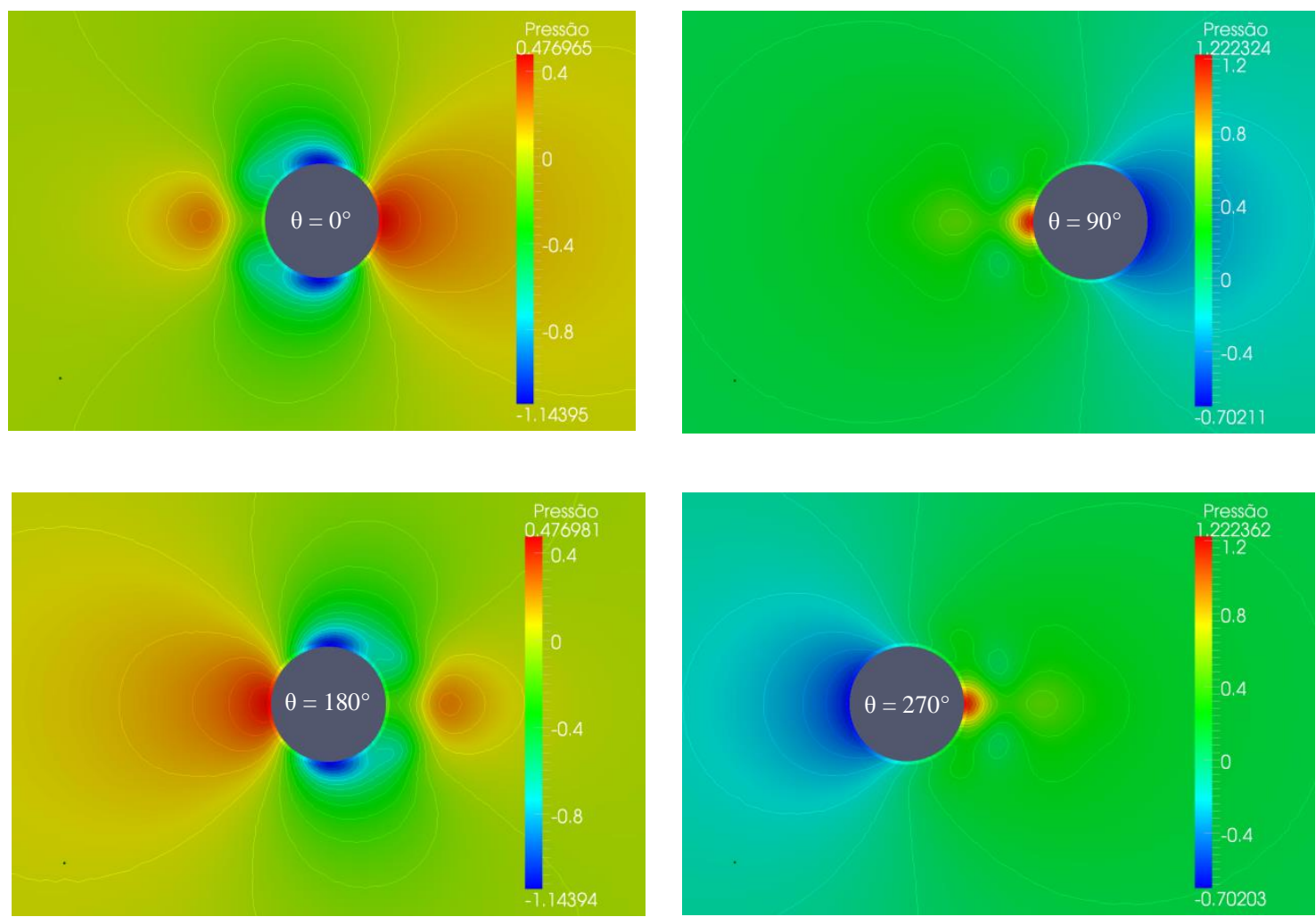

Figura 58 - Campo de pressão $(\operatorname{Re}=105$ e $\mathrm{KC}=5)$
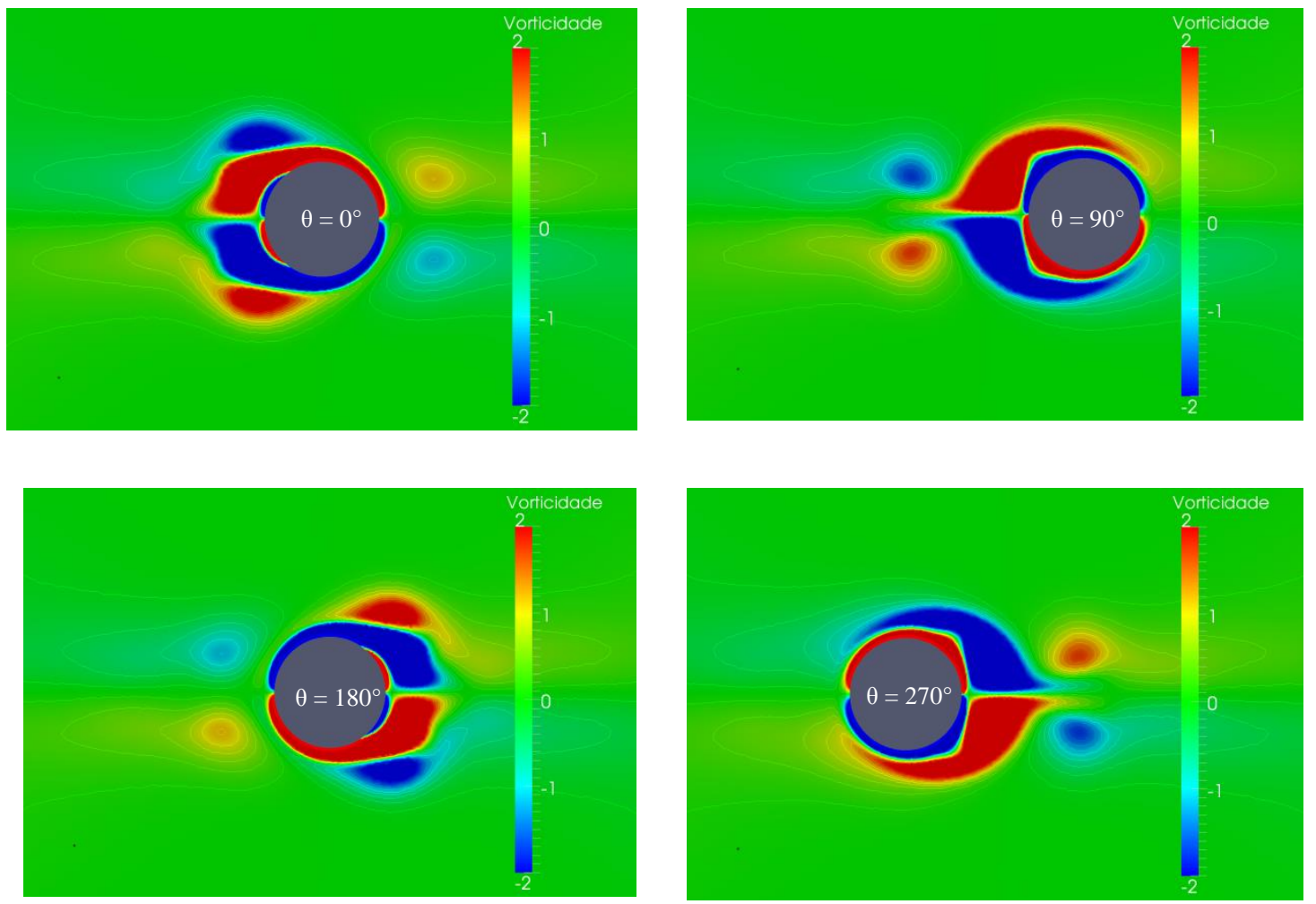

Figura 59 - Campo de vorticidade $(\operatorname{Re}=105$ e $K C=5)$ 


\subsection{Regime $\mathrm{E}: \mathrm{KC}=6$}

O cilindro oscila com uma amplitude de $0,95 \mathrm{D}$. O escoamento se enquadra no regime E, no mapa de Tatsuno e Bearman. O escoamento é inicialmente simétrico, e se torna instável a partir do terceiro ciclo, o que leva ao desenvolvimento de um escoamento assimétrico e o aparecimento de uma força normal. Vórtices são emitidos na parte inferior no cilindro a cada meio-ciclo e se deslocam em uma direção inclinada em "V". O escoamento induzido desvia do eixo de oscilação. Para o número de ciclos simulado, o padrão assimétrico se manteve em apenas um lado do cilindro. Apesar de nos últimos ciclos, nota-se uma mudança da força normal que está associada com início de uma inversão do padrao "V" para o outro lado do cilindro.

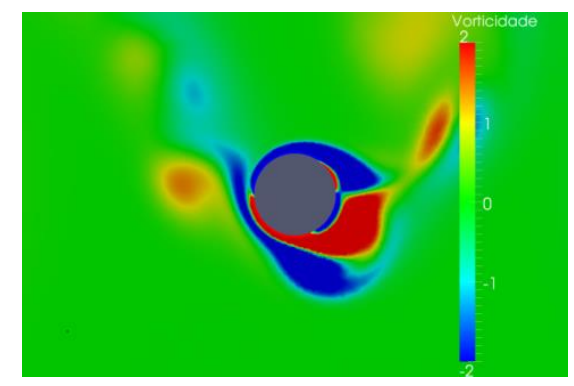

(a)

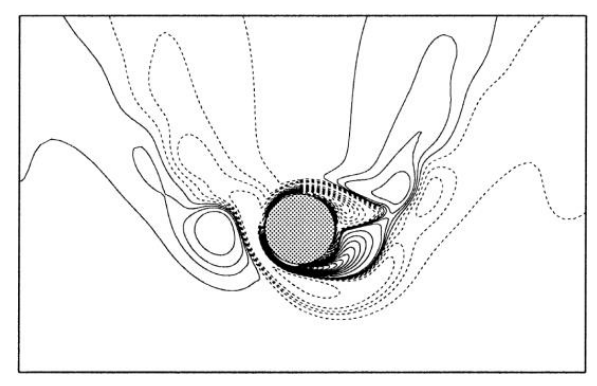

(b)

Figura 60 - Comparação da vorticidade: (a) Presente trabalho e (b) Dütsh et al. (1998) no regime $E$

A força normal é da mesma ordem da força de resistência e oscila com o dobro da frequência do movimento. A força de resistência se reduz levemente com o surgimento da força normal, e os picos positivo e negativo diferem, conforme detalhe do último ciclo na figura 62. Os campos de pressão e de vorticidade deixam de ser semelhantes entre si nas posições de deslocamento nulo $0^{\circ}$ e $180^{\circ}$, e também nas posições de deslocamento máximo $90^{\circ}$ e $270^{\circ}$, conforme figuras 65 e 66 .

A energia cinética do escoamento cresce a cada meio-ciclo e não se estabilizou. A amplitude de variação da energia cinética permanece constante nos ciclos iniciais e, após o desenvolvimento do escoamento assimétrico, varia a cada meio ciclo. 

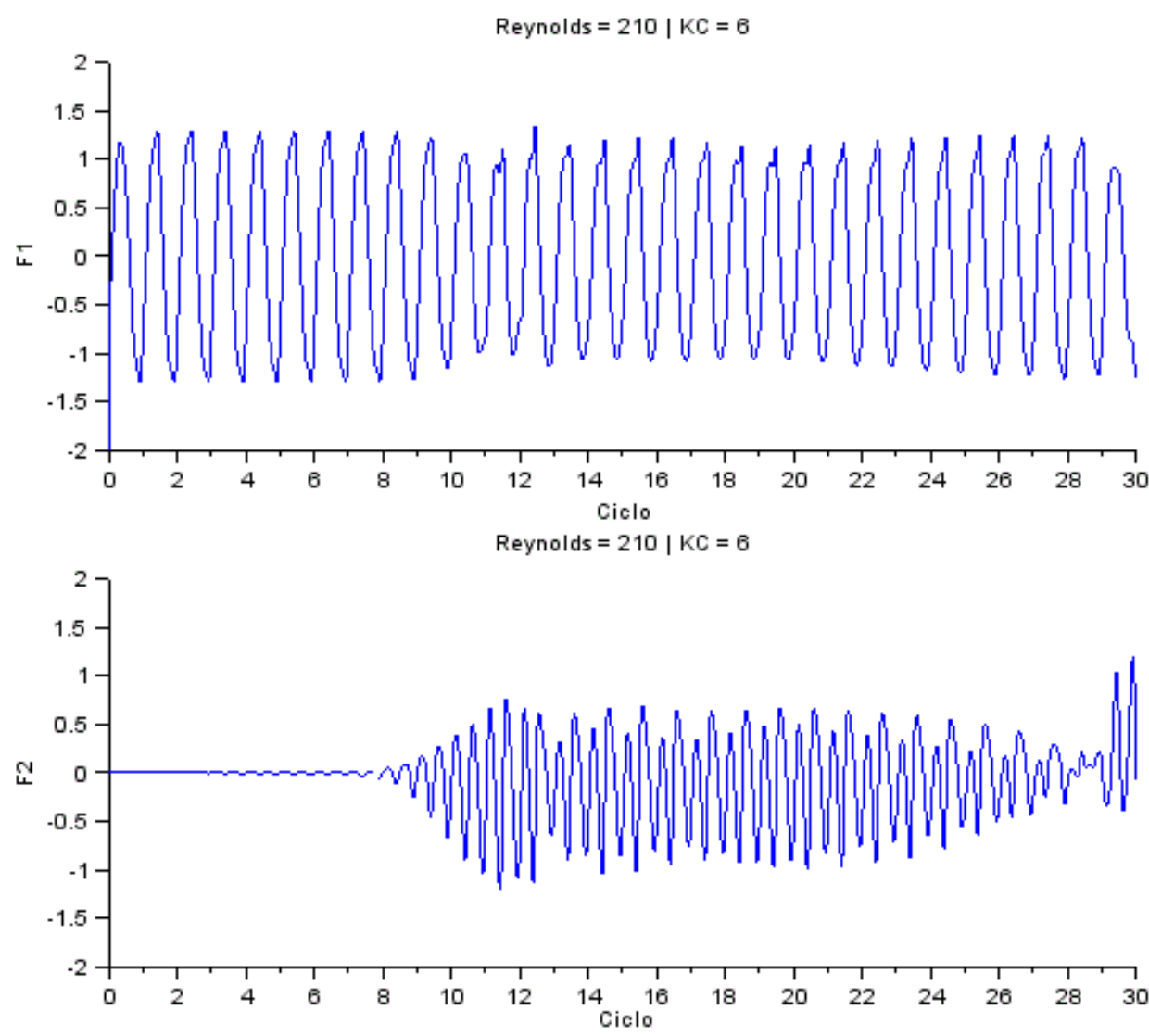

Figura 61- Forças de resistência e normal $(\operatorname{Re}=105$ e $\mathrm{KC}=6)$

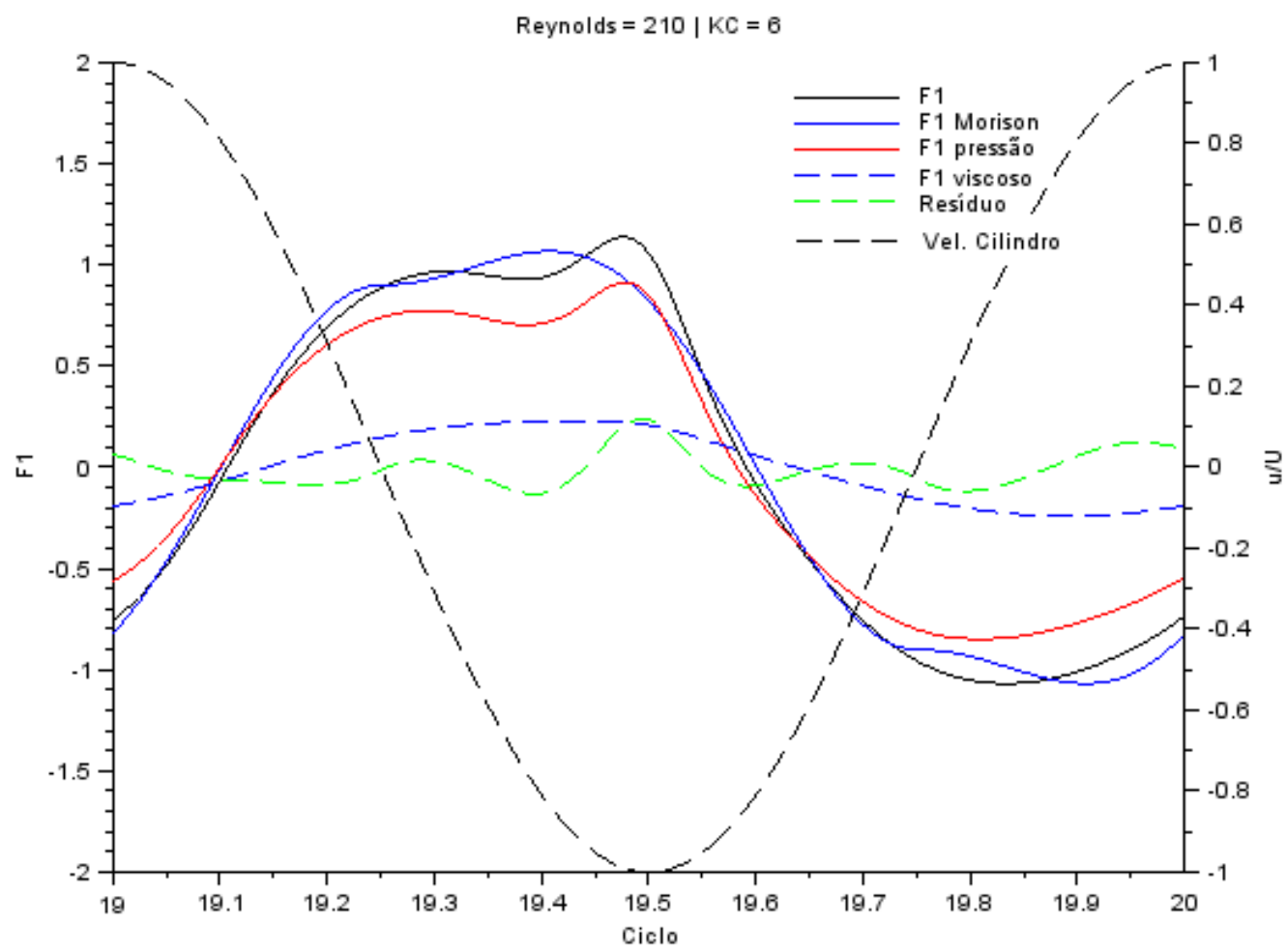

Figura 62 - Força numérica e de Morison $(\operatorname{Re}=105$ e $\mathrm{KC}=6)$ 


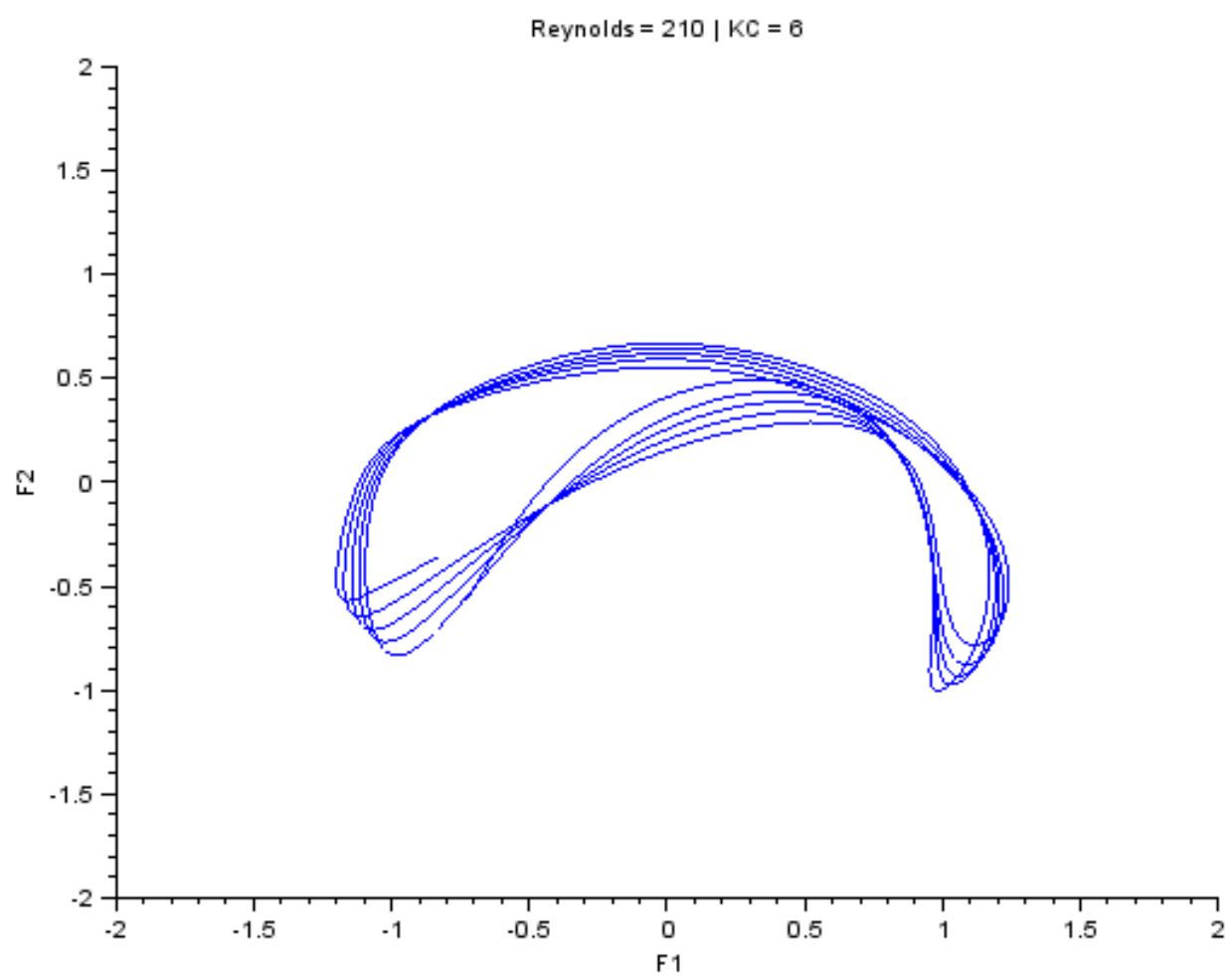

Figura 63 - Diagrama de fase da força resultante $(\operatorname{Re}=105$ e KC $=6)$

Reynolds $=210 \mid \mathrm{KC}=6$

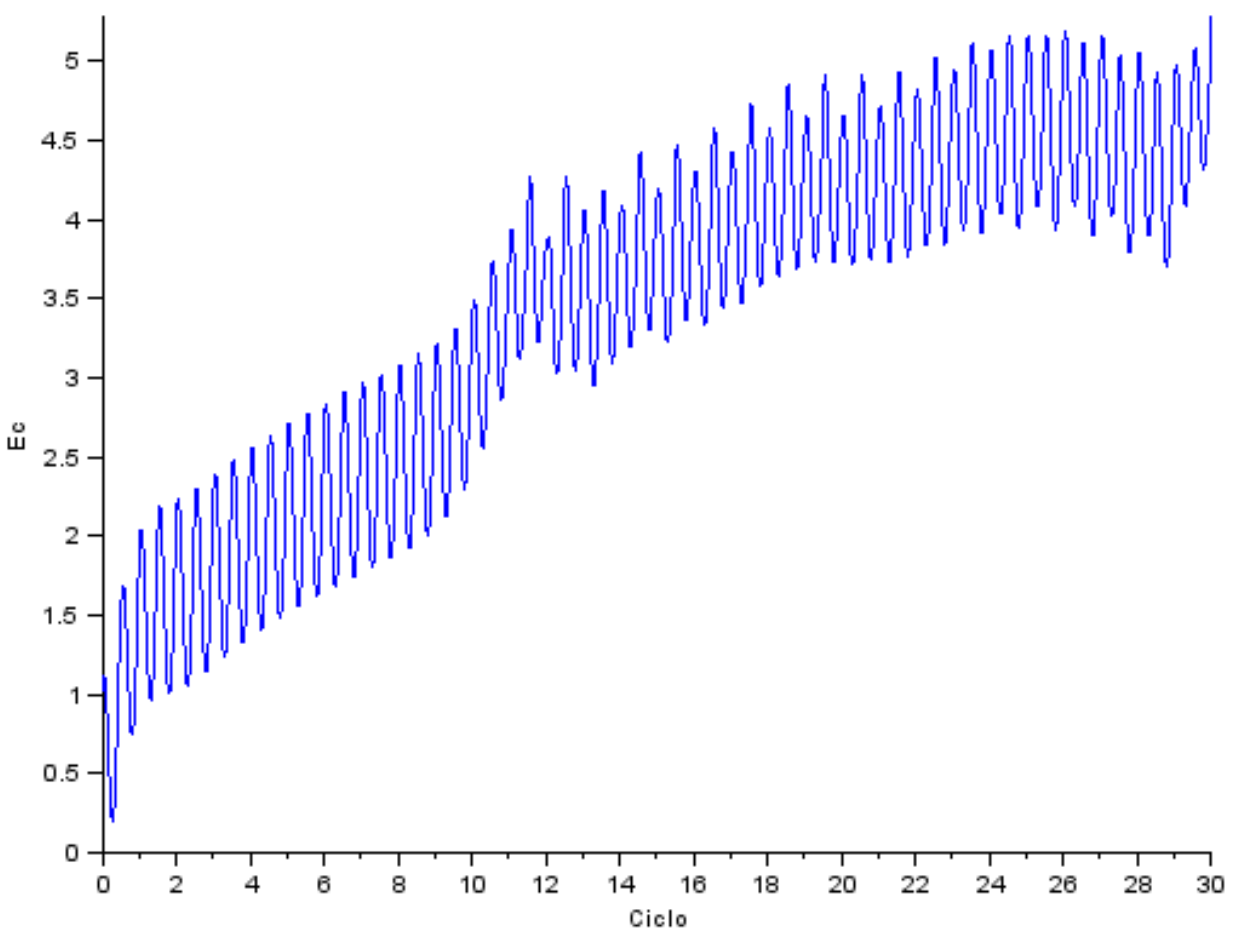

Figura 64 - Energia cinética do escoamento $(\operatorname{Re}=105$ e $\mathrm{KC}=6)$ 

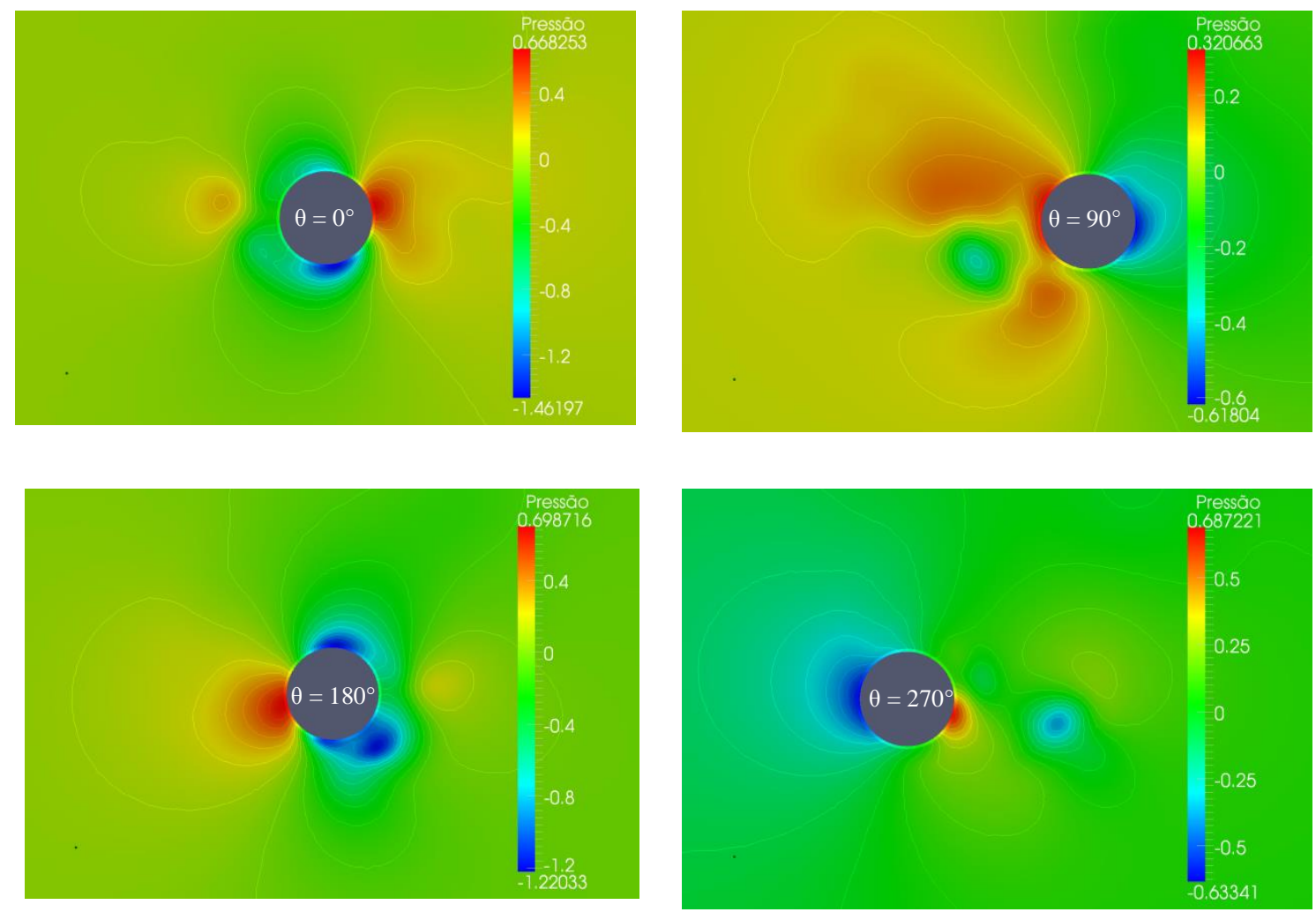

Figura 65 - Campo de pressão $(\operatorname{Re}=105$ e $\mathrm{KC}=6)$
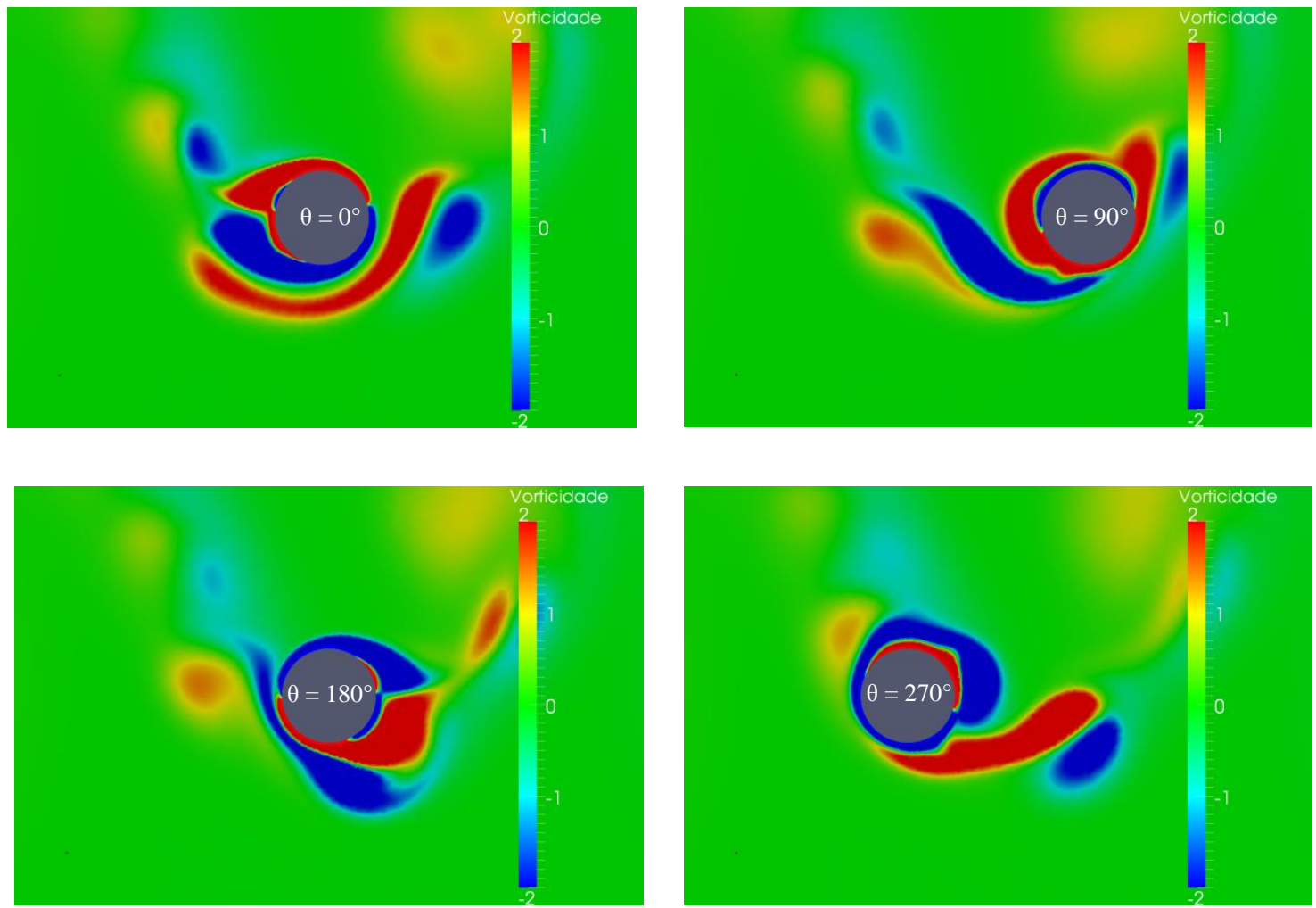

Figura 66 - Campo de vorticidade $(\operatorname{Re}=105$ e $\mathrm{KC}=6)$ 


\subsection{Regime F: $7 \leq K C \leq 10$}

A amplitude de oscilação do cilindro é de $1,11 D, 127 D, 1,43 D$ e $1,59 D$ para $K C$ igual a 7, 8, 9 e 10, respectivamente. $\mathrm{O}$ escoamento se enquadra no regime $\mathrm{F}$, no mapa de Tatsuno e Bearman. Para $K C$ igual a 9 e 10, o escoamento se enquadraria no regime $\mathrm{G}$, entretanto, não ocorreu o desenvolvimento deste regime para o número de ciclos simulado

O escoamento é inicialmente simétrico, e se torna instável, o que leva ao desenvolvimento de um escoamento assimétrico e o aparecimento de uma força normal. Vórtices são formados de maneira desigual de um lado e do outro do eixo de oscilação do cilindro. A cada meio-ciclo, dois vórtices de sinais opostos são emitidos de uma lado do cilindro, e no outro meio-ciclo, do outro lado. O escoamento induzido desvia do eixo de oscilação. Para o número de ciclos simulado, o padrão assimétrico manteve-se em apenas um lado do cilindro, exceto para $K C=9$, no qual o padrão assimétrico alternou de lado do cilindro após o $25^{\circ}$ ciclo. Esta mudança do lado de emissão reflete-se no histórico da força normal, conforme pode ser observado na figura 80. A força normal se torna mais complexa com aumento de $K C$, com o aparecimento de harmônicos de frequências superiores que aquele de oscilação do cilindro.

A figura a seguir compara o resultado do presente trabalho com aquele obtido por Tatsuno e Bearman (1990) para o regime F. Ressalta-se que os números $R e$ e $K C$ não são idênticos e, no presente trabalho, é mostrado o campo de vorticidade enquanto no trabalho de Tatsuno e Bearman (1990), as linhas de emissão do escoamento.

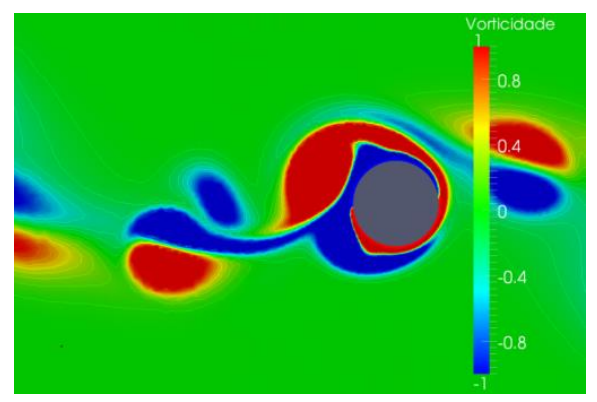

(a)

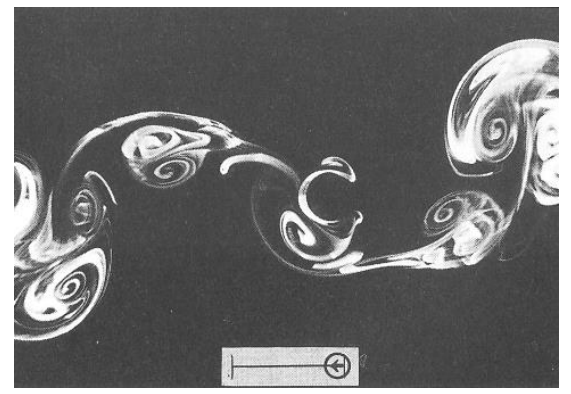

(b)

Figura 67 - Comparação dos resultados: (a ) Presente trabalho e (b) Tatsuno e Bearman (1990) para o regime $F$ 
A energia cinética do escoamento cresce a cada meio-ciclo e não se estabilizou. A amplitude de variação da energia cinética permanece constante nos ciclos iniciais e mesmo após o desenvolvimento do escoamento assimétrico para $K C=7$. Nos demais, a amplitude de variação da energia cinética permanece constante nos ciclos iniciais e, após o desenvolvimento do escoamento assimétrico, varia a cada meio ciclo. 

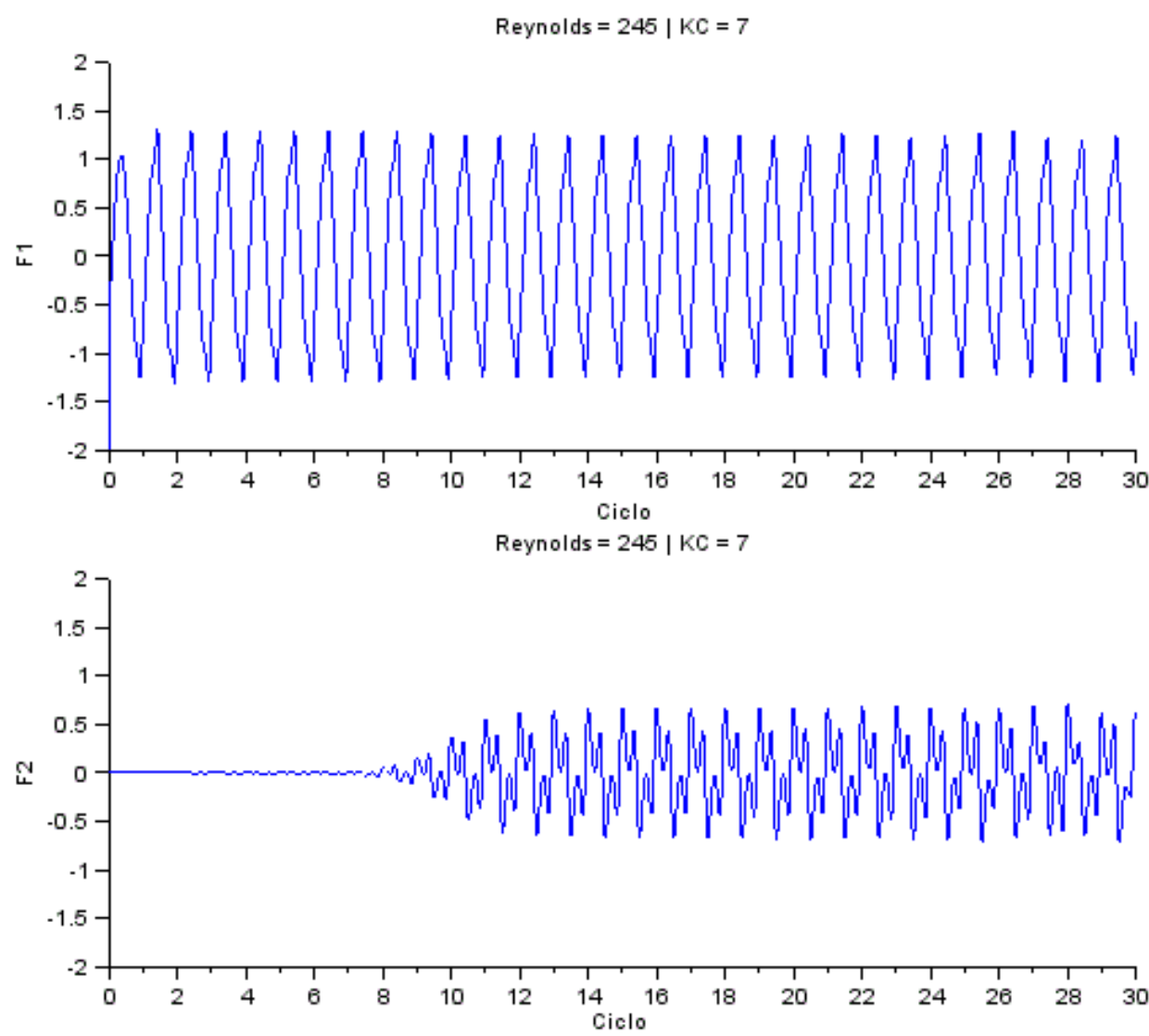

Figura 68- Forças de resistência e normal $(\operatorname{Re}=105$ e $\mathrm{KC}=7)$

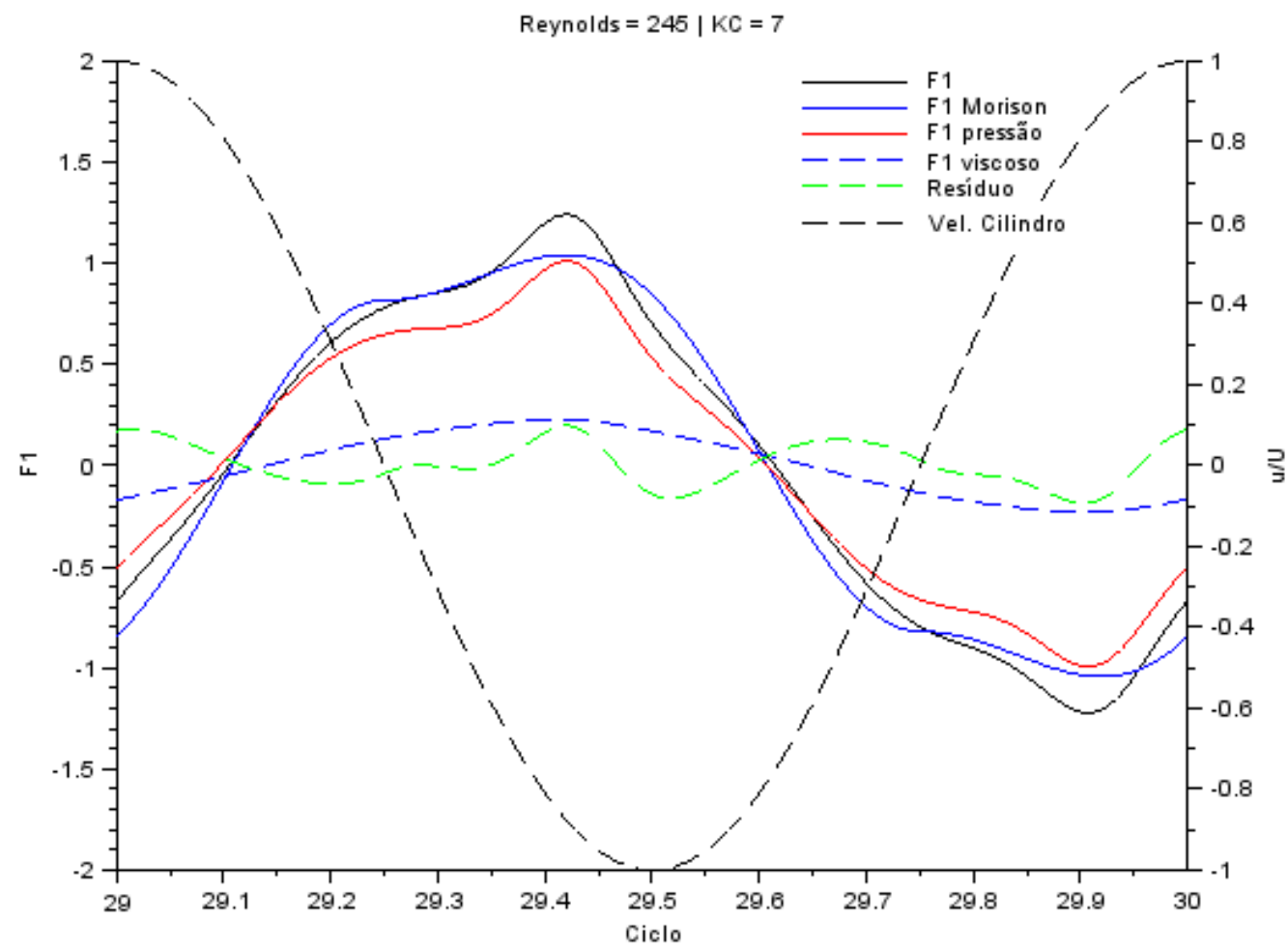

Figura 69 - Força numérica e de Morison $(\operatorname{Re}=105$ e $\mathrm{KC}=7)$ 


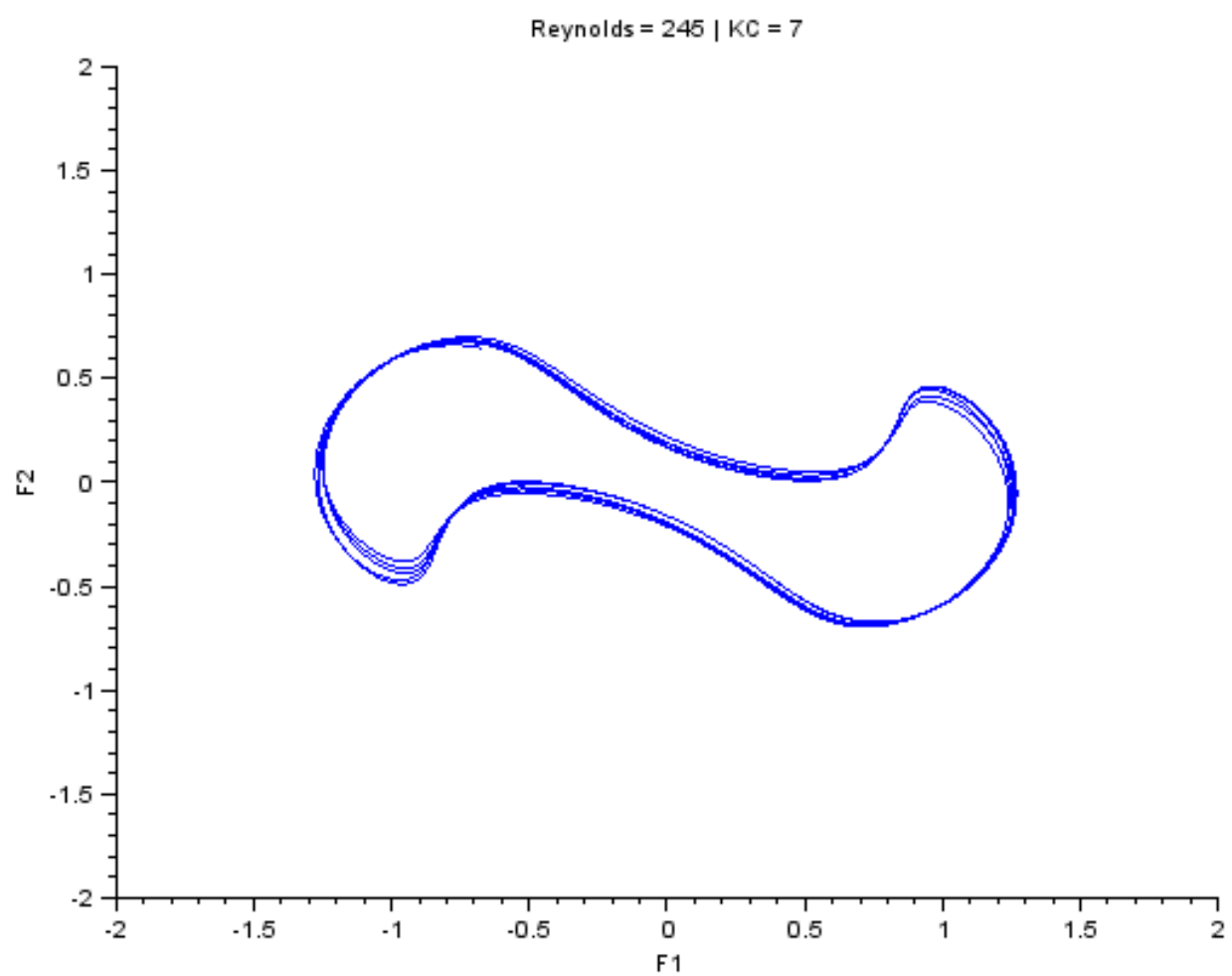

Figura 70 - Diagrama de fase da força resultante $(\operatorname{Re}=105$ e KC $=7)$

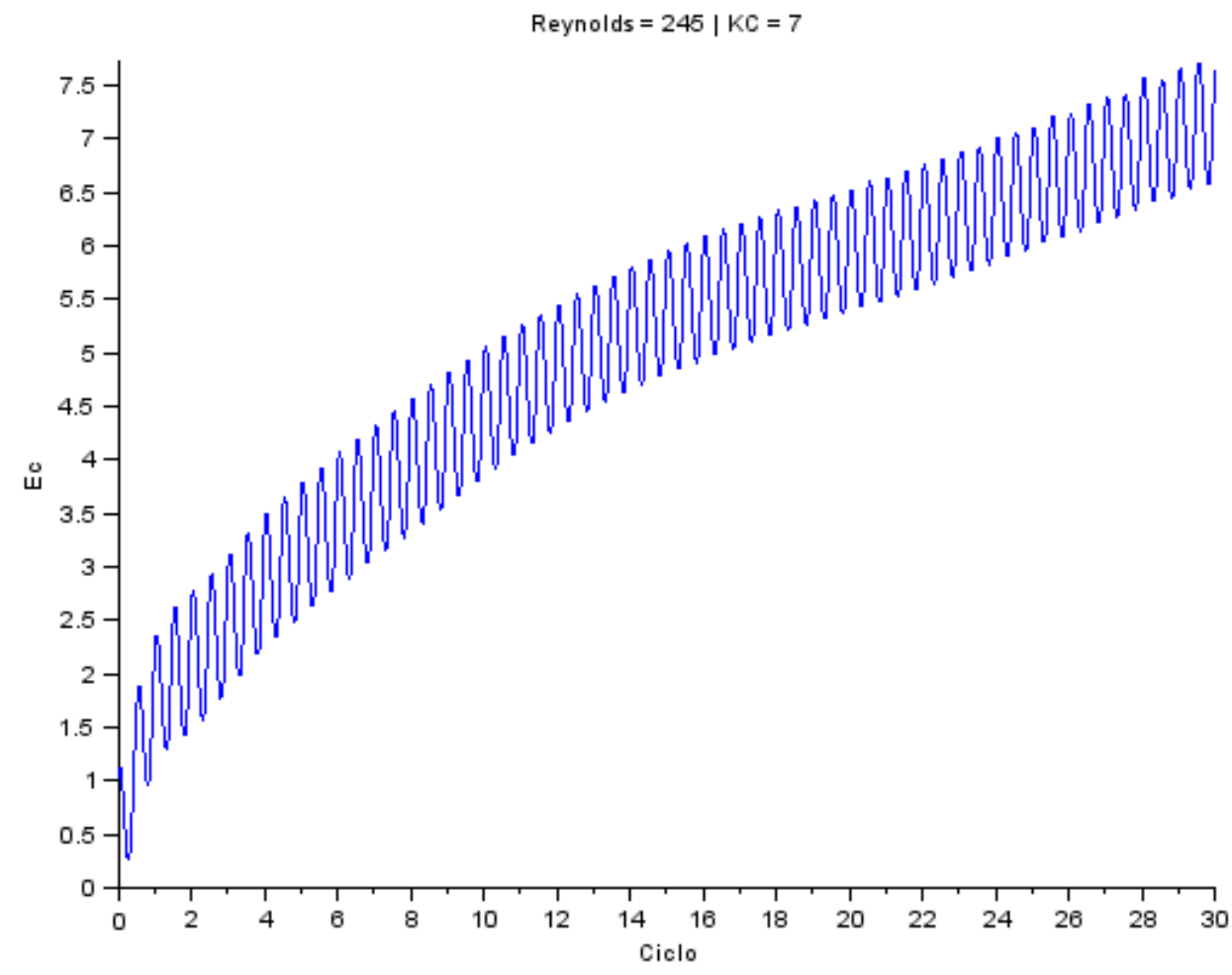

Figura 71 - Energia cinética do escoamento $(\operatorname{Re}=105$ e $\mathrm{KC}=7)$ 

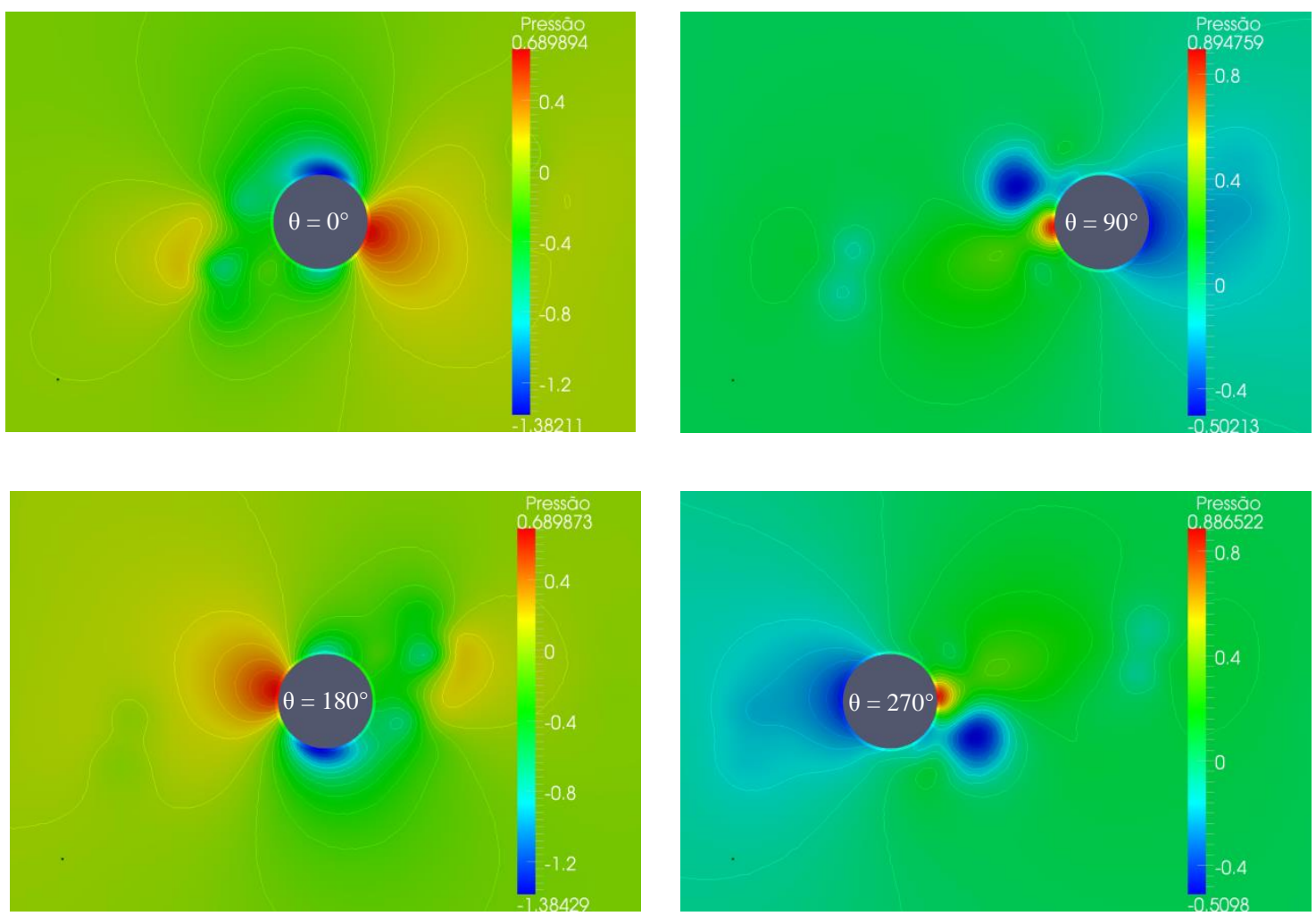

Figura 72 - Campo de pressão $(\operatorname{Re}=105$ e $\mathrm{KC}=7)$
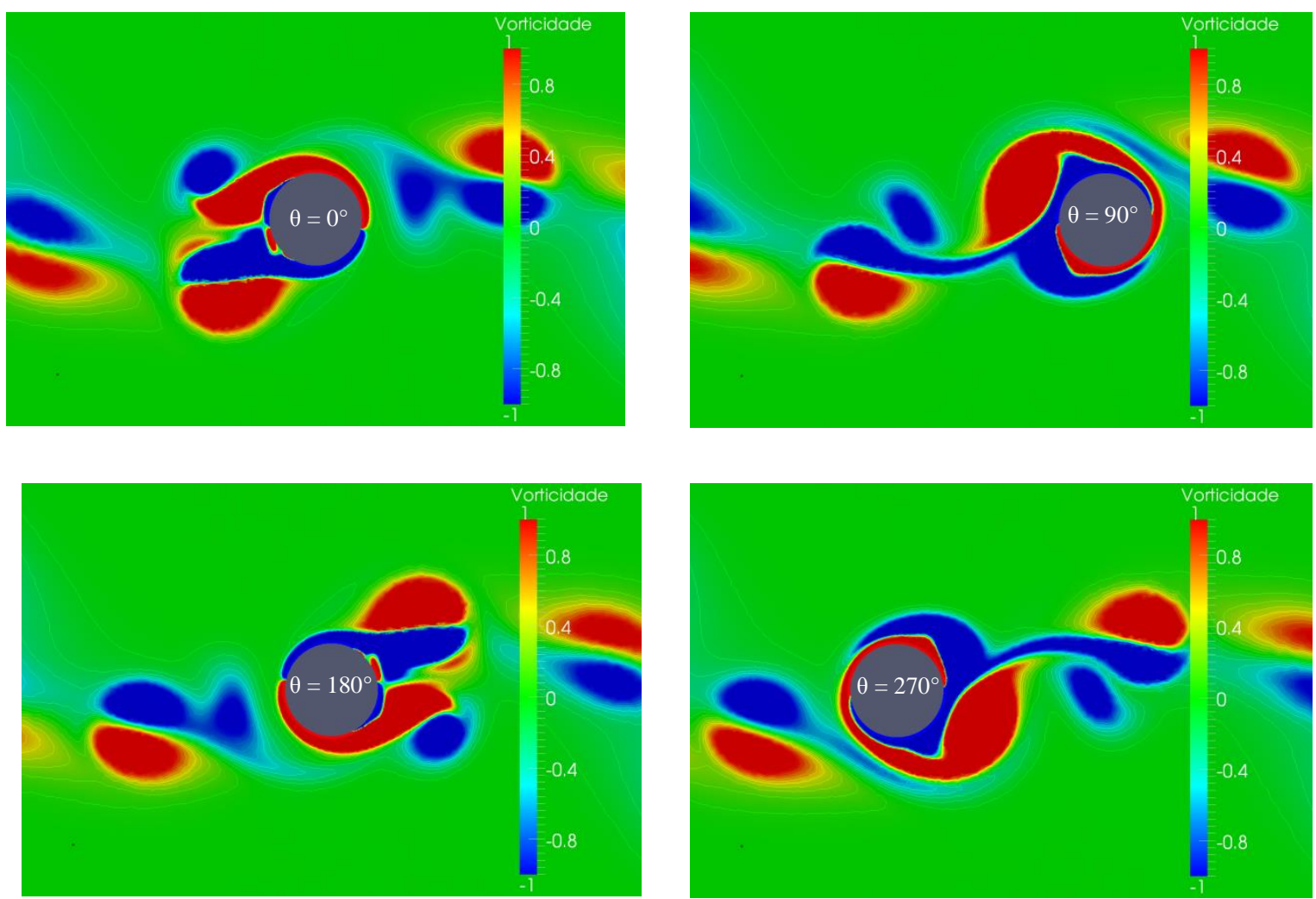

Figura 73 - Campo de vorticidade $(\operatorname{Re}=105$ e $\mathrm{KC}=7)$ 
Reynolds $=280 \mid \mathrm{KC}=8$
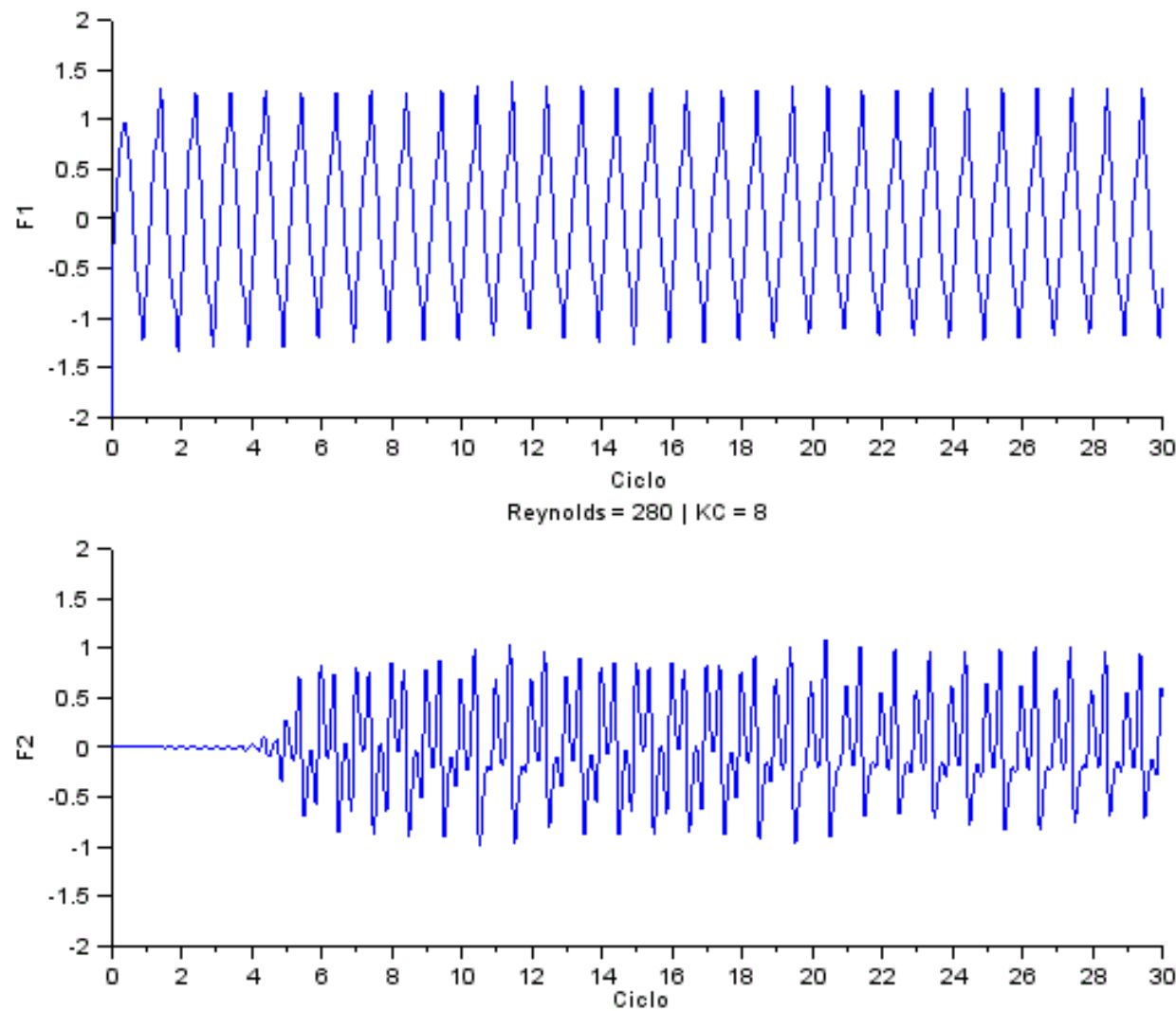

Figura 74- Forças de resistência e normal $(\operatorname{Re}=105$ e $K C=8)$

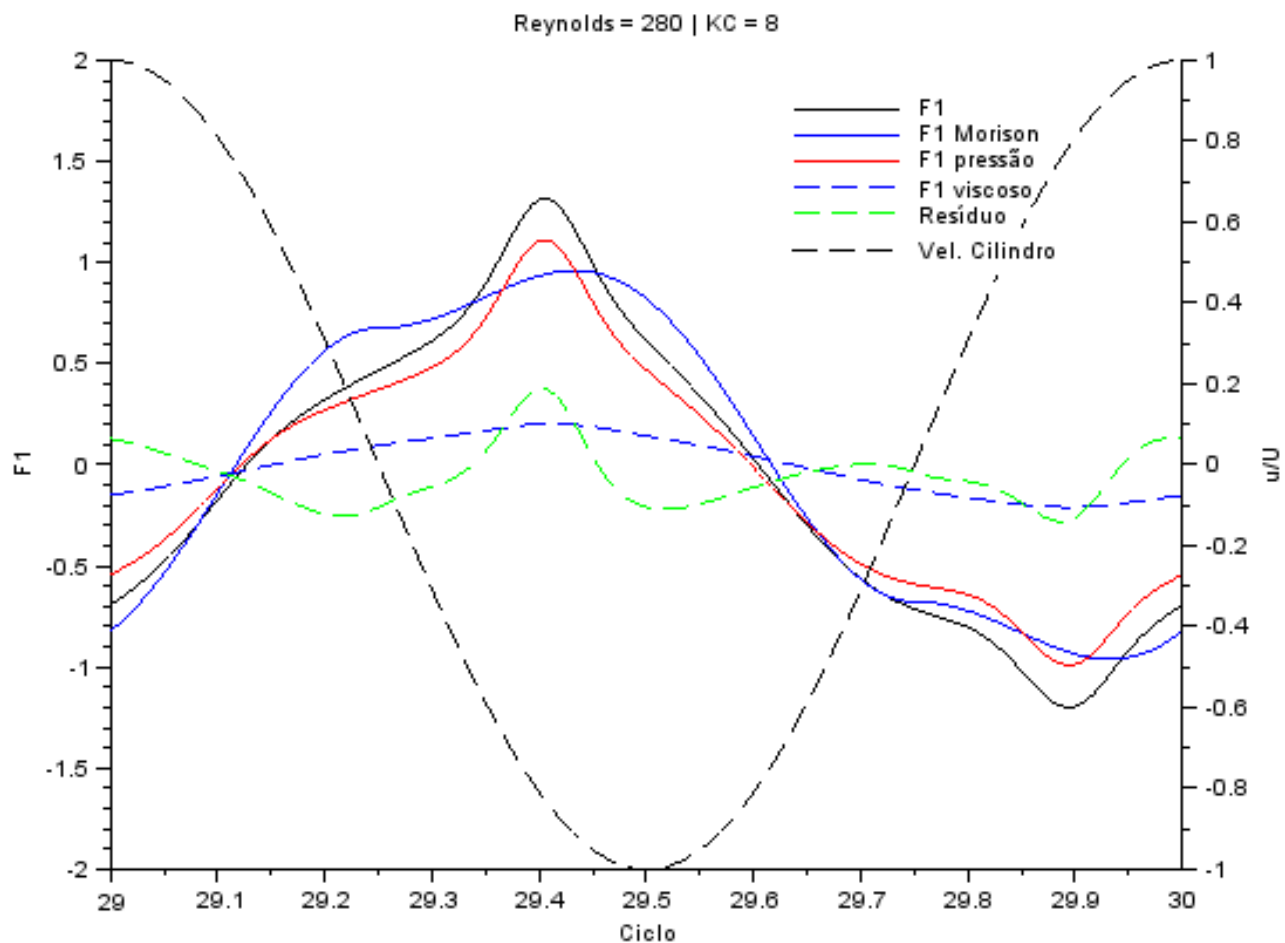

Figura 75 - Força numérica e de Morison $(\operatorname{Re}=105$ e $\mathrm{KC}=8)$ 


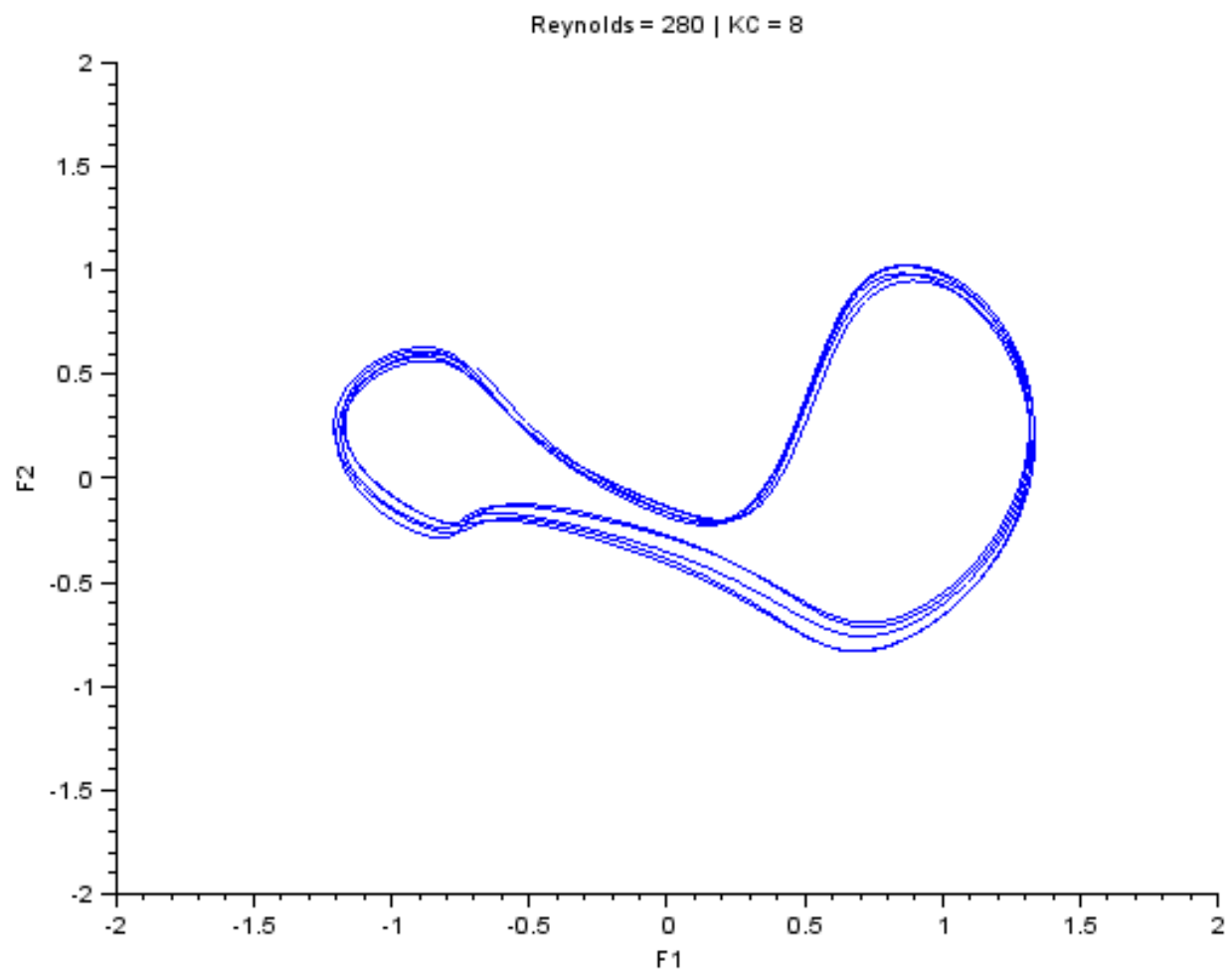

Figura 76 - Diagrama de fase da força resultante $(\operatorname{Re}=105$ e KC $=8)$

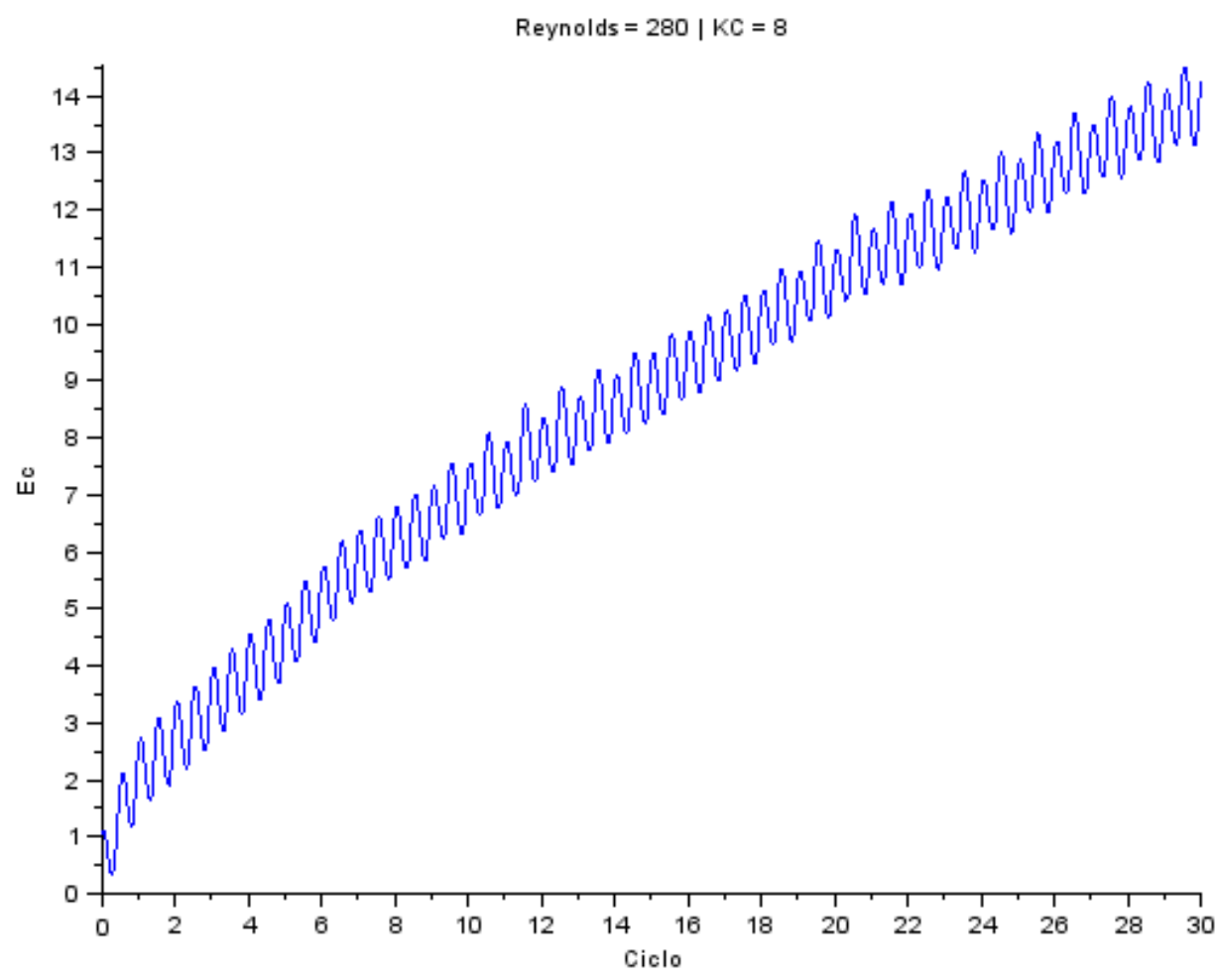

Figura 77 - Energia cinética do escoamento $(\operatorname{Re}=105$ e $\mathrm{KC}=8)$ 

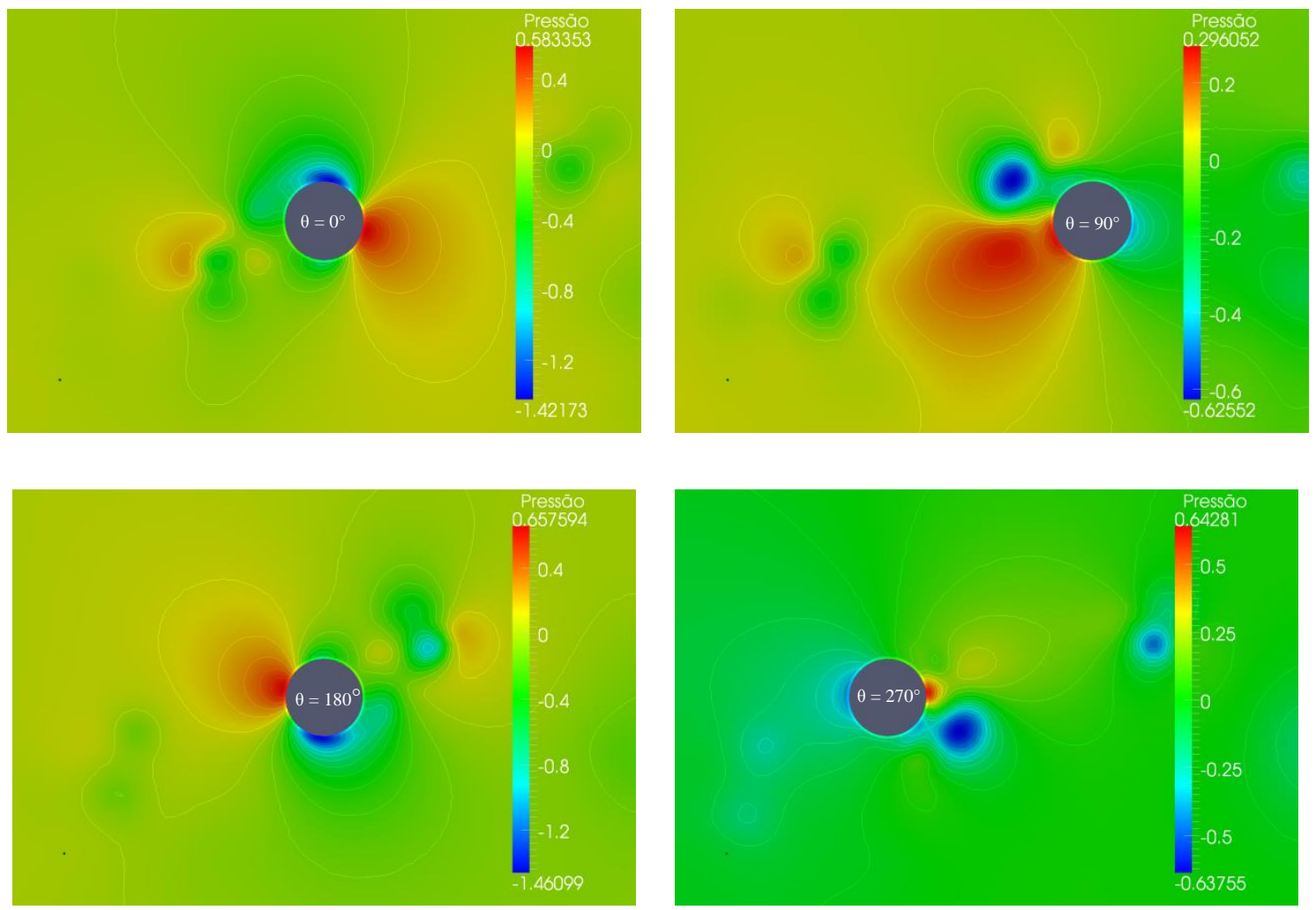

Figura 78 - Campo de pressão $(\operatorname{Re}=105$ e $\mathrm{KC}=8)$
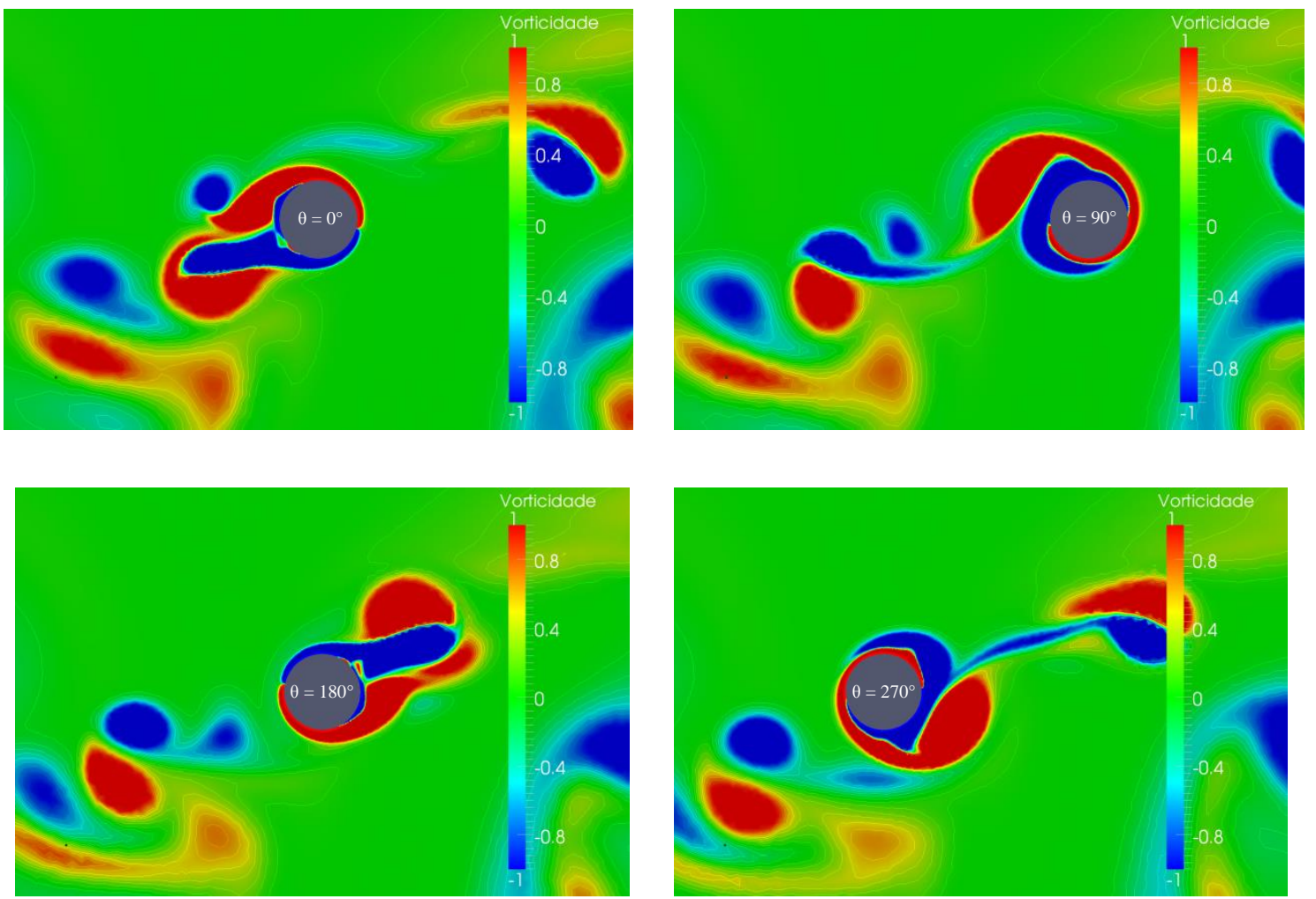

Figura 79 - Campo de vorticidade $(\operatorname{Re}=105$ e $\mathrm{KC}=8)$ 

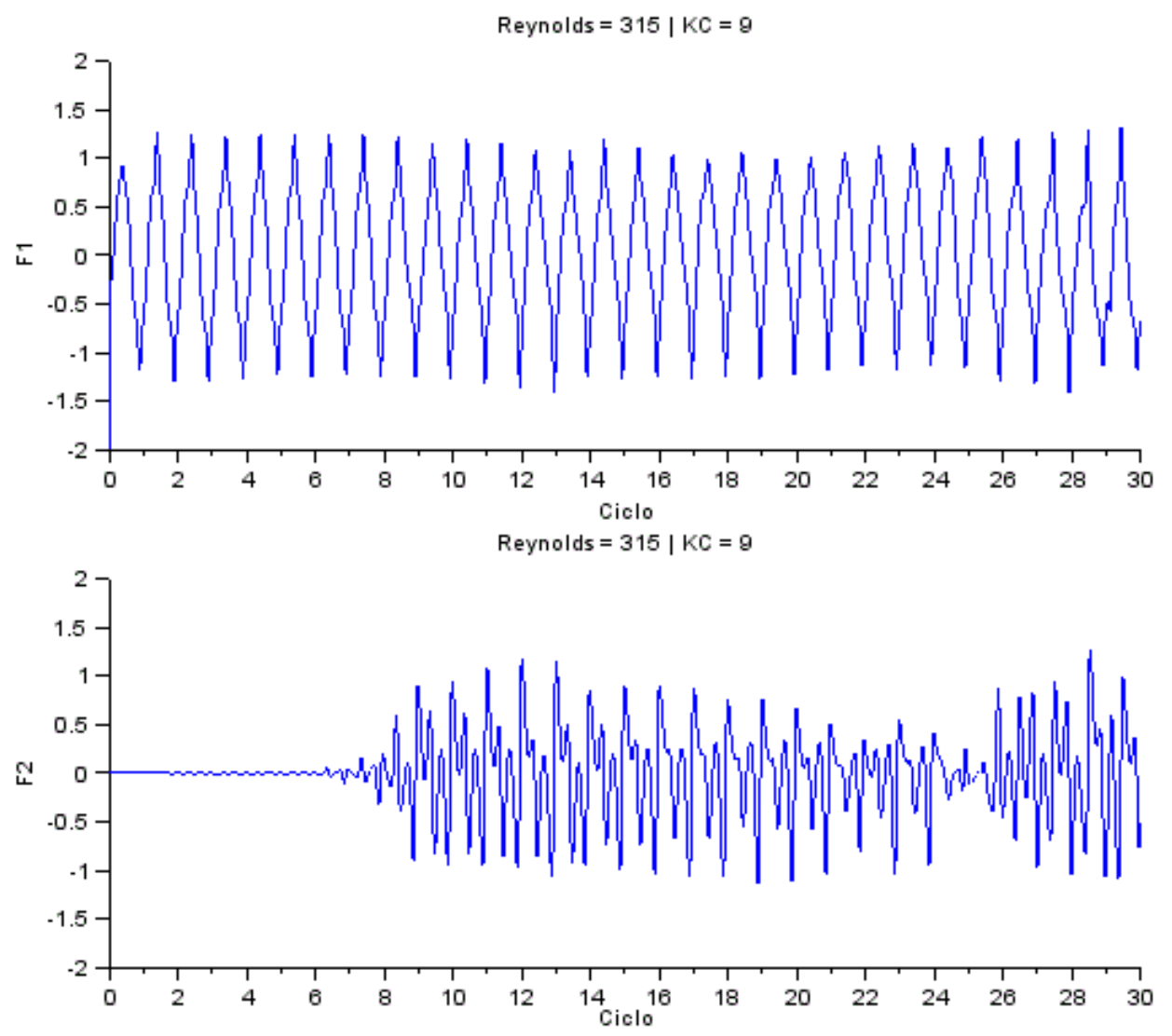

Figura 80- Forças de resistência e normal $(\operatorname{Re}=105$ e KC $=9)$

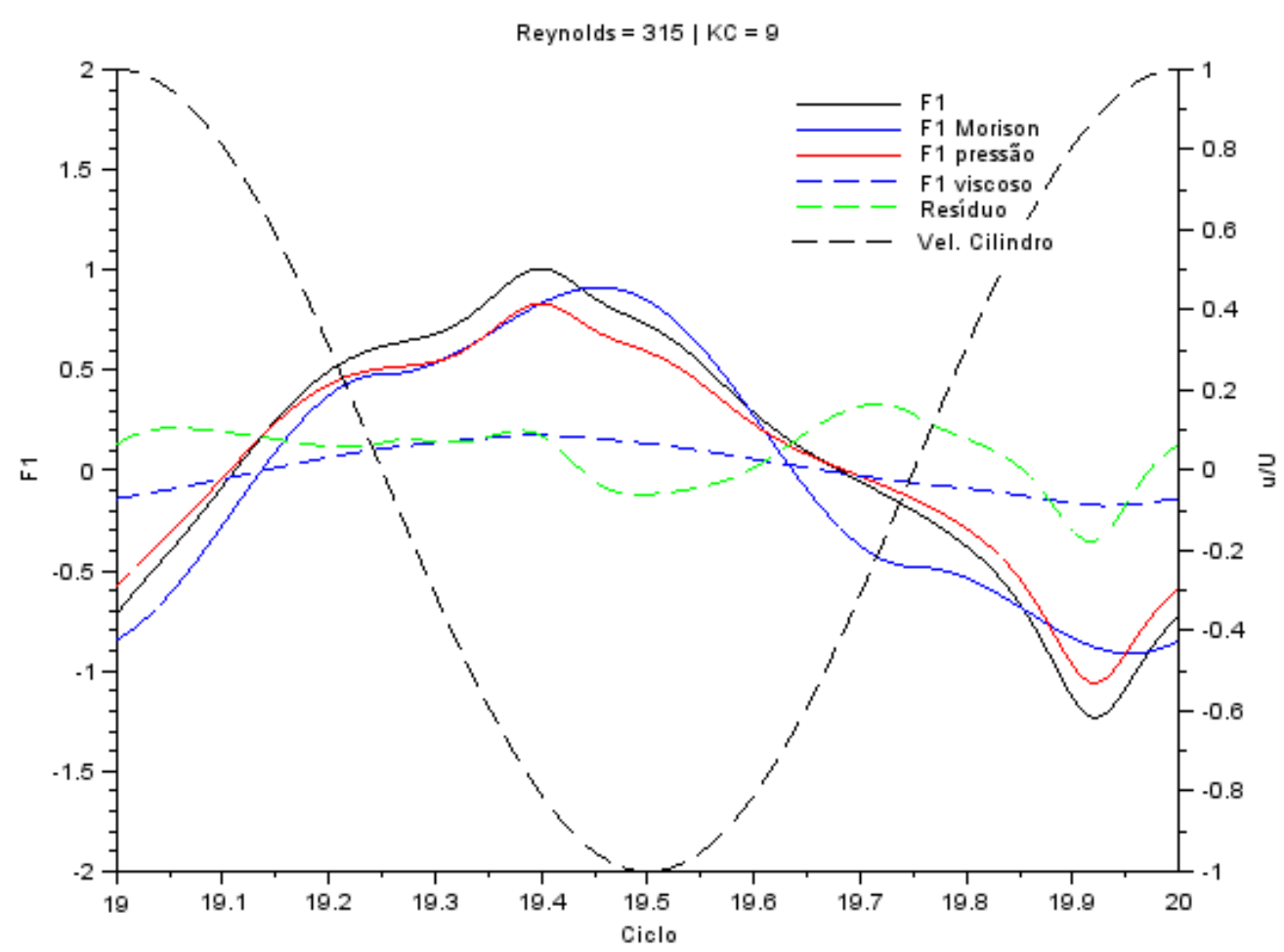

Figura 81 - Força numérica e de Morison $(\operatorname{Re}=105$ e $\mathrm{KC}=9)$ 


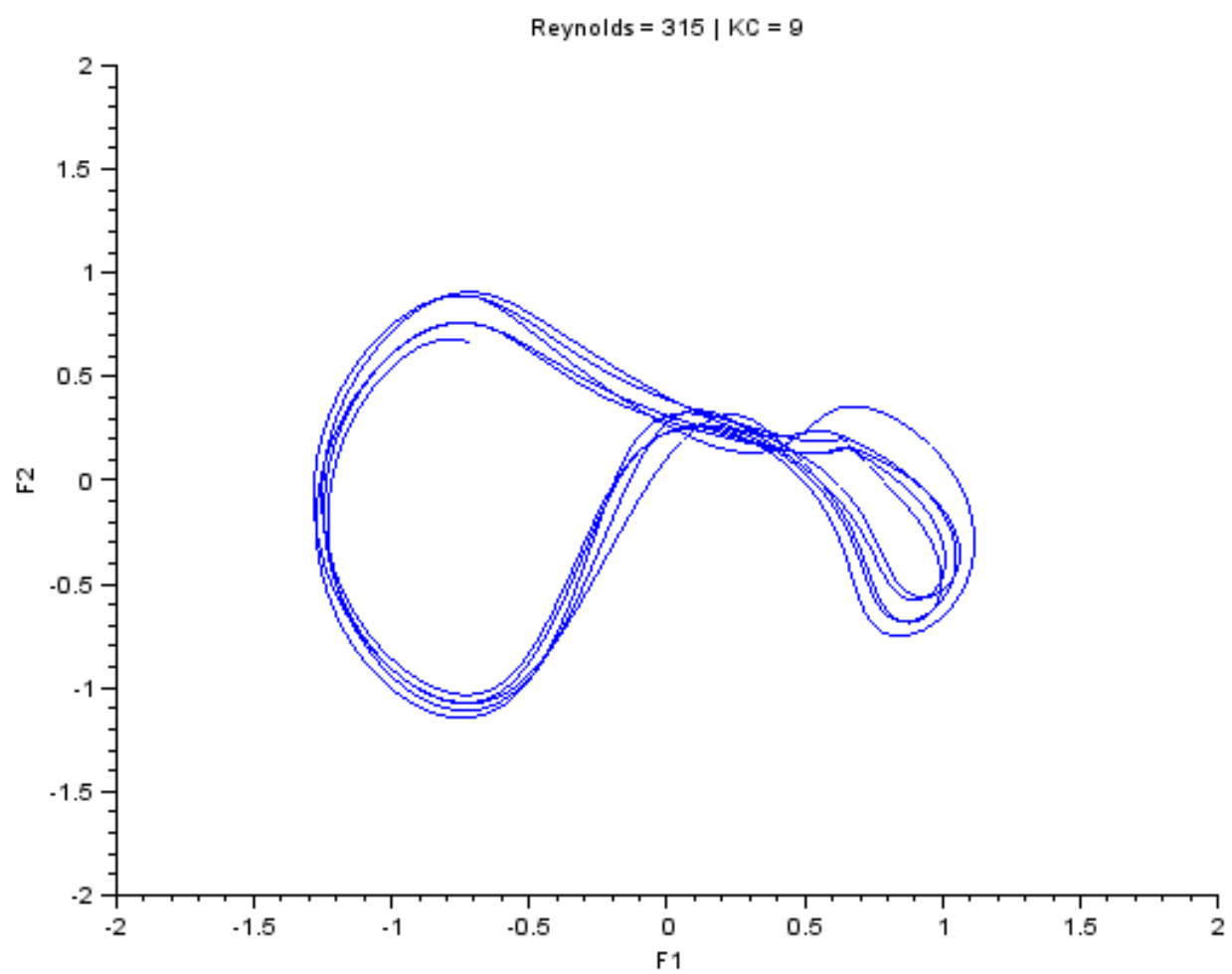

Figura 82 - Diagrama de fase da força resultante $(\operatorname{Re}=105$ e KC $=9)$

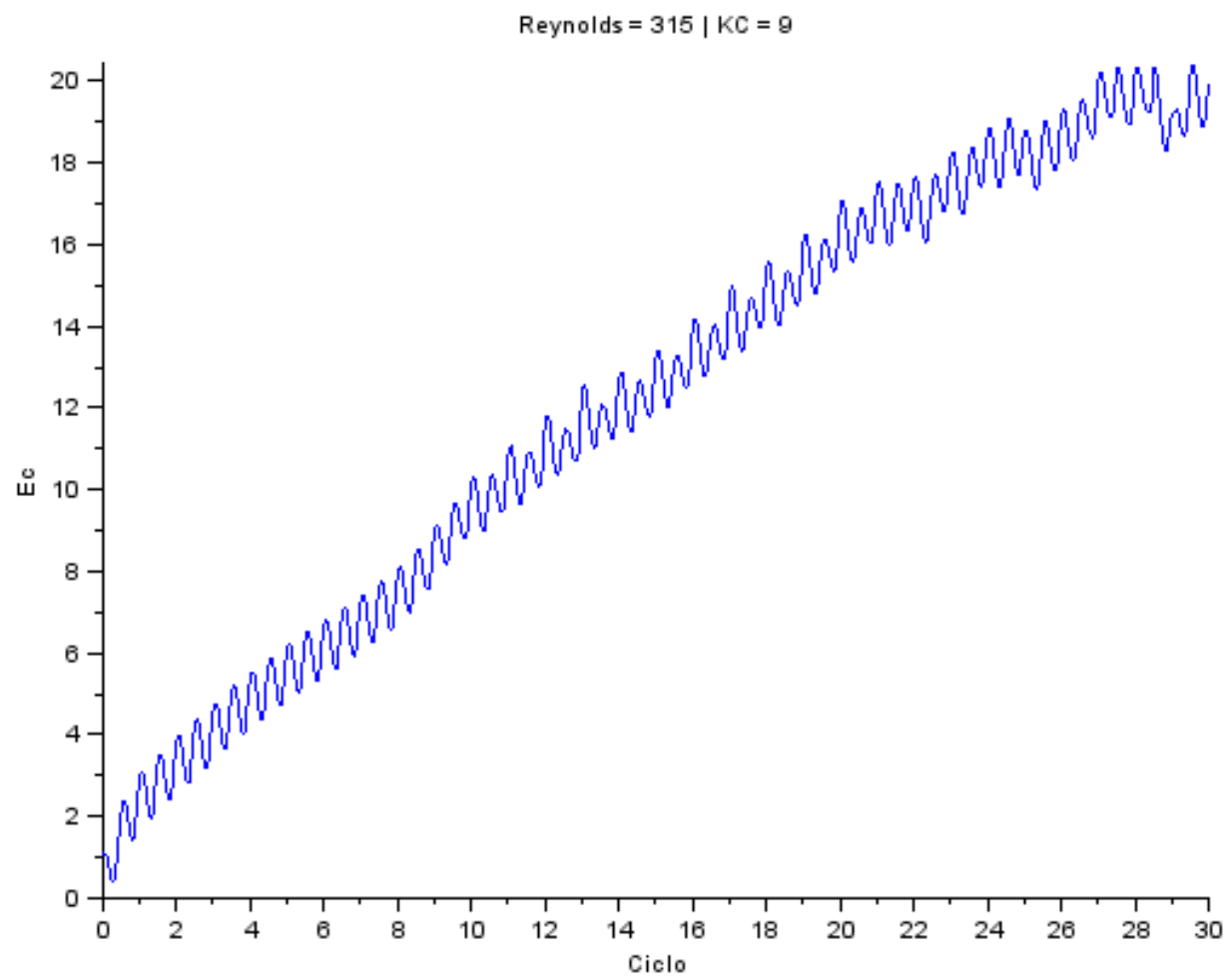

Figura 83 - Energia cinética do escoamento $(\operatorname{Re}=105$ e $K C=9)$ 

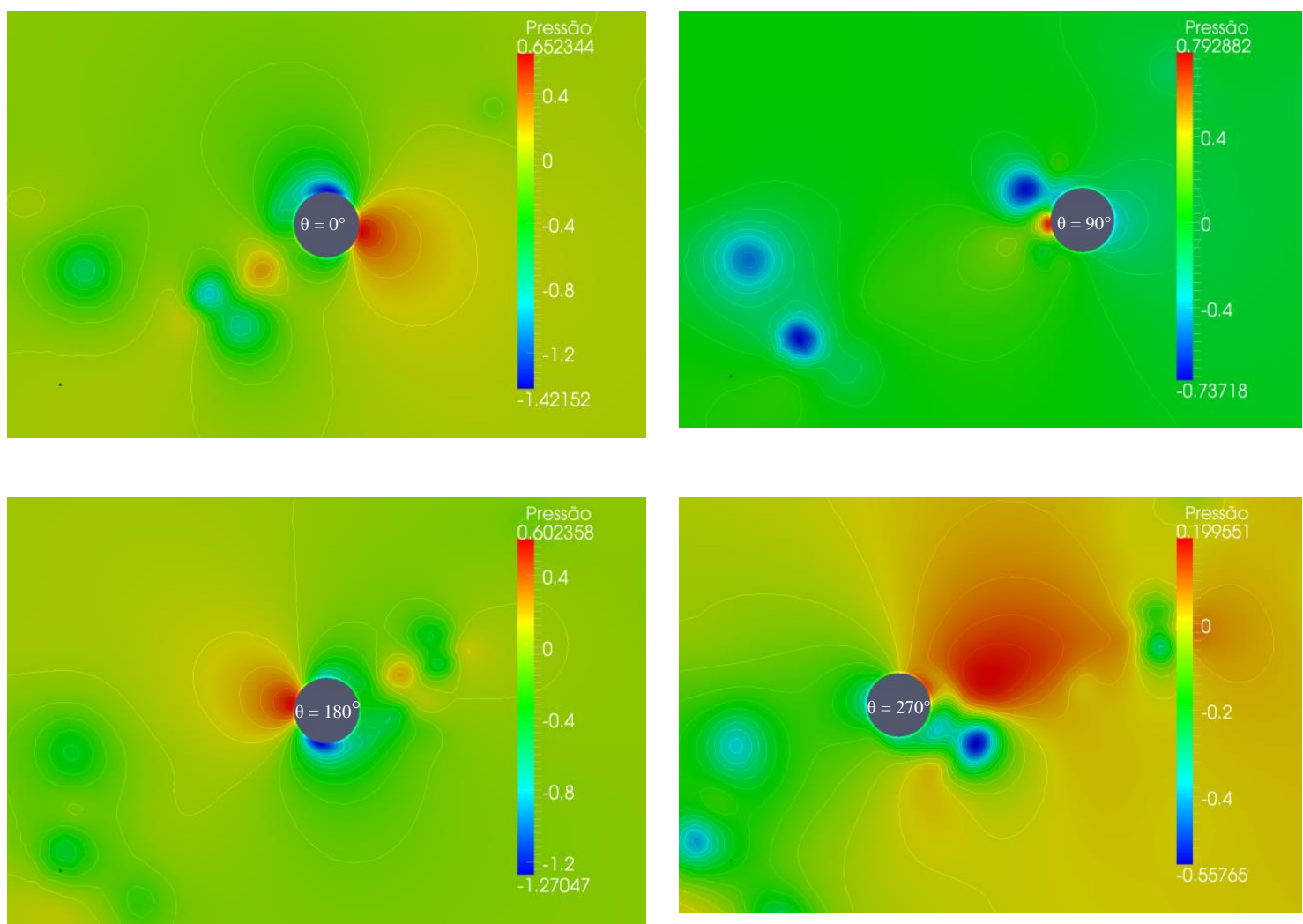

Figura 84 - Campo de pressão $(\operatorname{Re}=105$ e KC $=9)$
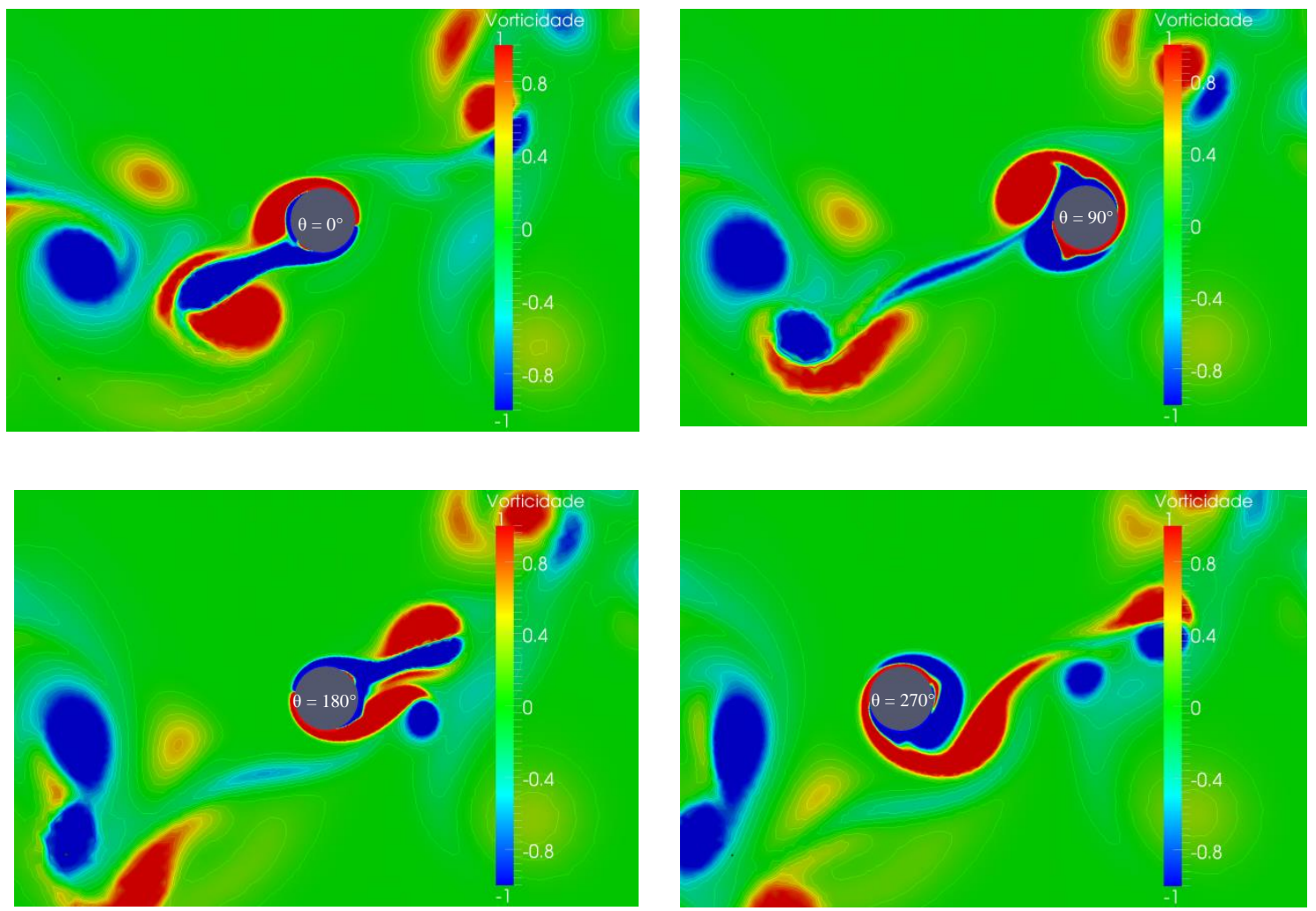

Figura 85 - Campo de vorticidade $(\operatorname{Re}=105$ e $\mathrm{KC}=9)$ 


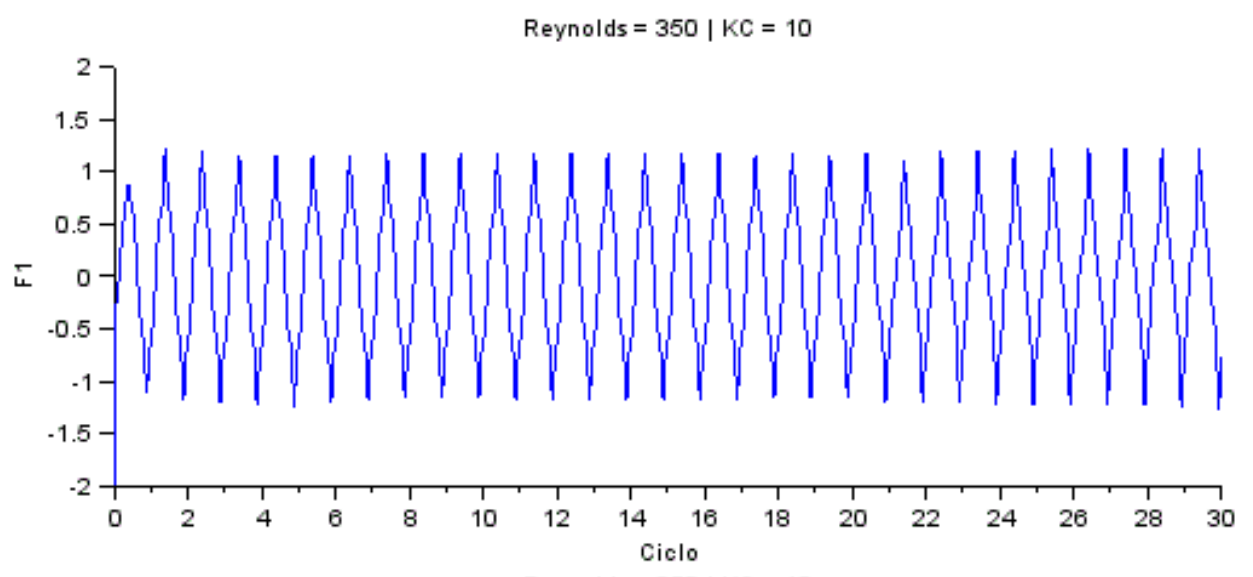

Reynolds $=350 \mid \mathrm{KC}=10$

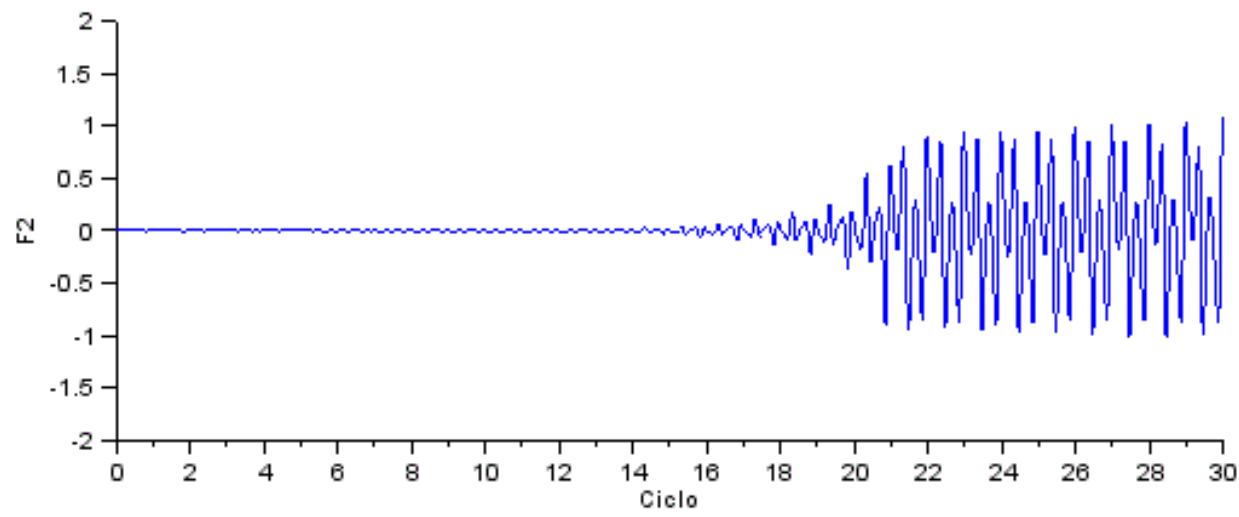

Figura 86- Forças de resistência e normal $(\operatorname{Re}=105$ e $\mathrm{KC}=10)$

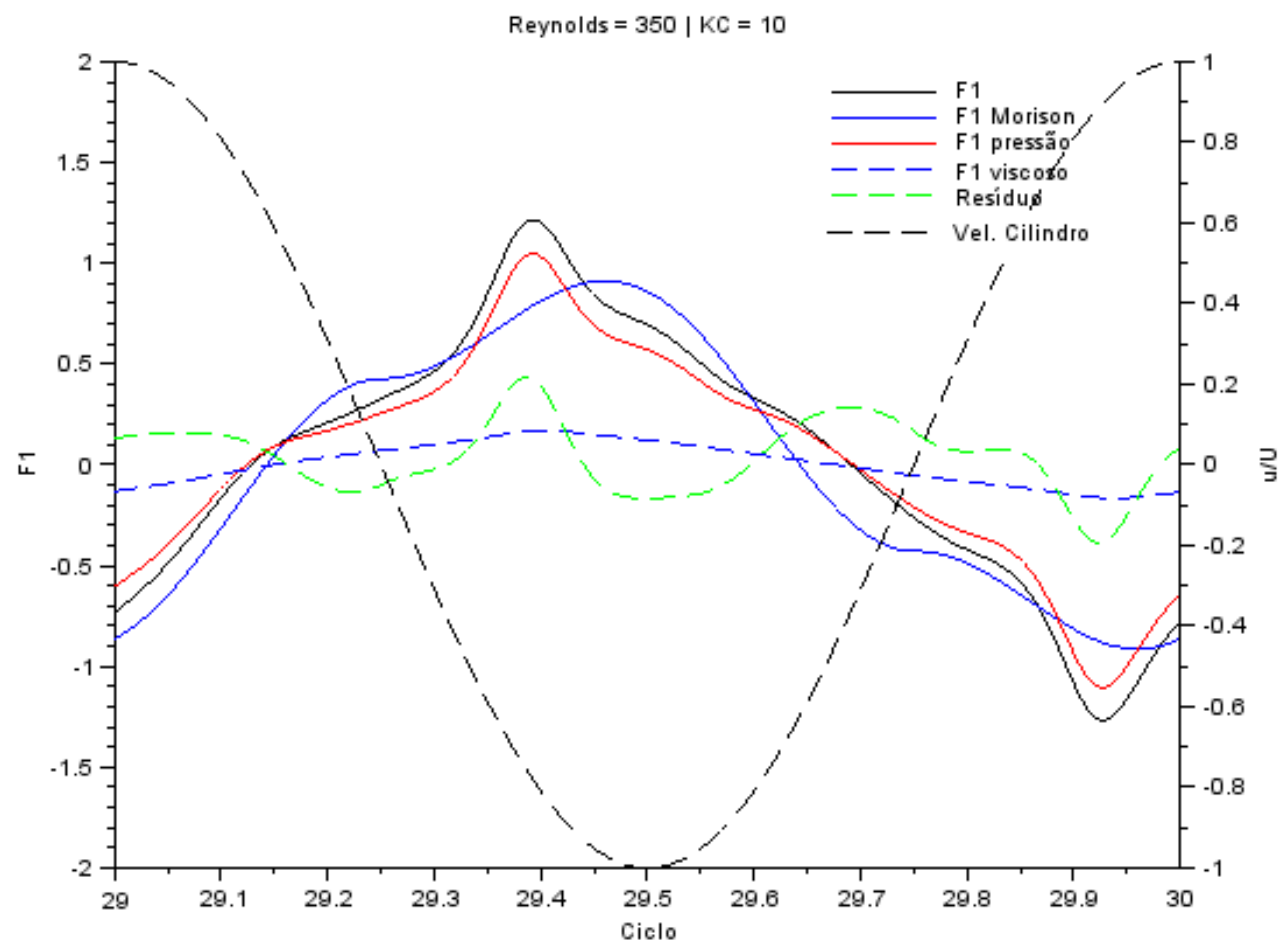

Figura 87 - Força numérica e de Morison $(\operatorname{Re}=105$ e $\mathrm{KC}=10)$ 


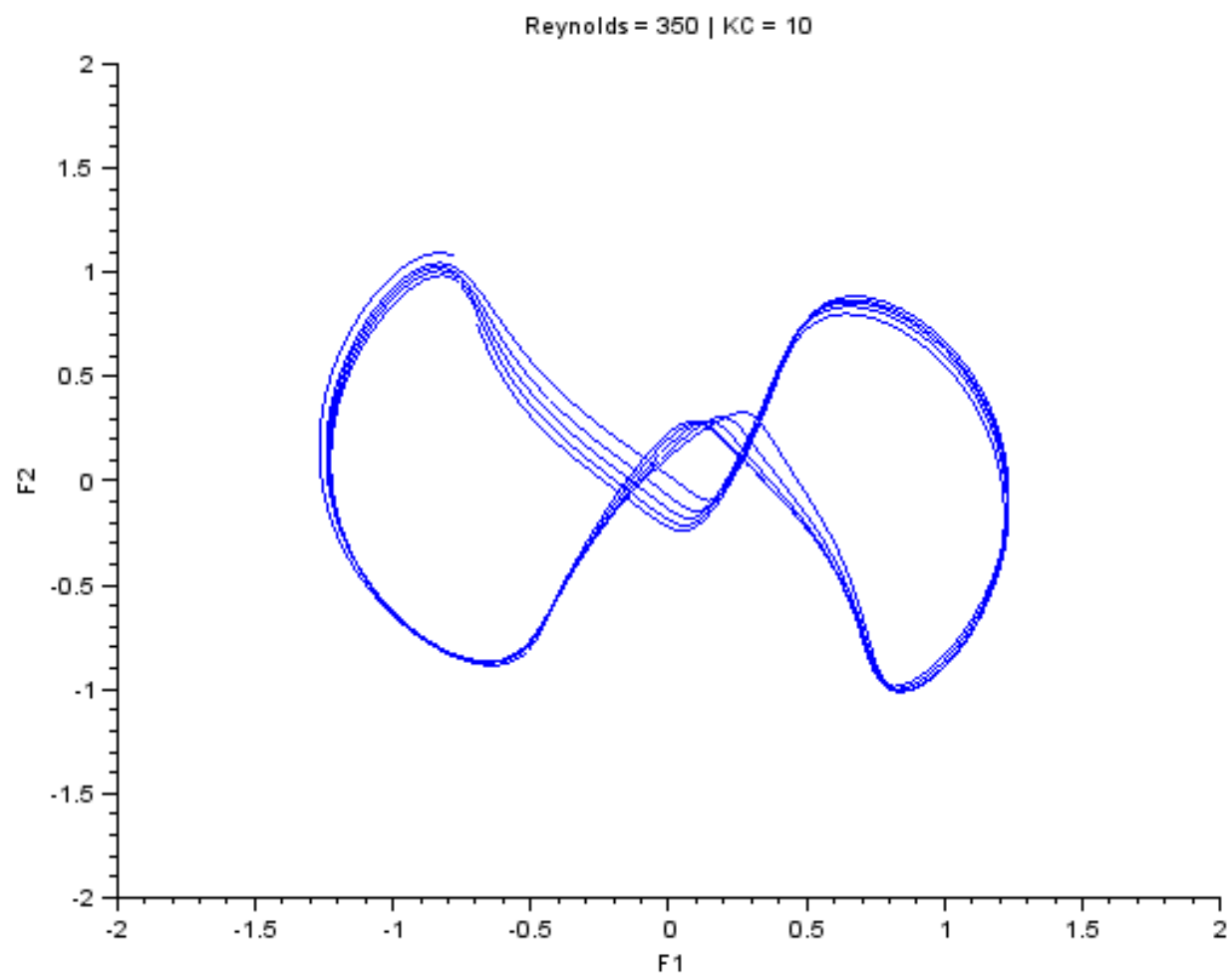

Figura 88 - Diagrama de fase da força resultante $(\operatorname{Re}=105$ e KC $=10)$

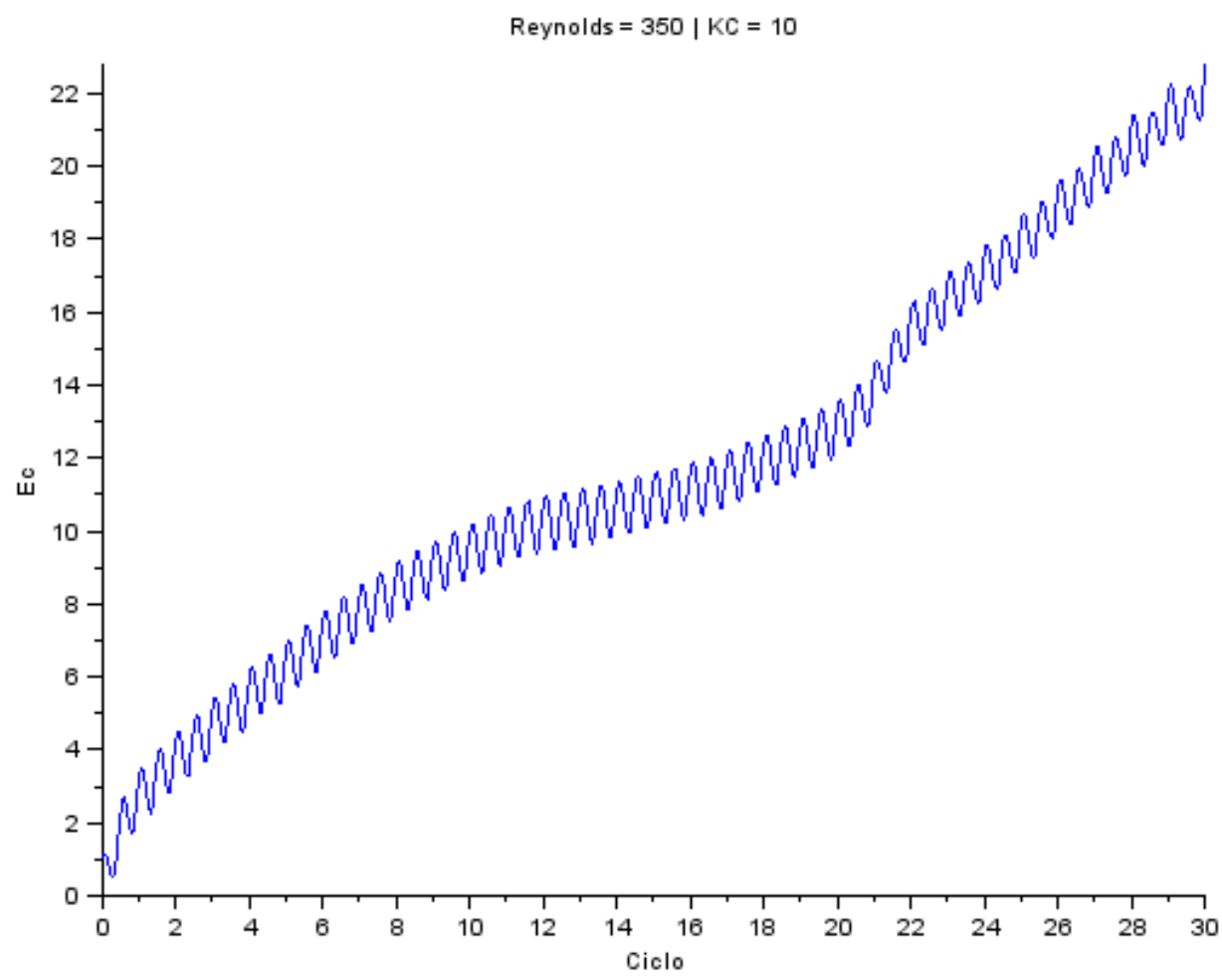

Figura 89 - Energia cinética do escoamento $(\operatorname{Re}=105$ e $\mathrm{KC}=10)$ 

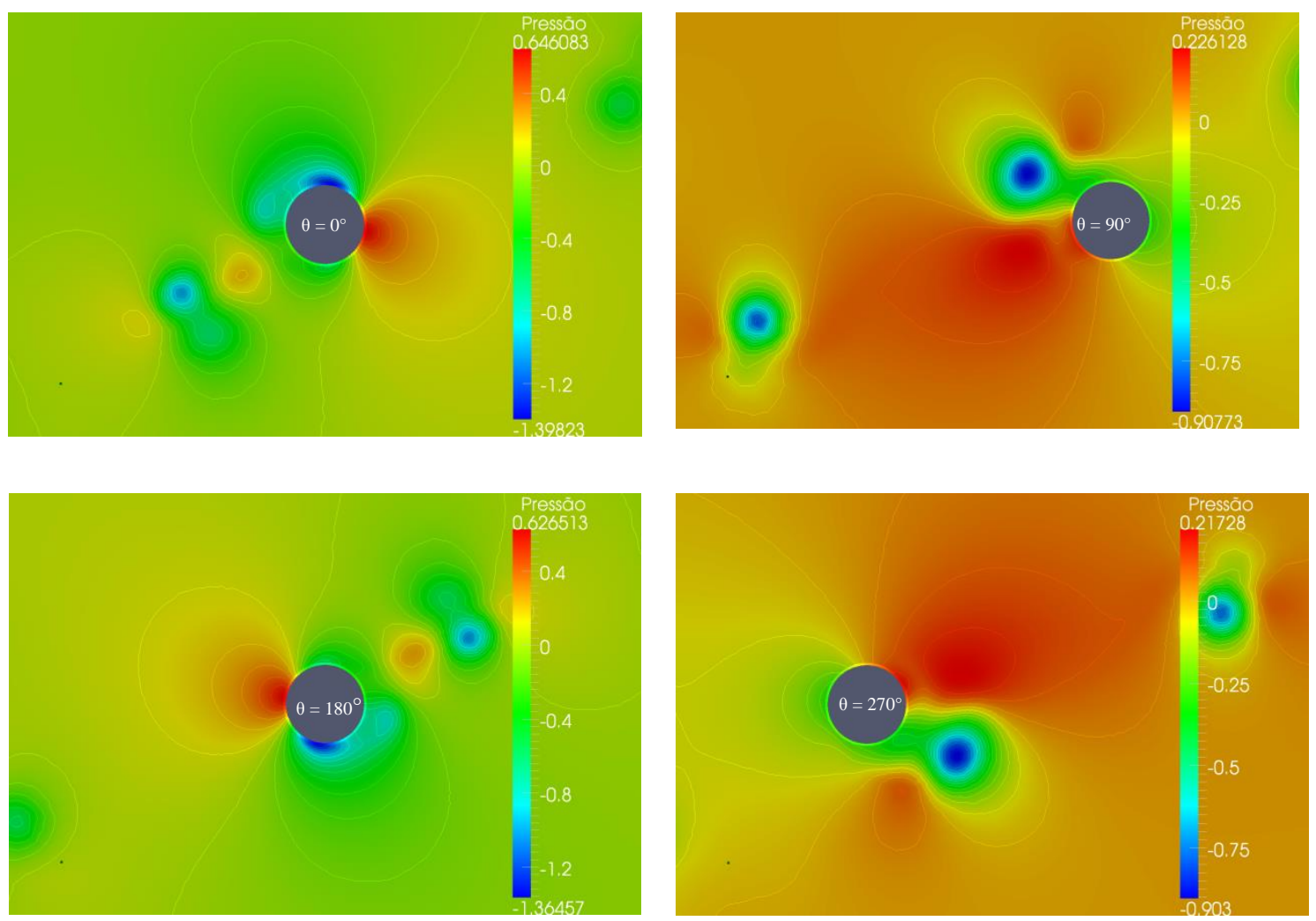

Figura 90 - Campo de pressão $(\operatorname{Re}=105$ e $\mathrm{KC}=10)$
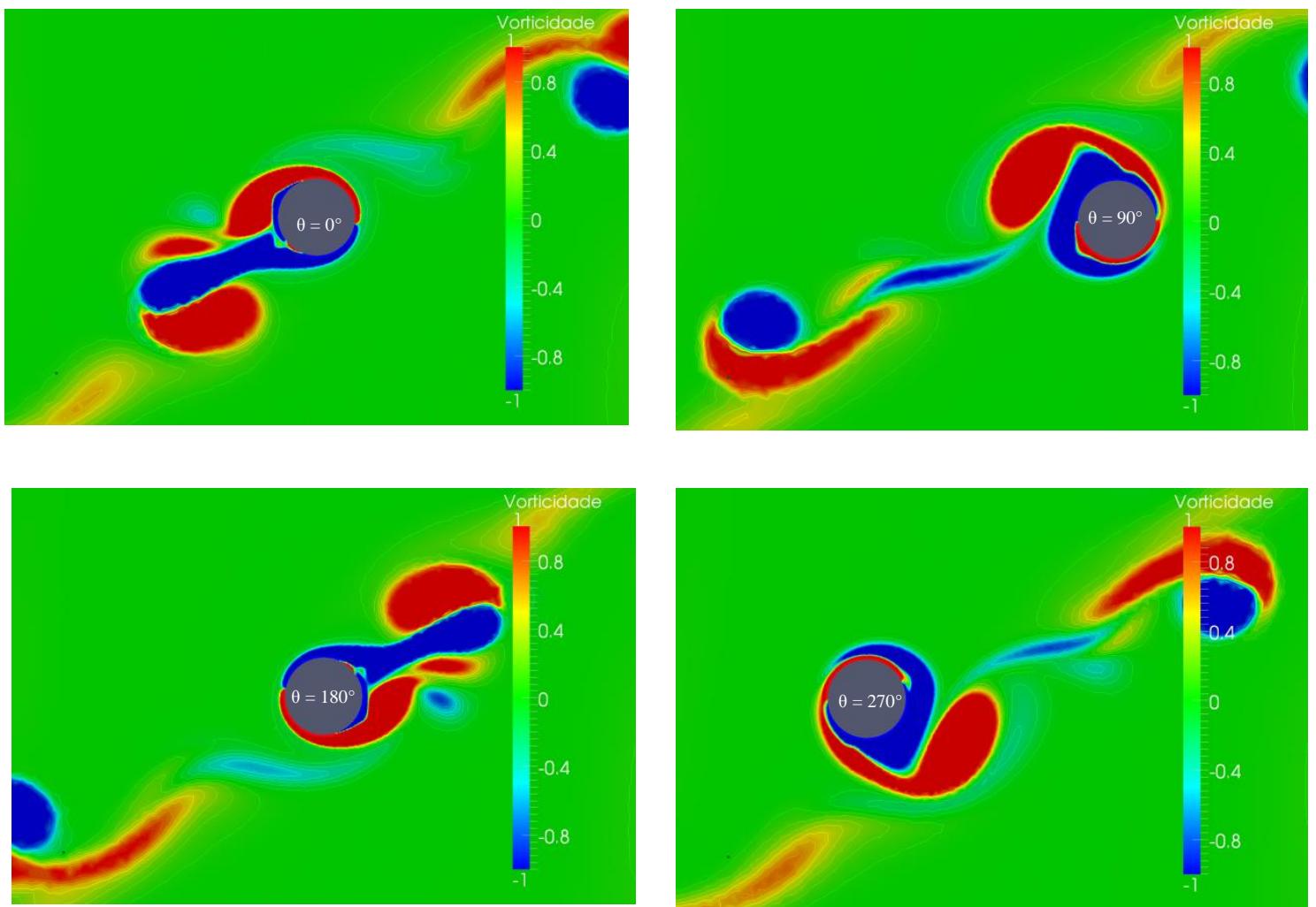

Figura 91 - Campo de vorticidade $(\operatorname{Re}=105$ e $\mathrm{KC}=10)$ 


\section{CONCLUSÃO}

Este trabalho revisitou alguns conceitos e trabalhos fundamentais sobre inércia adicional potencial e viscosa, focando o caso de um cilindro circular em movimento harmônico em um fluido em repouso ou de um cilindro em repouso e escoamento oscilatório harmônico ao longe.

Foram discutidos três métodos para calcular a massa adicional em escoamento potencial: (i) Interpretando-a como a componente inercial da força de resistência fluida, ou seja, aquela em fase com a aceleração do corpo, sendo este também um modo de indireto de estimá-la. (ii) Dentre diversos resultados clássicos, discutiu-se como a massa adicional está relacionada com a energia cinética do escoamento para uma dada condição cinemática (velocidades) do corpo. (iii) Pelo método de Darwin, a massa adicional de um corpo em translação uniforme é equivalente à massa deslocada de fluido entre uma seção perpendicular ao movimento antes e após a passagem do corpo.

A viscosidade contribui para a massa adicional, em um primeiro instante, através do aparente aumento do diâmetro do cilindro causado pela camada limite. Com o aumento da amplitude de deslocamento do cilindro, a viscosidade afeta a massa adicional através do surgimento, crescimento e emissão de vórtices. Nos instantes de velocidade nula e máxima aceleração (deslocamento máximo), formam-se uma zona de pressão elevada na frente e outra de sucção atrás do cilindro, na direção da aceleração. Essas zonas de pressão contribuem com a maior parcela da força de inércia fluida. A presença dos vórtices perturba essas zonas de pressão e afeta a força de inércia fluida significativamente.

Foram realizadas simulações numéricas do escoamento ao redor de cilindro circular em oscilação forçada para $0,5 \leq K C \leq 10$, mantendo-se fixo o parâmetro $\beta=35$. A complexidade do escoamento aumenta conforme $K C$. Nas simulações numéricas, foi utilizado o Método dos Elementos Finitos, com o uso do programa FreeFem++. O método numérico mostrou-se robusto e preciso. Os resultados possuem boa aderência com os trabalhos experimentais e numéricos disponíveis na literatura. Apesar de bidimensionais, as simulações capturaram as importantes estruturas vorticais dos regimes A*, A, E e F do diagrama de Tatsuno e Bearman (1990), e os coeficientes de massa e de arrasto da equação de Morison. Entretanto, para $K C=5$, o escoamento se manteve simétrico e não foi observada a esteira de vórtices do regime C. No regime $\mathrm{E}$, 
para $K C=6$, não foi observada a intermitência da esteira entre um lado e outro do cilindro. Para o regime $\mathrm{F}$, o padrão de vórtices se alternou apenas para $K C=9$. Esses fatos podem ser explicados pelo número limitado de ciclos simulados.

Com o cilindro oscilando rapidamente e com pequenas amplitudes de deslocamento, no intervalo $K C \leq 1$, o coeficiente de massa calculado é igual ao potencial (unitário) somada à contribuição de Stokes devida à viscosidade. Para $K C=0,5$, obteve-se $C_{A}=1,386$. Ressalta-se que os resultados de Stokes baseiam-se em um escoamento sem descolamento da camada limite, e, nas presentes simulações, a camada limite se descola muito cedo para $K C=3$. Com o aumento de $K C$ e da amplitude de oscilação, os coeficientes de massa e de arrasto começam a divergir da teoria de Stokes, como esperado. Para $K C=10$, foram obtidos $C_{A}=0,866$ e $C_{D}=1,721$. Observou-se intensa interação entre vórtices, com vórtices formados em um meio ciclo contornando o cilindro e interagindo com aqueles sendo formados do outro lado. Esta reversão de esteira influencia a futura geração de vorticidade. Para $0,5 \leq K C \leq 5$ e escoamento simétrico, os coeficientes de massa e de arrasto não dependem do ciclo. Para $K C \geq 6$, o escoamento é simétrico nos instantes iniciais e o coeficiente de massa é próximo do teórico de Stokes. A transição para o regime assimétrico causa uma variação por ciclo do coeficiente de massa até que o padrão de emissão de vórtices esteja desenvolvido. $\mathrm{O}$ coeficiente de arrasto mostrou-se fracamente dependente do ciclo de oscilação considerado.

Ao examinar em detalhe a força de resistência, a parcela inercial é dominante se comparada à parcela de arrasto, para altas frequências e baixo $K C$. As contribuições da inércia e do arrasto são da mesma ordem para $K C=6$. Com aumento de $K C$, a equação de Morison deixa de representar com rigor todas as nuances da força de resistência, conforme observado pelo aumento relativo do resíduo calculado entre elas. Em todos os casos analisados, a equação de Morison subestima a amplitude máxima e mínima da força de resistência. Essa discrepância da equação de Morison pode ser explicada pelo seu número limitado de termos. Apesar disso, ela funciona muito bem tanto para pequenos como para elevados valores de $K C$ e, por conseguinte, sua importância na engenharia é justificável e admirável. Utilizou-se a série de Fourier adicionalmente para analisar o espectro da força de resistência. $\mathrm{O}$ aumento da complexidade do escoamento é notado pelo número de harmônicos necessários para representá-la. O primeiro harmônico da força de resistência mostrou-se sempre atrasado em relação à posição do 
cilindro, e o atraso aumenta com $K C$. O ângulo de fase reduz com o aparecimento da esteira transversal e do escoamento assimétrico.

A força normal desenvolveu-se para $K C \geq 6$ nos regimes $\mathrm{E}$ e $\mathrm{F}$, assimétricos. Ela revelou-se da mesma ordem de magnitude da força de resistência e apresenta um padrão mais complexo, com harmônicos de ordem mais elevadas que àquele do movimento do cilindro. Caso o cilindro tivesse um grau de liberdade na direção normal, i.e., caso ele pudesse oscilar na vertical, a força normal seria capaz de levar a vibrações induzidas por vórtices (SUMER; FREDSØE, 1988).

\subsection{Trabalhos Futuros}

A equação de Morison é um método indireto de estimar a massa adicional, sendo conhecidos o movimento do cilindro e a força de resistência. Sugere-se o estudo teórico e o desenvolvimento de um método direto para cálculo da massa adicional com base na energia cinética do escoamento de Stokes de um cilindro em movimento harmônico.

A simulação do movimento geral, não periódico, no caso do cilindro é interessante, a fim de verificar se tal decomposição de Basset e Boussinesq da força de resistência da esfera também se verifica para o cilindro circular.

Igualmente é interessante a formulação do problema com um e dois graus de liberdade restritos elasticamente. No primeiro caso, problema análogo ao tratado por Sumer e Fredsøe (1988) seria abordado. Naquele problema é estudada a vibração em uma direção, induzida por vórtices gerados pela oscilação forçada em direção transversal. Este problema fundamental é base do estudo do fenômeno de VSIV (do inglês, Vortex Self-Induced Vibrations) que ocorre na dinâmica de risers em catenária sob excitação de movimento imposto ao topo; ver Rateiro et al. (2013), Le Cunff, Biolley e Damy (2005) e Fernandes et al. (2008a,b; 2011).

No segundo problema, sob a ação de correnteza incidente, o problema clássico de vibrações induzidas por emissão de vórtices (VIV) seria estudado. O estudo do conceito de massa adicional, na situação presente e nas duas outras situações aludidas, reserva interessantes questões, em parte abordadas em Paidoussis, Price e De Langre (2010), em seu livro texto. Particularmente no contexto de VIV com dois graus de liberdade, estudos experimentais têm mostrado a possível existência de invariantes de energia do 
meio fluido, para uma dada velocidade reduzida; ver Gonçalves et al. (2013). A abordagem numérica destas questões é sugerida fortemente.

Além disso, esforços poderiam ser envidados no sentido de:

i. Entender melhor a troca de energia entre cilindro e vórtices, principalmente para corpos susceptíveis a vibração induzida por vórtices, como o cilindro circular montado em base elástica e escoamento uniforme ou oscilatório.

ii. Realizar simulações tridimensionais, com aumento significativo de esforço computacional, dos casos apresentados, a fim de capturar a influência da tridimensionalidade do escoamento nos resultados apresentados.

iii. Desenvolver um programa específico para cálculo do tensor de massa adicional pelo método dos elementos finito ou pelo método dos elementos de fronteira para domínio grandes e geometrias complexas. 


\section{REFERÊNCIAS}

ARANHA, J. A. P. Mecânica analítica e método dos elementos finitos: equação de Navier-Stokes em domínio limitado. São Paulo: Notas de Aulas Pós-Graduação PME5020 (EPUSP), 2009.

ARIS, R. Vectors, tensors, and the basic equations of fluid mechanics. [S.1.]: Dover Publications, 1989.

BATCHELOR, G. K. An introduction to fluid dynamics. Nova Iorque: Cambridge University Press, 1967.

BEARMAN, P. W. et al. Forces on cylinder in viscous oscillatory flow at low Keulegan-Carpenter numbers. Journal of Fluid Mechanics, 154, 1985.

BRAZA, M.; CHASSAING, P.; H., H. M. Numerical study and physical analysis of the pressure and velocity fields in the near wake of a circular cylinder. Journal of Fluid Mechanics, 165, 1986.

CALHOUN, D. A cartesian grid method for solving the two-dimensional streamfunction-vorticity equations in irregular regions. Journal of Computational Physics, 176, 2002.

CASETTA, L.; PESCE, C. P. On Seliger and Whitham's variational principle for hydrodynamic systems from the point of view of 'fictitious particles'. Acta Mechanica, v. 219, 2011.

CASETTA, L.; PESCE, C. P. The generalized Hamilton's principle for a nonmaterial. Acta Mechanica, v. 224, 2013.

DABIRI, J. O. Note on the induced Lagrangian drift and added-mass of a vortex. Journal of Fluid Mechanics, 547, 2006.

DARWIN, C. Note on hydrodynamics. Proc. Cam. Phil., 49, 1953.

DUCLERCQ, M. Étude de l'interaction entre un fluide et une structure oscillante: régimes d'écoulement et de forces, du cylindre isolé au réseau de cylindres. École Polytechnique. Paris. 2010.

DÜTSH, H. et al. Low-Reynolds-number flow around an oscillating circular cylinder at low Keulegan-Carpenter numbers. Journal of Fluid Mechanics, 360, 1998. 
EAMES, I.; BELCHER, S. E.; HUNT, J. C. R. Drift, partial drift and Darwin's proposition. Journal of Fluid Mechanics, 275, 1994.

ERLSTON, J. R.; BLACKBURN, H. M.; SHERIDAN, J. The primary and secondary instabilities of flow generated by an oscillating circular cylinder. Journal of Fluid Mechanics, 550, 2006.

FERNANDES, A. C. et al. Comparisons between Full Scale and Experimental Data for Vortex Self-Induced Vibrations on Cylindrical Structures. Proceedings ot the 9th International Conference Flow Induced Vibration (FIV), 2008.

FERNANDES, A. C. et al. VSIV (Vortex Self-Induced Vibration) Kinematics. Proceedings of the ASME 2008 27th International Conference on Offshore Mechanics and Arctic Engineering, v. 5, 2008.

FERNANDES, A. C. et al. Further Investigations on Vortex Self Induced Vibration (VSIV). Proceedings of the ASME 2011 30th International Conference on Ocean, Offshore and Arctic Engineering, v. 7, 2011.

FERZIGER, J. H. Numerical methods for engineering application. $2^{\circ}$. ed. [S.1.]: Wiley Interscience, 1998.

FORNBERG, B. A numerical study of steady viscous flow past a circular cylinder, 98, 1980.

GIORIA, R. S. Estudo da estabilidade secundária da esteira de um cilindro em oscilação forçada. Escola Politécnica da Universidade de São Paulo: Tese de Doutorado, 2010.

GONÇALVES, R. T. et al. Two-degree-of-freedom vortex-induced vibration of circular cylinders with very low aspect ratio and small mass ratio. Journal of Fluid and Structures, v. 39, 2013.

GREEN, G. Researches on the vibration of pendulums in fluid media. Trans. Royal Soc. of Edinburgh, 1833.

GRESHO, P. M.; SANI, R. L. Incompressible flow and the finite element method. [S.1.]: John Wiley, v. I e II, 2000.

HALL, P. On the stability of unsteady boundary layer on a cylinder oscillating transversely in a viscous fluid. Journal of Fluid Mechanics, 146, 1984. 
HAMILTON, W. S. Fluid force on accelerating bodies. Proceedings of the International Conference on Coastal Engineering, 13, 1972.

HONGWE, A.; L., C.; ZHAO, M. Direct numerical simulation of oscillatory flow around a circular cylinder at low Keulegan-Carpenter number. Journal of Fluid Mechanics, 666, 2010.

HONJI, H. Streaked flow around an oscillating circular cylinder. Journal of Fluid Mechanics, 107, 1981.

ILIADIS, G.; ANAGNOSTOPOULOS, P. Viscous oscillatory flow around a circular cylinder at low Keulegan-Carpenter numbers and frequency parameters. International Journal for Numerical Methods in Fluids, 26, 1998.

JUSTESEN, P. A numerical study of oscillating flow around a circular cylinder. Journal of Fluid Mechanics, 222, 1991.

KEULEGAN, G. H.; CARPENTER, L. H. Forces on cylinders and plates in an oscillating fluid. Journal of Research of the National Bureau of Standards, 60, 1958.

KIRCHHOFF, G. Ueber die Bewegung eines Rotaionskörpers in einer Flüssigkeit. Crelle, 1870.

KOROTKIN, A. I. Added masses of ship structures. [S.1.]: Springer, 2010.

KÜHTZ, S. Experimental investigation of oscillatory flow around circular cylinders at low beta numbers. Imperial College London. 1996.

LAMB, H. Hydrodynamics. : Dover Publications, 1932.

LE CUNFF, C.; BIOLLEY, F.; DAMY, G. Experimental and Numerical Study of Heave-Induced Lateral Motion (HILM). Proceedings of the ASME 2005 24th International Conference on Offshore Mechanics and Arctic Engineering, v. 3, 2005.

LI, L.; SHERWIN, S. J.; BEARMAN, P. W. A moving frame of reference algorithm for fluid/structure interaction of rotating and translating bodies. Int. Journal for Numerical Methods in Fluids, v. 38, 2000.

LIGHTHILL, M. J. Fundamentals concerning wave loading on offshore structures. Journal of Fluid Mechanics, 173, 1986. 
LIN, X. W.; BEARMAN, P. W.; GRAHAM, J. M. R. A numerical study of oscillatory flow about a circular cylinder for low values of beta parameter. Journal of Fluids and Structures, 10, 1996.

LIU, C.; ZHENG, X.; SUNG, C. H. Preconditioned multigrid methods for unsteady incompressible flows. Journal of Computational Physics, 139, 1998.

MAXEY, M. R.; RILEY, J. J. Equation of motion for a small rigid sphere in a uniform flow. Phys. Fluids, 24, 1983.

MENEGHINI, J. R.; BEARMAN, P. W. Numerical simulation of high amplitude oscillatory flow about a circular cylinder. Journal of Fluids and Structures, v. 9, 1995.

MORISON, J. R.; JOHNSON, J. W.; SCHAAF, S. A. The force exerted by surface waves on piles. Petroleum Transactions, 189, 1950.

NEHARI, D.; ARMENIO, V.; BALLIO, F. Three-dimensional analysis of the unidirectional oscillatory flow around a circular cylinder at low Keulegan-Carpenter and Beta numbers. Journal of Fluid Mechanics, 520, 2004.

OLDHAM, K. B.; SPANIER, J. The fractional calculus. [S.1.]: Dover Publications, 2006.

PAIDOUSSIS, M. P.; PRICE, S. J.; DE LANGRE, E. Fluid-Structure Interactions: Cross-Flow-Induced Instabilities. [S.1.]: Cambridge University Press, 2010.

RATEIRO, F. et al. A model scale experimental investigation on Vortex SelfInduced Vibrations (VSIV) of catenary risers. Proceedings of the ASME 2013 32th International Conference on Ocean, Offshore and Artic Engineering, 2013.

SARPKAYA, T. In-line and transverse forces on smooth and sand-roughened cylinders in oscillatory flow at high Reynolds numbers. Naval Postgraduate School. Monterey, California. 1976.

SARPKAYA, T. In-line and transverse forces on cylinders in oscillatory flow at high Reynolds numbers. Journal of Ship Research, 21, 1977.

SARPKAYA, T. Force on a circular cylinder in viscous oscillatory flow at low Keulegan-Carpenter numbers. Journal of Fluid Mechanics, 165, 1986. 
SARPKAYA, T. On the force decompositions of Lighthill and Morison. Journal of Fluids and Structures, 15, 2001.

SARPKAYA, T. On the parameter $\beta=\mathrm{Re} / \mathrm{KC}=\mathrm{D}^{2} / v \mathrm{~T}$. Journal of Fluids and Structures, 21, 2005.

SARPKAYA, T. Wave forces on offshore structures. [S.1.]: Cambridge, 2010.

SCHLICHTING, H.; GERSTEN, K. Boundary Layer Theory. Oitava. ed. [S.1.]: Springer-Verlag, 2000.

SELIGER, R. L.; WHITHAM, G. B. Variational principles in continuum mechanics. Proc. R. Soc. Lond. A, 305, 1968.

STOKES, G. G. On the effect of internal friction on the motion of pendulums. Trans. Cambr. Phil. Soc., 9, 1850.

SUMER, B. M.; FREDSØE, J. Transverse Vibrations of an Elastically Mounted Cylinder Exposed to an Oscillating Flow. Journal of Offshore Mechanics and Artic Engineering, v. 110, 1988.

TATOM, F. B. The Basset term as a semiderivative. Applied Scientific Research, $45,1988$.

TATSUNO, M.; BEARMAN, P. W. A visual study of the flow around an oscillating circular cylinder at low Keulegan-Carpenter numbers and low Stokes numbers. Journal of Fluid Mechanics, 211, 1990.

TRITTON, D. J. Experiments on the flow past a circular cylinder at low Reynolds numbers. Journal of Fluid Mechanics, 6, 1959.

UZUNOĞLU, B.; TAN, M.; PRICE, W. G. Low-Reynolds-number flow around an oscillating circular cylinder using a cell viscous boundary element method. Int. Journal for Numerical Methods in Engineering, 50, 2001.

WANG, C.-Y. On high frequency oscillating viscous flows. Journal of Fluid Mechanics, 32, 1968.

YANG, Y.; ROCKWELL, D. Wave interaction with a vertical cylinder: spanwise flow patterns and loading. Journal of Fluid Mechanics, 460, 2002.

YIH, C.-S. Stream functions in three-dimensional flows. La Houille Blanche, 3, 1957. 
YIH, C.-S. New derivations of Darwin's theorem. Journal of Fluid Mechanics, 152, 1985.

ZIENKIWICZ, O. C.; TAYLOR, R. L.; NITHIARASU, P. The finite element method for fluid dynamics. 6. ed. [S.1.]: Butterworth-Heinemann, v. 3, 2005. 


\section{APÊNDICE A - MÉTODO DOS ELEMENTOS FINITOS}

Este apêndice foi elaborado baseando-se nas referências de Gresho e Sani (2000), Zienkiwicz, Taylor e Nithiarasu (2005) e Aranha (2009).

Para aplicação do método dos elementos finitos, é necessária uma formulação integral da equação de NS. Multiplica-se a equação de NS (30) por uma função-teste $\delta u_{i}$, e integra-se no domínio $\Omega$ (limitado):

$$
\int_{\Omega} \delta u_{i} \frac{1}{K C} \frac{\partial u_{i}}{\partial t}+\delta u_{i} u_{j} \frac{\partial u_{i}}{\partial x_{j}} d \Omega=\int_{\Omega} \delta u_{i}\left(-\frac{\partial p}{\partial \mathrm{x}_{i}}+\frac{1}{R e} \frac{\partial^{2} u_{i}}{\partial x_{j} \partial x_{j}}-\frac{1}{K C} \ddot{r}_{i}\right) d \Omega
$$

Aplica-se então o teorema da divergência de Gauss nos termos de pressão e difusivo:

$$
\begin{gathered}
\int_{\Omega} \delta u_{i} \frac{1}{K C} \frac{\partial u_{i}}{\partial t}+\delta u_{i} u_{j} \frac{\partial u_{i}}{\partial x_{j}}+\frac{1}{R e} \frac{\partial \delta u_{i}}{\partial x_{j}} \frac{\partial u_{i}}{\partial x_{j}}-\frac{\partial \delta u_{i}}{\partial \mathrm{x}_{i}} p d \Omega= \\
-\int_{\Omega} \delta u_{i} \frac{1}{K C} \ddot{r}_{i} d \Omega+\int_{\Gamma^{N}} \delta u_{i}\left(-p n_{i}+\frac{1}{R e} \frac{\partial u_{i}}{\partial x_{j}} n_{j}\right) d \Gamma
\end{gathered}
$$

A fronteira do domínio é particionada em $\Gamma=\Gamma^{D}+\Gamma^{N}$, com $\bar{\Omega}=\Omega+\Gamma$, o domínio e seu fechamento. $\mathrm{O}$ contorno $\Gamma^{D}$ corresponde àquele na qual a velocidade é conhecida, e faz-se a função-teste identicamente nula, $\delta u_{i}=0$. No contorno $\Gamma^{N}$, a velocidade é desconhecida e usualmente faz-se $-p n_{i}+\frac{1}{R e} \frac{\partial u_{i}}{\partial x_{j}} n_{j}=0$. Essas condições de contorno são denominadas, respectivamente, de Dirichlet e de Neumann.

Em seguida, o domínio $\Omega$ é discretizado em uma quantidade ne de elementos $\Omega_{e}$ adjacentes, no caso escolhidos como triangulares. Este processo corresponde à geração da malha, e a solução numérica converge para a solução exata, à medida que se refina esta malha. Os elementos são conectados entre si pelos nós das arestas comuns. Ao dividir o domínio, as fronteiras curvas são aproximadas.

$$
\Omega=\bigcup_{e=1}^{n e} \Omega_{e} \mathrm{e} \bigcap_{e=1}^{n e} \Omega_{e}=\varnothing
$$


Aproxima-se a integral no domínio da equação (66) por uma soma de integrais nos subdomínios dos elementos $\Omega_{e}$, e similarmente para a integral na fronteira:

$$
\int_{\Omega} d \Omega \approx \sum_{e=1}^{n e} \int_{\Omega^{e}} d \Omega_{e} \mathrm{e} \int_{\Gamma^{N}} d \Gamma \approx \sum_{b=1}^{n b} \int_{\Gamma_{b}^{N}} d \Gamma_{b}^{N}
$$

A equação de NS (66) na forma fraca é reescrita como:

$$
\begin{gathered}
\sum_{e=1}^{n e} \int_{\Omega_{e}} \delta u_{i} \frac{1}{K C} \frac{\partial u_{i}}{\partial t}+\delta u_{i} u_{j} \frac{\partial u_{i}}{\partial x_{j}}+\frac{1}{R e} \frac{\partial \delta u_{i}}{\partial x_{j}} \frac{\partial u_{i}}{\partial x_{j}}-p \frac{\partial \delta u_{i}}{\partial \mathrm{x}_{i}} d \Omega_{e} \\
=\sum_{e=1}^{n e} \int_{\Omega_{e}}-\delta u_{i} \frac{1}{K C} \ddot{r}_{i} d \Omega_{e} \\
+\sum_{b=1}^{n b} \int_{\Gamma_{b}^{N}} \delta u_{i}\left(-p n_{i}+\frac{1}{R e} \frac{\partial u_{i}}{\partial x_{j}} n_{j}\right) d \Gamma_{b}^{N}
\end{gathered}
$$

Dentro do elemento, a solução é aproximada por uma combinação linear das velocidades e pressões nodais (incógnitas) e de funções de interpolação. As funções de interpolação, também denominadas funções de forma ou de base, aproximam a solução dentro do subdomínio por polinômios lineares ou de ordem superior, são unitárias nos nós, alternadamente, e identicamente nulas fora do subdomínio. O subdomínio, os nós pertencentes a ele (internos e na fronteira) e as funções de interpolação constituem um elemento finito. Em princípio, emprega-se o método dos resíduos ponderados na formulação de Galerkin, no qual as funções-teste são iguais às funções de base. Neste trabalho utilizam-se elementos triangulares com 3 nós por aresta (total de 6 nós), denominado $\mathrm{P}_{2} \mathrm{P}_{1}$ :

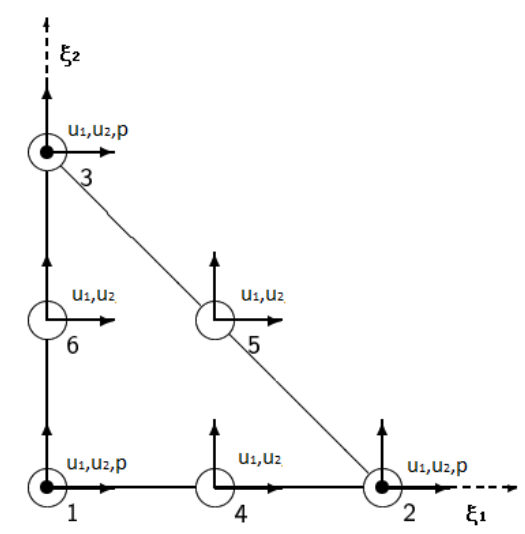

Figura 92 - Elemento triangular $\mathbf{P}_{2} \mathbf{P}_{1}$ 
Com elementos triangulares é comum utilizar coordenadas triangulares ou coordenadas naturais de triângulo $\left(\xi_{1}, \xi_{2}\right)$. Considere um ponto $\mathrm{P}$ de coordenadas cartesianas $\left(x_{1}, x_{2}\right)$ no interior do triângulo de vértices 1,2 e 3 :

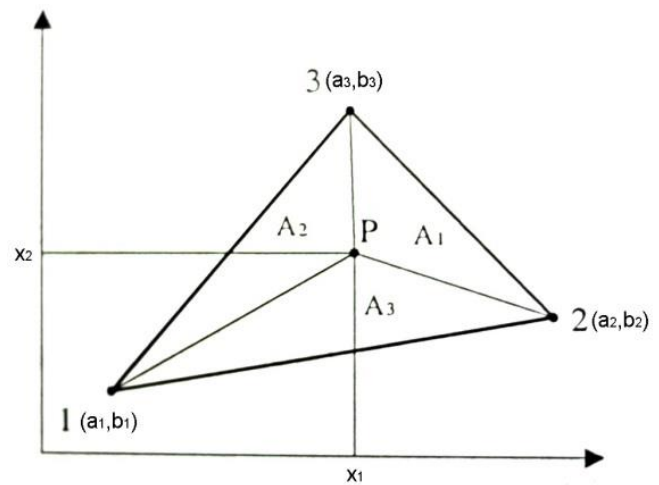

Figura 93 - Áreas formadas entre o ponto P e os vértices do triângulo

$\mathrm{O}$ ponto $\mathrm{P}$ forma com os vértices dos triângulos as áreas $A_{1}, A_{2}$ e $A_{3}$. As coordenadas naturais são obtidas pela razão entre a área $A_{e}$ do triângulo e aquelas áreas $A_{1}, A_{2}$ e $A_{3}$ :

$$
\xi_{1}=\frac{A_{1}}{A_{e}} \quad \xi_{2}=\frac{A_{2}}{A_{e}} \quad \xi_{3}=\frac{A_{3}}{A_{e}}=1-\xi_{1}-\xi_{2}
$$

No desenvolvimento a seguir será importante mapear as coordenadas cartesianas nas coordenadas naturais. Sendo conhecidas as coordenadas cartesianas do ponto $\mathrm{P}$ e dos respectivos vértices do triângulo, o mapeamento entre os espaços $\xi_{1} \xi_{2}$ e $x_{1} x_{2}$ é dado por:

$$
\xi_{1}=\frac{1}{2 A_{e}}\left|\begin{array}{lll}
1 & x_{1} & x_{2} \\
1 & a_{2} & b_{2} \\
1 & a_{3} & b_{3}
\end{array}\right| \quad \xi_{2}=\frac{1}{2 A_{e}}\left|\begin{array}{ccc}
1 & a_{1} & b_{1} \\
1 & x_{1} & x_{2} \\
1 & a_{3} & b_{3}
\end{array}\right| \quad \xi_{3}=\frac{1}{2 A_{e}}\left|\begin{array}{lll}
1 & a_{1} & b_{1} \\
1 & a_{2} & b_{2} \\
1 & x_{1} & x_{2}
\end{array}\right|
$$

Expandindo o determinante, obtêm-se:

$$
\begin{aligned}
& \xi_{1}=\frac{1}{2 A_{e}}\left|\left(b_{2}-b_{3}\right) x_{1}+\left(a_{3}-a_{2}\right) x_{2}+a_{2} b_{3}-a_{3} b_{2}\right| \\
& \xi_{2}=\frac{1}{2 A_{e}}\left|\left(b_{3}-b_{1}\right) x_{1}+\left(a_{1}-a_{3}\right) x_{2}+a_{3} b_{1}-a_{1} b_{3}\right| \\
& \xi_{3}=\frac{1}{2 A_{e}}\left|\left(b_{1}-b_{2}\right) x_{1}+\left(a_{2}-a_{1}\right) x_{2}+a_{1} b_{2}-a_{2} b_{1}\right|
\end{aligned}
$$

Adicionalmente, define-se a matriz jacobiana da transformação como: 


$$
[J]^{e}=\left[\begin{array}{ll}
\frac{\partial x_{1}}{\partial \xi_{1}} & \frac{\partial x_{2}}{\partial \xi_{1}} \\
\frac{\partial x_{1}}{\partial \xi_{2}} & \frac{\partial x_{2}}{\partial \xi_{2}}
\end{array}\right]
$$

Do cálculo diferencial é sabido que o determinante do jacobiano expressa a correspondência entre áreas infinitesimais nos espaços $x_{1} x_{2}$ e $\xi_{1} \xi_{2}$, respectivamente, $d x_{1} d x_{2}$ e $d \xi_{1} d \xi_{2}:$

$$
d \Omega_{e}=d x_{1} d x_{2}=\operatorname{det}\left([J]^{e}\right) d \xi_{1} d \xi_{2}
$$

No elemento $\mathrm{P}_{2} \mathrm{P}_{1}$, as funções de forma para a pressão são polinômios lineares nas coordenadas naturais. O campo de pressão é escrito como uma combinação linear entre a pressão nos vértices (3 nós) do elemento com as funções de forma:

$$
p^{e}=\sum_{j=1}^{3} N_{j} p_{j}^{e}=\left[\begin{array}{lll}
N_{1} & N_{2} & N_{3}
\end{array}\right]^{e}\left\{\begin{array}{l}
p_{1} \\
p_{2} \\
p_{3}
\end{array}\right\}^{e}=[N]^{e}\{p\}^{e}
$$

Na qual:

$$
N_{1}=\xi_{1} \quad N_{2}=\xi_{2} \quad N_{3}=\xi_{3}
$$

$\mathrm{O}$ campo de velocidades no elemento $\mathrm{P}_{2} \mathrm{P}_{1}$ é aproximado por funções de forma de segunda ordem (polinômios quadráticos) nas coordenadas naturais. Neste caso, são necessários nós intermediários nas arestas. Optou-se por funções de forma de segunda ordem para a velocidade, a fim de se obter maior precisão nos cálculos das forças viscosas e do campo de vorticidade. O campo de velocidades é uma combinação linear entre a velocidade nos nós do elemento (6 nós) com as funções de forma:

$$
u_{i}^{e}=\sum_{j=1}^{6} N_{j} u_{i, j}^{e}=\left[\begin{array}{llll}
N_{1} & N_{2} & \ldots & N_{6}
\end{array}\right]^{e}\left\{\begin{array}{c}
u_{i, 1} \\
u_{i, 2} \\
\vdots \\
u_{i, 6}
\end{array}\right\}^{e}=[N]^{e}\left\{u_{i}\right\}^{e}
$$

Na qual:

$$
\begin{array}{ll}
N_{1}=\xi_{1}\left(2 \xi_{1}-1\right) & N_{4}=4 \xi_{1} \xi_{2} \\
N_{2}=\xi_{2}\left(2 \xi_{2}-1\right) & N_{5}=4 \xi_{2} \xi_{3} \\
N_{3}=\xi_{3}\left(2 \xi_{3}-1\right) & N_{6}=4 \xi_{1} \xi_{3}
\end{array}
$$


$\mathrm{Na}$ formulação de Galerkin, utilizam-se as mesmas funções de forma para as funções-teste. Em resumo, escreve-se:

$$
\begin{array}{cc}
u_{1}^{e}=[N]^{e}\left\{u_{1}\right\}^{e} & \delta u_{1}^{e}=[N]^{e}\left\{\delta u_{1}\right\}^{e} \\
u_{2}^{e}=[N]^{e}\left\{u_{2}\right\}^{e} & \delta u_{2}^{e}=[N]^{e}\left\{\delta u_{2}\right\}^{e} \\
p^{e}=[N]^{e}\{p\}^{e} & \delta p^{e}=[N]^{e}\{\delta p\}^{e}
\end{array}
$$

As derivadas espaciais são diretamente obtidas pelas derivadas das funções de forma:

$$
\left[\begin{array}{c}
\frac{\partial u_{i}}{\partial x_{1}} \\
\frac{\partial u_{i}}{\partial x_{2}}
\end{array}\right]=\left[\begin{array}{llll}
\frac{\partial N_{1}}{\partial x_{1}} & \frac{\partial N_{2}}{\partial x_{1}} & \ldots & \frac{\partial N_{6}}{\partial x_{1}} \\
\frac{\partial N_{1}}{\partial x_{2}} & \frac{\partial N_{2}}{\partial x_{2}} & \ldots & \frac{\partial N_{6}}{\partial x_{2}}
\end{array}\right]^{e}\left\{\begin{array}{c}
u_{i, 1} \\
u_{i, 2} \\
\vdots \\
u_{i, 6}
\end{array}\right\}^{e}=\left[\begin{array}{c}
B_{1} \\
B_{2}
\end{array}\right]^{e}\left\{u_{i}\right\}^{e}
$$

Novamente a matriz jacobiana da transformação permite relacionar as derivadas espaciais no espaço $x_{1} x_{2}$ com aquelas no espaço $\xi_{1} \xi_{2}$ :

$$
\left[\begin{array}{l}
B_{1} \\
B_{2}
\end{array}\right]^{e}=[J]^{e^{-1}}\left[\begin{array}{llll}
\frac{\partial N_{1}}{\partial \xi_{1}} & \frac{\partial N_{2}}{\partial \xi_{1}} & \ldots & \frac{\partial N_{6}}{\partial \xi_{1}} \\
\frac{\partial N_{1}}{\partial \xi_{2}} & \frac{\partial N_{2}}{\partial \xi_{2}} & \ldots & \frac{\partial N_{6}}{\partial \xi_{2}}
\end{array}\right]^{e}
$$

A derivada local da equação de NS originará a matriz de massa $[M]$ do sistema discreto ao substituir a aproximação do campo de velocidades e as funções-teste da equação (79) no primeiro termo da equação (66):

$$
\begin{gathered}
\int_{\Omega} \delta u_{i} \frac{1}{K C} \frac{\partial u_{i}}{\partial t} d \Omega=\sum_{e=1}^{n e} \int_{\Omega_{e}} \frac{1}{K C}\left([N]^{e}\left\{\delta u_{i}\right\}^{e}\right)^{T} \frac{\partial[N]^{e}\left\{u_{i}\right\}^{e}}{\partial t} d \Omega_{e} \\
=\sum_{e=1}^{n e}\left\{\delta u_{i}\right\}^{e^{T}} \frac{1}{K C}\left(\int_{\Omega_{e}}[N]^{e^{T}}[N]^{e} d \Omega_{e}\right) \frac{\partial\left\{u_{i}\right\}^{e}}{\partial t}
\end{gathered}
$$

A integral do produto entre funções de forma origina a matriz de massa do elemento $\Omega_{e}$. Ressalta-se que ela é simétrica por construção:

$$
[M]^{e}=\int_{\Omega_{e}}[N]^{e^{T}}[N]^{e} d \Omega_{e}
$$


O segundo termo da equação de NS, a derivada convectiva, origina a matriz de rigidez, não-simétrica e não-linear, do sistema discreto. Inicialmente a integral no domínio é aproximada por uma soma de integrais nos subdomínios dos elementos $\Omega_{e}$ :

$$
\int_{\Omega} \delta u_{i} u_{j} \frac{\partial u_{i}}{\partial x_{j}} d \Omega=\sum_{e=1}^{n e} \int_{\Omega_{e}} \delta u_{i} u_{j} \frac{\partial u_{i}}{\partial x_{j}} d \Omega_{e}
$$

Em seguida, substituem-se as aproximações do campo de velocidades e da funçãoteste:

$$
\begin{aligned}
& \int_{\Omega_{e}} \delta u_{i} u_{j} \frac{\partial u_{i}}{\partial x_{j}} d \Omega_{e} \\
& =\sum_{e=1}^{n e} \int_{\Omega_{e}}\left([N]^{e}\left\{\delta u_{i}\right\}^{e}\right)^{T}\left(\left[[N]^{e}\left\{u_{1}\right\}^{e}[]^{e}\left\{u_{2}\right\}^{e}\right]\left[\begin{array}{l}
B_{1} \\
B_{2}
\end{array}\right]^{e}\left\{u_{i}\right\}^{e}\right) d \Omega_{e}
\end{aligned}
$$

Reorganizando os termos:

$$
\begin{aligned}
& \int_{\Omega_{e}} \delta u_{i} u_{j} \frac{\partial u_{i}}{\partial x_{j}} d \Omega_{e} \\
& =\sum_{e=1}^{n e}\left\{\delta u_{i}\right\}^{e T} \int_{\Omega_{e}}[N]^{e T}\left(\left[[N]^{e}\left\{u_{1}\right\}^{e}[N]^{e}\left\{u_{2}\right\}^{e}\right]\left[\begin{array}{l}
B_{1} \\
B_{2}
\end{array}\right]^{e}\right) d \Omega_{e}\left\{u_{i}\right\}^{e}
\end{aligned}
$$

A parcela central corresponde à matriz de rigidez do termo convectivo do elemento:

$$
[N(u)]^{e}=\int_{\Omega_{e}}[N]^{e^{T}}\left(\left[[N]^{e}\left\{u_{1}\right\}^{e} \quad[N]^{e}\left\{u_{2}\right\}^{e}\right]\left[\begin{array}{l}
B_{1} \\
B_{2}
\end{array}\right]^{e}\right) d \Omega_{e}
$$

A não-simetria e a não-linearidade da matriz de rigidez $[N(u)]$ ocasionam dificuldades e instabilidades na resolução numérica do escoamento. Conforme visto, neste trabalho ela foi tratada implicitamente, i.e., seus coeficientes eram recalculados (iterados) dentro de cada passo de tempo até que a solução convergisse.

O termo dissipativo da equação de NS resulta também em uma matriz de "rigidez", entretanto, simétrica e linear. Procedendo de maneira similar: 


$$
\int_{\Omega_{e}} \frac{1}{R e} \frac{\partial \delta u_{i}}{\partial x_{j}} \frac{\partial u_{i}}{\partial x_{j}} d \Omega_{e}=\sum_{e=1}^{n e} \int_{\Omega_{e}} \frac{1}{R e}\left(\left[\begin{array}{l}
B_{1} \\
B_{2}
\end{array}\right]^{e}\left\{\delta u_{i}\right\}^{e}\right)^{T}\left(\left[\begin{array}{l}
B_{1} \\
B_{2}
\end{array}\right]^{e}\left\{u_{i}\right\}^{e}\right) d \Omega_{e}
$$

Obtém-se a matriz de "rigidez" do termo dissipativo para o elemento:

$$
[K]^{e}=\int_{\Omega_{e}}\left[\begin{array}{l}
B_{1} \\
B_{2}
\end{array}\right]^{e T}\left[\begin{array}{l}
B_{1} \\
B_{2}
\end{array}\right]^{e} d \Omega_{e}
$$

A matriz do elemento para o termo de pressão da equação de NS e para a equação da continuidade (2) são similares. De fato, uma é a transposta da outra. Ao substituir a derivada da função-teste da velocidade e a aproximação do campo de pressão no termo de pressão da equação (66), obtém-se:

$$
\int_{\Omega}-\frac{\partial \delta u_{i}}{\partial \mathrm{x}_{i}} p d \Omega_{e}=\sum_{e=1}^{n e}\left\{\delta u_{i}\right\}^{e^{T}} \int_{\Omega^{e}}\left[B_{i}\right]^{e^{T}}[N]^{e} d \Omega_{e}\{p\}^{e}
$$

Define-se a matriz do termo de pressão para o elemento como:

$$
[C]^{e}=\int_{\Omega_{e}}\left[B_{i}\right]^{e^{T}}[N]^{e} d \Omega_{e}
$$

Procede-se similarmente para a equação da continuidade (2), i.e, multiplicando por uma função-teste $\delta p$ e integrando no domínio $\Omega$ :

$$
\int_{\Omega} \delta p \frac{\partial u_{i}}{\partial x_{i}} d \Omega_{e}=\sum_{e=1}^{n e}\{\delta p\}^{e^{T}} \int_{\Omega^{e}}[N]^{e^{T}}\left[B_{i}\right]^{e} d \Omega_{e}\left\{u_{i}\right\}^{e}=0
$$

A matriz do elemento para a equação da continuidade é a transposta da (91):

$$
[C]^{e^{T}}=\int_{\Omega_{e}}[N]^{e^{T}}\left[B_{i}\right]^{e} d \Omega_{e}
$$

O método numérico foi validado ao simular o escoamento uniforme ao longe sobre um cilindro fixo para $R e$ igual a 20,40, 100 e 200. Os valores dos coeficientes de sustentação e arrasto foram então comparados com aqueles disponíveis na literatura. 
Este modelo difere daquele do cilindro em oscilação forçada pelas condições de contorno constantes ao longe e pela de aceleração nula do corpo.

Para $R e$ igual a 20 e 40, dois vórtices contra rotativos são formados a jusante do cilindro e permanecerem solidários a ele. O coeficiente de arrasto calculado é apresentado na tabela a seguir:

Tabela 9 - Coeficiente de arrasto

\begin{tabular}{lcc}
\hline & \multicolumn{2}{c}{$\mathrm{C}_{\mathrm{D}}$} \\
\hline & $R e=20$ & $R e=40$ \\
\hline Tritton (1959) & 2,22 & 1,48 \\
\hline Fornberg (1980) & 2,00 & 1,50 \\
\hline Calhoun (2002) & 2,19 & 1,62 \\
\hline Presente Trabalho & 2,18 & 1,61
\end{tabular}

Para $R e$ igual a 100 e 200, ocorre o crescimento, desprendimento e emissão de vórtices a jusante do cilindro. Eles são convectados para jusante e uma esteira de vórtices é formada. Devida a essa dinâmica do escoamento, surge uma força de sustentação. A tabela a seguir apresenta os coeficientes de arrasto (médio) e de sustentação calculados:

Tabela 10 - Coeficientes de arrasto e de sustentação

\begin{tabular}{lcccc}
\hline & \multicolumn{2}{c}{$\mathrm{C}_{\mathrm{D}}$} & \multicolumn{2}{c}{$\mathrm{C}_{\mathrm{L}}$} \\
\hline & $R e=100$ & $R e=200$ & $R e=100$ & $R e=200$ \\
\hline Braza et al. (1986) & 1,36 & 1,40 & $\pm 0,25$ & $\pm 0,75$ \\
\hline Liu et al. (1998) & 1,35 & 1,31 & $\pm 0,34$ & $\pm 0,69$ \\
\hline Calhoun (2002) & 1,33 & 1,17 & $\pm 0,30$ & $\pm 0,67$ \\
\hline Presente Trabalho & 1.38 & 1.37 & \pm 0.34 & \pm 0.70 \\
\hline
\end{tabular}

